University of Louisville

ThinkIR: The University of Louisville's Institutional Repository

Electronic Theses and Dissertations

$12-2010$

\title{
Seeking a spiritual home for women : a comparative study of Chen Ran's and Amy Tan's fictions.
}

Jing He 1979-

University of Louisville

Follow this and additional works at: https://ir.library.louisville.edu/etd

\section{Recommended Citation}

He, Jing 1979-, "Seeking a spiritual home for women : a comparative study of Chen Ran's and Amy Tan's fictions." (2010). Electronic Theses and Dissertations. Paper 592.

https://doi.org/10.18297/etd/592

This Doctoral Dissertation is brought to you for free and open access by ThinkIR: The University of Louisville's Institutional Repository. It has been accepted for inclusion in Electronic Theses and Dissertations by an authorized administrator of ThinkIR: The University of Louisville's Institutional Repository. This title appears here courtesy of the author, who has retained all other copyrights. For more information, please contact thinkir@louisville.edu. 
SEEKING A SPIRITUAL HOME FOR WOMEN

- A COMPARATIVE STUDY OF CHEN RAN'S AND AMY TAN'S

FICTIONS

By

Jing $\mathrm{He}$

B.A., Beijing Foreign Studies University, 2002

M.A., Beijing Foreign Studies University, 2005

\author{
A Dissertation \\ Submitted to the Faculty of the \\ Graduate School of the University of Louisville \\ in Partial Fulfillment of the Requirements \\ for the Degree of
}

Doctor of Philosophy

Department of Humanities

University of Louisville

Louisville, Kentucky

December 2010 


\section{Copyright 2010 by Jing He}

All rights reserved 


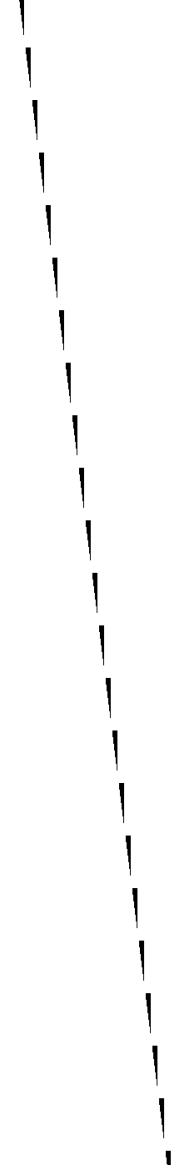


SEEKING A SPIRITUAL HOME FOR WOMEN

- A COMPARATIVE STUDY OF CHEN RAN'S AND AMY TAN'S

FICTIONS

By

Jing $\mathrm{He}$

B.A., Beijing Foreign Studies University, 2002

M.A., Beijing Foreign Studies University, 2005

A Dissertation Approved on

November 1, 2010

By the following Dissertation Committee:

Dissertation Director 


\section{DEDICATION}

This dissertation is dedicated to my parents,

Guangming He and Lihong Shu

for their endless love and absolute trust in my capability

to my parents-in-law

Wenying $\mathrm{Hu}$ and Shurong Liu

for their incomparable understanding and support to all my endeavor

to my husband

Yafeng $\mathrm{Hu}$

for his great love and all he has done for me beyond expression

and especially to my adorable daughter

Xuhan $\mathrm{Hu}$

for her charming smiles and sweet words 


\section{ACKNOWLEDGMENTS}

I am imbued with deep indebtedness to all the people who have provided me with tremendous help and enormous support during my doctoral pursuits.

The largest debt of my heartfelt gratitude undoubtedly goes to my dissertation director, Dr. Annette Allen, who has been guiding me all the way through my writing process. I am profoundly grateful to Dr. Allen for her absolute trust in me and her great encouragement for me to carry out the present challenging but fascinating comparative study of Chen Ran and Amy Tan. Without her scholarly inspiration, insightful comments, constructive criticisms, generous offering of research materials and the most meticulous and patient reading and correction of my draft, I could hardly imagine the completion of this dissertation.

My sincere gratitude also extends to the other three members of my dissertation committee: Dr. Li Zeng and Prof. Ying Kit Chan from the University of Louisville and Prof. Li Jin from Beijing Foreign Studies University. Dr. Li Zeng has guided me to embark on the right track of doing theoretical research. His illuminating comments on my dissertation proposal and logical way of thinking have sharpened my critical perception and initiated me into the present project. I am grateful as well to Prof. Ying Kit Chan for his admiring 
wisdom, artistic taste and kind personality. His encouraging words and valuable reference materials help me through the toughest time of my writing. I would like to pay special tribute to Prof. Li Jin, who enlightens me to venture into the field of comparative study and has spent tremendous amount of time on my dissertation out of her busy schedule as the vice president of Beijing Foreign Studies University, offering professional suggestions while correcting meticulously even the tiniest printing mistakes. Her scholarly attainment and academic carefulness will always remain my goal of lifelong pursuit.

During the past five years of my doctoral studies, I owe immeasurably to all the professors for their impressive courses and substantial help that open my eyes into the kaleidoscopic world of humanistic versatility and lay a solid ground for the interdisciplinary approach applied in my dissertation. They are: Prof. Osborne Wiggins, Prof. Elaine Wise, Prof. Robert St. Clair, Dr. Pamela Beattie, Dr. Diane Pecknold, Dr. Gabriela Nunez and Prof. Michael Williams from the University of Louisville and Prof. Youzhong Sun, Prof. Jian Zhang, Prof. Yi'an Wu, Prof. Zaixin Zhang, Prof. Guohua Chen and Prof. Dezhang Chen from Beijing Foreign Studies University. Their expertise and commitment have made my study both in China and in the U.S. a beneficial and most rewarding experience.

I am especially indebted to Prof. Longxi Zhang, a renowned Chinese comparatist and the Cheung Kong Scholar of Beijing Foreign Studies 
University. His inspiring series of lectures on comparative literature and personal chat with me on my doctoral project have benefited me extraordinarily in my current research. Special thanks are also extended to the writer Chen Ran, who not only acknowledges my efforts, but also expresses her best wishes through her E-mail communications with me.

I would like to express my appreciation to Ms. Xiujie Sun, Dr. Changying Shen and Dr. Tao Xie for their indispensable assistance as liaison persons for this joint doctoral program between the University of Louisville and Beijing Foreign Studies University, and to Ms. Courtney Kerr from The School of Interdisciplinary and Graduate Studies UofL for her professional editing help. My warm personal thanks are also due to my dear friends: Yaping Zhao, Xue Shi, Jun Zhang, Wenlong Sun, Tao Xu, Jing Chen, Yi Li, Xuan Li, Jin Shang, Lihua Ran, Changyuan Liu, Daliang Cai, Hong You, Riley Byers, C. W. Faulkner, Mark Collins, Jeff Moran, Paul Marchetti for their love and help during my stay in the U.S., and to my Chinese friends: Xiaoni Kang, Yuan Zhao, Xuefang Yan as well as all my classmates in this Ph.D. program, especially Yajuan Ding, Qin Ma, Yan Zhang, Hong Huang, Yi Feng and Nan Song, whose great encouragement and enlightening ideas have filled me with love and confidence. I owe my gratitude to my colleagues from the School of English and International Studies for taking up my responsibilities during my overseas studies: Prof. Huijuan Ma, Dr. Qing Wu, Dr. Wenan Wu, Ke'er Ke, Xiaowen 
Deng, Ning Wang and Zuqiong Ma, to name just a few.

Finally, I want to thank my family members for their spiritual support and caring words. Nothing is enough to express my deep gratitude to my parents for their ever-lasting trust, to my parents-in-law for their great understanding and especially to my sisters-in-law Jingxuan Hu and Yamei Hu. Without them who help my husband take such good care of my one-year-old daughter since I left China, this dissertation could by no means be possible. To my husband Yafeng $\mathrm{Hu}, \mathrm{I}$ want to say, your love and care has been around me since the first moment when we met in the subway. You persistent support, both academically and spiritually, is the biggest miracle in my life. 


\section{ABSTRACT \\ SEEKING A SPIRITUAL HOME FOR WOMEN \\ - A COMPARATIVE STUDY OF CHEN RAN'S AND AMY TAN'S FICTIONS}

Jing He

November 1, 2010

With increasing cross-cultural infiltrations and accelerated interflows among people of all nationalities in this globalized world, the focus of comparative literature has experienced a shift from traditional Eurocentric cannons to a broader space incorporating literary works from marginalized cultures in its exploration of both particularities and commonalities

This dissertation aims to address the loss and reconstruction of women's self-identities as reflected in the fictions of contemporary Chinese woman writer Chen Ran and Chinese American woman writer Amy Tan. Drawing ideas from identity theories and postmodern feminist theories, the author compares the major motifs, rhetorical devices and writing strategies of the two writers. While conducting a comparative texual analysis of the three overriding themes including mother-daughter relationship, heterosexual relations and sisterhood, the author explores the evolution of literary representations on each theme in both Chinese and American literary traditions. Socio-historical parameters in 
cultural studies are also considered for a thorough understanding of such evolution that helps explain the similarities and differences between the two writers and the significant roles they play in their respective cultures. Apart from thematic comparisons, metaphorical implications in the protagonists' dreams and illusions, the imageries of the mirror and birds are excavated to pinpoint the heroines' subconscious identity crisis and an awakening female subjectivity in the fictional worlds of Chen Ran and Amy Tan.

Based on a careful elaboration of Chen Ran's personalized writing with a "gender-transcendent consciousness" and Amy Tan's talk-story narrative of matrilineal tracing within specific social and history contexts, the author attempts to prove that both Chen Ran and Amy Tan could be interpreted from postmodern feminist perspectives in terms of their experimentation of a female discourse and deconstructive attacks on gender categories. Through personal narrations of a woman's bodily experiences and existentialist modern predicament in Chen's fictions as well as survival stories of Chinese American immigrants extending generations of mothers and daughters, the two writers have expressed their shared humanistic ideals for women's spiritual independence free from inequality and discrimination. 


\section{TABLE OF CONTENTS}

PAGE

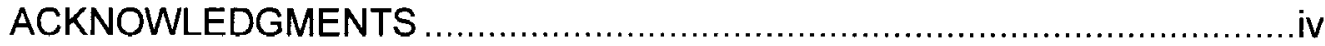

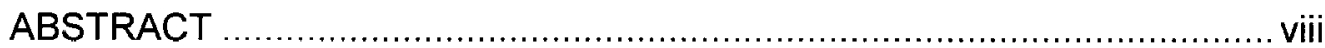

CHAPTER

INTRODUCTION

A. Chen Ran and Amy Tan - A Biographical Sketch.............................. 2

B. Rationale for a Comparison between Chen Ran and Amy Tan ........... 11

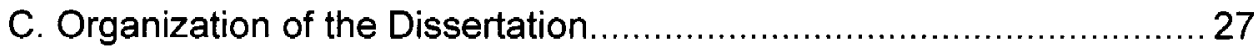

I. SETTING THE SCENE AND PREVIOUS SCHOLARSHIP REVIEWED ....31

A. Research Questions and Selection of Materials ........................... 31

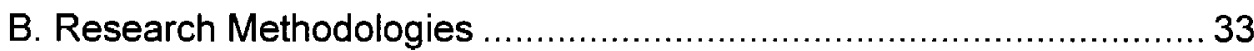

C. Previous Scholarship on Chen Ran and Amy Tan............................ 51

II. MOTHER-DAUGHTER RELATIONSHIP - FROM REBELLION TO

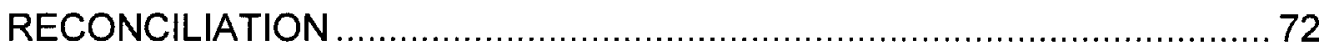

A. Tracing Mothers in Contemporary Western and Chinese Narratives .. 72

B. A Thematic Comparison on Mother-Daughter Relationship .............. 84

III. HETEROSEXUAL RELATIONSHIP - FROM ATTACHMENT TO

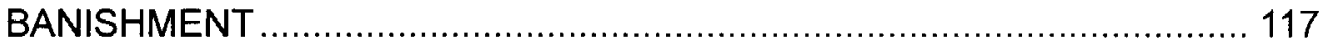

A. Awakening Identity in Western and Chinese Female Literary Tradition

B. A Thematic Comparison on Heterosexual Relationship ................ 127 


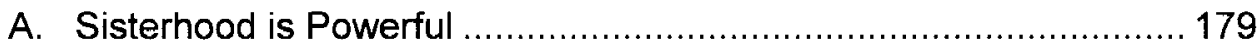

B. A Thematic Comparison on Sisterhood ........................................ 186

C. Acceptance of Sisterhood: A Cross-Cultural Comparison ............... 217

V. A COMPARISON OF METAPHORICAL IMAGERIES ........................236

A. Dreams, Illusions and Women's Identity Crisis ..............................236

B. The Mirror and Women's Self Recognition ...................................... 252

C. Birds and Women's Dream of Independence ................................. 261

VI. WRITING STRATEGIES OF CHEN RAN AND AMY TAN ....................2274
A. Chen Ran - Personalized Writing and Gender-Transcendent

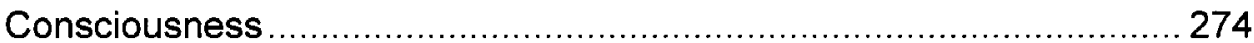
B. Amy Tan - Talk-Story and Matrilineal Reconstruction ..................... 299
C. Divergent Strategies, Same Pursuit ............................................ 316

CONCLUSION

REFERENCES

CURRICULUM VITAE

369 


\section{INTRODUCTION}

Against the background of globalization featured by cultural diversity and

cross-cultural communication, comparative literature is playing an ever-increasingly important role in bridging the cultural gap and deepening our understanding of the uniqueness within and the commonality between different cultures. It is "a methodological art of tightening the ties between literature and other fields of knowledge by establishing relations of analogy, influence, and kinship, or by bringing together facts and literary texts no matter their distance in time or space" with the aim of "better description, understanding, and enjoyment" (Pichois and Rousseau 174, qtd. in Chevrel 2). Comparative literature promises researchers a gold mine to excavate by transcending the confinement of national borders and reaching out for the merging points of different cultures: the ideas, feelings and values pertaining to their humanistic pursuit. As noted by Elizabeth Dahab, the contemporary trend of comparative literature studies witnessed a move away from "the canonical great book tradition to include literary texts and spaces previously marginalized," especially "the writings of women, the writings of ethnic minorities at the periphery of larger literary systems" (xiii). Acknowledging the importance of raising the voice of those marginalized in the literary scene, this dissertation takes two contemporary women writers Chen Ran and Amy Tan as subjects for 
comparison in order to explore their attempt, through literary practice, to search for, identify and reconstruct women's identities in their own names.

\section{A. Chen Ran and Amy $\operatorname{Tan}^{1}$ - A Biographical Sketch}

\section{Chen Ran: Four Stages of Literary Creation}

Chen Ran is one of China's avant-garde ${ }^{2}$ women writers of the 1990 s, an important figure in Chinese literary scene and the winner of the first "Contemporary Chinese Female Writer's Award." She was born in Beijing in 1962 into a traditional intellectual family. After a failed attempt in China's national College Entrance Examination in 1980 when she was eighteen years old, Chen spent two years at home, immersing herself in literary works, ranging from ancient Chinese writings to classical foreign novels. It was also during this period that she shifted her interest from music to literature during the "literary Renaissance sweeping through China in the wake of the Cultural Revolution"3 (Sieber 183). Her dream of becoming a writer was reinforced and substantiated after she was enrolled by Beijing Normal University as a major of

\footnotetext{
' Although Chen is the writer's surname, it is placed before her first name Ran without a comma in between in this dissertation to conform to common reference to Chinese writers by western scholarship. It is the same with other Chinese writers, critics and fictional characters mentioned in this dissertation. For critics sharing the same surname, first names would be followed after the surname to avoid confusion.

${ }^{2}$ Chen is regarded as an avant-garde writer of the 1990s for her personalized writing style that explores "the complex emotional territory of the female body, sexuality, homoeroticism, and fantasy" (Wang Lingzhen, qtd. in Shaffer and Song 163). As Shaffer and Song comment, such kind of writing is unprecedented in the Chinese literary scene and is "highly regarded amongst the avant-garde, none more so than that of Chen Ran" (ibid.). In an interview with Xiao Gang, Chen Ran also confirms the avant-garde nature of her writings, including innovative contents and a writing style that subverts textual order and destroys the established reading habits of readers. (Chen Ran and Xiao Gang 250).

${ }^{3}$ The Cultural Revolution is a radical public movement in China, initiated by Chairman Mao in 1966 with the aim to eliminate counterrevolutionary elements in the country's institutions and leadership. The ten-year long movement characterized by political zealotry and purges of intellectuals resulted in massive social chaos, extensive economic retrogression and a wasteland of literary scene thirsting for an eruption of literary creation.
} 
Chinese Literature in 1982.

During her four-year college life, Chen Ran devoted herself wholeheartedly to the world of literature and philosophy, "developing affinities for modernist writers such as Franz Kafka and Virginia Woolf" (ibid.). In order to balance the restless passion surging within her sensitive self "at a schizophrenia state," ${ }^{4}$ Chen wrote and published dozens of poems from the age 20 to 22 . The next year witnessed a transition in Chen's writing interest from poetry to fiction. Her maiden work "Hey, stop feeling so low" (hei, bie name sangqi) ${ }^{5}$ was published in Youth Literature (qingnian wenxue), a leading literary journal in 1985. Subsequent stories like "Century Sickness" (shiji bing)," received vigorously as "pure" or "avant-garde" fiction, distinguished Chen Ran as a budding young talent and "the newest representative of serious female writers" on China's literary stage (Howard-Gibbon xii).

Upon graduation in 1986, Chen Ran remained in her Alma Mater as a lecturer at the Chinese department. During this period, she published a series of short stories in various influential journals, which contributed to her first anthology Paper Scrap (zhi pian'er, 1989). Compared with the first period of Chen Ran's literary practice when she wrote poems and stories during college

\footnotetext{
${ }^{4}$ In "Without an Ending" (mei jieju), Chen writes, "At that time (at college), my life is at a state of schizophrenia. I'm shy and silent in public places, and only when I retreat to my own world can I pour out my swelling feelings into poems" (8-9).

5 All of Chen Ran's works are written in Chinese with their original title indicated in brackets through phonetic transcriptions in the form of pinyin. The English titles of Chen's works are translated by the current author, except for those already translated into English, in which case, the English translation of the published work would be adopted. For the sake of Western readers, the author cites the English titles before the Chinese pinyin when referring to Chen's works in this dissertation.
} 
years, depicting the solitude, anguish and rebellion of youngsters of her time who are eager to break through social conventions for an emotional outlet of their wild spirit, Paper Scrap symbolizes the second period of Chen's writing, which is characterized by mysterious plots, surrealist imagery and freakish characters. When reflecting upon the motivation behind her creation during this period, Chen explained that she intended to explore the origin of the universe, life, consciousness and humanity through mythological symbolism and philosophical parables (Zhou 313).

After a short trip abroad in 1988, Chen Ran returned to China and became an editor at the Writers Publishing House. Although Chen didn't claim to be a feminist writer, she was nevertheless influenced by Western feminist ideas with a growing awareness for an assertion of female identity. The 1990 s witnessed the publication of many of her representative fictions on women's unremitting pursuit of love and quest for the meaning of life, such as "Redundant Roles" (juese leizhui, 1990), "An Empty Window" (kongde chuang, 1991), "The Birth of a Hollow Man" (kongxinren de dansheng, 1991), "A Toast to the Past"6 (yu wangshi ganbei, 1991), "Nowhere to Bid Farewell" (wuchu gaobie,1992), "Sunshine between the Lips" (zuichun lide yangguang, 1992), "Standing Alone at a Path of Draft" (zhanzai wuren de fengkou, 1992), "Time and Cage" (shiguang yu laolong, 1992), "A Hidden Matter" (qianxing yishi,

\footnotetext{
${ }^{6}$ The novella was adapted into a film Yesterday's Wine, which premiered at the Fourth World Conference on Women held in Beijing in 1995, bringing Chen Ran's work to the attention of the feminist arena for the first time ${ }^{7}$ All the stories mentioned above are collected in Sunshine between the Lips (zuichun li de yangguang).
} 
1992), "The Wheat Woman and the Widow" (maisui nü yu shougua ren, 1993), "A Hungry Pocket" (ji'e de koudai, 1993), "The Sound of Anther Ear Knocking" (ling yizhi erduo de qiaoji sheng, 1994). ${ }^{8}$ According to the present author, these stories mark the third period of Chen Ran's writing, combining psychological struggle of the female characters trying to define the significance of life with existentialist concerns of human beings suffering from isolation, alienation and the indifference of modernity.

The fourth period of Chen's literary creation might be symbolized by the publication of the story "Breaking Open" (pokai, 1995) and the novel A Private Life (siren shenghuo, 1996). Unlike Chen's previous stories that are "intensely melancholy," portraying female protagonists' fruitless pursuit of refuge "in sexual relationships with men, in emotional relations with women, or in service to the state or to some other cause" (Sieber 184), "Breaking Open," with many sparkling remarks on female fate and identity by the two heroines as cofounders of a female society, carries a more optimistic tenor of celebrating "female intimacy grounded in close mother-daughter bonds" and is "heralded as a manifesto for women" (ibid.). A Private Life, the only novel by Chen Ran, has also attracted great attention from scholars home and abroad for its display of the protagonist's troubling growing experience, both psychologically and physiologically, accompanied by her ambivalent love with a widow, her

\footnotetext{
${ }^{8}$ Except for "The Wheat Woman and the Widow," which is included in the anthology of Chen's novella The Divorced (liyi de ren), all the other stories could be found in the anthology Nowhere to Bid Farewell [wuchu gaobie].
} 
loveless sexual entanglement with her obscene school teacher and her poet lover who flees the country amid the political turmoil, and the death of her mother, all of which finally draw the heroine toward a narcissistic infatuation with herself in the bathtub. In these experimental writings, Chen exhibits a stronger desire for the pursuit of female identity through her exploration of mutual affection and support among women as well as her shifting focus on women's inner world for strength and inspiration. Bringing into her writing the unique experience of being a woman, Chen invites the readers to feel, in her female characters' sensitive mind and body, the world around them. The protagonists' experience of growth and family, love and sex all point to a reconstruction of female identity lost in male dominance. It was also during this period that Chen Ran put forward the notion of "gender-transcendent consciousness" (chao xingbie yishi) ${ }^{9}$ which symbolizes a new height of women's awareness of their unique identity and reflects a philosophical quest for the common fate of human existence.

From the above analysis, we can sense a growing focus on women's psychological world in constant struggle and their sensual experience with all its multiplicities along the four stages of Chen's writing, which draws increasing

\footnotetext{
${ }^{9}$ The English translation of the term is borrowed from Sang Tze-lan when she discusses Chen Ran's novel $A$ Private Life in The Emerging Lesbian, Female Same-Sex Desire in Modern China. The notion of "gender-transcendent consciousness"was first proposed by Chen Ran in her lectures at British universities in 1994. Challenging the hegemony of heterosexuality, Chen believes that the conventional love driven by reproductive and economic concerns will be replaced by an emerging consciousness that transcends the concept of gender. From the perspective of a writer, Chen shares Virginia Woolf's vision of androgyny and deems the harmonious combination of male and female powers in one's mind as the prerequisite for a writer to attain absolute clarity and purity in expression of thoughts and feelings. For an elaborated interpretation of Chen's "gender-transcendent consciousness." please refer to Section A of Chapter Six.
} 
attention from researchers at home and abroad.

\section{Amy Tan: Legendary Stories}

Amy Tan is a renowned contemporary Chinese American woman writer enjoying high reputation and popularity among American readers as well as readers in other countries of the world. Born in Oakland, California in 1952, Tan grew up in a Chinese immigrants' family with legendary life experiences that supplied Tan with inexhaustible materials for her literary creation. Her father John Tan met her mother Daisy Du, wife of an abusive Chinese husband, on a boat trip in southwestern China while serving as a translator for the U.S. Information Service during World War II. Their love affairs resulted in a two-year imprisonment of Daisy for adultery accused by her former husband before her eventually marrying John and emigrating to the U.S., leaving three daughters in China. John, on the other hand, abandoned the chance of studying electrical engineering at M.I.T. and followed the family tradition as a Baptist evangelist upon graduation from Berkeley Baptist Divinity School.

Amy's parents "held high behavioral and intellectual standards for their three bilingual children" (Snodgrass 9). Ever since a little child, Amy was caught between the Chinese heritage she was trying to reject, and the American milieu she embraced as her home culture. Reared in various coastal Californian cities before moving to Santa Clara, Tan "was the perpetual loner," struggling to "harmonize American roots with her parents' Asian customs" 
(ibid.). Quarrels with and rebellion against her dominant and feisty mother with different viewpoints and values seemed to be an inseparable part of Amy's adolescent years. In 1967 when Amy was only 15 years old, her elder brother died of malignant brain tumor. The same fate happened to Amy's father seven months later. The death of two immediate family members within a year was a heavy blow to both Amy and her mother. While Amy retreated further into her insular self, her mother Daisy, attributing her tragic life to ancestral curse, became more superstitious and eccentric. Gaining a "divine directive" from a can of Old Dutch cleanser, Daisy decamped with Amy and her younger brother, travelled to Holland, Germany, and finally settled down in Switzerland, where Amy finished high school. In 1969, Amy moved back to California and enrolled in medical studies, which she abandoned three years later for a double concentration in English and linguistics and eventually earned a master's degree in linguistics from San Jose State University. Suffering from long-term depression and psychosomatic laryngitis resulting from the aftershock of a break-in murder on the twenty-fourth birthday of a friend and former roommate Pete, Tan quit her doctoral studies at UC Berkeley. In the following years, Tan fulfilled Pete's wish, working as a language development consultant for retarded citizens and a language specialist for children with developmental disabilities.

The turning point in Tan's career and her relationship with her mother 
was after Daisy had a stress-related angina and was hospitalized while Tan was on a vacation in Hawaii in 1985. It was the first time in Tan's life that she realized how fragile her mother was and how careless she had been toward her mother. While waiting to receive Daisy's news from intensive care, Tan made a solemn vow to God that if her mother lived, she would "get to know her," "ask her about her past," "actually listen to what she has to say," "even take her to China" and "write stories about her" (Tan, The Opposite of Fate 358). Although it was later diagnosed that Daisy suffered from no cardiac damage, Tan honored her promise. She began to listen to her mother's story and took Daisy on a three-week trip to China. The incident of her mother and their China trip prompted Tan to embark on her literary path and became a full-time professional fiction writer in 1988.

Tan's first novel The Joy Luck Club issued in 1989 ingeniously interlaced women's love-hate stories of three generations in four Chinese-American immigrant families, "a cross-cultural feminist novel" that won enthusiastic reviews and stayed on the New York Times bestseller list for eight consecutive months (Snodgrass 16). The novel "hit a nerve because women had begun to think about themselves and their mothers" (Fry 4, qtd. in Snodgrass 17), and Tan "emerged as a major American novelist and spokeswoman for women's liberation" (Snodgrass 18). As requested by her mother, Tan started to write her second novel The Kitchen God's Wife based on Daisy's true life of 
enduring a twelve-year torture by her former husband. ${ }^{10}$ Within a month of its publication in 1991, the novel topped the bestseller list on the New York Times, remained for thirty-eight weeks and won great honors, including "the Booklist 1991 Editor's Choice award, selection by Doubleday Book Club, and a nomination for a Bay Area Book Reviewers citation" (19).

After three years' venture into children's literature with two story books The Moon Lady (1992) and The Chinese Siamese Cat (1994), Tan launched her third novel The Hundred Secret Senses in 1995, incorporating her half-sister and her filming trip to China for The Joy Luck Club into the plot of "a woman-centered tale about a ghost-seer" (Snodgrass 22). Tan's mother died of Alzheimer's on November 22, 1999, and on the one-year anniversary of her mother's death, Tan released her fourth novel The Bonesetter's Daughter, crafting out of the legendary tales between her mother and her grandmother. Tan's memoir The Opposite of Fate (2001) was equally successful. The collection of her previous works, speeches and essays provided an autobiographical account of Tan's growing experience, her family stories and her philosophical quest for fate and hope of life. Tan's latest novel Saving Fish from Drowning was released in 2005 , signaling a shift in her writing from focusing on mother-daughter relations and women's experience in different historical and cultural contexts to a suspenseful journey of a group of American

\footnotetext{
${ }^{10}$ Amy Tan has said on several occasions that The Kitchen God's Wife develops out of her mother's true story. And both the outlines and specific details of the novel are congruent with the life of Daisy Tan (Huntley 83).
} 
tourists in Burma with religious and moral implications.

Tan's novels are "filled with engaging images of strong girls and women" determined to assert their own voice in the patriarchal world (Snodgrass 3), and the enthusiastic academic and public response to her writings "attests to her success at feminist and universal themes" (6).

\section{B. Rationale for a Comparison between Chen Ran and Amy Tan}

In the current dissertation, the author chooses Chen Ran and Amy Tan as subjects for comparative studies mainly for the following six reasons.

Firstly, both Chen Ran and Amy Tan rose to fame in late 1980s and are influential contemporary women writers in their respective cultures. ${ }^{11}$ Chen Ran is "the central and most-discussed figure in the recent critical debate in China over 'female writing' (nüxing xiezuo) and 'individualized writing' (gerenhua xiezuo)"12 (Sang 201). In the words of feminist critic Huang Lin, Chen Ran's importance in contemporary Chinese literary scene could be summarized into three aspects:

She has legitimated women's writing after centuries of marginalization; she has created a special discursive space for

\footnotetext{
$"$ Although Chen Ran's latest novel A Private Life was released in 1996 compared to Tan's Saving Fish from Drowning published in 2005, as a member of Chinese Writers Association, Chen keeps on writing prose, essays and poems. The recent decade witnessed the publication of Chen's several books including anthology of stories The Divorced (liyi de ren, 2004), collection of prose: Can We Reconcile with Life (women nengfou yu shenghuo hejie, 2001), Flashback in Time (shiguang daoliu, 2003), Who Robbed Our Face (shui lueduo le women de lian, 2007), Chen's dairy jotting Intermittent Words (shengsheng duanduan, 2002), and a book on Chen's interview transcript Beyond Words (buke yanshuo, 2002). As the current dissertation is proceeding, the author is gratified to know that Chen's novel $A$ Private life, which ran out of print shortly after its first release, was republished with a new edition in January 2010.

12 Often translated as "personalized writing," a strategy of writing about an individual's state of life against the grand narrative that is characterized by highlighting social significance and collective ideology. For a detailed analysis of Chen's personalized writing strategy, please refer to Section A of Chapter Six.
} 
exploration of private lives; and she has become the spokesperson for and most representative figure of this emerging literary genre. (Trans. and qtd. in Shaffer and Song 164)

In her distinctive blending of Western and Chinese influences, Chen "champions the voice and identity of women" and deviates from previous generations of women writers with "a genuinely alternative feminist aesthetics" (Zheng 53). As described by John Howard-Gibbon, the English translator of Chen's novel A Privet Life, Chen Ran is "a unique and important female voice ... [whose] unique and personal postmodern feminist story has created a different and very challenging image of women within Chinese literature of the 1990s (2004, xii-xiii). The Select Works of Chen Ran (Chen Ran wenji) published in 1996 with her stories, fictions and essays is forwarded admiringly by Wang Meng, a prominent Chinese modern writer and former Minister of Culture in addition to "a psychoanalytically oriented" afterword by Dai Jinhua, the renowned feminist critic (Sieber 183). Chen's works have been translated into many languages and published in U.S., Europe and Asian countries including Japan and Korea. ${ }^{13}$ Her novella "A Toast to the Past" was adapted into a film Yesterday's Wine, which premiered at the Fourth World Conference on Women held in Beijing in 1995, bringing Chen Ran's work to the spotlight of the feminist arena. Currently an editor for the Writer's Publishing House of China, Chen Ran is keeping her pen busy with her sharp female intuition and shining wisdom of life.

${ }^{13}$ Please refer to a brief introduction of Chen Ran on the opening page of Flashback in Time (shiguang daoliu). 
Likewise, Tan rose to fame by the end of 1980 s with the publication of her first novel The Joy Luck Club in 1989. The novel that ingeniously interlaces "the ethnic malaise" as well as conflicts and reconciliation among four pairs of Chinese immigrant mothers and their American-born daughters received "glowing critical reviews" and honors, including "finalist for the National Book Award and the National Book Critics Circle Award and winner of the Bay Area Book Reviewers Award for Best Fiction, the American Library Association Best Book for Young Adults Award, and the Comonwealth Club Gold Award" (Zeng, "Asian American Literature" 79). The success of Tan's subsequent novels The Kitchen God's Wife, The Hundred Secret Senses, and The Bonesetter's Daughter, verified Tan's resolution stated in "Angst and the Second Book" that each of her books, though based on the stories of her family, "would outdo its predecessor, increasing in scope, depth, precision of language, intelligence of form, and thus critical acceptance and perhaps even readership" (The Opposite of Fate 324-25). As "one of the most significant women writers in contemporary Asian American literature," Tan has enjoyed great popularity and appreciative criticism one novel after another (Zeng 79). The novels of Amy Tan are laurelled with various awards and have been translated into 35 languages. ${ }^{14}$ Her first novel The Joy Luck Club has been successfully adapted into stage performance and a Hollywood movie with Tan as the co-producer and co-screenwriter, winning her wider attention and world acclaim.

\footnotetext{
14 "Amy Tan." 24 Feb. $2010<\mathrm{http}: /$ www.barclayagency.com/tan.html $>$.
} 
Secondly, as a result of similar life experience, both Chen Ran and Amy Tan embark on the literary career under their mother's influence, and both highly value the relationship with their mothers, which is reflected in their depiction of mother-daughter relationship as an invariable theme in their writings. Chen Ran's mother Chen Yanci is a writer of children's literature, an intellectual with artistic temperament who bestowed high expectation on her daughter. When Chen entered the primary school in 1969, it was during the zealous period of China's Cultural Revolution that devalued literature. Therefore, Chen's mother chose the musical path for her daughter, sending Chen Ran to learn accordion and musical composition. As Chen recounted in "Without an Ending" (mei jieju), all she could remember about her childhood life was music and her mother's love (5). Chen's father is an eccentric scholar, burying himself into academic research all day long while paying little attention to the family. The personality conflict and lack of communication resulted in the divorce of Chen's parents in 1979 when she was 17 years old. The following four years of solitary life in an abandoned nunnery with her divorced mother played a decisive role in Chen's life, shaping her aloof and melancholy disposition and redirecting her interest from music to literature. As Chen confessed, she was a late comer to the field of literature. The first novel she got in touch with was Victor Hugo's Ninety-Three in Chinese translation read by her mother when she was taking a noon break during her preparing for a 
second try at the National College Entrance Examination. The fate of fictional characters kindled Chen's passion and led her into a new world where she "found her lost self" (6). Under her mother's influence, Chen plunged herself into a sea of novels, classic and modern, determined to follow her mother's steps to become a writer.

Chen's mother not only influenced her orientation in career development, but also served as a prototype in Chen's fiction and prose writings. For example, the setting for "A Toast to the Past" is a nunnery where the heroine and her divorced mother lived a reclusive dreary life, a fictional analogy to Chen's real experience after her mother's divorce. In "Nowhere to Bid Farewell" (wuchu gaobie), Chen dedicates a whole chapter entitled "Miss Dai Er and her Mother" to depict the conflicting mother-daughter relationship as she experiences in life. Chen's prose anthology Flashback in Time (shiguang daoliu) also includes several articles describing her mother's childhood memories (114-16), her habit of hoarding useless items (141-43), her forgetfulness of always looking for something missing (145-47), her refusal to give in to old age and her inclination to rake up Chen's shortcomings in comparison to others (259-61). Remaining single, Chen Ran is still living with her mother with their adjacent apartments linked into one. Chen's mother is her spiritual mentor and life companion. As Chen wrote in "Jottings about My Home Life" (jiaju suoji): "I'm weaker than my mother, but my mother is older 
than me. In addition to our overly democratic relationship, we are more like sisters to each other" (my translation, 310).

Similarly, Tan's mother exerted great influence upon her life. Like Chen Ran, Tan counted on her mother as the only life guide since the tragic death of her father. Although Tan's mother Daisy was not an intellectual, she set her daughter "impossibly high standards" to fulfill her unattained dreams (Tan, The Opposite of Fate 343). Similar to Chen, Tan also experienced a shifting focus in her career interest under the influence of her mother. Tan's mother imposed neurosurgery and classical music as the career goals for her daughter. Daisy chose classical music for Tan probably out of her dream for her daughter to enter into American high society that required a taste for fine art, and out of practical concerns to outshine daughters of her female friends, as alluded to in The Joy Luck Club with Suyuan Woo and Lindo Jong's constant comparison of their daughters. Neurosurgery was chosen because of the deaths of both Tan's brother and her father from brain tumors. As introduced in the previous section, the motivation for Tan to become a professional writer arose from her mother's angina outbreak and her promise to understand and tell Daisy's life stories. Although Tan failed Daisy's original plan of career development, she fulfilled the other dreams of her mother to be understood by her daughter and have her stories written and passed down. Daisy told her miserable life stories to her daughter with the hope that Tan could tell the whole world about her mother's 
suffering and change the past sorrows into a future with hopes (The Opposite of Fate 103-04). Daisy's life in China with an abusive husband, a son that died early, three daughters she left behind and her uneasy life in America have provided Tan with "an intricately woven tapestry of women's lives that furnished characters, settings, conflicts, and themes" in almost all her novels (Nelson 366). As Tan recounts in an interview: "When I was writing, it was so much for my mother and myself [...] I wanted her to know what I thought about China and what I thought about growing up in this country" ("Stories Written for Mother"). ${ }^{15}$ Tan's mother not only became a source of inspiration for Tan's literary creation, but also endowed Tan with an unusual perception of life and writing skill. In The Opposite of Fate, Tan wrote:

Looking back, I'm convinced it was also my mother who affected my imagination to such a degree that I now hear and see things that others do not. I see connections in coincidences, ironies in lies, and truths in contradictions, all sorts of things that others do not. (33-34)

In her mother's stories, Tan found "a lot of humor and wisdom and truth" about herself (Kanner 3). Though Daisy's English was broken and hard to understand for native American speakers, Tan found it "vivid, direct, full of observation and imagery," a language that helped her shape her perspective of seeing things, expressing things and making sense of the world (The Opposite of Fate 273). "The more I heard, the more I wanted to know. [...] I wanted to go back to the past. I wanted to be there with her, to be her witness, to agree with

${ }^{15}$ For short of "How Stories Written for Mother Became Amy Tan's Best Seller," an interview by Julie Lew published in New York Times on July $4^{\text {th }}, 1989$. 
her" (82). Naturally the stories between mothers and daughters have become an invariant theme in Tan's writing.

Thirdly, as women writers, both Chen Ran and Amy Tan proceed from their sensitive perceptions of women's experiences and aspirations in an authoritarian world of patriarchy yet different in degrees and forms. Female stories compose the cornerstone of their writing focus. For example, Chen Ran's novel A Private Life tells stories of several women from the retrospective narration of $\mathrm{Ni}$ Niuniu as she grows emotionally and sexually from an eleven-year old girl to an independent woman in early maturity. The stories about Niuniu's mother and one-eyed nanny submitting to her tyrannical father, Niuniu's longing for and corporal contact with Widow Ho, her paralyzed but sexually active friend Yi Qiu and her neighbor Mrs. Ge, who is murdered by her husband for her inability to satiate the man's sexual desire after mastectomy surgery for breast cancer, all build up an impressive female world of sufferings and desires. Likewise, Amy Tan's main characters are invariably women living in a "Herland." For example, Tan's first novel The Joy Luck Club is composed of 16 stories about four pairs of mothers and daughters, each revealing one perspective of a woman's life travelling through different cultures and generations. Her other novels probe similar themes from a female point of view.

In the fascinating female world created by the two writers, both Chen and 
Tan wrote about problems and dilemmas in the protagonists' growing experience and their perceptions of the world to reclaim their female identities, and their love relationships in a society still largely dominated by patriarchal mechanisms. The love relationship in the novels of the two writers could be categorized into three types: the love between mothers and daughters, between men and women and that among women in the form of sisterhood. ${ }^{16}$ It is in the struggle for love of these three kinds that heroines in the two writers' fictions change from the willing submission to patriarchal orders to the conscious reconstruction of their female identities separate from the patriarchal definition. Although living in different cultures, the common fate of woman and the preoccupation with human love bring the two writers to write about the same topic and persistently explore a way out for women to regain an equal status with their male counterparts.

Fourthly, both Chen and Tan lack a sense of belonging in their adolescent years partially due to the absence of a father and subsequent displacement with their divorced or widowed mothers. ${ }^{17}$ Because of such displacement, both physically and mentally, both writers are longing for a home

\footnotetext{
16 Sisterhood is defined as "psychological and political bonding among women based on the recognition of common experiences and goals" (Tyson 96). In this dissertation, the author intends to interpret sisterhood as a continuum of women's alliance that incorporates both female emotional friendship and female same-sex love with erotic implications. For a detailed discussion of the concept, please refer to Chapter Four of this dissertation.

${ }^{17}$ As mentioned above, Chen and her mother moved out of her father's house and lived in an abandoned nunnery for several years. Chen recounted this experience several times in her fiction and prose. In Who Robbed Our Face (shui lueduo le women de lian), Chen recalled that once on the balcony of her aunt's home, she couldn't help crying at the sight of warm lights from other buildings and asked her mother why they didn't have a home (112). Tan also couldn't forget the frequent relocation in her childhood, "By the time I graduated from high school, I had attended eleven schools. I had learned to lose friends, to remain the loner until I finally found new ones" (The Opposite of Fate 22).
} 
with warmth and security. In their writings, they keep on asking similar ontological questions about life with an aim to define their own identities and where they belong. The questions about life and the definition of the self lingered on Chen's mind since her adolescent years, during which time she took pleasure in probing the answers to questions like:

Who am I? Where am I? Who are they? Where are they? Why should I stay the same as others? How do I relate to others? Why do I try to establish such a relationship? What's the world all about? About man and woman? Life or death? When do I commit suicide? In what way? (my translation, Chen Ran, Who Robbed Our Face 222)

Like Miss Dai Er in many of Chen's stories and Ni Niuniu, the protagonist in $A$ Private Life, most of Chen's female characters are melancholy but rebellious, fragile but courageous. They plunge into a bold exploration of life with their dreams or disillusionment, love or hatred, friends or enemies, survival or death, through which Chen Ran unveils the rich experience of women with a growing consciousness of their inner power and self identity.

Similar to Chen Ran, Amy Tan has the same questions on her mind since childhood: "How did that happen? What's going to happen? How do I make things happen?" (Tan, The Opposite of Life 111). These ontological questions motivate Tan to write for "self-serving reasons," as she explains in The Opposite of Life:

I write about questions that disturb me, images that mystify me, or memories that cause me anguish and pain. I write about secrets, lies, and contradictions, because within them are many kinds of truth. In other words, I write stories about life as I have 
misunderstood it. (304-5)

For both Chen Ran and Amy Tan, their writings prioritize women's conscious pursuit of their identities from self exploration and reflection to self confirmation and realization.

Fifthly, from the writing strategies and major motifs prioritized by the two writers, we can find traces of postmodern feminist ideas. Postmodern feminism is a feminist trend emerging out of the third wave of feminist movement under the influence of deconstruction, psychoanalysis and post-structuralism. Unlike the advocacy of women's "legal advances and public emancipation" during the first wave (Humm 14), or the prioritization of gender difference and group consciousness during the second wave, postmodern feminism challenges the idea of essentialism or the belief that "there is a single and coherent feminine experience to which feminism can appeal" (Madsen 22). While American philosopher and postmodern feminist Judith Butler rejects the natural basis of sex through her elaboration on gender performativity, French feminists like Hélène Cixous, Luce Irigaray and Julia Kristeva emphasize the discursive power of femininity by advocating a new type of writing that celebrates multiplicity and multiple possibilities.

It is argued by the current author that traces from postmodern feminist ideas in the works of both Chen Ran and Amy Tan deserve special attention because they are important in our understanding and appreciation of their works. Chen Ran's personalized writing that foregrounds a woman's sexual 
desires and bodily potential coincides with Cixous's notion of "body writing" or "sext" that combines sex and text to realize the potential power of women. As Heinrich wrote in a review of $A$ Private Life, the novel is characterized by "confrontational omnipresence of bodies," populated by "a profusion of corpses, body parts, and adolescent bodies" (par. 5). Descriptions of female body and sexual desires could be found in most of Chen Ran's stories. In comparison, Amy Tan's writings center on a similar concern as postmodern feminists to trace the matrilineal line as a source of power. Tan's first novel The Joy Luck Club sets the tone for Tan's prioritization on matrilinear bond in her literary creation. With the four daughters' gradual understanding of their mothers' and grandmothers' life stories, they seem to find their root and true selves through the establishment of a matrilinear bond. Tan's other novels also embody the matrilinear root-searching journey of daughters, like Pearl in The Kitchen God's Wife and Ruth and her mother LuLing in The Bonesetter's Daughter, to reach understanding and reconciliation with their mothers, gaining emotional power with a full consciousness of their reconstructed gender and ethnic identities.

Besides, both writers stick to female perspectives in their story telling and touch upon, although with different emphasis, sisterhood as a source of women's consolation and salvation. As implied by postmodern feminist theories, one implication of the revolt against compulsory heterosexuality is the 
affirmation of sisterhood, which, in Chen's novels, is represented by women's emotional bond with and erotic desires for their female friends. In her earlier story "The Birth of a Hollow Man" (kongxin ren de dansheng), the narrator's mother, who, having fled from her abusive husband, finds mutual affinity in the tender love of another woman. Her other stories like "A Hidden Matter" (yixing yishi), "The Wheat Woman and the Widow" (maisui nü yu shougua ren), "A Hungry Pocket" (ji'e de koudai), "The Sound of Another Ear knocking" (ling yizhi erduo de qiaoji sheng) and "All Walls Are Gates" (fan qiang doushi men) depict similar themes on female same-sex love as a means for women to seek spiritual comfort and reconstruct their erased identities.

If Chen Ran is more interested in depicting female same-sex love in the continuum of sisterhood as a means to awaken her heroines to their self-defined identities and to rebel against the patriarchal and collective ideologies sustaining in contemporary Chinese scene, Amy Tan places more emphasis on female friendship and emotional bonding against unspeakable tragedies and male domination in the Old China. The founding of the Joy Luck Club by four women helps them survive the hardship of war and maintain a lifelong link among four families of Chinese origin in America; the mutual support of Winnie and Helen in The Kitchen God's Wife transforms their lives from misery to fulfillment, and as described in The Bonesetter's Daughter, the sisterly love in a Christian orphanage inhabited mostly by women and girls of 
different cultures and origins heals over LuLing's painful heart and injects hope in her to seek a brighter life.

In terms of literary devices, both writers are fond of using imageries connotating women's suppressed desires to seek their own identity. Imageries, such as the mirror, birds, illusions and dreams, coincidentally appear several times in both Chen and Tan's writings, which will be further elaborated in Chapter Five.

Sixthly, from the perspectives of cultural exchanges, both Chen Ran and Amy Tan have adopted an open attitude to reach out to other cultures. In the early 1990s, Chen Ran traveled to the U.K., Australia and Germany, giving lectures on her writings with gender specificity and the notion of "gender transcendent consciousness." 18 In her novella "Nowhere to Bid Farewell" (wuchu gaobie), Chen also develops a separate chapter entitled "Miss Dai Er and the Modern Civilization," describing the heroine's short trip abroad and her love affair with an American guy. From her experience as a college lecturer and editor, Chen Ran is more or less under the influence of feminist ideas and psychoanalytic theories she is exposed to. Apart from postmodern feminist traces in her writings, Chen's works are often compared with Virginia Woolf and Marguerite Duras for similar narrative styles and themes. Chen's openness to other cultures is also reflected in her familiarity with many foreign

\footnotetext{
${ }^{18}$ Chen Ran has given lectures as an exchange scholar in Chinese literature at Melbourne University, the University of Berlin, and London, Oxford, and Edinburgh universities in the UK (Howard-Gibbon xi).
} 
writers. In an interview in 1995, Chen comments on her favorite writers like Jorge Luis Borges, James Joyce, Franz Kafka, Rainer Maria Rilke and the French bisexual woman novelist Marguerite Youcenar (Lin and Qi 96). ${ }^{19}$ Besides, Chen Ran delivered lectures on her notion of "gender-transcendent consciousness" on several occasions around the world.

Intercultural experiences also characterize Amy Tan's life and works. Although Tan was born in Oakland California, both her parents were Chinese immigrants. Therefore, Tan grew up in a family with significant Chinese heritage. The fate and experience of Chinese women have become an inexhaustible well of inspiration for Tan's writing. After her father's death, Tan followed her whimsy mother and relocated in different parts of the world including Holland, Germany and Switzerland. To fulfill her mother's dream to find her three daughters left with her former abusive husband in China, Tan accompanied her mother to China in 1987. That trip helped her dissolve the longstanding conflict with her mother and has been written about in her first novel The Joy Luck Club, which captured the theme of women's search of a matrilinear root that transcends time and cultures. Tan's embracing attitude to different cultures can also be reflected in her attitude towards American literature. In The Opposite of Fate, Tan wrote:

I have this attitude that American literature, if such a classification

\footnotetext{
${ }^{19}$ Claire Huot also acknowledges Chen's overt reference to female writers like Woolf, Yourcenar, Duras and male writers like Borges, Joyce, and Rilke in her writings (36). The range of Chen's western reference is broad, from musicians to architects to film directors such as the most recurrent Ingmar Bergman, the Swedish film director whose works are characterized by heavy symbolism and an exploration of the characters' psychology.
} 
exists, should be more democratic than the color of our skin or whether rice or potatoes are served at your fictional dinner table. And so I ask myself and sometimes others: Who decides what is American fiction? Why is it that works of fiction by minority writers are read mainly for the study of class, gender, and race? Why is it so hard to break out of this literary ghetto? (306-307)

It could be argued that against the background of different cultures, the literary pursuits of both Chen Ran and Amy Tan represent uplifted status and enhanced awareness of women, whether Chinese or Chinese American, to place their own voice in the world arena.

From the above analysis, we can see that although living in different cultures, Chen Ran and Amy Tan have much in common. Both are renowned contemporary women writers who rose to fame in late 1980 s and are still writing about women's life with their busy pens. Due to similar life experiences, both writers, proceeding from their ontological concerns and female perspectives, are preoccupied with defining women's erased identities through writing mother-daughter bond and women's relationship with not only men, but also other women in the form of sisterhood. From the writing strategies of the two writers, we can find traces of postmodern feminist ideas on body writing and returning to pre-oedipal maternity. In terms of literary devices in their writings, both are fond of deploying imageries and metaphors opening up multiple possibilities as a means to subvert the patriarchal discourse and signifying system. Besides, both Chen and Tan take an active stance for cross-cultural and/or intercultural communication, representing a higher status 
of women of Chinese origin and their enhanced awareness for a louder voice in the world arena. All of these factors make a comparative study of Chen Ran and Amy Tan not only valid, but also meaningful for a thorough understanding of their works that mirror women's inner world, their social struggles and attempts to seek their own identities lost in patriarchal discourses.

\section{Organization of the Dissertation}

This dissertation is composed of six chapters in its exploration of Chen Ran and Amy Tan's shared dream of seeking a spiritual home for women. The Introduction sets the scene by introducing the life experiences, literary achievements and major works of the two writers, followed by an explanation of the reasons why the two writers are selected as subjects of comparison.

Chapter One states the research questions, selection of materials and methodologies applied in the current dissertation, with a brief review of New Criticism, identity theories as well as postmodern feminist theories set against the background of the three waves of feminist movement. Chinese and Western studies on each writer and those from comparative perspectives are also reviewed in this chapter to gain a full picture of previous scholarship and areas worth further exploration.

Chapter Two to Chapter Four comprise textual comparison of major themes in the fictions of the two writers pertaining to their attempt for identity 
reconstruction. A cross-cultural comparison of literary traditions on each theme is carried out from a diachronic point of view.

In Chapter Two, the author first traces the representation of motherhood and mother-daughter relationship in Western and Chinese literary tradition, followed by a textual comparison of the theme on mother-daughter relationship in the two writers' fictions. Love from the fictional mothers is mainly driven from their unfulfilled dreams and desires to establish a close bond with their daughters. From the daughter's perspective, the focus is on their perennial conflict with the mothers due to generational and cultural gaps. But against the endless quarrels and cold wars, the daughters will finally return to their mothers as a source of consolation and empowerment.

Chapter Three explores the similarities in the theme of heterosexual relationship in the two writers' fictional worlds. The author investigates a growing sense of identity consciousness in female characters from their deification of and fear of men to their protest against and banishment of men in order to lead a free life with an assertive identity of their own.

Chapter Four focuses on the two writers' portraits of sisterhood interpreted as a continuum of female bonding to seek refuge and psychological consolation away from the scourge of war and patriarchal oppression. By making reference to postmodern feminist ideas and the cultural particularities the two writers are situated in, the author attempts to argue that the depiction 
of sisterhood by Chen Ran and Amy Tan embodies their conscious struggle to assert women's repressed sexual and cultural identities.

Chapter Five encompasses a comparison of metaphorical imageries. Similarities could be found in the writers' choices of the same imageries as well as the implied meanings, such as the protagonists' dreams and their subconscious identity crisis, the image of the mirror and women's self recognition, and the use of different kinds of birds as a metaphor of women's dream for freedom. All of these similarities provide further proof of the shared concern of women writers like Chen and Tan to pursue their real identities that transcend geographical boundaries and cultures.

After a textual examination of similar themes and stylistic devices, Chapter Six aims to recapture the writings of Chen Ran and Amy Tan by investigating their respective writing strategies. Proceeding from an elaboration of Chen Ran's personalized writing with a "gender-transcend consciousness" and Amy Tan's talk-story on matrilineal recovery from cultural perspectives, the author revisits postmodern feminist theory in an attempt to round up the two writers' similarities as well as differences exhibited in the previous chapters. It is argued that although adopting divergent strategies that are conditioned by socio-cultural parameters, the two writers are actually driven by the same goal of women's identity-construction and self-empowerment. 
The concluding remarks highlights the main points of the whole dissertation, addressing the research questions set in the beginning of the paper, acknowledging the limitations of the current study and envisaging promising areas of research for future endeavor. 


\section{CHAPTER I}

\section{SETTING THE SCENE AND PREVIOUS SCHOLARSHIP REVIEWED}

\section{A. Research Questions and Selection of Materials}

Based on the above-mentioned comparability of Chen Ran and Amy Tan's literary creation, the current dissertation aims to address the following three questions:

First, how are the thematic similarities and differences, namely, mother-daughter relationship, heterosexual relationships and sisterhood demonstrated in the fictions of Chen Ran and Amy Tan? How to account for such similarities from Chinese and Western literary traditions on similar themes? How to analyze such themes as an indication of the oppressions of women who are gradually awakened to seek their own identities?

Second, how do the two writers coincide in their deployment of imageries and metaphors? What is the significance of such rhetorical devices and how do they relate to women's dilemma in a patriarchal society and their resolve to overthrow phallocentric domination?

Third, what are the writing strategies of Chen Ran and Amy Tan? How to account for their similarities and differences by bringing in feminist 
perspectives and socio-cultural backgrounds the two writers are exposed to?

As for the materials of my analysis, I mainly rely on three works of Chen Ran already translated into English: two stories ("Sunshine between the Lips"20 and "Breaking Open") and one novel (A Private Life). "Sunshine between the Lips" centers on female sexuality and identity crisis in a patriarchal-ruling society, and "Breaking Open" represents Chen's experimental attempt to probe the possibility of building a same-sex society of women. A Private Life depicts the puzzling growing experience of a girl while constructing her self identity in a labyrinth of a mother-daughter relationship, love-hate relationships with men and the heroine's ambivalent love with another woman. To reach a better understanding of Chen Ran's fiction, I may also make reference to the above-mentioned stories "A Toast to the Past," "Nowhere to Bid Farewell," "The Sound of Another Ear Knocking" ${ }^{21}$ as well as other short stories not yet translated into English. ${ }^{22}$

In comparison to selected works of Chen Ran, I would focus on three among five of Amy Tan's novels, namely, The Joy Luck Club, The Kitchen God's Wife and The Bonesetter's Daughter. For the other two novels, The Hundred Secret Senses mainly portrays the misunderstanding and reconciliation of two half-sisters across cultures "with its emphasis on spirits,

\footnotetext{
20 The novella is abbreviated as "Sunshine" in brackets for the convenience of citation.

21 The novellas are abbreviated as "Toast," "Nowhere" and "Sound" respectively in brackets for citation

22 For Chen's works not translated into English, my own translation of relevant Chinese texts is quoted for the sake of analysis.
} 
magical time-shifts and other unearthly phenomena"23 (Bloom 93). Tan's most recent novel Saving Fish from Drowning, though full of metaphorical connotations, is more like an adventure story with philosophical implications. Due to limited space of the current dissertation and degree of relevance to its research focus, these two novels would be excluded from discussion. Although themes like mother-daughter relationship, heterosexual relationships and sisterhood appear in all the three novels, The Joy Luck Club develops around stories of four pairs of immigrant mothers and their American-born daughters; The Kitchen God's Wife is predominated by the life experience of a woman surviving from a sadistic husband and the scourge of war with a growing sense of self-consciousness, and The Bonesetter's Daughter travels in time to repair a lost matrilineal tie over three generations. Therefore, the three novels ${ }^{24}$ would be given different weight but with cross-referencing in the textual analysis during theme comparison

\section{B. Research Methodologies}

To answer the above questions, I would adopt the close reading method of New Criticism but will not be necessarily confined by it. While conducting comparative studies of the themes, rhetorical devices and writing strategies of the two writers, I would also draw upon ideas from identity theories,

\footnotetext{
${ }^{23}$ The quotation is from "The Salon Interview with Amy Tan: The Spirit Within" (12 November 1995) by Salon magazine included in the anthology Amy Tan edited by Bloom.

24 The three novels would be abbreviated as $J L C, K G W$ and $B S D$ respectively in brackets for citation.
} 
postmodern feminist theories and cultural studies to tie in the subjects of comparison with the writers' pursuit of a redefined female identity. Before an in-depth analysis of textual evidence, it might be helpful to give a brief review of the key notions concerned in the current dissertation.

\section{New Criticism Revisited}

New Criticism has "dominated literary studies from the 1940s through the 1960s" (Tyson 117). Although it is disputed by contemporary critics for its formalist nature, it has "left a lasting imprint on the way we read and write about literature" (ibid.). The theory of New Criticism replaces the dominant biographical-historical criticism of the nineteenth century and early decades of the twentieth century, which focused on "authorial intention" of a literary work instead of the text itself. The text-centered stance of New Criticism prioritizes the importance of literary text as the source of analysis, "using concrete, specific examples from the text to validate our interpretations" (ibid.). For New Critics, it is impossible to reach an objective understanding of the author's real intention, since different critics might impose their own "affective fallacy" in the process of analysis. However, compared to idiosyncratic reading process by different people, the text itself remains the same, with its meaning objectively constructed by a specific combination of words "in a specific order" (120). Therefore, the best way to understand a work, as perceived by New Criticism, is through close-reading-of-texts in order to find its "formal elements" that work 
together to support the theme with "universal human significance" (134). The "formal elements" that require "close reading" include setting, plot, characterization, point of view, images, symbols and metaphors, etc. (119). In terms of the symbolic significance implied by repeatedly occurring images, which would be one of the focuses of the current paper, what matters, according to New Criticism, is not whether the approach to analysis matches the writer's intention, but whether it supports what is claimed as the text's theme (126).

Besides the "formal elements," literary ambiguity and tension are also crucial to reveal "the complexity of human experience and of the literature that portrays it" (121). The central tension is defined as the opposing tendencies of the work to support the theme behind. It is through a scrupulous exploration of the text's formal elements, literary devices and the overarching theme that the goal of finding the "organic unity," the criteria proposed by New Critics to judige the quality of a literary work, could be reached (121-24). According to New Criticism, the greatness of a literary work is measured by whether the textual complexity is "complemented by a sense of order" (123). Therefore, all the "multiple and conflicting meanings" of a text produced by its "formal elements" and literary devices "must be resolved, or harmonized, by their shared contribution to the theme" (123-24).

Although New Criticism has been criticized for its exclusive emphasis on 
literary text while neglecting the external environment in which a work is created, the current author deems it important to apply such methodology for a careful search of textual evidence that brings Chen Ran and Amy Tan together. By investigating the two writers' preferences for the same themes with universal significance as well as similar imageries with symbolic significance, we can reach a deeper understanding of women's identity formation that runs counter to phallocentric definition. The dissolution of the tensions between mothers and daughters, men and women and women themselves are also attempted in the works of both writers, which points to women's struggling experience and unfulfilled dreams for the road ahead. To make up for the one-sidedness of textual analysis offered by New Criticism, the author will incorporate ideas from cultural studies by locating the text in the literary and socio-cultural background throughout the contemporary period with a hope to reach a more balanced conclusion of a comparative study on Chen Ran and Amy Tan.

\section{Identity Theories}

Since one of the main objectives of the current paper is to investigate women's reconstruction of their identities in a phallocentric world as exhibited in the fictions of Chen Ran and Amy Tan, the crucial point of departure is how to define identity and what previous scholarship has achieved on identity studies, a tracing of which might lay a sound foundation for a comparative 
study of the two writers.

The notion of identity has been an important area of study in psychology and social sciences. From psychological point of view, identity is defined as one's "self-image (a person's mental model of him or herself), self-esteem and individuality." 25 Erik Erikson is among the earliest psychologists on the study of identity. His psychosocial framework rests upon three interrelated dimensions on identity formation: the subjective or psychological dimension of ego identity which is based on "the immediate perception of one's selfsameness and continuity in time" (Erikson, Life Cycle 22), the personal identity characterized by personal idiosyncrasies that makes one distinguishable from others, and the social or cultural identity, involving recognized social roles one has to play within a community. ${ }^{26}$ Although Erikson introduces social aspects into his multidisciplinary theorization, the main focus of his research is still on the psychological concept of the ego identity and how it is formed throughout one's lifespan. According to Erikson's theory on the eight stages of psychological development, the fifth stage of fidelity, ${ }^{27}$ typical for adolescents from 13 to 19 years old, is a crucial period of psychosocial crisis when a person begins to develop a sense of sexual identity. It is also during such a transitional period

\footnotetext{
25 "Identity (Social Science)." Wikipedia. 24 Feb. $2010<$ http://en.wikipedia.org/wiki/Identity_(social_science)>. 26 The three dimensions of Erikson's identity theory are summarized by Cote and Levine as three forms of continuity: "a sense of sameness of the self with itself; interrelationships between the self and the other; and functional integrations between other and other" (16). A discontinuity in the second realm might destabilize people's personal identity with others, though a strong sense of ego identity can help mend the relationship. Similarly, unstable community relations are detrimental to one's social identity in the third continuity (ibid.).

${ }^{27}$ Here, fidelity refers to the ego quality dependent on this stage, namely "the ability to sustain loyalties freely pledged in spite of the inevitable contradictions and confusions of value systems" (Erikson "Reflections" 23, qtd. in Stevens 50).
} 
that an adolescent encounters the problem of role confusion caused by "a reluctance to commit" (Stevens 50 ). However, given enough time and space for free experimentation and exploration, "a firm sense of identity, an emotional and deep awareness of who he or she is" might emerge as one enters into adulthood (ibid.). As Cote and Levine note, although Erikson has been accused of "various forms of androcentrism and Eurocentrism in his formulation of life-stages," and his theory of identity is "by no means exhaustive or fully formalized," Erikson lays the foundation for subsequent attempts by scholars to construct "a comprehensive, multidimensional theory of identity" (17). ${ }^{28}$

While psychologists are more interested in an individual's mental processes and perception of oneself, sociologists are more concerned about a person's interaction with social structures in the process of constructing one's identity. The notion of identity in sociological terms is defined as "the way that individuals label themselves as members of particular groups," from which springs different forms of identity at focus, be it ethnic identity as the major concern of post-colonialist enquiry or gender identity prioritized by feminist and queer theorists. ${ }^{29}$ Modernist approaches to identity in sociology, summarized by Weigert et al., encompass five theoretical traditions: "processual and

\footnotetext{
${ }^{28}$ Erikson's identity theory is followed by Marcia's neo-Eriksonian framework of empirical research known as the identity status paradigm, which argues that an individual's sense of identity is based on individual choice-making and commitments concerning certain personal and social conditions (Cote and Levine 18).

29 "Identity (Social Science)." Wikipedia. $24 \mathrm{Feb} .2010<\mathrm{http}$ ://en.wikipedia.org/wiki//dentity_(social_science) $>$.
} 
structural symbolic interactionism (SI), ${ }^{30}$ sociology of knowledge, structural-functionalism, and critical theory" (1-2). According to Symbolic interactionism, social reality is continuously created by humans through symbols they attach to things in their ongoing social interaction that create and modify their identities (Cote and Levine 33). Sociology of knowledge advocated by Berger and Luckmann combines nominal assumptions of the social world and physical reality of human existence. In other words, the construction of reality takes root in "cultural and historical circumstances," but can exert real consequences for human existence (37). The structural-functionalist tradition with Talcott Parsons as its main proponent is more concerned with the interdependent subsystems of a society that function to maintain social order, while the differentiation and pluralization of societies might create widespread identity problems (38). The trend of critical theory represented by Habermas interprets identity as grounded in an interaction between individual and social development through three layers of analysis, namely, the interactive-communicative, the cognitive-affective, and the social-structural (39).

Compared with modernist approaches to identity that are based on an authentic self or core, the postmodernist understanding of the self "is

\footnotetext{
30 The processual SI in identity studies is represented by the Chicago School that emphasizes qualitative investigations and nominalist perspective in its interpretation of identity in constant adjustment to the symbol system. The Iowa School of structural SI, on the other hand, favors "quantitative methodologies and realist assumptions" and believes in a fixed and relatively stable sense of self as against a precarious one "in need of continual reconstruction" (34).
} 
characterized as decentered, relational, contingent, illusory, and lacking any core or essence" (Gecas and Burke 57). Such an understanding, which obliterates the necessity of identity studies, is counterbalanced by late modernist perspectives on identity that the current paper finds more affinity with. In Modernity and Self-ldentity: Self and Society in the Late Modern Age (1991), Anthony Giddens incorporates earlier functionalist approach with symbolic interactionist views. Acknowledging the destruction of social contexts by industrial capitalism that causes identity crisis, Giddens deems it essential to establish a connection between the abstract system and the self as a "reflexive project" (32). Giving credit to Wallerstein and Blakeslee's study on the construction of a "new sense of self" by "reaching back to one's early experiences" (33), Giddens highlights the importance of the "altered self" in modernity to be explored and constructed "as part of a reflexive process of connecting personal and social change" (ibid.). To Giddens, self-identity "is not a distinctive trait, or even a collection of traits, possessed by the individual; it is the self as reflexively understood by the person in terms of his or her biography" (53). To explain this argument, Giddens writes:

A person with a reasonably stable sense of self-identity has a feeling of biographical continuity which she is able to grasp reflexively and, to a greater or lesser degree, communicate to other people. That person also, through early trust relations, has established a protective cocoon which "filters out," in the practical conduct of day-to-day life, many of the dangers which in principle threaten the integrity of the self. [...] A person's identity is not to be found in behaviour, nor - important though this is - in the reactions 
of others, but in the capacity to keep a particular narrative going (italicized in the original, 54)

Based on the above review, we may find much relevance between identity theories and the two writers' literary creations driven by their perennial quest for a spiritual home of women. Interpreted from Erikson's psychological dimensions of identity formation, both Chen Ran and Amy Tan have experienced an identity crisis due to an absence of a father figure in their life experiences and a sense of displacement in societies they do not feel at home. Correspondingly, a central theme in the two writers' literary creations is their heroines' crises in the ego, personal and social identities and their attempt to overcome such crises through a renewed understanding of mother-daughter relationship, heterosexual relations and sisterhood. Viewing from sociological dimentions, the multiple connotations of one's identities are tackled with by the two writers, whose heroines are searching and living out their own definitions of gender and cultural identities. Anthony Giddens's theory of identity formation through one's reflexive biography maintenance also converges with the writings of Chen Ran and Amy Tan, both bearing biographical features and self-reflection of past life experiences in their shared pursuit of women's wandering identities. ${ }^{31}$

\footnotetext{
${ }^{31}$ The autobiographical features of Chen Ran's writings, such as the recurrent heroine Dai Er in her stories who live with her divorced and over-protective mother just like Chen Ran herself and the writer's unique perspectives on the protagonist's growing experience in A Private Life, are recognized by several critics. For example, in Personal Matters: Women's Autobiographical Practice in the Twentieth Century China, Wang Lingzhen labels $A$ Private Life as an "autobiographical novel" that wins Chen Ran the "popular title of "privatized/personalized writer" (166-167). As for Amy Tan, she expresses on several occasions in interviews and her memoir The Opposite of Fate that the inspiration for her literary creation comes from the life stories of her mother, her grandmother and herself caught between the two worlds.
} 


\section{Feminism and Its Postmodern Turn}

Feminism, which could be defined as "a belief in sexual equality combined with a commitment to eradicate sexist domination and to transform society" (Humm 1), has experienced three waves of development in its historical evolution from a political movement to an interdisciplinary theory that draws upon and gives reference to seemingly divergent schools of thought. With its revolutionary spirit originating from Mary Wollstonecraft who argues in A Vindication of the Rights of Woman (1792) that women should be included in the "masculine project" to attain opportunities and access to public affairs as men of a similar class (Beasley 31), the first wave of feminism surged from mid nineteenth century to 1920 s with an aim to criticize the dominant Western thinking of Liberalism that excludes women from its idea of "a universal standard for social and political rights and selfhood" (18). First-wave activists "created a new political identity of women and won for women legal advances and public emancipation" (Humm 14) in the form of women seeking suffrage and equal rights in education, work and family.

The second-wave feminist movement that began in the 1960 s and lasted throughout the late 1970s mainly focused on "two aspects of women's difference" (Flotow 6), one prioritizing gender difference between men and women over biological difference and the other de-emphasizing differences among women themselves in order to stress the "collective consciousness" of 
women as a group to promote social change (Wright $X V$ ). Unlike the first-wave claim for universality, feminist approaches during the second wave evolved from calling for women's inclusion into the androcentric standard of liberal rights to an advocacy of "gynocentrism" or women-centered beliefs and identities that emphasized gender difference (Beasley 20). Hailed as "the mother of second-wave feminism," Simone de Beauvoir published her influential work The Second Sex in 1949. Although not popularized until almost two decades later, the work is regarded as a masterpiece in feminist literature and has a significant impact on the second wave of the feminist movement. In this book, Beauvoir examines the experience of women perceived as the "Other" throughout the patriarchal history and puts forward the famous sentence that "One is not born, but rather becomes, a woman" (267), which prioritizes a separation of sex from gender, ${ }^{32}$ a crucial distinction "to the long-standing feminist effort to debunk the claim that anatomy is destiny" (Butler, "Sex and Gender" 35). Beauvoir also points out the binary opposition between men with positive associations and women who are negatively defined as the lack, the Other and the second sex.

Another important figure during this timeframe is Betty Friedan, whose bestseller The Feminine Mystique published in 1963 is generally believed to signal the formal beginning of second-wave feminist movement. Friedan points

\footnotetext{
${ }^{32}$ According to Beauvoir, sex refers to one's biological constitution that is "invariant" and "anatomically distinct" (Butler "Sex and Gender" 35), whereas gender is the variable "cultural meaning and form" that body acquires as a result of social construct and acculturation (ibid.).
} 
out in her book "the problem that has no name" perplexing many American housewives at the time - the "nameless aching dissatisfaction" with their feminine roles designated by the patriarchal ideology (79). Based on an extensive survey on American women's satisfaction with their lives and a study of women's magazines in the early 1960s, Friedan hypothesizes that women fall victim to a false belief system that deprives their identity and locates their meaning of life in domestic obligations. Besides Friedan, activists like Gloria Steinem and Beatrice Faust took an active part in reform-oriented women's organizations like NOW (National Organization of Women) and NWPC (National Women's Political Caucus) in the U.S. and WEL (Women's Electoral Lobby) in Australia. ${ }^{33}$ They argued that although having gained basic social and political rights, women were still judged as the inferior and the outsider not based on their merits, but simply on their sex (Tuttle 182). Whereas first-wave feminism focuses on removing legal obstacles to equality, second-wave feminist movement helps to enhance women's awareness to "see their personal lives as politicized and reflective of the sexist structure of power seen throughout society."34

It should be noted that although common understanding of the second-wave feminism is often associated to the politics of Liberal feminism, which aims to free women from the enslavement of oppressive gender roles

\footnotetext{
33 Friedan cofounded NOW in 1966 and joined other influential feminist leaders like Gloria Steinem in founding NWPC in 1971. In the Australian scene, Beatrice Faust founded the Australian lobby group WEL in 1972.

34 "Second-Wave Feminism." Wikipedia. 31 Mar. $2010<\mathrm{http} / /$ en. wikipedia.org/wiki/Second-wave feminism>.
} 
through political and legal reform, there are in fact other schools of feminist thoughts during this period labeled as Radical, Marxist and Socialist feminisms (Beasley 255). Radical feminism emphasizes women's shared experiences of being deprived of their sexual and reproductive rights by patriarchal gender relations. While proclaiming that "the personal is political" and all women are "sisters" (Tong 49), radical feminists aim to raise consciousness of women as a group to fight against the sexist tradition. Marxist and socialist feminisms, on the other hand, attempt to trace the fundamental cause of women's oppression not from sexism, but out of class conflicts and social strata. Whereas Marxist feminism aims to liberate women by dismantling capitalism characterized by economic inequality and class oppression that place women in subordinate status, Socialist feminism moves beyond class exploitation as the only reason behind women's subjugated fate. They try to "understand women's subordination in a coherent and systematic way that integrates class and sex" (Holmstrom 1).

Feminism during its third wave from 1980 s to the present emerged as a response to "the failures of and backlash against initiatives and movements created by second-wave feminism." ${ }^{35}$ Unlike the emphasis on women's shared experiences and solidarity within a unified social grouping during the second wave, third-wave feminists celebrate women's unique experiences in

\footnotetext{
35 “Third-Wave Feminism." Wikipedia. 31 Mar. $2010<$ http://en.wikipedia.org/wiki/Third-wave_feminism\#Postfeminism>.
} 
different historical and cultural contexts, believing that women are of "many colors, ethnicities, nationalities, religions and cultural backgrounds" (Tong 285). The second feature of third-wave feminism is its challenge to the "essentialist" definition of the female identity and sexuality emphasized during the second wave, which, as implied in Friedan's The Feminine Mystique, often presupposes a universal female identity represented by "white, middle-class, heterosexual, educated women" (28). Influenced by the postmodernist denial of essentialism and objectivity, third-wave feminism adopts a "nonjudgmental, nonprescriptive stance" and passionately embraces the concept that "there is no all-encompassing single feminist idea" (288-289). It prioritizes the "discursive power and the ambiguity of gender," incorporating a variety of theories ranging from post-colonialism and anti-racism to queer theory and transgender politics. ${ }^{36}$ Sex-positivity also serves as a watershed between second and third wave feminism. Deviating from second wave's oppositions to pornography, third wave feminists like Naomi Wolf emphasize the power of sexuality and sexual freedom as a key to women's liberation.

Postmodern feminism is a postmodern approach to feminist theory that became prominent in the 1990 s and 2000 s during the third wave of feminist movement. Borrowing ideas from deconstruction, psychoanalysis and post-structuralism, postmodern feminism rejects phallocentrism and "any mode of feminist thought that aims to provide a single explanation for why ${ }^{36}$ (ibid.) 
women are oppressed" or the steps women should take to achieve liberation (Tong 270). In her 1990 book Gender Trouble: Feminism and the Subversion of Identity, Judith Butler deconstructs the previous distinction between sex and gender $^{37}$ and puts forward her idea of gender identity as a cultural performance. For Butler, the notion of gender does not have a given attribute, but is rather "fragile, provisional, unstable, the sum total of its appearances rather than the expression of a unifying core" (Clover and Kaplan xxvi). Butler deploys psychoanalytic theses on the ego and the Oedipus complex and argues that "heterosexual melancholy is culturally instituted as the price of stable gender identities" (Butler, Gender Trouble 89). Drawing upon Freud's psychoanalytic theory on the formation of one's gender identity, Butler argues that the ego is gendered and its gendering process is realized "by means of the passage through the Oedipus complex and the loss of debarred attachments to same-sex objects" (Harrison and Williams 192). However, Butler also challenges Freud's essentialist and heterosexual implications. For Freud, a boy overcomes Oedipus complex by choosing to identify with his father out of the fear of castration. This is problematic for Butler, who finds Freud's argument inconsistent with his assertion of bisexual disposition in children before they establish their gender identities, in which sense a child could actually internalize with both the father and the mother. According to

\footnotetext{
${ }^{37}$ Butler challenges the understanding among second-wave feminists that "sex" is biological and "gender" is culturally constructed. Such distinction is false because, according to Butler, "sex" is also discursive and cannot signify without "gender." Within the territory of heterosexuality, both "sex" and "gender" are constructed.
} 
Butler, the father is chosen by the boy because of the societal pressure to be heterosexual instead of being stigmatized as a homosexual. Therefore, heterosexuality is institutionalized through the suppression of the homosexuality naturally situated in one's disposition so as to maintain the patriarchal rule of law. Developing from this idea, Butler sees the potential of non-heterosexuals as transcending the binary opposition "to challenge the norms of gendering and expose them as constructed rather than natural" (Bradley 75).

French psychoanalytic feminist Julia Kristeva holds a similar view that masculinity and femininity are not binary oppositions but coexist in each individual in varying proportions (Grosz 96). In "Women's Time," Kristeva summarizes three phases of feminism that might be comparable to three waves of feminist ideological evolution. While rejecting the first phase that neglects sexual differences in its advocacy of universal equality and the second phase for its preoccupation with "the specificity of feminine psychology" and its pursuit of a language for women's "corporeal and intersubjective experiences" silenced by patriarchal cultures (208), Kristeva endorses what she terms as the third phase of feminism that explores multiple identities and sexualities. Opposing the idea of identifying the feminine with biological women or the masculine with biological men (Tong 159), Kristeva states, "The belief that 'one is a woman' is almost as absurd and obscurantist 
as the belief that 'one is a man.' [...] [A] woman cannot 'be'; it is something which does not even belong in the order of being" ("Woman Can Never Be Defined" 267). ${ }^{38}$ She argues that upon entering the Symbolic order, a child may choose to identity with either the father or the mother and will be more or less feminine or masculine depending on the choice made (Tong 159). With the dissolving of binary oppositions between the two genders, the presumption of heterosexuality is on a shaky foundation. Therefore, "undifferentiated identity" of androgyny or bisexuality ${ }^{39}$ is one of the major themes of postmodern feminism.

Another feature of postmodern feminism is to emphasize the discursive power of femininity and sexuality in its fight against the phallocentric culture. Recognizing the "discourse of power that designated the phallus as the defining centre of all systems of value and knowledge" depriving women of their own voice (Madsen 22), famous postmodern feminists like Hélène Cixous, Luce Irigaray and Julia Kristeva, or often categorized as French feminists, call for a new form of writing that welcomes diversity and multiple realities. Instead of following the tradition of "master narrative" characterized by "the patriarchal preference for singularity, coherence and unity" (ibid.), there is a shift to "feminine writing" or "body writing" that aims to replace singular, unitary and

\footnotetext{
38 "Woman Can Never Be Defined" was first published in 1974 and was included in New French Feminism: An Anthology. Ed. Elaine Marks and lsabelle de Courtivron. Sussex: Harvester Press, 1981. The page number for the quotation here is from Feminist Literary Theory: A Reader edited by Mary Eagleton.

The postmodern feminist idea on bisexuality could find its cultural trace from the works of many artists during late twentieth century, such as Mapplethorpe's portrait of Lisa Lyon (1982) that presents the startling union of feminine figures with masculine muscles and character.
} 
symmetric patriarchal Symbolic Order with the feminine Imaginary Order that is "associated with multiplicity, difference and asymmetry" (96).

From the above review, we may detect some similarities between postmodern feminist ideas and the writings of Chen Ran and Amy Tan. Sharing the concerns of Butler and Kristeva, protagonists in the fictions of both Chen and Tan are troubled by an identity crisis and attempt to reconstruct their own identities free from the essentialist and heterosexual definitions. Besides, the themes of mother-daughter relationship and sisterhood favored by both writers tally with, though with different emphasis, French feminists' advocacy of a revolutionary feminine writing. If Chen's portrayal of female same-sex love and her eroticized language converge more with Butler's subversive gender politics to challenge the heterosexual matrix and urge by Cixous and Irigaray for a new style of "feminine writing," Tan's preoccupation with matrilineal talk-story ${ }^{40}$ seems to put into practice Kristeva's call to reinforce women's maternal link with their mothers by returning to the pre-oedipal domain beyond the reach of patriarchal discursive power. The deployment of images and metaphors by Chen and Tan serves as a further proof to postmodern feminists' celebration of fluidity and multiplicity inherent in the long suppressed femininity. Therefore, a detailed investigation into the two writers' fictions from comparative perspectives, an area of research without much attention from

\footnotetext{
40 The talk-story narrative strategy is a marked feature of Tan's novels. It is defined by Maxine Hong Kingston, one of the most renowned Chinese American women writers, as "an oral tradition of history, mythology, genealogy [...]" that encompass "an essential part of family and community life" throughout generations (Medoff 257). For a detailed interpretation of Tan's talk-story narrative, please refer to Section B of Chapter Six.
} 
previous scholarship, might provide us with a fresh view on the literary pursuit of Chen Ran and Amy Tan.

\section{Previous Scholarship on Chen Ran and Amy Tan}

\section{Chinese and Western Studies on Chen Ran}

The previous studies on Chen Ran are mainly confined within the sphere of Chinese literature, mostly in the form of journal articles. According to China's Academic Journal Database, there are over 450 journal articles and 36 M.A. papers ${ }^{41}$ with "Chen Ran" as the keyword, mainly focusing on Chen's personalized writing style, the connotations of her "gender transcendent consciousness" and the feminist consciousness of Chen as reflected in the characters and plots of her novels. Dai Jinhua's paper on Chen Ran is influential and among the first critical reviews on Chen's personalized and female writing style. In this paper entitled "Chen Ran: Personalized and Female Writing" (Chen Ran: geren he nüxing de shuxie), Dai, the famous Chinese feminist critic, defines Chen's personalized writing and provides a comprehensive analysis of the major themes in Chen's writing including the scene of father's absence or replacement, of mothers and daughters, and of sisterly bond among women. Dai also traces in Chen's stories imprints from psychoanalysis and feminist ideas, giving credit to Chen for her bold attempt to set a landmark for women's writing in the 1990s (Dai, 56).

\footnotetext{
4) The papers were retrieved from China Academic Journal database on Feb. $2^{\text {nd }}, 2010$
} 
Xu Kun, another well-known Chinese critic and woman writer, also makes in-depth analysis of Chen Ran. In her critical review of Chinese female literary creation in the $1990 \mathrm{~s},{ }^{42} \mathrm{Xu}$ positions Chen to be the most representative writer in 1990s with a strong sense of female consciousness and feminist ideas. According to $\mathrm{Xu}$, Chen Ran is actively seeking feminist theoretical backup for her literary creation. Xu defends Chen's personalized writing against the accusation of "private sexual discourse" (xing siyu) by critics upholding the patriarchal discourse of domination. In Xu's eyes, the private experience depicted in Chen's writings is not exclusively female, but incorporates the uniqueness and qualities that set a thinking person apart from the others in the society. Xu highly values Chen's attempt to explain the dilemma of women in China that permits no private sphere and equates her study of Chen's writing of equal importance as investigating into the history of human civilization and women's struggle in a patriarchal tradition. In "Double Tunes on A Night Boat: Female Writing of the 1990 s", $^{43}$ Xu Kun connects contemporary Chinese women writers Tie Ning, Zhang Jie, Wang Anyi and Chen Ran with their attempt of tracing the matrilineal bond broken by phallocentric discourse through their rewriting mother-daughter relationship. Xu categorizes Chen's depiction of mother-daughter relationship as an extension of sisterhood. In Chen's fictional world, mothers and daughters experience love-hate

\footnotetext{
${ }^{42}$ Please refer to "Lamp Light behind Layers of Curtains: Chinese Female Writing in the 1990s" in Writers 8 . (1997) by Xu Kun. Xu's critique is in Chinese; its English title is translated by the current author.

43 The article is written in Chinese with its title translated by the current author.
} 
interdependence in the female castle built by their lonely selves. Though always trying to escape from their mothers' overwhelming love, the daughters ultimately return to the mothers with a deeper understanding of their shared fate and identity (Xu, "Double Tunes" 154).

Due to the marginal nature of Chinese literature in the world and the limited translations ${ }^{44}$ of Chen Ran's works, Chen Ran is almost invisible to Western readers and researchers though her writing and ideas are by no means in the shade when compared with Amy Tan. So far, the name of Chen Ran is only mentioned in a few anthologies on Chinese literature, ${ }^{45}$ mainly of introductory nature, commenting on Chen's status in Chinese literature and her personalized writing style. Among the few academic books in English - The Emerging Lesbian: Female Same-Sex Desire in Modern China includes some in-depth discussion on Chen Ran. In this book, Sang investigates shifting representations and effects of female same-sex love through four chapters, namely, premodern China, republican China, China after Mao and Taiwan after martial law. ${ }^{46}$ The discussion on Chen's writing is included in Chapter Three

\footnotetext{
44 The story "Breaking Open" was translated by Paola Zamperini and included in the anthology Red Is Not the Only Color: Contemporary Chinese Fiction on Love and Sex between Women, Collected Stories. The novel $A$ Private Life was translated by Howard-Gibbon and published by Columbia University Press. Another translated story of Chen is "Sunshine between the Lips" included in Chairman Mao Would Not Be Amused: Fiction from Today's China.

45 Please refer to the introduction and critical biography on Chen Ran in Red Is Not the Only Color: Contemporary Chinese Fiction on Love and Sex between Women. Collected Stories edited by Sieber, Patricia and a brief introduction of Chen Ran in Chairman Mao Would Not Be Amused: Fiction From Today's China edited by Howard Goldblatt.

${ }^{46}$ The watershed between "premodern China" and "republican China" is the year 1911, when Xinhai Revolution broke out that put an end to the reign of the Qing Dynasty and led to the founding of the Republic of China. The period labeled by Sang as "China after Mao" refers to the period since the People's Republic of China was founded in 1949. The Martial Law was imposed in 1948 by the Kuomintang-led Republic of China government with the aim to suppress Communist activists in Taiwan and was not lifted until 1987.
} 
under the subtitle "Gender-Transcendent Consciousness and Private Life." Sang states that Chen is wrongly "accused" as a writer of narcissism (zilian) and narrowness (zibi) by many critics in academic journals and that "detailed textual analyses" on Chen are "surprisingly few" (201). Supported by her interview with Chen and excerpts from the novel A Private Life, Sang explains the connotations of Chen's "gender-transcendent consciousness," which, in her opinion, challenges heterosexual supremacy and represents Chen's strategy to describe lesbianism "in a language that is acceptable to the heterosexist society and state" (214). Based on a detailed plot analysis of $A$ Private Life, Sang concludes that Chen's writing carries a deeper meaning: the portraying of sexuality and female eroticism serves as a mirror to reflect Chen's humanistic concerns about life, society and human nature (222). In the chapter on literary experiments from China's New Cultural Scene: A Handbook of Changes, Claire Huot conducts a close reading of Chen's story "Breaking Open" and narratives written by two other contemporary Chinese women writers (Can Xue and Xu Kun) and three male writers (Ma Yuan, Ge Fei and Yuhua). ${ }^{47}$ After analyzing two dream scenes in the story, Huot concludes that the story embodies Chen's attempt to "struggle against congealed substantive identity" while "unceasingly and playfully rehearsing scenarios of sexuality" $(41)^{48}$

\footnotetext{
47 The writers are commented on separately without much cross-reference and the section concerned only composes one chapter of the book, which is therefore not counted as comparative literature studies.

${ }^{48}$ Comments on Chen's feminist language, her portrait of the imaginary m/other and the features of her "private
} 
Besides academic books, there are a few English journal articles on Chen Ran. In "Women and the Discourse of Desire in Postrevolutionary China: The Awkward Postmodernism of Chen Ran," Wendy Larson locates Chen's writing in the postmodern era of China. She first traces four manifestations of feminist engagement in contemporary China, namely, continued socialist approach against gender inequalities as a legacy from Maoist time, thriving "academic feminist dialogue" both home and abroad, a strong interest in women-related issues in popular books, and "creative involvement of elite artists, filmmakers, and writers" with gender concerns (202-03). These developments of feminist ideas in China are then analyzed from the perspective of postmodern discourse of desire. According to Larson, popular fiction writers and film directors "reinterpret past revolutionary ideology" either as suppressing erotic and sexual desires, ${ }^{49}$ or as releasing sensual passions. Though all of such erotic writings and films carry gendered implications, many are attacked by feminist critics as carrying a misogynist attitude (205). In contrast, Chen Ran stands out as a contemporary Chinese woman writer whose works embody "strong feminist expressions" that belong to Western discourse of desire in its glorification of jouissance, or female erotic subjectivity and construction of "a theory of the body" as a source of resistance, pleasure and reality (ibid.).

[or personalized] writing" could also be found sporadically in Personal Matters: Women's Autobiographical Practice in Twentieth-Century China by Wang Lingzhen.

${ }^{49}$ Larson lists writers like Zhang Xianlian and Su Tong as well as film directors Zhang Yimou and Hu Mei for their reinterpretation of "Maoist politicism as the inversion of personal erotic passion," and Jiang Wen's film Those Brilliant Days (yangguang canlan de rizi), on the other hand, as a typical representation of passion and erotic desires during China's Cultural Revolution. 
Larson categorizes Chen's writing into postmodern literature that centers on experience, sensation, sexuality, instantaneous perception, and a mixture of realism and abstractionism (ibid.). However, citing examples from Chen's short story "The Sound of Another Ear knocking," Larson points out that Chen's "discourse of desire" deviates from ludic postmodernist theory of desire ${ }^{50}$ in the sense that desire in Chen's stories loses naturalness to be "atomized" and "disembodied" (215), and her heroines are more interested in their own private lives with female sensibilities instead of "the overarching concern with any kind of determining meaning" (223). Larson's interpretation of Chen Ran's discourse of the desire from postmodern point of view is enlightening to the current author, who attempt to apply postmodern feminist theories as one way of approaching the major themes and literary devices in Chen's fiction. However, the author disagree with Larson's point that Chen's desire discourse is denaturalized and is confined within the narrow space of a woman's private life. ${ }^{51}$

While Larson reads an indifference and apolitical note from Chen's writings, Bonnie S. McDougall regards Chen to be in active engagement with political criticism through her unique writing style, a way of interpretation shared by the current author. In "Discourse on Privacy by Women Writers in

\footnotetext{
50 Larson borrows from Ebert the term of ludic postmodem feminism, which "constructed a theory of desire to stand for ideology" and "the context and the goal of expression and reality" (Larson 214). Ludic feminism, in Ebert's words, refers to "a feminism that is founded upon poststructuralist assumptions about linguistic play, difference, and the priority of discourse and thus substitutes a politics of representation for radical social transformation" (3).

${ }^{51}$ The significance of Chen Ran's personalized writing strategy with universal and sexual implications is elaborated in Section A of Chapter Six.
} 
Late Twentieth-Century China," McDougall approaches Chinese connotations and manifestations of privacy by analyzing women's privacy fiction and journalism. Chen Ran is discussed together with other influential contemporary women writers including Lin Bai, Wang Anyi and Tie Ning. McDougall describes Chen's novel $A$ Private Life as "openly autobiographical" and "a shocking challenge to orthodox critics" in its acknowledgement of female sexual (including same-sex) desires and its focus on individual subjectivity (101). Citing Robin Visser's comment on A Private Life, McDougall draws the conclusion that Chen Ran's novel stands as "political criticism of the meaningless collective life that persist in contemporary China" (ibid.).

Kay Schaffer and Xianlin Song provide a post-traumatic reading of the political signification in Chen's writings. In "Narrative, Trauma and Memory: Chen Ran's A Private Life, Tiananmen Square and Female Embodiment," Chen is compared with diasporic Chinese writers whose semi-autobiographical fictions, either in English or Chinese, that allude to China's political turmoil of the late $1980 \mathrm{~s}$, transpose direct political commentary into "new channels of recovery and new psychic, philosophical and cultural landscapes" through narratives that are often "boldly sexualized" (162). Based on a detailed textual analysis of Chen's A Private Life, Schaffer and Song aptly conclude that Chen's introspective writing style that "aligns a troubled inner consciousness to an embodied female specificity" enables Chen 
to "transcend the political" (162); the novel's challenge to patriarchal authority and its pursuit of "a fluid, feminine identity" demonstrate Chen's "deconstructive feminist stance" (162-63). ${ }^{52}$

In terms of comparative literature, several papers and dissertations could be found in the Chinese scene, comparing Chen's writing styles and feminist ideas reflected in her fiction to domestic women writers ${ }^{53}$ like Wang Anyi (Qi), Lin Bai (Xu Shan; Yu and Zhang; Yi; Fu Xiaoling; Lu Xiaofeng; Qiao and Wang; Wang Guanghua; Liang Xiangwei), and Wei Hui (Zhao Mengying; $\mathrm{Li}^{\mathrm{F}} \mathrm{Fu}^{54}$ ) as well as foreign women writers like Virginia Woolf (Li Xinshuang; Lu Yu), Radcliffe Hall (Tian), Marguerite Duras (Zhong; Shen; Fang), and Doris Lessing (Huang Ling). ${ }^{55}$ In papers or dissertations written in English, however, Chen is seldom singled out for one-to-one comparison. Instead, she is only included in a comparison of several Chinese women writers for an exploration into Chinese female discourse and literary genre. Besides the aforementioned McDougall's paper that compares Chen with three other contemporary Chinese women writers, three doctoral dissertations on modern and

\footnotetext{
${ }^{52}$ Chen Ran's name is also mentioned in papers introducing Chinese literary trend in the 1990 s such as "Postmodernism and Chinese Novels of the Ninetics" (Zhang and Berry 257) and "Personalized Writing' and Its Enthusiastic Critic: Women and Writing of the Chinese 'Post-New Era'" (Zheng 49).

${ }^{53}$ Wang Anyi, Lin Bai and Wei Hui are contemporary Chinese women writers. Wang who was bom in 1950s could be set against the second peak of Chinese female literature with an awakened awareness for women's unique femininity and independent status. Lin was born in 1960 s and are always categorized together with Chen Ran into the third peak of Chinese female literature that aims at dissolving gender confrontation by prioritizing women's subjective experience and retumed gaze on men. In comparison, writers born in 1970 s like Wei Hui take radical step forward by writing bluntly about women's body and sexual experience to cater to the consumerist culture.

${ }_{54}$ Fu's paper compares Chen with Lin Bai and Wei Hui and is thus cited twice here

55 Chen Ran is compared with Woolf for the female consciousness as manifested in their writings, with Hall for the theme of lesbianism in Chen's A Private Life and Hall's The Well of Loneliness, with Duras for their respective feminist ideas and narrative strategy, and with Lessing for the protagonists' image of the split self in $A$ Private Life and The Golden Notebook.
} 
contemporary Chinese literature take Chen's works as one of the sources for critical analysis. In the fourth chapter of "Corporeal Reform: Figuring the Body in Contemporary Chinese Narrative," Fu Binbin compares Chen with Wang Anyi and Ge Fei on their portrayal of postrevolutionary individuals whose libidinal energy is released through their construction of a private space. The relationship between body and femininity is also the focus of Lo Man-wa. In "Body Politics and Female Subjectivity in Modern English and Chinese Fiction," Lo conducts a literary-psychological-cultural study of the female body, subjectivity and sexuality. Analyzing different portrayals of the New Woman by a blend of male and female writers including D. H. Lawrence, Doris Lessing, Mao Dun, Xie Bingying, Ding Ling, Hualing Nie, Li Ang, Lin Bai and Chen Ran, Lo gives credit to Freud's "biological-psychological-cultural" model for its explanatory power of defining the female identity. Similar to Lo, Wei also proceeds from a cross-cultural perspective, but on the topic of motherhood. In "Femininity and Mother-Daughter Relationships in Twentieth-Century Chinese Literature," Wei Yanmei analyzes the discourses on motherhood and femininity by comparing Bin Xing, Zhang Jie, Chen Ran, Maxine Hong Kingston and Gish Jen. ${ }^{56}$ Based on textual evidence and socio-historical backgrounds, Wei argues that the representation of motherhood is not unified but gendered, culturally framed and historically constructed; it can help us better understand

\footnotetext{
56 Bing Xin (1900-1999) is a representative of the first generation of Chinese women writers during the cultural rejuvenation after the May Fourth Movement, or the New Cultural Movement of 1919. Zhang Jie and Chen Ran are categorized by Wei as women writers during the Post-Mao era since 1979. Another group for comparison, which Kingston and Jen belong to, is contemporary Chinese American women writers.
} 
cultural and ideological differences as well as the evolution of feminism in China. Robin Lynne Visser's doctoral dissertation "The Urban Subject in the Literary Imagination of Twentieth Century China" also involves a comparison of Chen Ran with other contemporary Chinese writers. However, the focus is not literary analysis but the definition of the urban subject of the twentieth century China as reflection in urban fictions during the period.

\section{Chinese and Western Studies on Amy Tan}

Compared with studies on Chen Ran that are mainly conducted by Chinese scholars, the research on Amy Tan has drawn much more attention from both Chinese and Western scholars. A search from China's Academic Journal Databank locates over 374 journal articles, 102 M.A. theses and 4 doctoral dissertations with "Amy Tan" as the keyword. ${ }^{57}$ The first Chinese journal articles on Amy Tan are Yin Guoming's "Searching for History and Reconstructing Memory" and Feng Yidai's "Amy Tan and The Joy Luck Club" published in 1993. Yin analyzes Tan's root-seeking attempt through her novels to reconstruct her diasporic identity as a Chinese American. Feng's paper is mainly of introductory nature, describing Tan's life experience that leads to her first novel The Joy Luck Club. Among the four doctoral dissertations, only Zou Jianjun's dissertation "Positive and Negative Dimensions of 'Harmony" ('he' de zhengxiang yu fanxiang) takes Amy Tan as the exclusive focus in his research,

${ }^{57}$ The papers were retrieved from China Academic Journal database on March. $21^{\text {st }}, 2010$. The four doctoral dissertations are written by Xiao Wei (2002), Chen Xiaohui (2003), Shi Pingping (2003) and Zou Jianjun (2008). The last three dissertations have been published in 2007, 2004 (in English) and 2008 respectively and hence will be cited as books in this research. 
which is comprehensive and ground-breaking in its analysis of Tan's five novels from an ethical point of view. ${ }^{58}$ According to the current author, the Chinese studies on Amy Tan's novels could be mainly categorized into five aspects: (1) on cultural clashes, root-seeking and identification between mothers and daughters from the perspective of cultural studies (Cheng; Liang and Jing; Zhang Ruihua; Wang Yongmei); (2) on female images and mother-daughter relationship from feminist perspectives (Bai and Fei; Zhang and Peng; Wen; Wang Fang); (3) post-colonialist studies of Amy Tan as a writer of ethnic minority and of Orientalist traces in her writings (Zhan; Sun; Zhang and Yue; Kang); (4) stylistic analysis of Tan's narrative strategies (Tan Anqing; Dai Fan; Jia), and (5) studies on ethical themes and their implications in Tan's novels (Zou; Wang Xiulian).

As for comparative literature in the Chinese scene, Tan is mainly compared with other Chinese American women writers like Maxine Hong Kingston (Zeng; Shi; Yu Xiujuan; Cheng and Shao; Zhao Lingxia; Chen Xiaohui; Xiao), Geling Yan (Chen Xiaohui; Xiao; Long), Jade Snow Wong (Zhao Lingxia), ${ }^{59}$ Hualing Nie (Xiao) and Fae Myenne $\mathrm{Ng}$ (Shi). ${ }^{60}$ Besides, Amy Tan is also compared with Toni Morrison for significance in the

\footnotetext{
58 As Zou explains in his published dissertation, the ethical studies of literature aim to incorporate the ethical themes reflected from a piece of work with an analysis of the social and ethical norms in the history and culture the work is projecting into.

${ }^{39}$ It is in the same paper that Lingxia Zhao compares Jade Snow Wong, Maxine Hong Kingston and Amy Tan in a diachronic manner in order to trace the evolution of Chinese American literary tradition.

60 Xiao, Chen Xiaohui and Shi include Amy Tan in their doctoral dissertation on Chinese American writers. Xiao compares Amy Tan, Maxine Hong Kingston, Hualing Nie and Geling Yan in terms of their female writing style within a hybrid cultural context. Chen compares Maxine Hong Kingston, Amy Tan, Gish Jen and Geling Yan to trace the differences and similarities in their themes and narrative strategies. Shi's study is based on a textual comparison of Kingston's The Woman Warrior, Amy Tan's The Joy Luck Club and Fae Myenne Ng's Bone.
} 
construction of ethnic cultural identity $(\mathrm{Ye})$ and Eileen Chang in terms of the mother image in their writings (Zhao Leiyan).

Turning to the Western academic attention on Tan, except for three literary companions on Amy Tan and one anthology of critical reviews, ${ }^{61}$ the number of English journal articles seems to fall far short from that in Chinese: only thirteen papers could be found from $\mathrm{JSTOR}^{62}$ the online full-text database on literature, and ten articles from EBESCO, mainly in the form of biographical reports and interviews on Tan. ${ }^{63}$ The topics of these articles are mainly post-colonialist analysis of the Orientalist discourse (Hamilton; Xu Ben; Ma) and narratology studies (Heung; Souris; Dunick) of Tan's novels. Deconstructive interpretation of history represented in The Kitchen God's Wife (Adams) and theater studies on the adaptation of The Joy Luck Club to stage performance (Conceison) are also topics for investigation.

Among English journal articles on Tan, two in the realm of comparative literature are worth noticing. They are Chen Xiaomei's "Reading Mother's Tale: Reconstructing Women's Space in Amy Tan and Zhang Jie" and Sau-Ling Cynthia Wong's "Ethnic Subject, Ethnic Sign, and the Difficulty of

\footnotetext{
${ }^{61}$ The literary companions by Huntley and Adams contain an introduction of Tan's biographical experiences as well as analysis of the plots, characters and themes of Tan's fictions. While Huntley (1998) only covers the first three novels of Tan, the later version of literary companion by Adams (2005) includes Tan's four novels published at that time, including The Bonesetter's Daughter. Snodgrass's companion is featured by a keyword-sorted reference to Tan's works. The anthology edited by Bloom is a collection of nine academic articles and one interview on Amy Tan, six focusing on Tan's first novel The Joy Luck Club, two comparing Tan with Maxine Hong Kingston in terms of their narrative strategies as Chinese American writers, and one on Tan's The Hundred Secret Senses, an excerpt from Huntley's literary companion.

${ }^{62}$ The papers were retrieved from JSTOR on Mar. $21^{\text {st }}$, including articles discussing Chinese American literature and writers.

${ }^{63}$ The only academic paper on Tan retrieved from EBESCO is written by Ruth Maxey, comparing Tan to Kingston on their deployment of the trope of ancestral homeland to confirm their Chinese American identity.
} 
Rehabilitative Representation: Chinatown in Some Works of Chinese American Fiction." Relevant to a cross-cultural study that the current dissertation is dedicated to, Chen Xiaomei compares Amy Tan's The Joy Luck Club and Zhang Jie's short story "Love Must Not Be Forgotten" (ai shi buneng wangjide) on the theme of mother/daughter bonding. Citing from Meng Yue and Dai Jinhua, ${ }^{64}$ Chen Xiaomei argues that a close mother-daughter bonding is an important prerequisite for "the establishment of a woman's tradition" and a vital step for a daughter to become "a female agency in her own right" (112). However, Chen reads more than a feminist note from the two writers' depiction of mother/daughter bonding. Supplementing Western feminist approach of interpretation, Chen applies Foucault's theory of power and Jameson's association of Third World Literature with "national allegories" and concludes that both Chinese American and Chinese daughters take the act of rewriting their mothers' tales "as symbolic and cultural capital for advancing their own literary and political status in their respective cultures" (130). Chen Xiaomei's attempt to interpret women writers from two cultures within the framework of western theories represents an inclusive attitude among Chinese comparatists on cross-cultural infiltrations and commonalities, a promising point of departure for the current project.

\footnotetext{
${ }^{64}$ Meng and Dai's book entitled Emerging from the Surface of History: A Research on Modern Women 's Literature (Fuchu lishi dibiao: xiandai funü wenxue yanjiu) is credited as a groundbreaking one by Chen Xiaomei in her paper. The book is the first of its kind to study Chinese feminine writing from a systematic feminist perspective. It provides critical reviews on nine Chinese women writers during the period from May Fourth Movement in 1917 to the Founding of P.R.C in 1949
} 
Wong's paper compares Fae Myenne $\mathrm{Ng}$ with Chin Yang Lee and Amy Tan from post-colonialist perspectives in their depiction of Chinatown in fictions. Analyzing works of Chin and Tan, Wong argues that unlike Chin who tries to reach narrative truth of Chinatown in its "self-Orientalization and the fetters it imposes onto the young" (256), Tan's portrayal of Chinatown is presented as story telling and loaded with positive cultural signs that the Chinese culture would always prevail in the "drama of East-West confrontation" (257). However, as Wong also points out, in her ethnic subject gaze of Chinatown, Tan plays a similar role as Chin in their mediation between the mainstream readership and the Orientalist spectacle of Chinatown (258). The paper concludes with a confirmation of Fae Myenne Ng's depiction of Chinatown, which Chin believes to be a genuine picture of a cultural community where residents truly feel at home (259).

Compared with journal articles, a search for English dissertations from ProQuest is more rewarding, with 75 finding results that contain "Amy Tan" in the abstract. ${ }^{65}$ But unlike the limited number of journal articles from the perspective of comparative literature, almost all the dissertations proceed from a comparative perspective, ${ }^{66}$ placing Tan among other writers to trace common themes or literary devices in their works. Amid all these comparative doctoral studies involving Amy Tan, Wendy Ann Ho's dissertation entitled

\footnotetext{
65 The dissertations were retrieved from ProQuest, the online databank for digital dissertations on Mar. 22nd, 2010 .

${ }_{66}$ All except one M.A. paper on a feminist analysis of mother-daughter relationship in The Joy Luck Club and The Kitchen God's Wife (Curton 1993).
} 
"Mother-and-Daughter Writing and the Politics of Location in Maxine Hong Kingston's The Woman Warrior and Amy Tan's The Joy Luck Club" might be the only dyadic comparison on Tan, positioning Amy Tan to the center of the scene instead of placing her among a group of other writers. Reviewing previous scholarship, Ho states that many Asian American and white critics misread Kingston and Tan in their assertion that both writers reproduce "exotica" in fictions so as to appeal to mainstream readership. According to $\mathrm{Ho}$, Kingston and Tan attempt to demystify exotic stereotypes through their talk-story tradition "for people to envision their multiple sense of selves $[\ldots]$, their sense of agency in the creation of history in a dynamic, everchanging Asian American landscape" (23). In her study of Kingston and Tan's writings on mother-daughter relationships, Ho aims to illustrate that Chinese American mothers are associated with a rich women's culture deeply rooted in China and "the changing dynamics of Chinese America" (7), and that their voices passed down through generations serve as "a powerful counter-memory to the patriarchal/imperialist master narratives, which attempt to appropriate, devalue, or destroy their stories and culture" (ibid.). The dissertation concludes that in their "autobiographical and semi-autobiographical fictions," daughter-writers Kingston and Tan "imaginatively seek out and give voice to the silences, secrets, fractures, and resistances" through the stories of their mothers and themselves in order to restore the "primary bonds" between women before 
they are "disrupted and divided" by patriarchal discourse (278). Ho's dissertation situates Kingston and Tan in their Chinese root, but counteracts stereotypical colonist readings of their works. Her illuminating ideas on the significance of the two writers' autobiographical narratives and the need for women to restrore the "primary bonds" against disruptive attempt of patriarchal discourse deserve futher exploration, according to the current author, especially from a cross-cultural and postmodern feminist point of view.

For the rest dissertations, the author tentatively categorizes them into three groups. In the first category that compares Tan with other Asian American writers like Maxine Hong Kingston, Jade Snow Wong, Gish Jen and Lan Samantha Chang, Shawn Hsu Wong, Chang-Rae Lee and Shirley Geok-Lin Lim, ${ }^{67}$ etc., the research focus varies from the writers' endeavor to seek ethnic identities (Om 1999; Li Guicang 2002; Gaffney 2003; Su 2004; Girard 2006) ${ }^{68}$ and the evidence of Orientalist discourse in their writings (Liu Hong 1998; Amato 2005) to cultural studies (Keaton 2002; Wong 2003) and research from the perspectives of narratology (Li Huihui 2001; Lu Shujiang 2001), psychoanalysis (Chen Fu-jen 2001) and Christianity (Blackburn 2004; Faries 2005).

The second category of dissertations compare Tan with other American

\footnotetext{
${ }^{67}$ Chang-Rae Lee (1965-) is a first generation Korean American novelist whose novels explore themes of alienation and frustration experienced by American immigrants, while Shirley Lim is a Malaysian American writer of poetry, fiction and criticism. The rest of writers in the list are all Chinese American.

${ }^{68}$ For the convenience of the readers to grasp the changing trend of research focus during the years, the time of $\mathrm{PhD}$ graduation is indicated here in parenthesis.
} 
ethnic women writers like Toni Morrison, Alice Walker, Sandra Cisneros, Julia Alvarez and Cristina Garcia ${ }^{69}$ or white women writers like Edith Wharton, Anne Tyler, Dorothy Allison, Louise Erdrich and Kaye Gibbons. Like that in the first category, the topics for comparison also include studies on ethnic and gender identities from post-colonialist and feminist perspectives (Young 1990 , Aldrich 1994, Ryan 1995) and investigations into the writers' narrative strategies (Mitchell 1993, Reid 1994, Schofield 1996, Smurthwaite 1998, Jacobi 2009). Other dissertations mainly proceed from the writers' prioritization of motherhood and mother-daughter relationship (Williams 1999, Chen Shu-Ling 2000, Ghosh 2000, McDaniels 2004, Anderson 2004, Lautin 2007) as well as women's struggle against patriarchy (Kreiner 2001, Chantharothai 2003).

The third category, which shares similar nature with the current study, involves a comparison of Amy Tan with Chinese women writers. But unfortunately, there is only one paper from such a perspective. In her doctoral dissertation entitled "The Social Construction of Female Selves in the Fiction of Li Ang, ${ }^{70}$ Wang Anyi, and Amy Tan," Huang Shu-ying applies feminist theory to interpret the construction of femininity that rejects the essentialist definition of unified "womanness." In her comparative study of the three women writers,

\footnotetext{
${ }^{69}$ Both Toni Morrison and Alice Walker are well-known African American women writers. Sandra Cisneros is a Mexican American writer whose works mainly deal with the formation of Chicana identity in an Anglo-American culture. Julia Alvarez is a Dominican American writer, while Cristina Garcia is a Cuban-born American journalist and novelist.

${ }^{70} \mathrm{Li}$ Ang (1952-) is a Taiwanese feminist writer, whose works are characterized by relating the construction of the female selfhood to sexuality (Huang Shu-ying 16).
} 
Huang recognizes the shared female consciousness exhibited in their fictions on women's experience, perception and emotions that are "framed within the context of Chinese culture modeled by different social circumstances" (1). According to Huang, Li Ang's description of female sexuality strongly attacks phallocentrism that deprives women's self-development and calls for the cultivation of female mind. Amy Tan highlights motherhood and female bonding as "the reservoir of women's empowerment" (5). Huang argues that female identity in Tan's fiction is "shaped by female solidarity and self-reliance" in the sense that "the mother-daughter bond defines and sisterhood affirms female selves" (5). Compared with Li Ang and Amy Tan's shared concern on developing female identity to rebel against patriarchal oppression on women, Wang Anyi, who also deals with female subjectivity and motherhood, is believed by Huang to be more politically motivated to challenge "social, cultural and political forces" on behalf of not only women but their male counterparts. While investigating the "impact of industrialization, modernization and sexual commoditization" in contemporary Taiwan on Li Ang, China's sweeping movement of Cultural Revolution on Wang Anyi and the struggling identity of Amy Tan caught between American and Chinese cultures, Huang concludes that the formation of female selves is not stable but subject to cultural and historical contexts. Huang's comparative study of three women writers from Chinese origin and her culturally-framed definition of female consciousness 
from feminist perspectives are inspiring to the current author in her cross-cultural comparison of Chen Ran and Amy Tan.

\section{A Point of Departure from Previous Scholarship}

From the above review, we may detect the following features of previous scholarship on Chen Ran and Amy Tan, which could be a point of departure where the current study will make some contributions. Firstly, in terms of the scholarly attention on the two writers, the research on Chen Ran and Amy Tan is quite limited and imbalanced in nature. Chen is mainly studied by Chinese scholars in the form of journal articles. Although Chen Ran is an important figure in contemporary Chinese literature, so far there is no doctoral dissertation on an exclusive study of Chen and her writings. As for the Western scholarship, Chen is almost invisible - few extensive studies except for some sporadic reviews on Chinese literature. Compared with Chen Ran, Amy Tan has attracted much more attention both in China and in the West, as can be proved by the number of Chinese and English journal articles and doctoral dissertations on Tan. But it should be noted that the Western studies on Tan are mainly from comparative perspectives in the broad sense, among which Tan is seldom prioritized for dyadic comparison. ${ }^{71}$ Besides, most comparative studies from Western scholarship are confined within comparing writers from

\footnotetext{
${ }^{71}$ According to the previous literature review, only Chen Xiaomei's journal paper and Wendy Ho's doctoral dissertation compare Tan to Zhang Jie and Kingston respectively, both proceeding from the mother-daughter perspective in Tan's fiction.
} 
the same region instead of venturing into cross-cultural comparison. ${ }^{72}$ Therefore, by conducting a comparative study of Chen Ran and Amy Tan, the author hopes to invite the Western world to hear, more or less, the voice of Chen Ran, a Chinese woman writer as one of the representatives of contemporary Chinese women, and gain a fresher understanding on Amy Tan, an American best-selling novelist writing stories about Chinese women.

Secondly, the research by previous scholarship only follows with interest in one or two features of Chen and Tan's writings. For example, among studies on Chen Ran, most are focused on her personalized writing style from feminist perspectives. Few are interested in mother-daughter relationships that exert great influence on Chen and can be found in most of her writings. On the other hand, while too much attention is paid to mother-daughter relationships, ${ }^{73}$ post-colonialist analysis and narratology studies of Amy Tan's novels, few attempts have been made to investigate the writings of Tan on her depiction of sisterhood or from postmodern feminist perspectives. ${ }^{74}$ Therefore, the second contribution this dissertation might make is to examine, from the fictions by Chen Ran and Amy Tan, women's pursuit of female identity through their

\footnotetext{
${ }^{72}$ Only Huang Shi-ying's doctoral dissertation takes such an approach by comparing Tan with women writers from mainland China and Taiwan.

${ }_{73}$ As Huang Shu-ying comments, since Amy Tan hit the time with her fist novel, "critics have engaged themselves in tackling the problematic relationships between mothers and daughters in this novel and her subsequent works" (9).

${ }^{74}$ In this field, there is only one doctoral dissertation by Aldrich (1994) that includes Tan's novel The Joy Luck Club in his discussion of "postmodem feminist novel of manners," which, according to Aldrich, explores the ways in which female identity is constructed by social constituents within a cultural system of domination. In Chapter Four on Tan's The Joy Luck Club, Aldrich argues that by "a series of highly subjective narratives," Tan poses a postmodern feminist challenge to grand narratives as well as the essentialist notions about womanhood and a "single ethnic identity (82-83).
} 
interaction with the outside world, which incorporates the three overarching themes in the fictions of both writers; namely, mother-daughter relationships, heterosexual relations and sisterly bond among women, so that we may reach a more thorough understanding of the two writers' literary creation.

Thirdly, as for the content of analysis, most studies on Chen, especially in the Western scene, take Chen's novel A Private Life as the main source of textual evidence instead of including her stories sparkling with thought-provoking wisdom. Likewise, although Tan has written five novels, ${ }^{75}$ the majority of Western critics only consider Tan's first novel The Joy Luck Club in their academic exploration. The current dissertation, however, incorporates the other fictions by the two writers with an aim to understanding their works in a more comprehensive manner.

Finally, in terms of the organization of comparative studies involving Chen Ran and Amy Tan, most place them along with other writers at focus in separate paragraphs or chapters. The current dissertation, however, is organized by the major themes and literary devices for a more immediate cross-referencing of the two writers' works during texual analysis. It is hoped that such organization of the materials might provide a clearer illustration of not only differences, but more importantly, similarities between Chen Ran and Amy Tan in their common pursuit for a reconstruction of women's self-identities.

\footnotetext{
75 The number excludes the two children's books written by Amy Tan.
} 


\section{CHAPTER II}

\section{MOTHER-DAUGHTER RELATIONSHIP - FROM REBELLION TO}

\section{RECONCILIATION}

\section{A. Tracing Mothers in Contemporary Western and Chinese Narratives}

The representation of mothers and mother-daughter relationship has experienced several stages of variation in the Western literary tradition, which is well traced by Marianne Hirsch in her influential book The Mother/Daughter Plot. The celebration of mother images and an emerging interest in telling mothers' bygone stories became a dominant feature for women writers in the 1920s. Deviating from the Victorian emphasis on "heterosexual plot of courtship, marriage, and adultery" (Hirsch 96), writers like "Virginia Woolf, Gertrude Stein, Willa Cather, and Colette," all ground their stories of female artists on "a powerful, seductive, traditionally female mother-goddess" (ibid.). ${ }^{76}$ Yet it is also pointed out by Hirsch that the mother-texts during the time are "elegies," composed by daughters until the mothers' death. Based on a plot analysis of Colette's Break of Day, Woolf's To the Lighthouse and Edith

\footnotetext{
${ }^{76}$ As Hirsch acknowledges in her book, the observation was first made in Literary Women by Ellen Moers, who termed the emerging preoccupation with mother-daughter relationships in women's writings during $1920 \mathrm{~s}$ as "maternal seduction" (Moers 354) and cited the above-mentioned writers as examples.
} 
Wharton's The Mother's Recompense, Hirsch argues that the mothers' role of "connection, reconstruction, and reparation" in the writings of the 1920 s could only be realized through the daughters' retrospective memory and narratives (97), and mostly through male presence as a means of mediation, which, in essence, is still confined within the heterosexual framework and does not change the mothers' status as the subjectless Other.

With an enhanced consciousness on gender difference against the background of "emerging political feminist movement," women writers and critics of the 1970s attempt to create "a new feminist subject" free from patriarchal subjugation by deemphasizing the role of men (127). As Elaine Showalter notes, women's literature of the 1970 s "goes beyond matrophobia," the rejection of and alienation from the mother to "a courageously sustained quest for the mother" ("Toward a Feminist Poetics" 135). Showalter cites Margaret Atwood's Surfacing and Lisa Alther's Kinflicks, in which the daughter witnesses and transcends the death of the mother, as two examples of "the most profound occasions" in 1970s' female literature" (ibid.). In Of Woman Born, Adrienne Rich challenges the separation between mothers and daughters forced by institutionalized "matrophobia" and urges all women to acknowledge and explore the mother-daughter bond as "the most formative relationship" defining "their identity and self-definition as women" (Hirsch 129). In her discussion of motherhood and daughterhood, Rich writes: 
The first knowledge any woman has of warmth, nourishment, tenderness, security, sensuality, mutuality, comes from her mother. That earliest enwrapment of one female body with another can sooner or later be denied or rejected, felt as choking possessiveness, as rejection, trap, or taboo; but it is, at the beginning, the whole world. [...] This cathexis between mother and daughter - essential, distorted, misused - is the great unwritten story, [...] minimized and trivialized in the annals of patriarchy. $(218 ; 225-226)$

According to Hirsch, "the impetus to return to a pre-oedipal, pre-verbal moment of origin" through mother-daughter bonding is meant to "provide an instrument for binding the fragments of self," and serves as the foundation for "a definition of gender difference" and a framing structure of subject formation that displaces fathers and other male figures from the "feminist family romance" (130). Such a view is supported by psychoanalytic feminists such as Nancy Chodorow, Luce Irigaray, Julia Kristeva and Hélène Cixous from the postmodern school of thought.

For Chodorow, American feminist sociologist and psychoanalytic, female identity is not based on the oedipal expulsion of the mother, but on the pre-oedipal identification with the mother: "The character of the infant's early relation to its mother profoundly affects its sense of self, its later object-relationships, and its feelings about its mother and about women in general" (Chodorow 77). According to Chodorow, the role identification of a girl is determined by her on-going attachment to her mother as the primary caretaker. Different from a boy who is supposed to "detach his heterosexual orientation from his mother" and identify himself with the father out of the fear 
for castration so as to resolve the Oedipus complex, a girl's "relationship of dependence, attachment, and symbiosis to her mother continues" as she enters into the Oedipus stage (129). Although according to psychoanalysts an oedipal girl "oscillates between attachment" to both of her parents, given the "normal situation of parenting" and personality composition, fathers cannot match mothers as "emotionally exclusive oedipal object" for girls (ibid.). In other words, women's "closeness to the mother" instead of their "shift of allegiance to the father" defines their development process in culture (Hirsch 132). As Chodorow claims, "the mother is very important in the daughter's psyche and sense of self, such that core psychological and interpersonal experiences for women can be understood in terms of this internal mother-daughter lineage" (Chodorow viii).

Similarly, Irigaray argues that the mother should no longer be "killed" to safeguard patriarchal dominance. "We must give her new life. [...] We must refuse to let her desires be annihilated by the law of the father. We must give her the right to pleasure, to jouissance, to passion, restore her right to speech, and sometimes to cries and anger" "The Bodily Encounter with the Mother" 43). In "When Our Lips Speak Together," Irigaray seeks to "rebuild the sensual/emotional relationships of women with their mothers and with other women, which have been censured in psychoanalytic theory" (289-290). 
As for Kristeva, the pre-symbolic realm of the "semiotic" $" 77$ is crucial for the constitution of subjectivity, which is not "predicated on the subject's denial" of the mother-child experience but "on the possibilities of its "(re)symbolization'" (Lechte and Margaroni 24). Kristeva points out that the patriarchal culture is safeguarded through "abjection" of and breaking away from the "maternal entity" (Powers of Horror 13). Therefore, a new discourse of maternity and one on the relationship between mothers and daughters should be created to counteract the logocentric tradition.

Cixous also elaborates on 'the 'maternal metaphor' for innovative women's writing and women's cultural politics" (Suleiman 277). In "The Laugh of the Medusa," she states with passion that "even if phallic mystification has generally contaminated good relationships, a woman is never far from 'mother' [....] as nonname and as source of goods. [...] Touch me, caress me, you the living nonname, give me myself as myself" (881-882). In Cixous's text, it is the newly-defined mother that "allows the woman to oppose both the Name-of-the-Father and the father's parsimonious economy" (Suleiman 277). As Hirsch comments, the psychoanalytic feminists' emphasis on "the formative influence of the pre-oedipal period" and a desire to "reexperience symbiotic union with the mother" results in the birth of a language

\footnotetext{
${ }^{77}$ One contribution of Kristeva is her distinction of the "semiotic" and the "symbolic," the two elements composing the mechanism of signification. The semiotic element is the "bodily drive" associated with "the rhythms, tones, and movement of signifying practices" characterizing the maternal body as the origin of all human beings. The Symbolic element, on the other hand, is linked to "the grammar and structure of signification" that situates the referential nature of language in the traditional sense (Oliver, "Kristeva and Feminism")
} 
characterized not by "lack" but by "a form of plenitude, a myth of a mother-tongue" that defies patriarchal definition (132). As a result, the plot in women's writings in the 1970 s and early 1980 s is not on the daughters' successive separation and distancing from the mothers, but rather on their struggle with the maternal bond both powerful and painful that "threatens engulfment and self-loss even while it offers the very basis for self-consciousness" (133). ${ }^{78}$

Along with the postmodern challenge to the essentialist definition of woman "as a singular, unified, transparent category" (Hirsch 12), motherhood has been accredited with new significance. Being both mother and daughter, the figure of the mother symbolizes the multiplicity of women. Although her representation is subjected to her object status, the discourse of the mother, when voiced, turns her from object into subject (ibid.). Besides, the postmodern era also witnesses a shift from women's shared experience to a recognition of difference among themselves in terms of race, class and sexual orientations, which has exerted great influence on feminist theorizing as well as studies of motherhood and mother-daughter relationship (Shi 26). In "Shifting the Center: Race, Class, and Feminist Theorizing about Motherhood," African American feminist Patricia Hill Collins introduces a new theoretical framework that includes the unique experiences of women of color. For Collins,

\footnotetext{
${ }^{78}$ In The Mother/Daughter Plot, Hirsch analyzes three novels written between 1972 and 1984, namely Margaret Atwood's Surfacing, Marguerite Duras' The Lover and Christa Wolf's Patterns of Childhood, all reflect upon the narrators' childhood and adolescent experiences and portray "private relationships of several generations of female protagonists" amid historical events and displace male figures from the foregrounds of their stories (Hirsch 138).
} 
motherhood serves as a means through which women can "express and learn the power of self-definition, the importance of valuing and respecting themselves, and the necessity of self-reliance and independence" (Shi 46). She also explains the reasons behind ethic mothers' struggle for maternal power and different choices they make to prepare their children to "fit into, yet resist, systems of racial oppression" (52).

While a review of Western literary tradition concerning motherhood and mother-daughter relationship might help us better understand Amy Tan's fictional preoccupation with a strong bond between mothers and daughters, the depiction of the mother-daughter entanglement in Chen Ran's works is also inseparable from the evolution of Chinese women's literature with an enhancing awareness of women's subjective identity. The Chinese literary representation of motherhood and mother-daughter relationship undergoes several paradigm shifts as a response to changing socio-cultural environment. In traditional Chinese literature deeply rooted in the patriarchal feudalist ideology that objectifies women as the "Other" to be named by men, mother-daughter relationship is rarely depicted, and the role of the mother is simply to carry the will of the father. It is not until the sweeping "literary activism in the wake of the May Fourth Movement" during the 1920 s with ignited female consciousness that the maternal figure is celebrated and idealized as "a staple of China's New Literature" (Lieberman 19). In poems, essays and short stories 
of the time, the mother is generally portrayed as a "gentle, nurturing figure, selflessly and naturally loving" (ibid.). In Emerging from the Surface of History, Meng Yue and Dai Jinhua argue that May Fourth women writers like Feng Yuanjun and Bing Xin construct in their writings "an unprecedented mother/daughter bonding" as an rebellious act against "an antagonistic father/son relationship" expressed in male writers of the time (Chen Xiaomei 111-12). But it is also noted by Meng and Dai that due to a lack of a gender history, the mother image created by May Fourth daughters is intangible and idealized as a signifier for love and sacrifice. The mother image has become the embodiment of truth, justice, beauty and love, which could be explained by taking into consideration the social reality in the 1920s. As Lieberman points out, the idealization of the maternal figure is crucial for young intellectuals as they deliberately and collectively seek to discover a "genuine human nature" as the basic guidance for them to handle more "human social relations" in the newly-constructed modern society (20). According to Xu Kun, maternal love from the mother glorified in Chinese literature in the 1920s, where emotional solace could be found, serves to cover and heal the rift between old and new cultures during the revolutionary period before a new balance is established (my translation, "The 'Crazy' Femininity" 5). The mother embodies "instincts" for "racial evolution and social progress," "natural" qualities that could serve as "the foundation for modern personhood" if properly cultivated, and love that 
would sustain "social relations in an envisioned modern society (Lieberman 49). Accordingly, the mother-daughter relationship is portrayed as harmonious, interdependent and blissful. It is in the unconditional and singular love from the mothers that daughters betrayed by their male peers can find warmth and nestling place for their troubling spirits away from political turbulence and harsh reality. By relying on and identifying with their mothers, May Fourth daughters embark on the path to rebel against their fathers and the patriarchal rule of law.

Compared with the deification of mother goddess by May Fourth daughters in their awakened pursuit of individual spiritual freedom, women writers in the 1930s like Xiao Hong and Ding Ling are more concerned with national survival and women's real living conditions in their realistic portrayal of enduring working-class or peasant mothers struggling against the oppression from a feudalist patriarchal tradition and the hardship during the scourge of war. In their attempt to identify with their "suffering, loving" mothers, the daughters have retrieved their mothers' buried stories as women's "collective experience" and endeavor to reconstruct their "subject position as individuals" (18, qtd. in Chen Xiaomei 112). The mother-daughter bonding in these specific historical and cultural contexts constitutes an essential prerequisite for "the establishment of a women's tradition" and "a crucial step" for a daughter to acquire her own female agency (ibid.). 
Although the female writings on motherhood and mother-daughter relationships during 1920 s and 1930 s, either in deified or realistic forms, embody the writers' attempt to discover the value and subjugated fate of the maternal figure, they still cannot escape the pervasive influence of the patriarchal discourse. Mothers' stories are mostly narrated from the daughters' or third-person point of view and the mothers are always sacrificing figures giving themselves up either to traditional gender roles of raising children and maintaining household or to the revolutionary course for national liberation. Departing from such literary convention, women writers in the 1940 s with Eileen Chang as the most prominent figure, begin to probe the suppressed desires from the mothers' perspective, which finally erupt and are deformed into cruel morbidity. Mothers in Eileen Chang's fictions are depicted as despicable, mean, selfish, and rapacious, preying on their own daughters and destroying their chance for love and happiness to satisfy their possessive desires. Though Eileen's portrait of mothers' evil image is shockingly different from her predecessors, she is actually subverting the maternal myth defined by patriarchal ideology and piercing through, behind the glamorous halo of mothers, a scene of desolation and desperation of numerous desiring girls turned into demonized mothers brainwashed by the patriarchal tyranny.

The following three decades after the founding of People's Republic of China in 1949 witnessed a vicissitude of political movements that obliterated 
gender difference and individualistic desires in its eulogization of revolutionary ideals and socialist collectivism. Both the 17-year literature (1949 to 1966) created during the grand socialist construction and literature during the Cultural Revolution (1966-1976) are characterized with a masculization of women heroes, who "hold up half the sky" and passionately engage themselves in the revolutionary construction of a new nation. It is not until 1980s that women's self-consciousness is recovered in women writers' renewed tracing of a ruptured matrilineage and rewriting of mother-daughter relationship. The literary representation of the mothers and mother-daughter relationship since 1980s is no longer a clear-cut dichotomy of good or evil, but an image of plentitude and multiplicity. From Tie Ning's portrayal of women of three generations competing for existence with conspiracy that reveals the dark side of human nature in Rose Door (meigui men, 1988) ${ }^{79}$ to Zhang Jie's touching recollection of the narrator taking care of her dying mother during her last days in Gone is the Person Who Loved Me Most (shijieshang zui teng wo de nage ren qule, 1994), from Wang Anyi's interlaced ${ }^{80}$ painting of the narrator's growing experience in Shanghai and her mother's ancestral history

\footnotetext{
${ }^{79}$ All the works cited in the discussion about Chinese literary tradition in this and the following chapters are written in Chinese with their original titles and first date of publication included in brackets. The English titles, except otherwise indicated, are borrowed from accepted translations in the encyclopedic introduction of the author concerned or the published English versions of these works, which are listed in the References of the current dissertation for the convenience of the Western readers. For those works not yet translated into English, the publishing information for the available Chinese versions is listed in the References.

${ }_{80}$ The odd chapters provide a synchronic description of the narrator's growing experience and the even chapters diachronically trace the mother's family history. Such a structure, according to the current author, implies a mutually dependent web of mothers and daughters who live through and imprint upon each other to form a complete picture of women's stories.
} 
gradually surfaced in Truthful and Fictitious ${ }^{81}$ (jishi yu xugou, 1993) to detailed depiction of mother-daughter entanglement that entails both conflicting torture and symbiotic bond in Chen Ran's fictions, the stories between mothers and daughters, mostly based on these writers' autobiographical experiences, are recounted through multiple perspectives free from phallocentric definition of the maternal myth. Featured by the absence of the father image, female writings in 1980s and 1990s represent the writers' conscious seeking and reconstruction of their identities lost in the patriarchal definition. In their painstaking unfolding of stories belonging to mothers and daughters, contemporary women writers like Chen Ran are determined to write a true history of her own, defying the Name-of-the-Father and the political agenda.

From the above review, we may discern some merging points between Chinese and Occidental literary representation of mothers and mother-daughter relationship since around 1980s, which might explain the similarities between Chen Ran and Amy Tan in their portrayal of mother-daughter relationship. Tallying with the postmodern challenge to authority, the mothers in their works have stepped out of the patriarchal rule of law as a source of the daughters' inspiration and power for their spiritual independence, while the fathers have receded into the obscurity behind the scene. As Hirsch advocates, "only in combining both voices" with not only the daughter's narrative, but also the voice of the mother empowered as a

${ }^{81}$ The title is the author's translation since the novel has not been rendered into English. 
speaking subject "that would yield a multiple female consciousness, can we begin to envision ways to 'live afresh'" (161). Secondly, the dichotomous division between the "Mother Madonna" and "Mother Demon" in women's writings of the previous generations has been deconstructed by a new discourse of mother-daughter relationship of multiple possibilities. Mothers are not always selflessly sacrificing, they also have their own dreams and desires; their love may not only provide comfort and protection, but also be threatening and stifling for the daughters who are eager to break away from the potentiality of over-identification and lost of selfhood. Thirdly, both writers emphasize the discursive power of language, giving a voice not only to daughters, but also to mothers to let out their own recount of women's forsaken history.

\section{B. A Thematic Comparison on Mother-Daughter Relationship}

The depiction of mother-daughter relationship in the works of both Chen Ran and Amy Tan plays a crucial role for the heroines' formation of their respective identities. For the mothers, their dreams unfulfilled are channeled into their daughters with all their life-long hopes as an important component in the process of their identity-formation. Falling victim to the male-centered power system, the mothers are also unconsciously acting as the surrogate of the patriarchy to control the daughters' lives. The daughters, on the other hand, rebel fiercely against the mothers' imposition of wills and desperately pursue 
their own identities free from the mothers' intervention. ${ }^{82}$ Nevertheless, after numerous conflicts, attempted escapes and even imagined matricides, the daughters finally see themselves in their mothers and return to a symbiotic reunion with the maternal origin. The following section would analyze and compare the evolving relationship between mothers and daughters in the fictions of Chen Ran and Amy Tan.

\section{Mothers' Dreams and Daughters' Rebellion}

One major form of mother-daughter relationship in the fictions of Chen Ran and Amy Tan is the misunderstanding between over-protective mothers and rebellious daughters. The mothers, with their dreams left unfulfilled due to collapsed marriage or sufferings in life, hold on to their daughters as an extension of their incomplete identities.

The mother image in Chen's fictional world is always characterized as an intellectual divorcee, living alone with her single or divorced daughter. For a mother already passing the primetime of her life, struggling alone in the world without a husband or other relatives, the daughter naturally becomes her only family and the whole meaning in life. As a result, the mother is forever on guard against any external force that attempts to "lure" the daughter away. As it is described in "Nowhere to bid Farewell," "after Dai Er's mother gets divorced,

\footnotetext{
82. The author is also aware of the cultural gap between Chinese mothers and their American-born daughters in Amy Tan's novels, which is one of the major reasons causing unavoidable mother-daughter conflicts. However, due to the limited space, the focus of the current dissertation is mainly from a feminist point of view without extensive elaboration on the cultural clash between the mothers and the daughters, a topic that has been well-explored by previous scholarship on Amy Tan.
} 
she directs all her attention and emotion to Dai Er," picking one of her daughter's most treasured friends in different stages of her growing experience as the "imagined enemy" to provoke an argument with Miss Dai Er when she feels "cold-shouldered or having received less attention than deserved" (my translation, ${ }^{83}$ 105). In "Redundant Roles," the mother would "pray for me when I'm not at home or when she feels for no reason at all that I might have an accident" (my translation, 197). Such "hysteric" love of the mother for the fear of losing her daughter has become an unshirkable burden for the daughter:

Her love becomes so burdensome for me. If there is someone in this world who loves you this way, you must be living an exhausted life. Sometimes, I'm trying to find out what's wrong between my mother and me. She is tiring herself out, making all kinds of sacrifice for the love of me; I'm also worn down with all kinds of uneasiness for her love. I couldn't figure out why we treat each other like this. But everything just goes on beyond our control. (ibid.)

In "The Sound of Another Ear Knocking," Dai Er, the daughter figure in most of Chen's stories, experiences an even more intense feeling of her mother's choking love, which she compares to "scissors cutting every single strand of passionate nerve within [her] body full of desires for the outside world" and "prison clothes sealing without a trace each pore [of her] from head to heal desperate for a loud cry" (my translation, 103). From the mother's perspective, the daughter Dai Er is her "only fruit" and "the sole support" for her "weary life" (131). Now in her declining years, when "men have long paled into

\footnotetext{
${ }^{83}$ Since only three fictions by Chen Ran have been translated into English, namely, "Sunshine between the Lips," "Breaking Open" and A Private Life, citations from all the other fiction are translated by the author and would be indicated as "my translation" in brackets only during first appearance.
} 
insignificance" and happiness long erased from her life dictionary, she is determined to "clench [her] teeth," gathering all her remaining strength to "make a way upstream" and "surmount the highest point of wind and waves" to resist, even at the cost of her life, any incoming calamities that might break down her mutually-dependent life with her daughter (ibid.). Sensing the impending death, the mother reflects upon her entire life of constant struggle in turbulence filled with regrets and despair. Her only wish is to protect her fragile and inexperienced daughter, the one that she cannot let go, away from the sufferings she has been through. The mother's whole-hearted love for her daughter is clearly reflected in her long soliloquy:

Nothing can obstruct my aging and infirm spirit to get a hold on my Dai Er. That is the last straw sustaining my life, the most brilliant trump card in my gamble with fate. My love for Dai Er would continue after death. [...] My epitaph would be inscribed by Dai Er in person, in a language we both love. Through a handwriting invested with her drifting spirit and soft body, we would be entwined together once and for all. [...] Dai $\mathrm{Er}$ is mine, alive or dead. ("Sound" 132)

Whereas the mothers' possessive love is deemed a heavy burden to the daughters in Chen's stories, mothers in Tan's The Joy Luck Club who are ambitious about their daughters' successful integration into the American mainstream society are "completely baffled by their daughters in whom they have put all of their hopes" (Huntley 51). The dreams of the Joy Luck mothers are metaphorically embedded in the novel's opening vignette about the story of the duck-turned-swan that the immigrant woman carries across oceans as she 
embraces the new world with limitless possibilities. Her future daughter would fulfill all her dreams in America with a woman's worth not "measured by her husband's belch," her English so perfect that nobody would look down upon her and her stomach "too full to swallow any sorrow" (JLC 17). Just like the ugly duck that grows into a beautiful swan way beyond the woman's expectation, she has full confidence to turn her daughter, who would carry her dreams, into an intelligent and capable woman with a complete control of her life and a clear sense of her self-identity.

Driven by the desire to reconstruct a lost identity dislocated by patriarchal subjugation and diasporic status in a country of immigration, the Joy Luck mothers put their past miseries behind and divert all their passion to the daughters. A typical example of such ambitious mothers in The Joy Luck Club is Suyuan Woo. Being forced to abandon her twin baby girls in China during the turmoil of war before fleeing to the U.S., Suyuan places all hopes on her American-born daughter June, whose Chinese name "Jing-mei" literally meaning "best quality" and "younger sister," embodies the mother's wish for June to be the essence of her three daughters. Suyuan's dream-building cultivation starts since June's childhood, exhausting all the possibilities arising out of ludicrous ideas. Believing her daughter's potential to be a Chinese Shirley Temple, Suyuan takes June to a beauty training school for a perm of curly hair which ends up in "funny Peter Pan haircut" (133). While cleaning up 
for other houses to make a living, Suyuan collects all kind of magazines with stories about prodigies and trains June accordingly every night after dinner. The tests become harder and more absurd each time, asking the little June to do mental arithmetic, find "the queen of hearts in a deck of cards" (134), stand on her head without the support of her hands and even predict daily temperatures in cities around the world. Inspired by The Ed Sullivan Show on TV, Suyuan finally pins down her great plan for June to be a concert pianist. To achieve this goal, she does housecleaning for her neighbor Mr. Chong, a retired piano teacher, who would in turn give June piano lessons two hours a day. Even though June fails all her mother's expectations, Suyuan is still optimistic about her daughter, comparing her to Einstein, only "late-blooming," yet to surprise everyone who held a doubt.

In The Reproduction of Mothering, Chodorow explains the on-going link between mothers and daughters: "a mother is likely to experience a sense of oneness and continuity with her infant" (109). Compared with sons, "[p]rimary identification and symbiosis" with daughters is "stronger" and "lasts longer" (ibid.). The mother's cathexis of her daughter is probably driven by the mother's need to "retain and emphasize narcissistic elements" in the sense that the daughter is deemed as "an extension or double of mother herself" (ibid.). Such a mutually-reflective bond is clearly stated by Ying-ying St. Clair, another Joy Luck mother, when reflecting upon her daughter: "She and I have 
shared the same body. There is part of her mind that is part of mine" (242). Ying-ying's name - "Clear Reflection" also symbolizes her mother's wish to seek identification in her daughter (243). Similarly, the name "Waverly" Lindo gives her daughter after the street they live on embedded the mother's wish that the daughter would remember the life with her mother, identifying with her, even if she leaves the street in the future while walking up the social ladder.

The belief in the daughters as a continuity of their own identities could also explain the lifelong contest between Lindo and Suyuan, who "spent a lifetime comparing their children" (JLC 37). Like Suyuan, Lindo Jong has a miserable life back in China. Being a strong-willed woman never bowing down to life, Lindo wants her daughter to have "the best circumstances" and the "best character" (265). As the best friends and arch enemies, both Lindo and Suyuan measure the worth of their lives by their daughters' degree of success. While June is trained to be a pianist "master," which ends up in another failure after she screws up a church talent show, Waverly, guided by Lindo's teaching on "the art of invisible strength" (89), obviously wins the battle for her mother, becoming a national chess champion at the age of nine and is predicted in one of the top journals to be the next woman grand master.

While mothers in the fictions of both Chen Ran and Amy Tan live vicariously through their daughters to derive the meaning of their lives or to fulfil their unaccomplished dreams, their daughters, feeling the threat of 
suffocation and over-identification, either evade from or rebel against their mothers in different ways. For Dai Er in "The Sound of Another Ear Knocking," the mother's routine calling for her to "chat casually" in her bedroom every night becomes a torture for the daughter. In order to disobey the mother's "summon," Dai Er pretends to be occupied with her work or simply remains silent, but nothing could stop the incessant request coming from the mother that is like "tile splinters cutting through one's skin" ("Sound" 103). When finally forced into her mother's room to make the perfunctory "I love you, mom" vow, Dai Er feels her slippers "break away from her mind by turning automatically toward the door" (104). Suppressing the strong compulsion to shout "Mom, spare me, please!" $(104 ; 130)$, daughters in Chen's stories, more often than not, would shut themselves in their own rooms or flee out of the house to breathe in moments of fresh air. In "Nowhere to Bid Farewell," Miss Dai Er is tired of countless quarrels with her mother. Whenever the war breaks out again, she would swear in her heart to "leave this woman who tortures her with a loving heart" ("Nowhere" 107).

Compared with avoidance as a mild form of protest deployed by daughters in a Chinese culture that emphasizes filial piety and absolute obedience to parents, daughters in Tan's The Joy Luck Club, more influenced by the American culture of individuality, engage in a direct confrontation to resist their mothers' efforts to define their lives. The war between June and her 
mother break out when June refuses to turn off TV and practice piano after the Waterloo of her first public recital. With an upsurge of self-identity while feeling crippled to think and act on her own, June refuses to obey what her mother tells her to do like a "slave." Crying out a loud "No," June "felt stronger, as if [her] true self had finally emerged," the suppressed self that had been inside her all along (141). In her attempt to defy her mother's definition, June consciously fails Suyuan one time after another, each time "asserting [her] own will," her right to "fall short of expectations" (142). For Waverly, the conflict with her mother is triggered by Lindo's pretentious showoff on Saturday market, boasting to every passer-by that she is the mother of a prodigy child. The reaffirmation of her identification with the mother is so embarrassing for Waverly that she openly protests: "I wish you wouldn't do that, telling everybody I'm your daughter. [...] If you want to show off, then why don't you learn to play chess" (99). Waverly's intentional separation from the maternal identification leaves a deep rift between the mother and the daughter, which not only results in an extended cold-war in the family, but also puts an end to Waverly's invincible vigor at chess games. As Amy Ling comments, the mother-daughter relationship in The Joy Luck Club is "an overt battle between two equally strong forces": while cutting loose the spirit of her daughter with her past pains, the mother instills her own spirit in the daughter (139). The daughter struggles because she is also "fiercely independent" as a tiger, 
"fighting against invasion, even from her own mother" (ibid.).

The possessive love from Dai Er's mother is driven by her resolution to protect her "weak" daughter in a hostile male world she is disillusioned about. As Dai Er recounts in the novel, almost ten years have passed since her mother's "last divorce;" "her wisdom, intelligence and elegance, both in appearance and in spirit, rule out any possibility of finding someone who could share a bed with her. She's destined to live a lonely life" ("Sound" 106). Therefore, the daughter naturally becomes the mother's life companion in her spiritual home. In comparison, the Joy Luck mothers express their love by projecting their dreams onto their daughters so that they would not duplicate the mothers' past mistakes and life miseries. Drowned in their mothers' flooding love and dreams to have matrilineal continuity through their daughters' life, the daughters in both cases rise up to rebellion. Dai Er attempts to escape from her mother for the fear of self-annihilation and total identification already showing a sign: "I have inherited and extended my mother," "an outstanding widow." "Now, l'm a young widow of a new generation. l've inherited part of her beauty, loyal and classic fashion of love and her indomitable fighting spirit, in addition to her eccentricity, contradiction, morbidity and desperation" (ibid.). As for the Coca-Cola daughters in The Joy Luck Club, conflicts with the mothers are mainly caused by their ignorance of their mothers' past stories and their hardship as immigrant women in a racist, sexist and classist society on the one 
hand, and the invisible linguistic and cultural gaps between mothers and daughters on the other. As the daughters grow into beautiful "swans," the mothers are left with only one feature bridging the past and the future, forever waiting for the day to tell those forgotten stories to their daughters "in perfect American English" (JLC 17).

\section{Detective Mothers and Fugitive Daughters}

While portraying mother-daughter relationship, both Chen Ran and Amy Tan touch upon another form of tension, one that is between detective mothers and fugitive daughters. No matter what they intend to hide, nothing could escape the sharp eyes of their detective mothers. In Dai Er's case, the secretive "detective" and "anti-detective" activities are becoming "an enormous and invisible web, shrouding every minute of their daily life" ("Sound" 132). To be alert against her mother's surprise attack at any time, Dai Er feels a pressing anxiety and necessity to deploy a guard in "every single pore of her skin" (ibid.). But her mother's amazing detective skill always give the lie to a rumor. Dai Er's firm statement that she has not received any male friend at home, which is supported by her meticulous clean-up of all possible traces, is easily denied by her mother based on the evidence of three empty beer bottles beside the sink in the kitchen, the only area ignored. To prove that she only smokes one cigarette the other day, Dai Er ventilats the room long before her mother returns home and empties the ashtray, leaving only one cigarette butt 
and the well-calculated amount of tobacco ash. Even so, her mother judges immediately that a smoking woman must have paid a visit to Dai Er based on the brand of the cigarette left and the red smear on the filter tip which couldn't come from her daughter who never uses lipsticks (135). In The Bonesetter's Daughter, although Ruth invents different "anti-detective" strategies to judge whether her diary has been peeped at by her mother, such as arranging the way the diary is put or placing a pair of panties on its top, LuLing seems to be superior in her detective capability, knowing all Ruth's secrets like the palm of her hand. On another occasion, LuLing easily infers that Ruth had gone to the beach simply by the sand trapped in her sneakers (146).

The daughters in both writers' fictions are not only invariably seen through in their tricks during the hide-and-seek games to evade the mothers' interrogation, but also threatened by an omnipresent gaze from their mothers. Living in the shadow of their mothers, the daughters feel themselves under constant surveillance of the mothers' all-pervasive gaze. In "Nowhere to Bid Farewell," whenever Miss Dai Er and her mother fall out and bears a grudge against each other, "she could always feel her mother's gaze peeping through the chink in the curtain of the door window, the gaze of a woman filled with love-turned hate scanning to and fro in her room" (107). Dai Er dares not turn back to look at the door, seized by "an inexplicable fear" to encounter that gaze from behind (ibid.). In "The Sound of Another Ear Knocking," Dai Er feels like a 
noble breed of dog in her mother's menacing castle painted in warning yellow. Trying to protect her last room of privacy, Dai Er gets into a habit of closing the door tightly and gingerly stretching the edge of the curtain to fit with the window (102). Even so, she could still perceive her mother's firing gaze shooting from every corner of the wall that "stands alarmingly forever, too anxious to disarm because of her mother's worries and precautions for some reason" (ibid.). Dai Er describes more than once the suffocating feeling of being spied on by her "omnipresent, omnipotent and all-pervasive" mother: "the walls are her eyes, the fixed gaze are like a sharp sword penetrating my heart" $(132 ; 102)$. The awe-inspiring love from her "imperial" mother keeps back any attempt of Dai $\mathrm{Er}$ to step out of the castle into the world outside. Afraid of her mother's total erasure of her own identity, Dai Er keeps a secret calendar notepad, which however, carrying her truest inner-self and unknown stories, disappears one day mysteriously from the edge of her window (110).

A similar scene also appears in Amy Tan's The Bonesetter's Daughter. While clearing up the apartment of her mother who suffers from Alzheimer's disease, Ruth remembers her childhood as an unhappy girl "full of passion, rage, and sudden impulses" (137). Troubled by all kinds of questions about faith and ghosts as a result of her mother LuLing's paranoid, superstitious behaviors and her own emerging sense of self-identity, Ruth is resolute "to be exactly the opposite of her mother" and "be as truthful as she wanted to" by 
keeping a diary, which would be "proof of her existence," a means of leaving something behind to testify to the significance of her life (138). But just like Dai Er, Ruth feels her mother's "sneaking looks" into what she has written (ibid.). In order to keep her secret, Ruth hides her diary "in the bottom of her closet, between her mattresses, behind her dresser" (139), but LuLing always manages to find it, a conclusion Ruth draws based on "what she [is] next forbidden to do: 'No more go beach after school.' 'No more see this Lisa girl.' 'Why you so boy-crazy?'" (ibid.). Ruth's protest is repressed evasively by LuLing's refutation "A daughter should have no secrets from a mother" (ibid.). Compared with Dai Er's helpless submission to her mother, Ruth makes a frontal assault with LuLing and writes "in two-inch block letters" in her diary: "STOP!!! PRIVATE!!! IF YOU ARE READING THIS YOU ARE GUILTY OF TRESPASSING!!! Yes! I DO MEAN YOU!" (140). The fight culminates after a bitter quarrel when LuLing finds Ruth smoking in her bedroom. Asserting her "right to privacy" and to "pursue [her] own happiness," Ruth shuts herself in the room and writes hateful indignations about her mother, urging LuLing to honor her words of committing suicide: "You talk about killing yourself, so why don't you ever do it? I wish you would. Just do it, do it, do it! Go ahead, kill yourself!" (141). Although Ruth intends her mother to read the words, she does not expect the fatal consequences of her rash revenge. It is not until LuLing almost kills herself by jumping out of the window of their apartment that Ruth realizes 
what she means to her mother and her mother to her. But the temporary truce between mother and daughter only lasts for a month before they "argued with increasing vigor and assurance," knowing "they had survived the worst" (146).

The maternal gaze aimed to keep the daughters within absolute control could be interpreted as a sign of the mothers' internalization of the patriarchal ideology. As Chodorow argues, the reproduction of mothering is realized "through social structurally induced psychological processes" (7). It is a defining feature for the institutionalization of gender and "is implicated in the construction and reproduction of male dominance" (9). For Rich, it is through the mother that the daughter is taught from childhood what is to be expected in patriarchy: "A mother's victimization does not merely humiliate her, it mutilates the daughter who watches her for clues as to what it means to be a woman" (Rich 243). Falling victim to the patriarchal gaze, the mother becomes "unwitting conduits or controlling agents of the dominant ideology" (Shi 28). Institutionalized motherhood demands of women a maternal "instinct" instead of intelligence, "selflessness rather than self-realization, relation to others rather than the creation of self" (Rich 42). The sacredness of motherhood depends on the cultivation of "legitimate" offspring, who bear "the name of a father who legally controls the mother" (ibid.). It is through this process that the sacrificing mother, without her own sense of selfhood, unconsciously turns her invasive love into a form of oppression and exploitation, alienating her further 
away from her daughter, who must "distance and differentiate herself" from her mother, "the epitome of patriarchal oppression," in order to "assume an autonomous identity as an adult" and define a womanhood of her own (O'Reilly 144).

According to Dai Jinhua, "what causes the pains in the mother-daughter dyad is not only the unconscious imitation of the patriarchal order: power, control, generation gap and rebellion, but more crucially, the deep self-doubt and blind transference of a fear of individual crisis for women no longer as subordinates to men" (my translation, "Personalized and Female Writing" 53). The ongoing tension between mothers and daughters, in the form of possession or rebellion, identification or confrontation, is "an incurable syndrome of women's culture," tangled up in "a profound identification of the same blood ties, gender and fate" and "a strain against such identification to the verge of desperation due to the unfair fate based on gender" (ibid.). Viewing from this angle, the aggressive and dangerous maternal love depicted by both Chen and Tan could be seen as "an outlet for the pressure of life" for mothers who are struggling to "have legitimacy for their independent lives on their own" (ibid.).

Whereas the mothers attempt to reproduce obedient daughters conforming to social convention, the daughters resist such identification because they hate to live a powerless life like their mothers or ally with the 
latter's "compliance to and complicity in male domination" (Shi 29). The daughter's fear of becoming her mother is discussed by Rich in terms of "matrophobia." Seeing their mothers submitting to "compromise and self-hatred" that they are eager to escape from, a daughter is prone to "hate and reject a mother outright than to see beyond her to the forces acting upon her" (Rich 235). Explaining the reason behind "matrophobia" from the daughters' perspective, Rich writes:

Matrophobia can be seen as a womanly splitting of the self, in the desire to become purged once and for all of our mothers' bondage, to become individuated and free. The mother stands for the victim in ourselves, the unfree woman, the martyr. Our personalities seem dangerously to blur and overlap with our mothers'; and, in a desperate attempt to know where mother ends and daughter begins, we perform radical surgery. (236)

Therefore, the daughters' rejection of maternal definition depicted by both Chen Ran and Amy Tan carries a positive meaning of protesting against the patriarchal victimization of women and constitutes an important step in the construction of their self-defined identity.

The daughters' rebellion against patriarchal embodiment in their mothers as portrayed by the two writers is reflected not only in their matrophobic behaviors, but also in an escalated form of subconscious matricide, which is often preceded by the daughters' imagined scenes of being (almost) killed by their mothers. In "Nowhere to Bid Farewell," Dai Er is always troubled by her mother's morbid, staring eyes. Lying on bed one night, "she felt in a trance a ghastly woman with hair disheveled springing at her in silence," her icy and stiff 
hand almost clutching Dai Er's neck" (113). In "The Sound of Another Ear Knocking," Dai Er dreams of a similar scene: "a woman-shaped body covered from head to waist by a large black cloth was bending over my bed, pressing close to my face, and her long icy fingers hung over my eyes" (107). In Amy Tan's The Joy Luck Club, there is also a nightmarish scene imagined by Lena when she hears loud noises caused by a fight between a woman and a girl across her bedroom wall. Horrified by the "scraping sounds, slamming, pushing and shouts" followed by repeated whacking noise, Lena witnesses with her "ears and imagination" a mother holding "a sword high above a girl's head" and starting to slice "the point of her cheek, the slant of her nose, until there was noting left, no sounds" (JLC 110). Contrary to the girl who comes back to life night after night, continuing her fierce battle with her testy mother, Lena, an obedient daughter since childhood, is just like the sliced girl, losing her sense of selfhood to her over-protective mother bit by bit.

The scary mother figure trying to kill the daughter in her hallucination reflects the daughter's fear of erased identity. According to Erickson, the development of one's identity is preconditioned by his or her ability to pass through periods of commitment and crisis. Commitment entails conscious decision-making ability, and crisis is characterized by "personal exploration of and investment in a system of beliefs" (Bermudez and Burleigh par. 6). If the young people feel they are too radically deprived of "all the forms of expression 
which permit him to develop and integrate the next step," they may "resist with the wild strength encountered in animals who are suddenly forced to defend their lives" (Erikson, Identity, Youth and Crisis 130).

The daughters' identity crisis in face of their domineering mothers is represented in fictions of both Chen and Tan as subconscious matricide through scenes of the mothers either committing suicide or being murdered by their daughters. In "Nowhere to Bid Farewell," Miss Dai Er is forever haunted by a nightmarish scene. Having stayed in her room for a long time, she pushes open the door of her mother's room and sees immediately "that woman - her only relative having died of suicide, her hair drooping and blood dripping, a pale and scarlet sight, bombarding Dai Er with a mixed feeling of cruelty, injury, disgust and grief" (113). Although in Dai Er's hallucination, the cause of her mother's death is suicide instead of premeditated murder by the daughter, it is actually fulfilling her secret wish she is afraid to admit. Threatened by her mother's choking love, the daughter is left with no other way except to end the mother's life so as to regain her deprived identity. Compared with the daughter's passive involvement in murdering her mother, the matricidal drive in The Joy Luck Club has a more active agent of implementation. Gaining power from the neighboring girl, who defiantly and mischievously rebels against her autocratic mother, Lena feels hope with an emerging identity of her own. Instead of envisioning the routine fights across the wall as the mother's slicing 
torture of the daughter, Lena sees in her mind's eye a girl complaining about her unbearable pain of being invisible, pulling out "a sharp sword" and asking her mother to "die the death of a thousand cuts" (115). As if even "a thousand cuts" and her mother's screaming and shouting "in terror and pain" couldn't vent her anger, the girl "grabbed her mother's hand and pulled her through the wall" for the worst yet to be experienced (ibid.). Here, the brutal corporal punishment imagined by Lena implies her irresistible urge for the mother to reexperience the daughter's chronic suffering of a lost identity.

As Kristeva states in Black Sun, matricide "is our vital necessity, the sine-qua-non condition of our individuation," provided that the loss of the mother can be "eroticized," either "recovered as erotic object" as in male heterosexuality or female homosexuality, or transformed through cultural constructs into a "sublime" symbol (27-28). While Kristeva is providing a feminist explanation of the necessity for matricide desired by both man and woman in their efforts to abject the maternal body and become subjects in a patriarchal culture, the daughters' matricidal drive in the above examples could be better interpreted, according to the current author, as the daughters' conscious rejection of their mothers' compliance with the patriarchal rule of order. For Dai Er, her mother has become a surrogate for the Law of the Father that sets the law for conformity. In face of her unchallengeable mother, Dai Er takes the position of the Other, with neither autonomy nor a voice of her own. 
The rehearsal of her mother's death in her subconscious mind symbolizes Dai Er's innermost desire to break through her mother's fortress of love, blazing a path of spiritual independence. Though Lena's mother Ying-ying is totally different from the authoritarian mother of Dai $\mathrm{Er}$, her ghostly disposition with her self-identity devoured piece by piece by "unspoken terrors" has a similar gripping effect on Lena (103). For Lena, the only way to save Ying-ying and herself is to awaken the lifeless mother from the subjectless condition that women have been gradually assimilated to. Only when the $(m)$ other survives the worst, namely, gaining a consciousness of her lack of selfhood, could the mother-daughter bond be reestablished and a new form of reconciliation reached. With an enhanced sense of self-identity, Lena imagines herself to be the girl cutting the submissive passivity from her mother, injecting both of them with a spirit of their own.

It should be noted that the matricidal drive of the daughters cited above is never carried out in reality but only exists at their subconscious level. To purge the sense of guilt while being unable to sever the tight bond with their mothers, the daughters divert their rage towards themselves: "She would rather die than lose her mother while she is alive" (Chen, "Nowhere" 113). The self-inflicted death of the daughters can be found in both Chen Ran and Amy Tan's fictions. Chen Ran's "Nowhere to Bid Farewell" ends with Miss Dai Er's self-pitying envisaging of a scene many years later: on a dreary morning, gathering by the 
side of an old, tall banyan tree blossoming with pink flowers at an inconspicuous street corner, people finds Miss Dai Er "hanging herself serenely from a branch. Her emaciated body seems to shrink away with only a black windcoat dangling in the morning breeze... That is the last dignified sanctuary" (128). In Amy Tan's The Bonesetter's Daughter, Ruth experiences similar "death" of herself. When hearing that LuLing has jumped out of the window to commit suicide and is seriously injured, Ruth rushes to the hospital hysterically in tears, knowing the "accident" is actually what she "had wished for," caused by the cursing words she wrote on her diary (143). Unable to forgive herself of the guilty intention, "she cried until she had dry heaves and was faint from hyperventilating" (ibid.). However, nothing could alleviate her self-reproach but her own death along with her mother:

She became weightless, all worries lifted from her limbs and mind. A dark, warm blanket was placed over her body, then pulled over her head. In this nothingness, she could hear her mother's voice pronouncing to the doctors that her daughter was quiet at last because they were both dead. (ibid.)

As Kristeva points out, when the violence of matricidal drive is hindered, the daughter would introject the maternal object and kill herself in a "depressive or melancholic" manner:

In order to protect mother, I kill my self, while knowing phatasmatic and protective knowledge - that it comes from her, the death-bearing she-Gehenna... Thus my hatred is safe and my matricidal guilt erased. (Black Sun 28)

From this perspective, the imageries of their own death envisioned by Dai $\mathrm{Er}$ and Ruth serve to provide temporary relief of their concealed urge to kill their 
mothers, whom they are afraid of but cannot help identifying with. As the next section shows, against the daughters' unceasing attempt to escape from the maternal influence, once silence is broken and misunderstanding cleared away, they would ultimately return to their mothers for comfort and empowerment in a reestablished symbiotic bond.

\section{Mother-Daughter Bonds and a Return to Pre-Oedipus}

Despite countless arguments and estrangement, the conflicts between mothers and daughters in the fictions of Chen Ran and Amy Tan are ultimately resolved when the daughters finally come to terms with their mothers, who are not their fearful enemies but firm allies suffering from the same plight as women in search of a spiritual home in a male-dominant world. Recovering the pre-oedipal bond with their mothers beyond the symbolic order of patriarchal control, daughters in Chen Ran's fictions find peacefulness and strength to trudge through a hostile world. Learning the stories of their mothers' dreams and hardships, daughters portrayed by Amy Tan comprehend the great pains taken by their mothers to instill them with a fighting spirit so that they could control their own fate without repeating the same sufferings in cowardice.

In Chen Ran's writings, the daughter's bond with her mother could never be separated despite fierce battles and cold wars. In both "Nowhere to Bid Farewell" and "The Sound of Another Ear Knocking," the protagonist Miss Dai

Er would resume, during the truce, the daily walk with her mother at dusk 
("Nowhere" 113), or return home, after aimless wandering on the street, "to the unbounded love of that woman" ("Sound" 105). The daughter's realization of an inherited connection and mutual dependence with her mother is best demonstrated in the protagonist's soliloquy in Chen Ran's novella "A Toast to the Past":

Her breast reminds me of my own breast; her figure leads my thoughts to my own future. [...] She imparts knowledge to me, so is her gender passed on to me. [...] She places weariness and calamities on her slim shoulders. She has an intimate talk with me even when I could not talk back during infancy. She cries for my tears, which I inherit from her, or maybe she is infected by me. She passes her sadness to me, or maybe mine to her. (33)

Living alone with her divorced mother in a desolate temple, the daughter feels identified with her mother. The two women have similarities both in physical experience and in disposition. They "eat and excrete in the same way, demand men in the same manner and share the same secrets" (ibid.). The mother's bosom is like "a mountain, a shelter from catastrophes" and "the ocean, the cradle of all the sorrows" (ibid.). Although such identification sometimes poses threat to the daughter's formation of her distinctive identity, from mother's full breast that the daughter used to suckle for life-sustaining milk, she locates a remote homeland for her spiritual rest (53). In this homeland the daughter used to bury herself into, "there is only a mother, not a woman" (33).

The text here alludes to the postmodern feminist emphasis on the pre-oedipal cathexes between mother and daughter. When emphasizing the need to return to maternal power, Cixous states that there is "more or less the 
mother" who situates in women, making everything all right, nourishing and standing up against separation, a force "that will not be cut off" but link the origin of womankind to "every form and every period of her body" (882). When the mother is seen not as a gendered woman acting on behalf of men but the origin of life not yet polluted by the phallocentric discourse, the daughter could repair the severed link, gaining invincible power in this restored bond of womanhood. As Wang Lingzhen notes, a mother's devotion to and sacrifice for her daughter would not only "enable the daughter to value herself as a woman from an early age," it also, more importantly, "initiates a loving intersubjective relationship" with a potential to "negotiate an alternative way of constituting the female self" (95). Maternal love and mother-daughter bond "assume the place of both origin and destiny of the self and the world," bringing about a unique history of a woman with "her different desire, her relational identity, and her own specific psychic reality" (97).

If Chen Ran gives priority to the daughters' epiphany of an indispensable connection with their mothers, in Amy Tan's novels, it is the mothers who take the initiative to break the silence by recounting their past miseries, determined to reconstruct the lost identity of both themselves and their daughters through mutual understanding and reconciliation. The underlying reasons for maternal silence in Tan's The Joy Luck Club are aptly summarized by Shi Pingping from three perspectives (141-142). Firstly, the silence is caused by the influence of 
feudalist Chinese tradition on the Joy Luck mothers. In the story of "Magpies," An-mei's mother recollects that when she was still a little girl, her mother taught her to behave like a lady. She was not allowed to shout or cry even if she was disappointed; the only fate waiting for her if she disobeyed her elders would be living with Buddhist nuns with her hair cut off (217). The same instruction Ying-ying received from her mother and nanny since childhood to refrain from asking and uttering her desires melts into her mind, resulting in her self-denial and alienation with her daughter. As Ying-ying confesses in her old age, "For all these years I kept my mouth closed so selfish desires would not fall out. [...] All these years I kept my true nature hidden, running along like a small shadow so nobody could catch me. And because I moved so secretly now my daughter does not see me" (JLC 67). The second reason behind maternal silence, according to Shi, is the immensity of wretchedness the Joy Luck mothers suffered in pre-1949 China. Suyuan's compelled abandonment of her twin daughters while fleeing for life during the war, An-mei's longing for her mother who was held in disgrace and tragically committed suicide, Lindo's unspeakable misery in an arranged marriage her mother prepared her for since childhood, and Ying-ying's disillusionment in and hatred of her first husband that drove her to abort her baby - all incurrs insurmountable pains to the mothers, who choose to heal the wound by concealing their past sufferings in silence. The third reason, Shi cites, is the language and cultural barrier that 
stand between mothers and daughters. According to Anderson and Jack, "women often mute their own thoughts and feelings when they try to describe their lives in the familiar and publicly acceptable terms of prevailing concepts and conventions" (11, qtd. in Abbey and Harris 248). Afraid of being disdained or misinterpreted by their daughters who are assimilating the Caucasian culture, the Joy Luck mothers remain silent, waiting for the day to recount the story of the swan in perfect English.

Therefore, it is silence that foretells the estrangement and conflict between mothers and daughters, the silence that passes down through generations, demeaning women to the fate of unconditional subordination and identity deprivation. However, as deBold et al. suggest in Mother Daughter Revolution, "the loss of female selfhood may be resisted, or at the very least negotiated, when the mother connects with the daughter through story" (O'Reilly and Abbey 5). While reflecting and sharing with her daughter "her own narrative of adolescence," the mother could help her daughter learn "strategies of struggle" and hence construct "an alternative script of coming into womanhood" (ibid.).

Seeing the daughters lost in marriage and life directions and wishing to curtail the risk of repeating their own miseries, the Joy Luck mothers are no longer silent. They are determined to regain the lost voice, reopening old wounds. Only through this way can they "break down the stereotypes" the 
society has imposed upon them and transform "Self-Other opposition into mother-daughter reconciliation and re-identification" (Shi Pingping 143). As Ying-ying recounts in "Waiting Between the Trees," her daughter Lena springs away from her body "like a slippery fish since born, and has been swimming away ever since." Having watched her "as though from another shore" all her life, and worried about Lena's being crushed in her marriage to Harold without even knowing, Ying-ying feels imperative to tell Lena everything about her past, reconstructing herself as a "tiger," "the only way to penetrate her skin and pull her to where she can be saved" (JLC 242). As deBold et al. claims in Mother Daughter Revolution, a mother can aid her daughter in their resistance against patriarchal oppression, preconditioned by the mother's reclamation of her own self: "Reclaiming is the first step in women's joining girls' resistance to their own dis-integration. Reclaiming is simply a process of discovering, describing and reappropriating the memories and feelings of our preadolescent selves" (101, qtd. O'Reilly and Abbey 11). Telling her own story about the strong and decisive girl she used to be and how she has been trying to find herself, Ying-ying wants Lena to see beyond her shadowy existence and identify with the strong side of her, the "gold stripes," or the aggressive power to strike "as part of the tiger identity" both of them share (Ryan 96, 106).

Recalling her mother's suicide as a means to instill a fighting spirit into her daughter to carry on her life anew, An-mei tries to wake her daughter Rose, 
who is on the verge of divorce due to submissive compliance in marriage. Comparing her daughter to a young tree, An-mei instructs Rose to be strong-minded with the support of maternal power, "you must stand tall and listen to your mother standing next to you. That is the only way to grow strong and straight. But if you bend to listen to other people, you will grow crooked and weak" (JLC 191). Like An-mei who "learned to shout" from her mother's death, Rose is empowered to stand up to her chauvinist husband Ted by demanding her divorce rights with an unyielding attitude. Confronting Ted without fear, Rose sees what she wants: "his eyes, confused, then scared. [...] The power of my words was that strong" (196).

Another daughter June is also a drifter uncertain of her own identity. Although her mother Suyuan died at the beginning of the novel, the maternal power sustains the entire storyline, starting with June's taking up the fourth corner at the Joy Luck Club, replacing her mother's place in a female bond connecting four families in political and cultural vicissitudes, and ending with June's China trip where she finally finds herself and affirms a close tie to her mother and her cultural heritage. It is the unveiling of Suyuan's hidden stories and her lifelong dream that prompts June to carry out her mother's unaccomplished mission by returning to China, her real root, and telling her half-sisters about their common mother. In the final scene of the long-awaited family reunion, June is not only "embracing her newly constructed ethnic, 
subjective, and gender identities" (Ryan 106), but also fulfilling the wishes of all the Joy Luck mothers to be understood by their daughters, who would listen to their stories, inherit their spirit and stand with them side by side in an unbreakable bond.

The suppression of voices is also a recurring theme in Tan's second novel The Kitchen God's Wife. Over the years, the relationship between Winnie, the Chinese immigrant mother, and her American-born daughter Pearl has been blocked by silence. Winnie's dreaded life of sufferings with her sadistic husband in China remains totally unknown to her daughter; nor is she able to express her deepest love for Pearl. Uncomfortable with Winnie's "bossy criticisms and pervasive superstitions," Pearl also feels estranged both emotionally and culturally with her mother (Huntley 80 ). Seeing her mother sitting alone one table away during a family gathering, Pearl realizes "the enormous distance" separating the two of them, making them "unable to share the most important matters of [their] life" (KGW 34). The fact that she is diagnosed of having multiple sclerosis has been kept a secret from her mother for years, a painful secret that Pearl feels suffocated and wanting to run away (ibid.).

The wall of silence between mother and daughter finally melts down because of Winnie's determination to reveal the secret about her disaster-ridden life: "I'll call her, long, long distance. Cost doesn't matter, I will 
say. I have to tell you something, can't wait any longer. And then I will start to tell her, not what happened, but why it happened, how it could not be any other way" (86). As Pearl truly hears her mother's stories, she comes to understand why and how Winnie has become the woman she is. Gradually and carefully, mother and daughter begin to forge a relationship "in truth and open communication" (Huntley 81). When Pearl finally plucks up courage to tell Winnie about her illness, she underestimats the extent of her mother's outburst. But instead of protesting against the fuss her mother makes out of nothing, Pearl suddenly realizes how she doesn't want her to stop. "I was relieved in a strange way. [...] She was tearing it away - my protective shell, my anger, my deepest fears, my despair. She was putting all this into her own heart, so that I could finally see what was left. Hope" ( $K G W$ 401-402).

In Tan's The Bonesetter's Daughter, Ruth suffers from silence both in terms of her annual weeklong aphonia starting on August twelfth for eight consecutive years and her ignorance of her mother LuLing's past experiences. The lost of voice that women become accustomed to not only blocks their insight for their own identities and creativity, as reflected in Ruth's job as a ghostwriter transferring other's ideas without recognition of her own, but also keeps mother and daughter at an unreachable distance. In an attempt to save her memory before suffering from severe Alzheimer's disease, LuLing wrote her life down years ago with Ruth as her presumed reader. As Ruth is 
increasingly attracted by her mother's life stories, she comes to understand why LuLing has a "difficult, oppressive, and odd" disposition, and wants to "hang on to her mother as if she were her life preserver" (BSD 58, 304). Like the mutual dependence and interchangeable roles between Dai Er and her mother in Chen's stories in which the mother is also "a loyal friend" and the daughter's child ("All Walls Are Gates" 187), the novel The Bonesetter's Daughter ends with a renewed symbiosis of identification between Ruth and LuLing: "She was her mother's child, and mother to the child her mother had become. So many combinations, like Chinese names and characters, the same elements, seemingly simple, reconfigured in different ways" (302).

The maternal bond restores voice to LuLing, whose story with Precious Auntie, her real mother not known till the latter's death in regret, is filled with the mother's tearful love and the daughter's unwitting harm. The same story happens between LuLing and Ruth, propelled by their inability to talk to each other. When silence is finally broken, Ruth gradually regains her own voice and the lost identity. Another August the twelfth arrived, but Ruth still keeps her voice. "Her ability to speak is not governed by curses or shooting stars or illness. She knows that for certain now. [...] Before, she never had a reason to write for herself, only for others. Now she has that reason" (351).

Compared with the return to mothers in Chen's stories, the mother-daughter reunion in Tan's novels carries a special significance for 
women of ethnic background to reconstruct their identities by tracing their cultural roots and rewriting the buried history of patriarchal and racial oppression. Alice Walker, in her famous article "In Search of Our Mothers' Gardens," urges ethnic American women to recognize and honor their mothers' hardships "as part of accepting themselves and understanding the forces which shaped them as women of color in a white man's world" (Curton 43). For the minority women struggling in a racist, male-dominant society, understanding one's mother constitutes "the first step to understanding oneself" (ibid.). As Walker puts it in her own words:

[T]hrough years of listening to my mother's stories of her life, I have absorbed not only the stories themselves, but something of the manner in which she spoke, something of the urgency that involves the knowledge that her stories - like her life - must be recorded. [...] Guided by my heritage of a love of beauty and a respect for strength - in search of my mother's garden, I found my own. (240, 243) 


\section{CHAPTER III}

\section{HETEROSEXUAL RELATIONSHIP - FROM ATTACHMENT TO BANISHMENT}

Heterosexual relationship, namely, the relationship between man and woman, constitutes an important part in the construction of one's identity. This chapter focuses on a comparison of the female perception of the father and other male images manifested in the fictions of Chen Ran and Amy Tan. Following the trend towards women's awakening gender roles in Western and Chinese literary representation, heroines depicted by the two writers have experienced a changing relationship with their male counterparts from blind attachment to resolute banishment as they gradually develop their own sense of independent identities.

\section{A. Awakening Identity in Western and Chinese Female Literary Tradition}

Tracing the Western and Chinese literary tradition, we may find a similar journey of women writers in pursuit of gender equality with a growing awareness of their autonomous identities. In her famous work $A$ Literature of Their Own, American feminist literary critic Elaine Showalter summarizes three 
major phases in the history of women's writing almost all literary subcultures go through:

First, there is a prolonged phase of imitation of the prevailing modes of the dominant tradition, and internalization of its standards of art and its views on social roles. Second, there is a phase of protest against these standards and values, and advocacy of minority rights and values, including a demand for autonomy. Finally, there is a phase of self-discovery, a turning inward freed from some of the dependency of opposition, a search for identity. (13)

In "Toward a Feminist Poetics," Showalter reiterates the categorization of the three stages respectively as the phase of the Feminine, the Feminist and the Female. Citing examples of English women writers, she indicates that a distinguishing feature of the Feminine phase from 1840 to 1880 is "the male pseudonym" and narratives in masculine disguise for women writers who wish to assimilate into the mainstream literature. ${ }^{84}$ The Feminist phase from 1880 to 1920 coincides with the first wave of the feminist movement. During this period dominated by women's advocacy of their social rights and rejection of "accommodating postures of femininity" (138), women's literature either dramatizes "the ordeals of wronged womanhood" through depictions of class struggle and factory life by writers like Elizabeth Gaskell and Frances Trollope, ${ }^{85}$ or as represented by Charlotte Perkins Gilman, ${ }^{86}$ envisions a

\footnotetext{
${ }^{84}$ Showalter cites in the article the names of George Eliot (the pseudonym for Mary Anne), Currer, Ellis, and Acton Bell (the pen names for the Bronte sisters Charlotte, Anne and Emily, each maintaining the first letter in their pseudonyms) as examples for illustration (137).

${ }^{85}$ Elizabeth Gaskell (1810-1865) is a British novelist during the Victorian era known for her biography of Charlotte Bronte and the class consciousness in her novels covering all strata of society: Frances Trollope (1780-1863) is an English novelist known for her novels of social protest like Michael Armstrong: The Factory Boy.

${ }^{86}$ Charlotte Perkins Gilman (1860-1935) is a famous American sociologist, writer and social activist. As an eminent figure of Amazon uopias, Gilman is a prolific writer and best known for her semi-autobiographic story
} 
Utopia of perfect female societies to revenge against male governance. The Female Phase, ongoing since 1920, is characterized by women's renunciation of both forms of dependency - imitation and protest - in their searching for and self-discovery of female experience as a source of an autonomous identity (138-39). Distinguishing between two types of feminist criticism, namely "feminist critique," which centers on "women as reader," or "the consumer of male-produced literature" and "gynocritics" concerned with "women as writer," "the producer of textual meaning" (italicized in the original, 128), Showalter highlights the importance of gynocritics. Gynocritics, according to Showalter, is the study of the historical evolution of women's writing and female literary tradition with "recurring images, metaphors, themes, and plots" emerging from "women's social and literary experience" and from the writers' exposure to "both male and female precursors" (Showalter, A Literature of their Own xx).

Although focusing on an interpretation of the mother/daughter plot, Hirsch's account on the changing status of male figures in Western literary tradition provides an important footnote to Showalter's analysis of the three stages in women's writing. Conforming to the characteristics of the Feminine Stage in terms of patriarchal institutionalization of women writers, Hirsch states that the female family romance in nineteenth century, the first peak of women's literature within the Western European and North American traditions, revolves

"The Yellow Wallpaper" and her utopian trilogy Moving the Mountain (1911), Herland (1915) and With Her in Ourland (1916). 
around women's attachment to "the brother or 'man-who-would-understand"" (133). But unlike Showalter who mainly reads a positive meaning from both the Feminist and the Female phases in terms of women's protest for autonomy under the influence of a sweeping suffrage movement, Hirsch penetrates to the point that the female family romance of the 1920 s, the second peak on his timeline, still falls victim to a discourse of "compulsory heterosexuality." It is not until the 1970s, according to Hirsch, that the role of men is de-emphasized and "displaced from the foregrounds of the stories" (129).

There seems to be an inconsistency of the time division between Showalter and Hirsch. The three stages of women's literary tradition elaborated by Showalter mainly range from 1840 to the 1940 s. Works by what Showalter terms as "contemporary women novelists" from 1940s to 1970 s are discussed in a chapter entitled "Beyond the Female Aesthetic." Moving beyond the Female phase, Showalter does not name the upcoming stage but only believes that female literature around 1970s preludes new phases combining "[f]eminine realism, feminist protest, and female self-analysis $[\ldots]$ in the context of twentieth-century social and political concern" (A Literature of Their Own 304). According to Hirsch, however, the third peak of female writing, which complies with the Female stage of self-discovery in Showalter's analysis of gynocritics, starts from the 1970s, a stage featured by "the retreat to the pre-oedipal as basis for adult personality, the concentration on 
mother-daughter bonding and struggle, and the celebration of female relationships of mutual nurturance," leaving "only a secondary role to men" (ibid.). As far as the author is concerned, both Showalter and Hirsch have aptly summarized the changing trends of Western women's literature from nineteenth century up to their respective times. But when we take contemporary women's literature into consideration in a larger timeframe, it seems that Hirsch's extended timeline based on Showalter's three-stage model provides more insightful observations on the evolution of occidental women's literature characterized by a growing awareness of and departure from male hegemony as well as compulsory heterosexuality.

Similar to Western literary tradition that experiences three stages with an ever-enhancing sense of selfhood among women writers, Chinese female literature also undergoes three peaks of development, although on a different timeline and with its unique characteristics. The first peak is during the late 1920 s to the early 1940 s. Influenced by the democratic ideas introduced with the New Culture Movement in the wake of May 4th Movement in 1919, women writers like Bing Xin and Ding Ling join the rushing torrent of the nation in its iconoclastic fighting for freedom and equality. For women just awakened to break away from feudalist social evils, the embodiment of their dreams, as reflected in women's writings of the time, lies in a search for idealized family romances. While Bing Xin turns to a magnanimous mother figure who guides 
the daughter to find her proper place in life and marriage, in "Miss Sophia's Diary," (shafei nüshi de riji, 1928) the sensational novella that brings Ding Ling lasting fame, the heroine Miss Sophia, though bold and independent, still becomes lost in her spiritual aspirations and sensual desires for love from men. Writing within the patriarchal discourse with weak gender consciousness, the women writers are still attached to their male counterparts and fail to return their straight gaze to men. As Li Youliang points out, the male figures in the women's novels of May Fourth period are vague and obscure in terms of indistinctive description of their appearance, stereotyped depiction of their characters and detail-deprived generalization in the choice of verbs indicating their behaviors (24-30). Therefore, the major themes and narratives of Chinese women's literature during the first peak still tie in with the male-driven political movement against feudalism and colonialism, and lack a conscious exploration of gender difference.

During the anti-Japanese War and the protracted civil wars ${ }^{87}$ of China, women's literature in the 1930 s and 1940 s is dominated by themes of war and class struggles. Female consciousness manifested in the novels of Ding Ling and Xiao Hong is mingled with male discourse and revolutionary ideals ( $\mathrm{Li}$

\footnotetext{
${ }^{87}$ China experienced three major civil wars in modern history. The first civil war was also known as the Northern Expedition from 1926 to 1928, led jointly by Kuomintang and Communist Party to liberate the warlord-controlled northern China in its struggle against imperialism and feudalism. The second civil war known as the Agrarian Revolution broke out following the split between the two parties. During the decade from 1927 to 1937, the Communist Party led a peasant war against the Kuomintang from the countryside and took control over several areas in southern China. The third civil war in which by People's Liberation Army led by the Communist Party of China defeated the Kuomintang lasted from 1945 after the end of the Anti-Japanese War to 1949 before the founding of the People's Republic of China.
} 
Youliang 39). Heroines in Ding Ling's When I was in Xia Village (wozai xiacun de shihou, 1941) and Xiao Hong's Tales of Hulan River (hulanhe zhuan, 1941) are portrayed as tough and fortitudinous women passing through an ordeal of wretchedness. Although a feeling of disappointment in men was prevalent in the text of these women writers, they are still uncertain about a future free from male control. Women's blindness to their gendered identity persists during the period of socialist construction after the founding of People's Republic of China when women enjoy "equal pay for equal work" in economic sense as well as the political right to vote and be elected as representatives for people's congress at all levels. The obliteration of gender difference is reinforced during the Cultural Revolution that requires similar dressing styles (either green army uniform or blue Mao suit) and thinking mentalities of both men and women. As a result of socio-historical environment, women's literature between the founding of New China in 1949 and the end of the Cultural Revolution in 1976 is a virtually blank page. When individual desire is depressed in favor of collective interest and the theme of love gives way to socialist production, the flicker of female consciousness ignited since the 1920 s dies out without a trace. All heroines in the eight model revolutionary dramas (geming yangban xi) are masculinized or genderless female heroes, sacrificing love and family for the national course of liberation. Although women seem to take a leading role in most of these works, giving an impression of overt feminist success, it is 
actually an exclusion of female consciousness in that women have become a surrogate for men, celebrating dominant patriarchal ideologies without an identity of their own.

Recovering from the ten-year turmoil of the Cultural Revolution and following Deng Xiaoping's famous statement to "emancipate the mind" and the adoption of the reform and opening-up policy, ${ }^{88}$ the second peak of Chinese women's literature is ushered in by the end of 1970s. If the first peak from the end of 1920 s to early 1940 s fits in with Showalter's Feminine stage, the second peak during the 1980s shares the characteristics of the Feminist Stage in the Western tradition. The fast spread of Western feminist ideas and the earthshaking reforms in China gradually enhance women's awareness for their downplayed status behind the seemingly gender equality. In the works of women writers of the time, we may detect a train of thought with an emerging female identity. From women's spiritual infatuation of and selfless sacrifice for an idealized male lover, as in Zhang Jie's short stories "Love Must Not Be Forgotten" (ai shi buneng wangjide, 1979) to their disillusionment in men's cowardice and barbarism while pursuing a female identity in Yu Luojin's reportage A Chinese Winter's Tale (yige dongtian de tonghua, 1980), women embark on a path to seek autonomy for their own lives. From women's suicidal choice and self-reproach for their violation of male-defined social ethics in the

\footnotetext{
${ }^{88}$ The reform and opening-up policy put forward by Deng Xiaoping was adopted in 1978 at the third plenary session of the eleventh central committee of the Chinese Communist Party. The policy redirected the focus to liberating and developing the productive forces and reforming outdated mechanisms for social progress and introduced the socialist market economy that brought about historical changes to China's socio-economic life.
} 
early works of Wang Anyi such as Love on A Barren Mountain (huangshan zhilian), Brocade Valley (jinxiugu zhilian) and Love in a Small Town (xiaocheng zhilian) published in 1987 to a passionate satisfaction of the heroines' sexual desires on their own initiative in Wang's later works $A$ Century on the Hillock ${ }^{89}$ (gangshang de shiji, 1989), women begin to advocate their long-deprived rights to realize female sexual potentials. From Shen Rong's realistic depiction of women's overburdened life under the dual pressures from both family and career in her novella "At Middle Age" (ren dao zhongnian, 1980) to Tie Ning's resolute exposure of female weakness and alienation as a result of patriarchal repression in Rose Door (meigui men, 1988), women file their strongest protest against the invisible male hegemony obstructing the formation of a distinctive female identity.

Similar to Showalter's definition of the Female stage, the third peak of Chinese female literature since the early 1990 s is characterized by women's returned gaze on and ostracism of men and a focus on female subjective experience and self-affirmation. Writers like Chen Ran, Lin Bai and Hai Nan refuse to submit themselves to male standards. Instead of looking up to males for support or reliance like their predecessors, the new generation of women writers born in the 1960s are proud of their self-definition and the ability to make judgment of their male counterparts. Heroines in their works have seen through the nature of male infirmity under the disguise of the phallocentric

\footnotetext{
${ }^{89}$ Since the novel was not published in English, the translation is provided by the current author.
} 
myth and cultivate "a confidence and spiritual power strong enough to stare men down" (Yu Zhansui 30). Assimilating the ideas from Western feminist movement and the postmodern school of thought, these women writers realize the power of discourse and are determined to seize that power from the males. The dethroning of male hegemony and the self-naming of women become one of the dominant themes during the third peak of Chinese feminist literature. Like women writers during the Female stage in the Western tradition, Chinese writers embark on the same road of self-discovery towards the construction of their erased identities.

From the above analysis, we may find an affinity between Western and Chinese women's literature, both of which, though on different tracks, have gone through an evolution of female self-consciousness in heterosexual relationship from submission to protest and the ultimate detachment. Based on the timeline of their literary creation and the characteristics of their fictions, both Chen Ran and Amy Tan could be classified as women writers during the Female stage. In their depiction of heterosexual relationship that the heroines are entangled with, we can find the same evolving process through which women gradually learned to appreciate their own beauty, stand on their own feet and construct their own identity. 


\section{B. A Thematic Comparison on Heterosexual Relationship}

The heterosexual relationship, both in terms of a woman's relationship with her father and the other male figures, determines, to a large extent, the development of her female identity. Having experienced different stages of heterosexual relationship from woman's submission to a deified or tyrannical man to her dethronement of a disappointing man, heroines portrayed by Chen Ran and Amy Tan gradually learn to be masters of their own destiny and set out to seek a spiritual home of their own.

\section{Fathers in the Daughters' Eyes}

Compared with the mother and the female friends, the father figure in the fictions of both Chen Ran and Amy Tan is given much less weight in depiction. The father is either absent or seldom described in terms of their appearance and characters. However, from the sporadic account of the father, we may discern some similarities in the works of the two writers. Firstly, as the absolute authority of a family in a phallocentric society, the father figure, whenever present, is depicted as unchallengeable power and a source of fear for the daughter, threatening the formation of the latter's independent identity. Secondly, it is worth pointing out that for both Chen Ran and Amy Tan, the fear of the father only serves as a nightmare in the heroines' childhood memories. With an awakened self-consciousness when they gradually come to realize the weak nature of such authority, the father is either resented or "murdered" 
through the daughter's act of subconscious patricide.

In Chen Ran's A Private Life, the heroine Ni Niuniu grows up in the shadow of her irascible father. She could clearly remember the day when her beloved nanny, the housekeeper looking after the family for years, is forced to leave for some unknown reason that might have displeased the father. When she hears Father's shouting on the way back home, "the rain suddenly stopped" as if the raindrops were filled with terror (14). Trying to "suppress the fear and confusion in [her] heart," Niuniu is quite conscious that speaking of "authority, physical dominance [...], or economic power," her father is "unquestionably number one" in the family (19-20). In his "straightforward" treatment of Niuniu's mother, nanny and herself, he has nothing to fear, always "[playing] his cards on the table" with no "hidden agenda" and his displeasure "clearly written on his face" (19). Therefore, when Father orders the banishment of the nanny, Niuniu dares not look at her father, who is sitting in a big chair with his back to the others "as imposing as a mountain peak" (21). Instinctively fearing that her father might get angry, Niuniu could not even show any sign of discontent or grief. She keeps on washing her face until she finally stems the tears that are not to be noticed. Afraid of being like Nanny who has lost sight in one eye when she was beaten by her husband years ago, Niuniu "instinctively closed [her] eyes" when "Father's shouts crashed down upon [her] like thunderclaps" (17). 
Similar descriptions of the paternal terror are also evident in Chen's other fictions. In "A Toast to the Past," the heroine recalls the intensity of her father's fury: "He thumped on the table with dust flying, a noise so loud and the shake so violent that even the Great Tangshan Earthquake ${ }^{90}$ would be deterred away. Shaken with fright, I was terrified and humbled to the dust; [...] a strong sense of inferiority had taken root and started to grow since that moment" (my translation, 9). In "Breaking Open," the narrator, Miss Dai Er could not forget the "hopeless, angry gaze" of her father, which "stifled the fresh and unaffected childish voice" in her mouth (57). Years later, she could still see "this little girl who, in her barren, delusional dreams, would hug her bony and shaky knees with both arms, her eyes wide with fear and her hair dried-up and yellowed like wild wheat in the wind" (ibid.). Spending her entire childhood under the menace of the father's reign of terror, the daughter is "in dread of every man acting for patriarchy" ("Toast" 10). As the epigraph of the chapter "My One-eyed Nanny" in A Private Life reads, "Our most profound self-denial comes when we say yes to our fathers and yes to our lives" (14). It is daughter's docile obedience to the father that determines, from the very beginning, that dooms her objectified fate.

As Kate Millett states in her famous Sexual Politics, "patriarchy granted the father nearly total ownership over wife or wives and children" (56), treating

\footnotetext{
${ }^{90}$ The Great Tangshan Earthquake is one of the severest earthquakes in China's contemporary history. Striking North China's Hebei Province at midnight on July $28^{\text {th }}, 1976$, the 7.8 -magnitude earthquake claimed the lives of more than 240,000 people and caused huge damage to the entire nation.
} 
them as personal property at his disposal. Like the ruthless father in Chen Ran's fictions, the father figure in Amy Tan's novels also haunts the daughter's childhood life. In The Kitchen God's Wife, Winnie recollects her feeling when coming to her father's house after twelve years' of no communication. After her mother's mysterious disappearance, Winnie is sent to live on an island with her uncle and his two wives. Throughout the years, her father has never written a word to her, or come to see her on the island where she lives or visits her boarding school. Even so, Winnie is scared while waiting for her father to give an approval of her marriage and an unknown future. When she finally sees her father coming downstairs, he walks "one slow step at a time," staring at Winnie with "no color in his face" like "a god descending from heaven" (KGW 139-140). Sensing the hatred her father must have felt when seeing Winnie's mother in her face, Winnie bows her head in obedience, a gesture that symbolizes women's acceptance of their otherness, giving way to male definition.

As a matter of fact, like the daughter in Chen's fictions who lives either by herself or with her divorced mother, most heroines in Tan's novels are bereaved of their fathers since childhood. For Joy Luck mothers living in Old China, their stories seem to have nothing to do with their fathers, who either died long time ago, or are not mentioned at all. In The Kitchen God's Wife, both Winnie and her daughter Pearl live in a family without a father. The absence of the father also provides the setting for Tan's another novel The Bonesetter's 
Daughter, in which three generations of women lose their fathers in different ways. For Precious Auntie, LuLing's real mother, both her father and her husband are tragically killed on her wedding day, separating LuLing from her father before she is born. LuLing's foster father is operating an ink shop in Peking hundreds of miles away from the village where the rest of the family, mostly women and children, live in. The first appearance of him, together with LuLing's Big Uncle and Little Uncle is when they return home to attend Great-Granny's funeral.

Though the father is absent most of the time, in a patriarchal family, even a dead father is so powerful to "watch over" whatever the daughter says or how she behaves. For An-mei in The Joy Luck Club, the only father she knows is a big painting hanging in the main hall, "a large, unsmiling man, unhappy to be so still on the wall" (JLC 43). But even a portrait of a deceased father would pose dire threats to the little daughter. An-mei could always feel his father's "restless eyes" following her around the house, even when she hides in her room "at the end of the hall" (ibid.). The father's gaze is so piercing that she dares not do anything against the will of the father, or the patriarchal norm stifling her own budding identity. In The Bonesetter's Daughter, Ruth, like An-mei, also loses her father when she is a toddler. When staring at her father's photo, she "felt angry he was dead," but soon her anger is overtaken by fear and a strong sense of guilt: "She tried to convince herself that she 
deeply loves his father she could not even remember" (BSD 56).

As Erikson argues while discussing the formation of womanhood, much of a young woman's identity is already defined in the way she presents herself to be attractive and in the criteria she sets forth to search for "the man (or men) by whom she wishes to be sought" (Youth and Crisis 283). Denying the biological determinism to explain women's passivity in comparison to men, Erikson sharply points out that in a male-dominant society, it is the woman herself who "lent[s] herself to a variety of roles conductive to an exploitation of masochistic potentials" to "be confined and immobilized, enslaved and infantilized, prostituted and exploited" (284). The self-imposed servitude of women is institutionalized within each family, starting from the father's dictatorship in the daughter's eyes and sustained by the elder women through their instructions on female submission. The nanny in the afore-mentioned example could be seen as a representative of countless women who have been silenced by the tyrannical men. Her blind eye that would "never shed tears" because it "couldn't feel grief anymore" alludes to women's strangled identity in patriarchal rule of law. When Niuniu vows to find Nanny's husband and ask him to "pay for that eye" (A Private Life 16), instead of being encouraged by Niuniu's awakening statement, Nanny still has illusions about men and advises Niuniu in all earnestness, "[I]f you marry a good man when you grow up, then you won't suffer" (ibid.). It is in a similar manner that Popo, 
An-mei's grandmother assimilated by the patriarchal mentality, warns An-mei to behave herself because her father's portrait hanging on the wall is forever watching her "for any signs of disrespect" (JLC 43).

But unlike their nanny and grandmas, daughters of a new generation are born to be different. Denying Nanny's wish for a good husband as a woman's best life goal, Niuniu says without hesitation that when she grows up, she would make her future husband suffer ( $A$ Private Life 16). Terrified by her father's domineering supremacy, she never gives up her own sense of female identity, which has been concealed beneath her seeming obedience, only biding its time to take hold. Departing with her nanny, Niuniu turns her helplessness and unspeakable sorrow into rage and hatred: "Nanny, when I grow up and earn some money, I'll bring you back home. I'll make him leave. I'll make him pay!" (22). When the day finally comes for the adolescent daughter to be freed from her divorced father, Niuniu feels herself forced "to stand up among the ruins of this civilized battlefield and take on the role of a mature woman" (98). But it is not until many years later when she has "grown up" that Niuniu understands the source of her father's menacing power. In a statement similar to Erikson's explanation of male dominance, she says:

$[\mathrm{H}]$ is aggressiveness, his despotic ways, and his power were freely given to him by Mother, Nanny, and me. We handed him the power to oppress us through our gentleness and submissiveness. The more tolerant and obedient we were, the more violent and dictatorial he became. (20) 
The impotent nature of the father, gaining power from his daughter and the other women in the family, is also implied in Winnie's daughter Pearl's troubled memory of her deceased father. Unlike Niuniu's father who is "an arrogant and pushy civil servant" diverting his undervalued career ambition to his domestic reign, Pearl's father is a mild minister of a Chinese Baptist Church who died when Pearl was only fourteenth years old. Although Pearl tries to keep some sweet memories of her father, she always ends up realizing that her father's smile and charm are only "images from photos" and what she remembers most vividly are "those times when he was ill" (KGW 46). In Pearl's various nightmares of her father, he is always "hidden in a hospital, in one of a hundred rooms with a hundred cots filled with sick people" (ibid.). Contrary to Pearl's idealized image of her father, the latter is "old and pathetically thin, his hair now white and patchy after years of waiting and neglect" (47). Sitting beside her father on a dirty cot "in soiled bedclothes," Pearl could hardly recognize the man in front of her. When those "helpless searching eyes" finally catch sight of Pearl, her father gives "a startled cry," so happy her daughter has finally come to take him home (ibid.).

Overthrowing the myth of the Father, the daughter finally is able to pluck up courage to erase paternal control from her life. Resenting her father's domination in and negligence to the family, Niuniu has a strong desire to banish her father forever. When her father swaggers into his car and goes for 
work one morning, the familiar sight is changed into another scene in Niuniu's mind:

Then, unexpectedly, the little car suddenly turned into a police car, its siren bleating, and Father into a felon in dark brown prison garb, his hands and feet tightly fettered. He was trying desperately to free himself, but the police car took him to a place so far away that it would be impossible for his ever to come home again (A Private Life 31)

With an emerging self consciousness, Niuniu not only sentences her father to life imprisonment, but also carries out patricide, the fiercest form of a daughter's rebellion against her father, at the subconscious level. In the same chapter "Scissors and Seduction," Niuniu implements her plan to take revenge on her father. On the same morning after Nanny's departure, Niuniu notices her mother taking the job of Nanny to iron Father's woolen trousers. The "tense and overly careful" movement of the mother arouses "inexplicable dislike" in Niuniu (33). Gaining "a strange feeling of strength" from the sound of running water that seemes to have an "desire to flow unceasingly," Niuniu quickly picks up a pair of scissors, goes straight to the trousers lying on the bed and shears off "the legs of the neatly ironed trousers" (34). The bold act gives Niuniu "a cold lightning flash of dangerous joy" that leaves her with "a sort of postclimactic numbness" (ibid.). Feeling "tense yet satisfied," she bounds out of the house "like a frightened rabbit" (ibid.).

The detailed description of Niuniu's cutting of her father's trousers is ridden with metaphorical messages. What has infuriated Niuniu is actually her 
mother's tacit acceptance of male ruling, which, like Nanny's leaving in silence, reinforces the father's unchallengeable role in the family. Unlike her mother, however, Niuniu has seen through the fact that she "couldn't depend on [her] father" (12), an arrogant and self-centered man who not only has no interest in his wife and daughter, but is "no good at" physical work (12-13). The sound of running water from the kitchen probably reminds Niuniu of the quarrel her father picks with the workers hired by her mother to renovate the kitchen, which ends up no help but more trouble for the woman to handle the mess by herself. Through the open window sending the sound of water from the kitchen to Niuniu's bedroom, the daughter's "window of heart" is opened, leading her into a true picture of women's misery under male oppression. The "desire" of the water to "flow unceasingly" symbolizes the inexhaustible female power that is fluid and unrestrained in nature. Charged with such a power, Niuniu achieves a renewed sense of self-identity. Her resolute action to cut the trousers is by no means a girl's mischief out of naughtiness, but a deliberate patricidal declaration to denounce and turn away from her father as well as all that stands for patriarchal stipulation. Although Niuniu's patricidal drive is only released subconsciously through the action of cutting her father's trousers, it is a crucial step of getting rid of the father's psychological deterrence in a daughter in the process of forming her own identity. 
Compared to reckless acts of Niuniu's patricidal attempt, Winnie in Tan's The Kitchen God's Wife fights a hard psychological struggle when she tries to persuade herself to leave the feeble father for her own happiness. Clearly aware that if she leaves her father by eloping with Jimmy Louie, a Chinese American who truly loves her, Wen Fu, Winnie's abusive husband and a Kuomintang airforce officer, would use her father "as a weapon" and "have him killed as a traitor (359). Arguing with herself, Winnie thinks more of reasons to abandon her father against her filial obligation to take care of him, who has given in to the Japanese for self-protection and is unable to speak after a stroke that finally breaks him down:

He was the one who mistreated my own mother! He was the one who let me marry a bad man. He did not care that he was giving me an unhappy future. Why should I sacrifice my happiness for him? There had never been love between us, father to daughter, daughter to father. (ibid.)

Struggling between the pricks of conscience and a grudge against his father who is the culprit behind all the sufferings, Winnie finally makes up her mind to lead a life of her own. Never would she allow others to determine her fate. By making the choices "Let me live. Let my father die," Winnie performs a patricidal act similar to that of Niuniu, through which a woman is born with spiritual independence.

The formation of a woman's individual identity is not only facilitated by the dethronement of her father as a guardian of the phallocentric order, but more importantly, it is accomplished through a changing relationship with her 
husband and male lover(s). Like father-daughter relationship, in the fictions of Chen Ran and Amy Tan, heroines also develop a growing sense of selfhood as they travel from male deification to female self-identification.

\section{Deified Men and Submissive Women}

As a result of lacking paternal love since childhood, heroines depicted by the two writers direct their attachment towards their male lovers. For a woman brainwashed by the patriarchal discourse that honors male superiority, her husband or lover is worshiped as a god. While heroines in Chen Ran's fiction cannot get away from the lingering effect of an Electra complex, ${ }^{91}$ Tan's characters rather cheat themselves into a fairy tale in conformity to the social norm.

In Chen Ran's fictions, it seems like a paradox that most female characters harbor a love-hate attitude towards their fathers. A broken family in girlhood and a lack of love from their fathers cast a shadow over their incomplete growing experience. Although they wish to dispel paternal influence out of their lives, they also dream to seek psychological compensation from authoritative male figures: elderly men and male doctors who perform a healing role as an idealist father the daughter can return her love to. As Beauvoir states, women are habituated to living on their knees,

\footnotetext{
${ }^{91}$ In analogy to a boy's attachment to his mother according to the Oedipus complex developed by Freud, the Electra complex is the psychoanalytic theory proposed by Carl Jung explaining a daughter's sexual attachment to her father that forms an essential part in a female's psychosexual development. The term derives its name from a Greek myth about Electra, who persuaded her brother Orestes to kill their mother Clytemnestra and stepfather in order to avenge the death of their father Agamemnon. "Electra Complex." Wikipedia. 18 June. $2010<$ http://en.wikipedia.org/wiki/Electra_complex>.
} 
"[b]e it doctor, priest, or God, woman will feel the same unquestionable certainties, as handmaiden she will receive in her heart the love that comes flooding from on high" and seek salvation "through her union with the Whole embodied in a supreme Person" (670).

Through the words of Ni Niuniu in A Private Life and on several other occasions, ${ }^{92}$ Chen Ran expresses her criterion for love:

I wanted a man who was like a father to pour my love upon, a man whose views on humanity accorded with my own, of whom I would be a female extension, my thinking taking up where his male thinking stopped. (133-134)

In her tireless pursuit of a substitute for an ideal father, Chen Ran establishes a special link between her heroines and the former U.S. president Richard Nixon. In A Private Life, Niuniu expresses her adolescent infatuation with "this handsome, profound, and also highly successful man" who "accorded very closely with [her] conception of the ideal father" (131-132). The longing for father's love is so strong that it almost becomes "the most destructive flaw" in Niuniu's life to judge men "by how they measured up against the ample intelligence and capability of" a man like Nixon, an idealized father image who could "overwhelm" 93 her (132). In both A Private Life and Breaking Open, a glimpse at a newspaper report on Nixon's death in 1995 arouses an intense sentiment in Chen's grown-up heroines. For Niuniu and Dai Er, Nixon represents an unforgettable youthful dream of the two with a lasting imprint

\footnotetext{
92 Chen Ran quoted the same sentence during Xiao Gang's interview included in Selected Fictions of Chen Ran (450) and in the essay "The Personal Is Political" collected in Beyond Words (196).

93 The original Chinese emphasizes the phrase "overwhelm" (fugai), which is missing in Howard-Gibbon's English version and thus added by the current author.
} 
even in their adulthood. This might explain Niuniu's secret adoration of a Chinese artist when she attends an art symposium "as a mature young woman" many years later (ibid.). The physical presence of a man strikes "a similar emotional chord" in Niuniu as Nixon, who makes up her deficiency in paternal love (ibid.). Their second encounter intensifies such a desire of Niuniu to "take his calm, confident hand" and "bask in the security and comfort" that his age makes her feel (133). As she stands beside him by chance in a hotel lobby, Niuniu totally loses herself to this godlike man:

[M]y mind seemed to have stopped working and I had lost all ability to respond. I was slipping slowly into a state of bliss where I seemed to float unanchored in the sumptuous lobby, now steeped in sentimental tints of rose. When we said good-bye, as timid as an inexperienced little girl, I stuffed a letter that I had previously written into his hand. All my intelligence seemed to have drained from my head, leaving it an empty hole, and any remnants of my sensibility had retreated into my ice-cold fingertips. (ibid.)

Even though the letter is not about love confession but simply asking him for academic help, when the artist calls back, Niuniu feels as if she "were talking to God" (ibid.).

Apart from a father substitute to fill up the daughter's psychological lack, another type of idealized man in Chen's fiction is a male doctor. The heroine's yearning for a doctor to heal her mental wound inflicted since childhood is best illustrated in Chen Ran's short story "Sunshine between the Lips." The story unveils in flashback the love between Miss Dai $\mathrm{Er}$ and a dentist she encounters when suffering from two painfully impacted wisdom teeth. Like 
what is recounted at the beginning of the story, "Dentists always fire Miss Dai Er's imagination" (113). Leaning back in the chair during examination, Dai Er couldn't help associating the dentist's "ceaselessly" probing with his equipments "in the cramped space" of her mouth and "tremendous cohesive force" pulling the tooth that requirs her counter force with a sex scene (114). Although willing to entrust herself to this "reticent young man, tall but stocky and sedate, with focused yet limpid eyes" that would distinguish him from a sea of people (113), Dai Er cries out a loud "No!" when the dentist approaches her with a hypodermic syringe for anesthesia before dental extraction. The setting reminds Dai Er of her helplessness when she was a seven-year-old girl hospitalized for meningitis, facing alone "the cold needle" held by a man in white uniform (116).

In this description full of sexual innuendos, the needle and the woman's mouth respectively symbolize male and female genitals. Dai Er's refusal of being injected by a needle is just an embodiment of her awakened gender consciousness. As a grown-up woman with her own sense of identity, she is no longer the little girl who had no choice but to obey the unvarying command of "Lie on your stomach, and pull down your pants" (ibid.). Growing up with the needle that "entered her buttock and stabbed at her heart," Dai Er makes a rebellious attempt to pull out the needle as well as her spiritual imprisonment imposed by the dominating order, an order disturbed by her scream of "No." 
Just as the reader is about to celebrate the symbolic victory of the heroine, however, a fortuitous encounter with the dentist brings Dai Er back to the "normal" track of patriarchal discourse. Chen Ran ingeniously reveals through plot development Dai Er's gradual abandonment of her individual identity. After a play Dai Er and the dentist see together, the heroine comments on the absurdity of the "rib theory," defending earnestly that women are independent just like Adam and Eve who each "had their own heads, their own thoughts, and their own spirits" (119). If Dai Er still cherishes a belief in women's spiritual independence during her first encounter with the dentist at the theater entrance, she surrenders her selfhood submissively after falling in love with the assertive doctor, who always introduces himself to be born "in the year of the male horse," intentionally adding "the male gender to the animal representing his birth year" (123). As Dai Er describes, when walking with this tall and powerful man, she only needs to hang on to his left arm, because he would propel both of them forward: "Like the earth itself, he bore my all" (ibid.). When they kisses, Dai Er feels her heart "emptied" and her limbs turning weak; "the strange fear hidden within [her] gradually dispersed" (ibid.). When her body is "roamed" by his gaze, she feels "drained, nothing but a hollow container," the top of her head "cold and numb" and her body becoming "a vast wasteland" (124). Although Dai Er has never "known all the implications of love" (ibid.), she desperately needs the warmth and security from this man's 
arms "to rescue her from her memories" (127).

The last scene of the story is the reappearance of Miss Dai Er, now wife of the dentist, sitting "peacefully and confidently" in the dental chair to accept the symbolic hypodermic needle stabbing her soft palate (128). Cooperating "obediently and meekly" as her husband is extracting the impacted teeth, with sunshine dancing "trippingly" and singing "gracefully" in her mouth, Dai Er recalls "sharing her husband's bed on their wedding night" (129). When the two bloody wisdom teeth are noisily dropped onto the milky tray, "the secret anguish deeply buried in Miss Dai Er's remote past is finally uprooted" (ibid.), gone at the same time a woman's self-directed identity to be defined in male terms.

As what Kate Millett explains about the socializing force for gender formation, cultural expectations about one's gender identity encourage the young male to "develop aggressive impulses, and the female to thwart her own or turn them inward" (53). Such a force took effect since one's childhood: "Every moment of the child's life is a clue to how he or she must think and behave to attain or satisfy the demands which gender places upon one" (ibid.). In "Sunshine between the Lips," it's from her mother's obedience to "the white uniform," leaving her alone to the "cold and hard" hypodermic that the little Dai Er came to realize that "her mother, too, was afraid of the man": "It was useless to resist. [... Everyone had his own needle to face" (116). Therefore, when Dai 
Er finally adjusts herself to social conformity, she calmly allows her own needle, or the dentist, to penetrate both her body and soul.

Compared with Chen's female characters who desire to seek protection from an idealized man because of a subconscious Electra complex, women in Tan's fictions surrender themselves to a deified man while falling victim to the brainwash effect of the dominant ideology. In Tan's The Joy Luck Club, Lindo is betrothed to a baby boy Tyan-yu one year younger than her at the age of two, because her future mother-in-law, Huang Taitai believes in the words of the matchmakers that Lindo "would raise proper sons, care for the old people, and faithfully sweep the family burial grounds after the old ladies had gone to their grave" (51). Since then her mother begins to treat her as Huang Taitai's daughter, telling her it is improper to eat too much or show "a sour look" on her face that might displease her future husband (ibid.). When Lindo is at the age of twelve, a flood drives her family away to another city, leaving her alone with the Huangs. Hurried to the kitchen, a place for cooks and servants, Lindo knows her standing the moment after her arrival in this new home. Even though, Lindo still firmly believes in her mother's choice and pretends her happiness by shouting, "What a lucky girl I am. I'm going to have the best life" (55).

As Beauvoir comments, being taught to accept masculine authority, a woman would give up "criticizing, investigating, judging for herself, and leaves 
all this to [...] the masculine world [that] seems to her a transcendent reality, an absolute" (600). It is in such a self-defeating manner that Lindo learns to "be an obedient wife" (JLC 56). Following Huang Taitai's instruction, she gradually adapts herself to the role of a virtuous wife, learning to embroider her future family's name on pillowcase in such small stitches as if painted, to "wash rice properly so that the water runs clear" and to be able to "smell if the meat stuffing was too salty" or not (ibid.). Losing her own identity to patriarchy, Lindo is rather contented with her subordinate role when she hurts so much that numbs her true feelings:

What was happier than seeing everybody gobble down the shiny mushrooms and bamboo shoots I had helped to prepare that day? What was more satisfying than having Huang Taitai nod and pat my head when I had finished combing her hair one hundred strokes? How much happier could I be after seeing Tyan-yu eat a whole bowl of noodles without once complaining about its taste or my looks? (ibid.)

Sharing a similar fate as Lindo, Winnie, the heroine of Tan's second novel The Kitchen God's Wife has also been taught to yield to man since childhood. Influenced by the feudalist morality Old Aunt was raised in, Winnie is told that the girls' eyes "should never be used for reading, only for sewing;" her ears "should never be used for listening to ideas, only to orders," and her lips "should be small, rarely used, except to express appreciation or ask for approval" (KGW 102). When Winnie's father tells her before marriage that she must take her husband's opinion over her own, Winnie "nodded eagerly," grateful to her father for such a "useful lesson" (145). Like Lindo who is 
indifferent to sufferings she has to endure, Winnie is also instructed by her mother-in-law that "A woman always had to feel pain, suffer and cry, before she could feel love" (168). In a state of spiritual paralysis, Winnie fools herself as she suffers intensely from her sadistic husband Wen Fu: "I thought my love was growing bigger and bigger. I thought I was becoming a better wife" (ibid.). Fulfilling her obligations as a good wife according to social expectations, Winnie spends almost all her dowry money to entertain Wen Fu's fellow soldiers, submits to Wen's "rough assaults on her body" and endures his daily "taunts and accusation" (Huntley 107). But what she receives over the years is not love and respect, only more abuses from her husband without mercy at all.

While discussing the fate of women, Beauvoir aptly indicates that it is by the reference of marriage that both married and celibate woman are defined, "whether she is frustrated, rebellious, or even indifferent in regard to that institution" (Beauvoir 425). When marriage becomes a woman's "only means of support and the sole justification of her existence" (427), she is left with no other choice but to surrender herself to his flame without resistance. In the eyes of an obedient wife, her husband is mystified as a god: "[H]is gaze envelopes her in a supernatural light; he is a man of God, he is God present in human form" (671). That is why even if Tyan-yu acts "like a big warlord" and makes "special efforts to make [her] cry" (JLC 56), Lindo has nothing to complain about. Instead, she "came to think of Tyan-yu as a god, someone 
whose opinions were worth much more than [her] own life" (ibid.). As for Winnie, she is no different as the wife of the Kitchen God, ${ }^{94}$ who gets "all the excuses" and is forgotten even if she endures all the sufferings with magnanimous conduct, whereas her husband wins "all the credit" for his misdeed and is worshipped by all (KGW 255).

The female deification of man is not only true for Lindo and Winnie living in the feudalist old China, but also for the American-born daughters. A typical example is Rose Hsu, who gradually loses herself and the decision-making ability to her American husband Ted. Moved by Ted's defiance to his mother's obstruction to the lovers' cross-racial marriage, Rose confesses her feeling about Ted when they are still dating each other:

I was victim to his hero. I was always in danger and he was always rescuing me. I would fall and he would lift me up. It was exhilarating and draining. The emotional effect of saving and being saved was addicting to both of us. (JLC 118-119)

Over the years after marriage, Rose continues to indulge herself in such an imagined role of submission. She obeys her husband's decision as for what new furniture they should buy or they should postpone having babies before moving to a better neighborhood. As time goes by, the initial discussion between the two was drops completely, since each time Rose would repeat the same words "Ted, you decide" (119). Similar to the fact that it is from a

\footnotetext{
94 According to Chinese mythology, the Kitchen God is one of the Chinese domestic gods that protect the heath and the family. He was originally a mortal man named Zhang Lang, who abandoned his wife to pursue a younger woman. But he squandered all the money in a short time and ended up a deserted beggar. Saved by his former wife who forgave his past deeds, Zhang was so ashamed that he threw himself into the kitchen hearth. Before his wife came to rescue him, Zhang had been burned into ashes that flew up to heaven. Instead of punishing him, the Jade Emperor appointed Zhang as the Kitchen God, who would report to heaven the activities of every household during the previous year before each Chinese Lunar New Year.
} 
submissive woman that the man reinforces his feigned authority, Rose's compliant attitude without objection dooms her erased identity and a secondary place in the heterosexual relationship.

The interjected commentary in Chen Ran's story "Breaking Open" clearly points out the reality about the heterosexual relationship the world wants women to accept calmly:

She is the body, he is the brain; she is the foil, he the mainstay; she is the empty vessel, the mud basin in the corner, he is the pillar of the state; $[\ldots]$ he puts chains on her neck, she ties freedom and dreams on his leather belt; she is like a little bird in the nest built with grass in his bosom, he piles chests on her ankles; her strength is a signal of danger, his strength is a wall to keep off the wind... (61)

In both Chen Ran and Amy Tan's fictions, the heroines, institutionalized by the dominant social discourse, enter into love and marriage with a rosy dream about an idealized man who could provide a spiritual harbor and promise her a happy life ever after. But as the true picture begins to unveil, what they experience is not only a life of compromise and loss of self-identity to male adoration, but also fear and disappointment caused by the male reign of terror.

\section{Despotic Men and Mute Women}

Wielding power and authority over their female menials, the male figures depicted by the two writers become a source of constant terror threatening the formation of women's self consciousness. Daring not to challenge the male domination, female characters in both cases choose to remain silent, burying all the unspeakable miseries deep inside. 
In A Private Life by Chen Ran, when Niuniu's defiant attempt of cutting her father's trousers is found out by her mother, the mother's reaction is hysterical. To Niuniu, her mother's scream "sounded like she had discovered a man with his legs severed, spurting out fountains of hot blood" (35). She spends the whole day on those "gaping wounds," "desperately trying to think of some way to close them" (ibid.). The detailed description of the mother's overreaction implies the strong effect of male menace to women, even if it is posed by a pair of ruined trousers. Compared with Niuniu's father whose threat is mainly psychological in nature, the male character in Chen's fiction "The Birth of a Hollow Man" inflicts both mental and physical pains to his wife. The woman, an innocent radio announcer in a small town, is cheated into marriage at the age of nineteen after she is brutally raped by the man when, taking the advantage of his work, he arranges a training for her in the provincial city. The man's ferocity is fully displayed on their wedding night. Tying up her wife's limbs to the bed, he "ripped up her clothes, biting her body as if with the teeth of a wolf, shrieking in a high pitch of excitement he enjoyed from her" (my translation, 225). Believing in his husband that all women must undergo the same thing or elsewise be divorced, the woman endures the painful humiliation throughout her marriage life, since in their unenlightened town, the term divorce is widely considered as stigma, especially for a woman.

When women accept their oppression as a fact of their lives under the 
influence of cultural conditioning, they are actually perpetuating their own fate of victimization through passivity and silence. Like Chen's characters who yield to the overpowering force of their husbands and social conventions, the heroine of Tan's The Kitchen God's Wife Winnie is also trapped in "a degrading marriage" for years, enduring "humiliation, abuse, and even rape at the hands of her husband" (KGW 91). Learning by heart the teaching of Old Aunt not to "strike a flea on a tiger's head" or to settle one trouble by inviting bigger ones, Winnie decides to "say nothing, do nothing", just like the other onlookers when she is slapped by her husband and forced to kneel down in public, begging forgiveness simply because she has talked to the male guests without her husband's permission (260). That is why Winnie remains silent after she lets go the service girl abused by Wen Fu, reasoning with herself that she would gain nothing but "a big fight" from her husband, "pitiful looks" from her friends and more abuse in bed if she accuses Wen Fu of the affair (ibid.). For forty years, Winnie lives under the shadow of Wen $\mathrm{Fu}$, a name she dares not mention even after she immigrates to America across the vast ocean. The fear stays until Wen Fu's death. But still, as Winnie recounts when her friend Helen brings the news, "And now, just to hear Helen mention his name, I could feel his breath on my neck, remember him laughing and telling me he had finally found me and would drag me back, no choice" (78).

Besides outright horror and violence imposed by men, there is another 
form of male abuse, one that is in a mild disguise but performs the same function of erasing female identity, as in the case of Ying-ying in Tan's The Joy Luck Club. Escaping her former husband in China, "a vulgar, arrogant womanizer," Ying-ying marries Clifford St. Clair, an Anglo-Irish man from America, as a ticket out of her previous life in misery, allowing him to construct an identity for her without objection:

I let myself become a wounded animal. I let the hunter come to me and turn me into a tiger ghost. I willingly gave up my chi, the spirit that caused me so much pain. (JLC 251)

Since the first day she arrives in the new country as a displaced refugee, Ying-ying has sunk into a state of depressive self-denial. With "the sweep of a pen" (104), Clifford changes Ying-ying's given name into Betty St. Clair and puts as her birthyear 1916 instead of 1914, the Year of Tiger that symbolizes Ying-ying's unruly nature. Over the years, Ying-ying washes away her pain and self-consciousness "the same way carvings on stone are worn down by water" (67). In the eyes of her daughter Lena, Ying-ying not only looks at everything around her "with empty eyes," always lying in bed as if dead (113), but she loses her discourse power, waiting for Clifford to "put words in her mouth" (106). Though engulfed by her husband's overwhelming affection, Ying-ying lives a dispirited life "without a strong commitment, romantic attachment, or passion for life" (Snodgrass 142-43). Ying-ying's erasure of her self-identity stems from a deep-rooted fear of man. Imagining an "evil and hungry" man living in their basement for thousands of years, Ying-ying barricades the basement door with 
a wooden chair and secures it "with a chain and two types of key locks" (JLC 103). She warns Lena to keep away from the door, or she would be implanted five babies by the bad man, who would eat both of them "in a six-course meal, tossing [their] bones on the dirty floor" (ibid.). It is just through such invisible threats that women are deprived of their voices and the fighting spirit against the phallocentric tradition.

Growing up under the influence of their mothers' mute obedience to the Name-of-the-Father, the daughter-generation makes a similar choice to remain silent when molested by men. In A Private Life, Niuniu's first experience of heterosexual relationship outside the family is from $\mathrm{Mr}$. Ti, her head-teacher in primary school. Having a crush on Niuniu, Mr. Ti behaves in a morbid way by isolating Niuniu and embarrassing her in front of the whole class. One day, when singling Niuniu out to his office after class for an accusation that she has passed around pornographic pictures of the human body, Mr. Ti shows the obscene pictures one by one, putting his hands on Niuniu's breasts and between her legs to teach her what the "private parts" are referred to. "In a confused state of anger," Niuniu wants to defend herself and strike out by "putting [her] hand on the same places of his body" while crying out, "These are your private parts, these are your private parts" (27). But what she does in reality is only taking a deep breath and running away. Enduring sexual harassment, Niuniu swallows hard, accepting a cruel, "incontrovertible fact" 
from her mother's humble obedience to and the other girls' admiration of Mr. Ti that he is a male: "[E]ven when I grew up, I would not be as tall or strong as he was, nor would I ever be able to get the best of him" (11). For Niuniu, the only thinkable solution is to "marry the Dean of Instruction," who would "rake Teacher Ti over the coals, even box his ears" (13). Being a powerless girl, Niuniu is not yet able to counteract the unchallengeable authority of the man. However, a seed of revenge has already taken root in her rebellious mind. Even within the patriarchal framework, she could still use men against each other to reclaim woman's deprived power.

Similar scenes turn up in Amy Tan's The Bonesetter's Daughter. Like Niuniu who is forced by Mr. Ti to explain the meaning of the "private parts," Ruth is harassed by her neighbor and dream lover Lance. Sitting accidentally on Lance's damped toilet seats one day when she comes to watch TV at his house, Ruth is proud of keeping Lance's urine as "a pledge of love" and mistakenly thinks she is pregnant ( $B S D$ 116). The girl's ignorance causes Lance's split-up with her girlfriend and makes Ruth a laughingstock in his eyes. When questioning Ruth whether she truly understands the cause for a woman's pregnancy, Lance first tickles the shy girl under armpit, then touches "her stomach, her breasts, her bottom" and "pinche[s] her nipples" (130). Seeing no obvious rebellion from Ruth, who only keeps on laughing till tears pour out, Lance intensifies his offense, shooting down both of his hands "to pull 
off her flowered panties" (ibid.). If it is not for Ruth's screeches "as though another person had burst out of her" (131), Lance might not have stopped his sexual abuse. Under the pretext of just having fun with her, Lance threatens Ruth that if she dares tell others what happened a moment before, he would "get really mad" and "make [her] sorrier than hell" (132). Nodding dumbly, Ruth leaves without a word. That night when Ruth tells LuLing she is scared of Lance, the mother who always "saw danger where there wasn't" is blind to her daughter's fear, thinking it must be Ruth who bothers their neighbor and makes trouble for him. Left with no one to save her, Ruth decides to draw support from Precious Auntie, ${ }^{95}$ through whose imaginary voice from the other world, Ruth succeeds in persuading her mother to move to Land's End in San Francisco, a place far away from the potential danger of Lance.

Faced with sexual harassment, both Niuniu and Ruth chose to endure the humiliation and escape from the male culprit in silence. However, both, guided by their emerging female identity, try to differ from their mothers and resist male oppression in an indirect way. Niuniu's mental revenge on $\mathrm{Mr}$. $\mathrm{Ti}$ and Ruth's devious tactic while taking advantage of her mother's superstition represent an awakening moment in women when the patriarchal myth is on the verge of collapse.

\section{Disappointing Men and Awakening Women}

\footnotetext{
${ }^{95}$ Suffering from a lifelong remorse for causing the death of her real mother - Precious Auntie, LuLing would always ask this imaginary spirit for instructions on major decisions in life. Though out of sheer coincidence, it is firmly believed by LuLing that her daughter Ruth is the mouthpiece of Precious Auntie who would convey the message through Ruth's writing on a sand tray.
} 
Like the aforementioned father-daughter relationship that changes from the daughter's fear of the paternal power to her recognition of the impotency of such power that exists in name only, women in the two writers' fictions experience a similar change of mentality. Behind the formidable mask of man, the awakening woman finds a disappointing male figure who is neither invincible nor the one to rely upon.

Niuniu's story changes by the time of her last days in high school. She is no longer the naïve girl cowering in the shadow of male tyranny. On the registration day of the last semester after the winter holiday, Niuniu is ordered by Mr. Ti to sweep up the snow in front of the classroom. Trying to accomplish this hopeless task with fresh layer of snow covering the area just swept clean, Niuniu suddenly realizes that what she has been doing is "all part of a plot or trap devised by Mr. Ti" (A Private Life 94):

I suddenly thought of all his rudeness, cunning, oppression, and unfairness. Not only did he hold back on my grades and criticize my morals, he also controlled my speech, my thinking, and even my feelings. All this was grossly unfair! How could I put up with this sort of humiliation? Why did I always submit to him, let him push me around as if I were a stupid melonhead? (ibid.)

Harboring all the hatred towards "the men that Ti and [her] father stood for," Niuniu bursts into Ti's office in a fury and glares at him "with daggers flashing in [her] eyes," sharp enough to "slash his hypocritical face to ribbons" (95). Though Niuniu's revenge to jab Ti's "private parts" with all her strength is, like the first time when she is molested, only performed in her imagination, it is 
much more intense and emotionally involved. With a new sense of identity awakening inside her, Niuniu fights a fierce struggle in her mind as if there were "two opposing people" trying to control her at the same time and is indignant at her ineffectual retaliation (96). If Niuniu's fear of Ti's authority begins to be shaken off since her awakening moment, another encounter between the two exposes $\mathrm{Ti}$ as a spineless scoundrel. One evening in the long summer before Niuniu is about to begin her college life, Mr. Ti pays an unexpected visit to her new apartment in an attempt to make his love confession. When Niuniu goes to her bedroom to put on proper clothing, she suddenly finds $\mathrm{Ti}$ standing sneakily at the door with "a hopeless look" and "tears streaming down his face" (102). In Niuniu's eyes, the "tall, strong frame" of Ti turns into "a crumbling stone monument that was about to collapse in ruins" (ibid.). After a choking expression of love, Ti's "arrogant face was as pale as a girl's" and his pretended masculinity "had crumpled into a great heap of garbage" around Niuniu's shoulders (103).

When women set free their own independent spirit from male manipulation, it is men who are uprooted from their power that is sustained by female submission. Chen Ran subverts the conventional characterization of male heroes by depicting a crying man in sharp contrast to a strong woman, a common scene in Chen's other fictions. While expressing her disappointment in man, Yunnan, Dai Er's female friend in "Breaking Open," tells a story about a 
pair of lovers who are determined to jump off the cliff and sacrifice their lives for frustrated love. When the moment comes, the man refuses to jump first and explaines to his lover that it is easier for him to find the woman who jumpes before him so that they could get reunited in the next world. But after the woman "clenched her teeth, stamped her feet, and jumped in the bottomless precipice," the man begins to be afraid ("Breaking Open" 50). Like Mr. Ti who collapses in tears for a cry of unrequited love, he cries piteously overnight for his lover and his own cowardice. By the next morning when the sun rises again, the man simply feels hungry and goes back home.

A similar image of a disappointing man is Mo Fei in Chen's novella "Nowhere to Bid Farewell." As one of Miss Dai Er's male friends and former pursuer, Mo Fei regards Dai Er as his confidant. Once Mo Fei pays a visit to Dai Er's home without invitation. Over a bottle of wine, the man who is desperate to divorce his wife, grabs Dai Er's hands to confess his unquenched love and rests his head heavily on her shoulder for psychological comfort. When rejected by Dai $\mathrm{Er}$ in slight annoyance, Mo Fei locks himself in the bathroom and sobs for almost ten minutes before he comes out with swollen eyes and a self-assuring excuse: "Only a crying man is a real man" to save his face (my translation, "Nowhere" 86). In Chen Ran's fictional world, it is typical that the male characters behave in a way traditionally deemed feminine, whereas the heroines, in comparison, are independent and assertive, judging 
the world according to their own principles. Voicing her disappointment over man, Miss Dai Er firmly believes that "a woman thinks with emotions, while a man thinks with his buttocks." (83). Commenting in a satirical tone, she tries to make a defense for males by connecting their brainless nature with androgenic hormone, adding that "it's against the woman's nature if she resorts to her buttocks to solve problems" (84).

Chen Ran's deconstruction of phallocentricity is embodied not only in the allusion of feminine temperament in her male characters in face of awakening women of spiritual independence, but also, more directly, in her depiction of male insanity caused by a loss of their phallic authority, both literally and symbolically. The architect in "Sunshine between the Lips" is a typical example of such an impotent man. This "gaunt, weary, middle-aged man" is the only friend of Miss Dai Er in her childhood. They spend most of the time together playing games beyond the girl's comprehension. Different from little Dai Er's favorite play of digging holes in the sand, the architect's game is to build high towers with a mixture of stones and mud. He builts them so high that Dai Er is led to believe them "truly lofty" (126). Then the two would stand in front of the towers, with Dai Er following the architect "in squeals of delight" (ibid.). Another game they would routinely play is to turn on all the three faucets in the courtyard, shooting three streams of water forcefully, which almost drive the man wild. "He would howl excitedly; the sounds reverberating through the 
deserted yard sound especially horrible, both thrilling and frightening little Dai Er" (ibid.). As an innocent girl without female knowledge, little Dai Er couldn't understand why the man's wife is never proud of and often quarrelled with this excellent architect "whose certificates of merit cover a wall in his home," nor could she decipher until years later in her adulthood the meaning of such games, "the connection between his frenzied need to work and play and the loss of his manhood - a compensation for failure" (ibid.). Their friendship ends one rainy day when the architect exposes himself in front of her, casting a lifelong shadow over Dai Er who is frightened to confront males and any form of phallic resemblance until healed by the dentist and reintroduced into the phallocentric order. The architect, losing his last hope of reconstructing a fake male authority over woman, is taken away by "a white ambulance" with its "siren blaring" to an asylum and ends up in a suicidal arson that finishes up his "vexations, regrets, and powerless desires" (127).

The metaphorical text above might be better understood from psychoanalytical point of view that man achieves dominance over woman through his possession of phallus as opposed to the female lack of it. According to Freud, the penis-determinant Oedipus complex serves as a critical point of one's development of gender identity. Threatened by the phallic authority of the father, which causes the child's castration anxiety, a boy has to repress his sexual desire for the mother and imitate the father's posture of 
masculinity. In a girl's case, the discovery that she lacks a penis as a possible result of castration turns her away from her similarly castrated mother to seek protection from the father. Deviating from Freud's belief in anatomical influence on one's self-identity and sexual inclination, Lacan argues for the symbolic role of the phallus, which is not a physical organ as what penis denotes in Freud's psychoanalytic theory, but a signifier for the presence and absence of access to power and self-definition, a symbolic object dividing the two sexes in giving power to those who have it (Elliot 23). Therefore, the architect in Chen's fiction attempts to compensate for his sexual impotence by creating a symbolic phallus, the lofty mud tower, and derives pleasure out of the shooting spouts. But this imagined restoration of authority could only deceive the little Dai Er, who has not developed a clear sense of sexuality. When Dai Er renounces her friendship after his obscene offense, the architect loses his final audience as source of power. Unable to measure up to social expectations on a man, he is left with no other choice but madness and self-destruction.

The feeling of disappointment in men is also evident in Amy Tan's novels. As a woman learns to value her true self, the man, who used to be as perfect and powerful in her mind, gradually changes into a petty coward who falls far short of her expectation. In The Joy Luck Club, Lindo describes the behavior of Tyan-yu at their wedding ceremony when she turns sixteen, four years after living with her husband's family. The showy manner in which Tyan yanks the 
scarf off Lindo's face reminds her of "a young peacock" she once sees "that acts as if he has just claimed the entire courtyard by fanning his still-short tail" (59). Tyan-yu's weak nature is even more apparent when it comes to the sex life between the newly-weds. As a fifteen-year-old boy, Tyan-yu is sexually immature and refuses to sleep with his wife. In order to avoid his mother's anger of seeing no sign of a grandchild, Tyan puts all the blame on Lindo, who has actually been forced to sleep on a sofa for several months. Threatened by her mother-in-law in bitter remarks, Lindo swallows the insult and takes the initiative to arouse Tyan-yu's interest in her. But when she takes off her gown at her husband's bedside, he is scared and turns his face (62). It is the first time that Lindo realizes "what was underneath Tyan-yu": his fear reveals that he is like a little boy who has never grown up, having no desire not only for Lindo, but also for any woman (ibid.). The realization of Tyan-yu's inmaturity drives off Lindo's fears for the fabricated authority of her husband. Ensured he would never touch her, Lindo is rather contented that since then she would have "a comfortable bed to sleep on" (ibid.).

For Rose, an obedient wife who follows every word of her husband Ted, everything changes after Ted loses a malpractice lawsuit because of his failure in a plastic surgery. Sinking into depression and inaction, Ted starts to push Rose to make decisions, from on which brand of car they should buy to most trivial matters like whether the dinner should include one appetizer or two. The 
sudden repossession of decision-making power makes Rose confused and frustrated. Whenever Rose replies as usual "You decide" or "Either way is fine with me," Ted would kick back the ball impatiently, "No, you decide. You can't have it both ways" (120). Like Tyan-yu, Ted vents a resentment over his own failure on his wife. The daily squabble escalates into an unbridgeable chasm between the couple. It is only when Ted asks for a divorce that Rose begins to be awakened to a cruel fact: "[A]fter you pick yourself up, you realize you can't trust anybody to save you" but yourself (121).

It is through projecting their own fears and undesirable traits onto women as the Object that men confirm their power as a perfect Subject. As Beauvoir clearly states in The Second Sex:

Appearing as the Other, woman appears at the same time as an abundance of being in contrast to that existence the nothingness of which man senses in himself. [...] In woman is incarnated in positive form the lack that the existent carries in his heart, and it is in seeking to be made whole through her that man hopes to attain self-realization. (142)

Lena, another daughter in The Joy Luck Club, suffers a similar fate as Rose when her husband Harold shirks his responsibility under the pretext of gender equality. Lena meets Harold while working for an architectural firm of which Harold serves as a partner. Since their first date, Harold has been upholding the principle of absolute equalitarianism, a principle encouraged by Lena from the very beginning, when, taking it as a sign of her economic independence, she insists on paying for the whole meal when they dine out even if she only 
orders a salad. Coaxed by Harold that she is "really extraordinary," better than any other woman who is eager to get matey with him, Lena feels "awfully lucky" and deeply worried that all the "undeserved good fortune" would slip away from her and that "she would be caught someday, exposed as a sham of a woman" (156). Throughout the years, Lena has been struggling to prove she is equal to her husband. Such a fear is trickily utilized by Harold, who applies "the logic of middle-class patriarchy" to benefit from Lena's original designing ideas without sharing the profits with her, to keep her in an inferior position earning seven times less than him, and to deny her any voice in their family life (Ryan 98). Blind to the fact that if it is not for Lena, he would neither dream of starting his own business nor turn his loss-making company into a profitable one, Harold assigns Lena to work under the interior designer with the excuse that it might seem unfair to other employees if he promots his own wife. As time goes by, Lena begins to doubt Harold's ideal that as long as they "keep the money thing separate," they would "always be sure of [their] love for each other" (157). But "victimized at both the material and ideological levels," Lena is unable to challenge the patriarchal discourse Harold uses against her (Ryan $98)$.

The confrontation is triggered by a list stuck on the refrigerator for daily expenditures shared between the couple. While staying in her daughter's house, Ying-ying catches sight of the special list and questions why Lena has 
to pay for the ice cream that she hates since childhood. Her mother's words make Lena suddenly realize the unfairness she has long been treated both in family and at workplace. Disappointed in Harold's selfishness and miserly behavior that aims to "eliminate false dependencies" and "love without obligation" (162), Lena feels that her marriage, in which she surrenders everything to her husband without caring about the returns, is just like the precarious table Harold makes: once losing balance, it would collapse into pieces. Spurred on by an awakening sense of self-identity, Lena goes straight up to the refrigerator and crosses out "ice cream" that symbolizes female submission.

In The Kitchen God's Wife, Winnie also experiences a transition in her relationship with Wen Fu from dutiful servitude to contemptuous revelation. After finding out that Wen Fu takes the place of his dead brother in the air force by using the latter's diploma and application, Winnie begins to see her haughty husband as a liar, a combination of two people: "One dead, one alive. One true, one false" (171). Wen Fu's depravity is not only evident in his fraudulent scheme to join the army, but also in his acts of cowardice in the battlefield. Although he behaves ferociously at home, it is perfectly plain to Winnie that Wen $\mathrm{Fu}$ is a pigeon-hearted pilot who always turns his plane around after taking off for the fear of being shot down by the Japanese. This is the reason why he saves his life while many other pilots have died (327). Winnie's 
disappointment goes deeper when Wen Fu spends a significant amount of her dowry on a used car to show off while the money has been originally reserved to meet an emergency in wartime. The car ends up getting burned on top of a rocky graveyard as the engine is overloaded. But instead of being exasperated for the pointless waste of money, Winnie laughs so hard that even tears run down her face. Demolishing the deified male god, she could see the dumbfounded expression of Wen Fu and "the little car burning up on a pile of rocks, the same way mourners send gifts to the dead" (212). With the destruction of the car, the unchallengeable power of man also comes under question in Winnie's mind. The second time she sends a telegram to have another portion of her dowry withdrawn from the hometown bank, the message is directed to her sister Peanut instead of her sister-in-law, and unlike the first time without mentioning the recipient of the money, this time Winnie indicates expressly her name on the telegraph: "Send four hundred yuan directly to Jiang Weili only" (ibid.).

As an independent spirit starts to brew within Winnie, she is awakened to the truth behind male hegemony. When she returns to her father's house as a strong-willed woman after years of ordeals during the war, she finds much similarity in her weak-spirited Uncle and her palsied father:

They shared the same lost mind, the same weak spirit. Their eyes moved slowly back and forth, as they took in everyone else's opinions, unable to make up their own minds. And this made me think how both had always been this way. All those years, they only 
pretended to lead, shouted when they did not know how to speak, frightened people when they were afraid themselves. (335)

Awakening from their subdued numbness, the female characters set out to reclaim their lost self.

\section{Dethroned Men and Self-Defined Women}

It is interesting to note that for both Chen Ran and Amy Tan, their fictional heroines have experienced a spiritual journey from self-sacrifice for the protection from a deified man to a feeling of disappointment in their male counterparts accompanied by an awakening female identity. Dethroning the myth of patriarchal power, the liberated women proceed to define their own identities with boldness and determination.

For most female characters depicted by Chen Ran, once they have seen through the feebleness of men, they would subvert the male dominance by taking the lead in heterosexual relationship, especially in terms of sexuality, to fulfil their inner drives for self-determination. In "Nowhere to Bid Farewell," Miss Dai Er expresses acutely an incompatibility between her bodily needs and spiritual demands for men. Over the years, she has been involved with several men. She even flies to the U.S. to live with Jones, an American man whose lifelong dream is to marry a delicate and graceful woman like Dai Er. Although Dai Er would always become intoxicated by an overwhelming sexual experience with Jones, "her emotion has never been aroused; the satisfaction of corporal desires cannot replace the fulfillment of certain spiritual aspirations, 
and without the latter, there is no difference between sex and work, both lacking passion" (77). The distinction between corporal satisfaction and spiritual fulfillment marks a significant advancement in women's identity awareness. Discarding traditional morality that requires a woman to honor both her virginity and spiritual purity, Chen's self-defined heroines like Miss Dai Er not only thirst for an emotional reverberation that cannot be offered by men, but also take the lead in guiding those "feminine" males, quenching their bodily desires fully released.

As Li Youliang elucidates in To Name Men, the cutting point to subvert patriarchal discourse in Chinese women's literature since mid 1980s is through "sex" - what a man is most proud of but at the same time sensitive and vulnerable about. Since men are traditionally granted absolute privilege of dominance in sexual activity, women are permanently locked into a passive position and brutally deprived of their natural desires, pleasures and joys originating from their own life experiences. Therefore, a restoration of female sexual initiative long suppressed by phallocentrism is of vital importance for a woman to develop her own sense of individuality and value judgment, reconstructing an equal relationship between men and women (218-19). From this perspective, we may better understand why Niuniu allowed herself to have sex with $\mathrm{Mr}$. Ti in a private dining room named "Yinyang Grotto." After the embarrassing encounter with $\mathrm{Ti}$ at her home, Niuniu realizes the hidden power 
in her body which she is yet to explore. Acknowledging her delight in seeing $\mathrm{Ti}$ tormented out of his desire for her body, she feels at the same time that her body is "covered with mouths panting with longing" (115). Instead of being a vulnerable prey, Niuniu's choice to experience her first sex in "Yingyang Grotto" is rather driven by her own sexual desires as a woman, than the result of plotted seduction by Mr. Ti:

[S] he was not gripped by any feeling of love for him. All she felt was the lust that had been aroused in her body and the urge to use his body to reach that deep ecstasy she had never totally experienced before. What she delighted in was this sensual ecstasy, not this man before her. [...] Her mind and her body had distanced themselves from each other. She had become another person, controlled totally by her body's need for sexual gratification. (116)

From the description of Niuniu's inner feelings, we may sense a revolutionary transformation in women's position in heterosexual relationship. Turning themselves from a passive Object to an active Subject of sexuality, female characters in Chen Ran's fiction are determined to make their own choices and play a leading role in their sexual relationship with men. What is worth noting is that the name of the "Yinyang Grotto" carries a symbolic meaning in the text. According to Chinese dualist cosmology, yin (the negative feminine principle) and yang (the positive masculine principle) serve as the origin of the world. The imagery of the grotto is also symbolic of woman's womb where the journey of everyone's life begins. Therefore, by naming the room as "Yinyang Grotto," the author implies Niuniu's intentional choice to merge her female force with the male one in order to experience a rebirth of 
her sexual identity.

In "A Toast to the Past," the relationship between Xiao Meng and Lao Ba, the heroine and her Chinese-Australian boyfriend, is also characterized by female initiation and male submission. Moved by Lao Ba's boyish shyness and his irresistible urge to be guided in sex, Xiao Meng, a precocious girl who has tasted the forbidden fruit with her elderly neighbor at the age of seventeen, decides to arouse her own desires, lead him in his first sexual experience, and give up the holy law made by God that designates man as an active agent and woman as a passive recipient of love (my translation, 57). Reminded of the bygone days when her female identity begins to take root as she discovers the power within her body, Xiao Meng takes Lao Ba as a continuation of something belonging to herself (59). When she later finds out that Lao Ba happens to be the son of the very neighbor who plants on her virgin land with a lasting influence, Xiao Meng resolutely turns away from Lao Ba no matter how piteous he entreats her in tears, which directly causes his death in a car accident.

If Xiao Meng's sexual enlightenment of Lao $\mathrm{Ba}$ is out of the latter's innocent love, and her parting from him, a heartbreaking choice with regret, heroines in Chen's later works are more detached in their love relationship with men. In "The Sound of Another Ear Knocking," Chen Ran describes the power of Miss Dai Er's eroticism from the perspective of a male character Big Branch. Unable to resist the radiating charm of Dai Er, the enigmatic single neighbor he 
used to date several years ago, Big Branch has sex with her when she pays a visit to his house. But when the male hero is immersed in his successful conquest of "a fainted female prisoner who yields herself to him," Dai Er sarcastically compares the two of them as "panting quadrupled animals" and stares into the eyes of Big Branch "as if she was looking at a satisfactory whoremonger" (my translation, 118). It is only at that moment that Big Branch realizes that he has been fooled with by Dai Er, who purposely comes to "utilize his penis" to suffice for her physical needs (121). The plot subverts the traditional power relationship between man and woman. Overthrowing their expected roles of passivity, Chen's female characters like Dai Er proudly exercise their control over men in sexuality by separating their sensual pleasures and spiritual pursuits. In comparison, Big Branch, as a representation of man in general, is portrayed as someone who is only driven by his lust for female beauty and has been utilized as a tool to satisfy woman's erotic desires. Finding out the truth of losing the battle to Dai Er, Big Branch simply reassures himself, "I used my penis for a delicious feast of desire. That's all the world is about" (ibid.).

Women's leading role in affirming their sexual selves is even more radically portrayed in another story of Chen: "The Silent Left Breast." Disillusioned about finding a soul mate who could match her both in appearance and spiritual maturity, the heroine Dai Er ridicules and subverts 
the patriarchal logic that only man could seduce woman. Separating physicality from spirituality, Dai Er justifies herself in her intention to entice a handsome, young barber named Ah Long:

At least there is one thing I'm exactly sure of: I couldn't fall in love with such a simple-minded boy. Love requires an extensive amount of collision and entanglement within one's heart. But such an ideal is far too difficult to realize for those women who have experienced internally all the vicissitudes of life with intellectual complexity and good analytical ability. In that case, what's the point of rejecting our body to enjoy those natural, authentic and concrete joys in life? (my translation, 202)

Faced with Dai Er's sexual invitations and teasing overtures, Ah Long is "in a state of panic, standing rooted, his face reddened with sudden excitement" (my translation, 208). In Dai Er's eyes, he is uneasy and jubilant "like a little stag that looks for food for itself for the first time" (ibid.). She encourages him to come to the bed where she is lying, gives herself to him and enjoyes the ecstasy unleashed from her energetic body. Although Dai Er indulges herself in erotic satisfaction, she never gives up her pursuit of spiritual fulfillment. Just as what she tells Ah long, her right breast is called "Mr. Talk" that could be touched by him and her left breast, "Miss Silence," is reserved only for herself and the one who is far away or does not exist at all (210).

Unlike Dai Er's relationship with Ah Long, which remains at the corporal level, Niuniu's love for Yin Nan is truly sincere. As Niuniu recalls her impression of Yin Nan during their first encounter: "Seeing him gave me a thrill that quickly overwhelmed me, filling my heart and dominating my thoughts" ( $A$ 
Private Life 144). For Niuniu, Yin Nan represents "another type of man totally different from the father figure" that always wins her affection (134), radiating "an uncommon inner clarity and authority" that resonates in her heart string (136). Yin Nan might be the only perfect male character depicted in Chen Ran's fiction besides the dentist doctor in "Sunshine between the Lips." But unlike the dentist who heals Dai Er's childhood wound by conquering her weak spirit, in this later novel of Chen, it is Niuniu who guides her boyfriend Yin Nan through his first sexual experience.

Before Yin Nan is about to fly to Berlin the very night, ${ }^{96}$ the lovers meet for the last time in an abandoned warehouse. When Niuniu tells Yin Nan that she wants him to remember her with his body and leads him to a battered wooden bench on the heap of straw, she feels him "tremble slightly" and he acts as if he were "an obedient little sick boy who had to have everything done for him" (175). With his "delicate hands [hanging] down helplessly on either side of the bench (ibid.), Yin Nan is like "a willing, eager prisoner," letting Niuniu do with him whatever she wishes (176). Chen Ran gives a detailed description of Niuniu's sexual inducement on Yin Nan, arousing his desires and guiding "that lost and hungry lamb into the sweet pasture of its yearning" (ibid.).

Revolutionizing the phallocentric tradition that treats women either as

\footnotetext{
${ }^{96}$ The reason why Yin Nan suddenly moved to Germany was not specified in the novel that was intentionally detached from the overall political environment the story was set in. But it was implied that Yin Nan's escape was related to the student protest he might have been involved in during China's political turmoil in 1989 .
} 
objects of desire or abstinent virgins without sexual desires, heroines in Chen Ran's fiction take a bold step forward to explore the outside world as well as their inner selves with an experiencing body. The male characters, however, seem to be timid and unenlightened, waiting to be rescued or comforted in women's embrace. As a Chinese critic Jiang Bo states, the female characters in Chen's fiction are spurred on by the libido drive to explore the dialectical relations between spirituality and physicality. Disencumbered of traditional restraints on women, they mount a quiet resistance through their body against the dominant discourse of patriarchy (my translation, 50).

Women's confidence to control their own fate after the dethronement of men is best symbolized in a scene following the lovers' first and last sex in $A$ Private Life. Seeing Yin Nan disappear at the end of the street, Niuniu lifts her head to the sky above the airport. There she sees a silver-gray flying object like a huge kite that is pulled into her through a long cotton string at her hand. As the object comes nearer, she finds it is not a plane, but a person. As Niuniu feels at the moment, "[W]hat was strange was that it was not Yin Nan. The person soaring up there like some huge bird was myself. There on the ground was the real me holding a kite string, controlling another self-same me up there in the blue" (178). With their spiritual and bodily power erupting out of male control, women finally reconstruct an identity defined in their own terms. 
While heroines in Chen's fiction assert their self-identity by overthrowing the patriarchal morality on female chastity and sexual passivity, in Tan's novels, women rewrite their own fate through a resolute rebellion against their former reliance on men. In Amy Tan's The Joy Luck Club, Lindo has an epiphany on her wedding day. Seeking power from the wind that foreshadows a heavy rain that would fill the rivers and cause "men to yelp and dance" (JLC 58), Lindo stops her self-pitying sorrows for a fate beyond her control. For the first time, she sees in herself something valuable: "I was strong. I was pure. I had genuine thoughts inside that no one could see, that no one could ever take away from me. I was like the wind" (ibid.). Seeing what lies inside her, Lindo is no longer scared. Although she complies with the marriage tradition to cover her face under a red scarf, beneath the scarf, she makes a promise to herself: "I would never forget myself" (ibid.).

The climax of Lindo's story centers on a red candle. As a symbol for the marriage bond, the candle is expected to burn continuously at both ends on the wedding night, which would seal Lindo with Tyan-yu and his family for her entire life: she could not remarry even if her husband dies. Denied by Tyan-yu to share the same bed with him, Lindo sneaks outside and sits by a tree across the courtyard, watching the candle that is guarded by a matchmaker's servant. When a loud cracking thunder frightens away the servant girl, Lindo couldn't help running to the yellow-lit room where her fate would be decided. Even 
though she prays "to Buddha, the goddess of mercy, and the full moon" to make the candle go out (60), both ends of the candle still burn strong. Fearless to control her own destiny and with her throat filled with fervent hope, Lindo finally blows out her husband's end of the candle, dispelling the patriarchal terror that aims to subdue women to their oppressed fate. The moment Lindo performs this bold act, she is overtaken by an intense fear to be cut down dead with an invisible knife or blown away by the mouth of sky, but she soon finds out nothing happens at all. The next morning when the servant proudly declares the successful job she has done to keep the candle burning all night, Lindo has emerged as a strong woman of individuality, never to be deceived by the myth of man. She recomposes herself, carries out a well-contrived plan by taking advantage of the superstitious fatuity of her in-laws and really changes her fate with "[her] clothes, a rail ticket to Peking, and enough money to go to America" readily provided by her mother-in-law (66).

Winnie, the heroine of The Kitchen God's Wife also demystifies the patriarchal power and discoveres in herself "additional capabilities, including a strong will to live and an urge to fight for her future" (Huntley 91). Like Lindo, Winnie grows up in Old China that privileges the Confucian ideal, "raising women to be passive and silent in their roles as daughters, wives, and mothers" (Huntley 100). Her mother, an educated Shanghai woman, is forced to leave her beloved and marry Winnie's father Jiang as a replacement of his 
second wife, who commits suicide when she is rejected by Jiang to take the place of his deceased first wife. Insulted as the "Double Second" by Jiang and his other three wives, Winnie's mother chooses to leave her loveless marriage and seek her own happiness. The day after she has a secret meeting with a man in a theater, she mysteriously disappears. Winnie has no clue about what happens to her mother apart from the funeral banners hanging in Jiang's house, implying the presumed fate of a rebellious woman renounced by a male-dominant society.

After that, Winnie's mother becomes a riddle in her heart. Throughout the years, Winnie has imagined countless versions of "an unhappy ending to [her] mother's life" and allows herself "to be scared by those sad tales" (KGW 340), but her blind submission to the dominant discourse does not protect her from miseries similar to what her mother has experienced. Having endured sexual and emotional abuse inflicted by her husband, grieved over the deaths of her babies, and suffered "the brutality of the Japanese war with China, hunger, poverty, homelessness, and the horrors of a countryside ravaged by bombs and fighting" (Huntley 81), Winnie has grown into an unyielding and determined woman. Compared with Lindo who draws spiritual power from the sweeping wind, Winnie's epiphanic moment comes up on her way to see her sister Peanut, who abandons her feudal marriage and gentry lifestyle to "serve egalitarian Communist ideals" with a web of women aiding each other 
(Snodgrass 130). Walking along the street, Winnie catches sight of a bargain stall selling "forbidden stories" about girls who scandalizes the family names by marrying for love, the same stories Winnie recalls she and Peanut used to read in a secret place of their house. In such stories, the endings are usually wretched, with "scary morals at the end," like "'Lose control, lose your life!' 'Fall in love, fall into disgrace!' 'Throw away family values, throw your face away!'” (KGW 340). It is not until then that Winnie realizes that her mother's life, as she imagined and heard from others, might not be tragic at all: "Perhaps my mother's life was now filled with joy! Perhaps I too could still find the same thing. This was my hope" (ibid.).

Recreating a true story about women, Winnie is no longer deceived by the male definition of a woman's fate. She keeps the divorce paper Wen Fu forces her to sign as hope for a new life and moves to live with Jimmy in true love even at the cost of being sued by Wen Fu on fabricated charges. Before the verdict is to be announced in court, Wen Fu unexpectedly offers to recall the lawsuit as long as Winnie begs for his forgiveness. But instead of falling on her knees as before, Winnie proclaims in a loud voice: "I would rather sleep on the concrete floor of a jail [...] than go to that man's house!" (375). Though Winnie is sentenced to a two-year imprisonment, she is smiling, because this time Wen Fu "was the who was humiliated" (383). Winnie not only overthrows the patriarchal ruling, but also invents a deity for women. By naming the 
Kitchen God's wife not as Mrs. Kitchen God, but Lady Sorrowfree, and by worshipping the female goddess forgotten in the folk legend instead of the Kitchen God, "who became a fearsome god under dubious circumstances" (Adams 95), Winnie transforms the Kitchen God's Wife and herself from a helpless victim into an empowered figure.

In her discussion of the relationship between love and female identity, Suzuki highly values the "internal transformation" of women because of their "lack of political or legal authority" (7). She borrows Foucault's notion of "technologies of the self," among which love is deemed as an important means for women to transform their "bodies and souls, thoughts, conduct, and way of being" in order to discover their true selves (Foucault 18). For heroines in both Chen Ran and Amy Tan's fictions, they have experienced a growing sense of self-consciousness in their heterosexual relationship with their fathers, husbands, lovers and other male characters. Deprived of paternal love since childhood, some women put their hopes on a deified man as a source of comfort and protection; others submit themselves to the fear of a despotic man. However, what awaits them is not eternal bliss as they have dreamed before, but bitter disappointment at male cowardice and vulgarity. Killing the patriarchal lies, women begin to stand on their own feet, emerging with a self-defined identity from the collapsed ruins. 


\section{CHAPTER IV}

\section{SISTERHOOD - FROM CONSOLATION TO SALVATION}

Sisterhood, which is defined in this dissertation as a continuum of a close bond among women that accommodates both female friendship and female same-sex love, is another major motif in the fictions of Chen Ran and Amy Tan. In their story telling from female perspectives, both writers touch upon, although with different emphasis, sisterhood as a source of women's consolation and salvation. This chapter will trace the theoretical discussions on sisterhood in Western scholarship, followed by a thematic comparison of the two writers' portrait of sisterhood, the affirmation of which is a powerful means to revolt against compulsory heterosexuality prescribed by a male-supremacist norm. An analysis of Chinese and American socio-historical realities and literary representations on sisterhood is also carried out at the end of this chapter to account for the variations of the role sisterhood plays in the fictions by Chen Ran and Amy Tan.

\section{A. Sisterhood is Powerful}

Either in a radical form of lesbianism, or a mild manifestation of female 
friendship, the concept of sisterhood has been an issue of common concern among feminist theorists and practitioners. In a patriarchal society where heterosexuality is deemed as the only legitimate orientation in love, women are doomed to an objectified fate, deprived of their own identity and value of existence. Sisterhood provides an alternative to women in their pursuit of spiritual independence. By turning to their female allies suffering from the same plight, women can truly enjoy freedom and equality in addition to appreciation and comfort from each other.

In The Bonds of Womanhood, Nancy F. Cott dedicates one chapter to "sisterhood" in her discussion on the social derivation of "womanhood" in New England from 1780-1835. To explain the reasons "that impelled women toward friendship and sisterhood with each other" during the eighteenth century (168), Cott indicates that the deep-rooted sex-role division, which identifies women with "the heart" in comparison to men's superiority "in strength and in all of the rational capacities (discernment, judgment, etc.)," is driven by the need to gloss over gender inequality (161). Characterized by "heart," women are deemed inferior to men in rationality and could only find "reciprocal interpersonal relationships" and equivalent emotional sympathies from their female friends. While the accessible diaries and letters of young women from the late eighteenth century suggest "a pattern of reliance on female friendship for emotional expression and security" (173), by the early nineteenth century, 
female friendship became a way of life when it assumed a new significance of forming "peer relationships" (185-87). As Cott elucidates, the nineteenth century is an era when relations between equals supersedes hierarchical relations "as the desired norms of human interaction" (187). Since women were not regarded as peers of men, they would turn to their own sex as true peers and value female friendship in their pursuit of equality and individuality. It is also acknowledged by Cott that women's attachment to each other symbolizes the construction of their gender identity. Discovering their gender-prescribed "talents, needs, outlooks, inclinations," women realize that their best chance to escape male-defined inferiority is to uphold and celebrate, through a strong female bond, their distinctive gender attributes, which is no lesser than, or even better than those of men (190).

Although women's affinity and bonding with each other has been in existence for centuries, it is kept silent by the male-enforced norm of heterosexuality, which is denaturalized by lesbian feminism that gained its popularity in the 1970 s and early 1980s. In 1980, Adrienne Rich published "Compulsory Heterosexuality and Lesbian Existence," generally considered as a manifesto for sisterhood. In this paper, Rich explores the reasons why women's choice of sisterly relations among themselves is "crushed, invalidated, forced into hiding and disguise" and why a discussion on lesbian existence is left out of most writings including feminist scholarship (131). Citing Kathleen 
Gough's listing of eight characteristics of male power ${ }^{97}$ to subdue women and reviewing the studies by Catharine A. Mackinnon on sexual harassment of working women as well as Kathleen Barry's hypothesis that attributes the underlying mechanism behind female sexual slavery to compulsory heterosexuality, Rich concludes that heterosexuality is enforced for women "as a means of assuring male right of physical, economic, and emotional access" (135). In response to the debate over lesbianism that surfaced to public attention since the sexual revolution and the advent of second wave feminism in the 1970s, Rich proposes a continuum of lesbian existence to replace the clear-cut distinction between lesbian and heterosexual women. For Rich, all relationships between women comprise a lesbian element, whether a woman claims a lesbian identity or not:

I mean the term lesbian continuum to include a range - through each woman's life and throughout history - of woman-identified experience, not simply the fact that a woman has had or consciously desired genital sexual experience with another woman. If we expand it to embrace many more forms of primary intensity between and among women, including the sharing of a rich inner life, the bonding against male tyranny, the giving and receiving of practical and political support, [...] we begin to grasp breadths of female history and psychology. (italicized in the original, 135-36)

According to Rich, the introduction of the lesbian continuum could enable women to unite and seek power from each other and "discover the erotic in female terms", which is by no means confined to bodily experience, but is

\footnotetext{
${ }^{97}$ The list Gough summarizes to explain the enforced mechanism behind sexual inequality includes men's efforts to deny women's sexuality or to force male sexuality upon women; to command or exploit female labor; to control or rob their children; to confine or prevent their physical movement; to objectify them in male transactions; to curb their creativeness and to deny their access to the majority of social knowledge and cultural attainments (Gough 69-70, qtd. in Rich 131-132).
} 
interpreted as an omnipotent energy in the sharing of physical, emotional and psychic joy that empowers women to shake off "resignation, despair, self-effacement, depression, self-denial" imposed by men (Lorde qtd. in Rich 136). Rich also cautions that the denial of reality and visibility to "women's passion for women, women's choice of women as allies, life companions, and community" under the lie of compulsory female heterosexuality has incurred an immeasurable loss "to the power of all women to change the social relations of the sexes, to liberate ourselves and each other" (italicized in the original, 139). Rich's elaboration on a lesbian continuum provides a theoretical basis for the generalized interpretation of sisterhood in this dissertation. When we extend our understanding of sisterhood from a narrow sense of female friendship to a broader concept of any forms of female bonding including what has been defined as lesbianism by a compulsory heterosexual mentality, then more women would be united so as to realize their shared fate and seek a more equal relationship with their male counterparts.

In Unpacking Queer Politics, another lesbian feminist Sheila Jeffreys also places a paramount emphasis on woman-loving to be fundamental to feminism (19). Citing Charlotte Bunch's ideas on woman-identified lesbian existence $^{98}$ and Janice Raymond's elaboration on the coined notion of

\footnotetext{
${ }^{98}$ According to Bunch, a lesbian is woman-identified, since her sense of self and energies center around woman and she dedicates herself to other women for political, economical, emotional and physical support (332, qtd. in Jeffreys 20).
} 
"Gyn/affection, $99 "$ Jeffreys concludes that for the survival of a feminist movement, solidarity of the oppressed through women's love for one another is a necessary basis for women to identify and reject atrocities against them (20). Another key element for lesbian feminism, as Jeffreys summarizes, is that lesbianism is based on choice and resistance instead of sexual relationships; it is more like the "romantic friends" of the nineteenth century who prioritize affection and companionship (22).

Be it "lesbian continuum" in Rich's analysis, "Gyn/affection" proposed by Raymond or lesbianism according to Jeffreys' understanding, the major concern of lesbian feminists is to subvert the compulsory mechanism of heterosexuality by discovering and utilizing the hidden power of women in sisterly bond, or what the current author categorizes as sisterhood. For postmodern feminists, the power of sisterhood is also one of the central themes in their deconstructive challenge to established norms and binary oppositions. In Gender Trouble, Butler has an extensive discussion on Monique Wittig, who envisions lesbianism as a political strategy to launch "a full-scale refusal of" normative heterosexuality (158). Although Butler cautions against Wittig's radicalism that might mislead feminism into another form of binary oppositions by overemphasizing the power of homosexuality that

\footnotetext{
${ }_{99}$ Raymond invents the concept of "Gyn/affection" to refer to women's passion for each other, or "the experience of profound attraction for the original vital Self and the movement toward other vital women" for full power (Raymond 7, qtd. in Jeffreys 20).
} 
assumes instead of overthrows the role of heterosexuality ${ }^{100}$, she seems to tally with Wittig on the point that non-heterosexual women and men encompass a promise to "transcend the binary restriction on sex imposed by the system of compulsory heterosexuality" (26).

Luce Irigaray, another postmodern feminist, also confirms the power of sisterhood for women's self-salvation in a phallocentric world. In her famous work Speculum of the Other Woman, Irigaray deems lesbian and lesbian relationships as the only alternative to "the hegemonic phallocentric model" that should be harshly condemned (Holmlund 287). In This Sex Which is Not One, Irigaray contests the inability of Freudian psychoanalysis "to conceptualize women except as the 'same' as men" (ibid.). For Irigaray, by masquerading and playing with masculinity and femininity of psychoanalytic discourse, a lesbian demonstrates both notions as constructions and performances. The shift to sisterhood, according to Irigaray, not only challenges the male-defined gender identity, but also grants women "exhilarating pleasure" when they partner with someone like themselves (Speculum 103). In "Women-Amongst-Themselves: Creating a Woman-to-Woman Society," Irigaray acknowledges that the need for women's "love of the same" is a historical fact obliterated by the heterosexual ethics. For

\footnotetext{
${ }^{100}$ For Butler, a more frontal challenge to normative heterosexuality should come from a deconstruction of gender. Since the concept of gender has been stabilized by the heterosexual mechanism that designates women to their feminine roles, a deconstruction of gender by emphasizing its performative nature, such as the subversive acts of wearing drag and cross-dressing constitutes, in Butler's eyes, "a counter-performance that questions the naturalness of heterosexual matrix" (Bradley 75).
} 
Irigaray, the relationship of affidamento, or "a bond between one woman and the other" based on a recognition of their distinguishing qualities, could be seen as "a mode of energetistic support and potentialization" asserting and deploying female values (Irigaray, Reader 193). Irigaray's exhortation of sisterhood is well illustrated in her essay "When Our Lips Speak Together":

I love you who are neither mother (forgive me, mother, I prefer a woman) nor sister. Neither daughter nor son. I love you - and where I love you, what do I care about the lineage of our fathers, or their desire for reproductions of men? Or their genealogical institutions? [...] I love you, your body, here and now. I/you touch you/me, that's quite enough for us to feel alive. (209)

As Rosi Braidotti notes, the realization of a sisterly bond among women "is the starting point for feminist consciousness in that it seals a pact among women," the moment of which serves as a cornerstone to articulate "feminist position or standpoint" (415). For heroines in the fictions of Chen Ran and Amy Tan, when what they experience in a male-world is tyranny and disappointment, they naturally turn to their female friends, from whom they realize not only their shared fate of male suppression, but also the power of sisterhood to rediscover their shining points and reconstruct an emerging self. Reaching for each other, women in the fictions of the two writers are no longer afraid, hopeless, numb or insignificant, because sisterhood is powerful.

\section{B. A Thematic Comparison on Sisterhood}

As an important source of female power and origin of self-discovery, 
sisterhood, or the bond among women, is an indispensable component in fictions by Chen Ran and Amy Tan. It is through sisterhood that female characters take emotional refuge from great worries or calamities, provide mutual support and psychological consolation, confide secrets to each other, pursue the same dreams, and reconstruct their individual and collective identities.

\section{Seeking Refuge in Sisterhood}

For heroines in the two writers' fictions, a trusted female friend is where they can find true peace of mind and an extended form of maternal love during crisis in life. While sisterhood in Chen Ran's works could heal the mental wounds inflicted by male hegemony, a bond with women suffering from the turmoil of war in Tan's novels promises a brighter future of a dream coming true.

In Chen's A Private Life, after Niuniu commits the appalling "crime" of cutting her father's trousers, she runs away from home and wanders aimlessly in the street. Feeling deserted in a hostile world inhabited by people like "wolves in human form," a world where she "could neither exist as an independent individual nor change [herself] into a female wolf" (37), Niuniu suddenly thinks of Widow Ho, the neighbor with "wonderful, enchanting voice," always sitting in the courtyard, waiting for her to return home from school. The moment Niuniu enters Ho's home and moves toward her extended arms, her 
"agitation amazingly began to subside" and a feeling of complicity arose from the soles of her feet (38). This young widow ten years older than Niuniu could always generate a fantastic sense of conspiracy and rekindle a faint hope in her, no matter what she does (38-39). As Niuniu describes the role of Ho in her life:

She was a kind of light in my otherwise bland inner life. In her I had found a warm and close friend, a special kind of woman who could take the place of my mother. When she was near me, even if we were silent, a fragrant warm feeling of security and gentleness enclosed me. This feeling was a kind of intangible glow that bathed or illumined my skin. (78)

From Widow Ho, Niuniu finds the kind of love and understanding she wishes to receive from her mother, who is victimized and silenced by male tyranny. In this female bond without any interference of men, Niuniu could enjoy temporary relief both psychologically and physically:

She was almost the only light, the only support in my life. After a tasteless and depressing day, she would help me shuck off the pressure and the indefinable sense of emptiness that school engendered and let me enjoy for a moment the warmth of her conversation. (91)

After receiving an injection when she has fever, Niuniu is taken care of by Widow Ho when her mother goes for work. Like a loving mother, Ho comforts Niuniu to forget the pain and lightly rubs the swelling with her fingers. Intoxicated by Ho's soothing touch, Niuniu describes her special feeling for Ho: "[T]he skin of her entire body bespoke a tender readiness to rush to me at a moment's notice, to watch over me, to protect me, and to drive away any pain or misfortune that threatened me" (83). When Niuniu has fears over her 
mother's health, who suffers from breathing difficulties due to unknown reason, her feet carry her directly to Widow Ho's. Relaxing against Ho's shoulder, Niuniu memorizes a familiar scene: "I knew this shoulder very well. I had been enchanted by its fragrance ever since I was a tiny girl. It seemed as if these soft but strong shoulders had always been the keepers of my body, giving me support as I grew toward maturity" (142). Afraid of being separated from the maternal embrace of Ho, Niuniu clasps her arms "tightly around her neck" and uttered her strong desire for Ho: "I can't [...] live without you" (ibid.).

In her discussion about the psychodynamics of the family, Chodorow explains the need of women to be loved and to "reexperience the sense of dual unity they had with their mother" (199-200). For women, especially those raised in families that are "organized around women's mothering and male dominance," they tend to look elsewhere for love and emotional gratification" because of men's difficulties with love and their own relational history with their mothers (200). According to Chodorow, one way to resolve and recreate the mother-daughter bond and define women's relational capacities and selfhood is through "the creation and maintenance of important personal relations with other women" (ibid.). Living under the constant threat of her father's domineering existence and submitting to the humiliation of being isolated and harassed by Mr. Ti, Niuniu longs for a maternal love as her spiritual sanctuary. While her rebellious nature finds no hope of salvation in her mother's 
compliance with male ruling, as evident in the latter's panic-stricken reaction to the destroyed trousers and her respectful obedience to Ti's reprimand of her daughter, Niuniu directs her love to Widow Ho, who represents both a maternal affection embracing Niuniu with warmth and security and an independent identity free from male definition. Contrary to her parents, who are "perpetually wrapped up in their own work" and take no interest "in the little events of everyday life," Ho assumes "an intense motherly air" that attracts Niuniu beyond all reason" (A Private Life 118). From the depth of Niuniu's heart, Ho is like her ideal mother, feeling all her joy and grief:

The way she would stand just outside her door, with one hand raised to shield her eyes from the piercing sun, the other resting feebly on her hip, watching me as if I were some kind of big bird leaving the nest to begin my lonely quest for food, made me feel like she was my mother. (122)

In the novels of Amy Tan, sisterhood also plays the role as a substitute for the lost maternal love. In the end of The Joy Luck Club, Jing-mei describes the miraculous feelings after being reunited with her two half-sisters in China, fulfilling her mother's lifelong dream. When she sees somebody waving to her, Jing-mei has a strange feeling of familiarity: "I know it's not my mother, yet it is the same look. [...] As soon as I get beyond the gate, we run toward each other, all three of us embracing, all hesitations and expectations forgotten. [...] 'Mama, Mama,' we all murmur, as if she is among us" (287). In Tan's The Kitchen God's Wife, when Winnie realizes that she is separated with Hulan in the crowd as they flees for shelter from Japanese bombing, she couldn't help 
crying in desperation "Ma! Ma!" Those words comes out of Winnie's throat so naturally even though Winnie has been abandoned by her mother long time ago. Yet as Winnie recounts, "I was walking through the crowd, calling for my mother, looking for Hulan" (KGW 216). When Winnie almost loses hope, assuming the death of Hulan, her female ally comes to her rescue. Riding up to Winnie on a pedicab she takes by force from a man, Hulan hands Winnie a stick, the leg of a stool, to beat away any man who tries to steal the cab from their sisterly oasis. Later in the novel, when Hulan promises to help Winnie escape her torturous marriage, Winnie throws her arms around Hulan "like a child against her mother" (310). A similar scene occurres in Tan's The Bonesetter's Daughter. Reading the letter from her half-sister GaoLing, who arrives at the U.S. earlier and takes great trouble to arrange for LuLing's immigration, LuLing feels like "a child now being guided by a worried mother" (BSD 296). When LuLing suffers from the Alzheimer's disease, it is GaoLing again who takes care of LuLing attentively to relieve the burden for Ruth. Miss Grutoff, the nurse and head mistress of the American orphanage, also embodies maternal and sisterly love in the eyes of the other female members: "We love Miss Grutoff. She is mother and sister to us all" (274).

In both writers' fictions, sisterhood in the form of female trust and friendship injects the heroines with maternal love and a strong will to struggle in an oppressive world no longer alone. As Irigaray clarifies, "the ethical order 
of love cannot take place among women" without the "verticality" of the mother-daughter bond (Ethique 106, qtd. and trans. Hirsch 43).

\section{Mutual Help in Female Alliance}

In their literary creation, both Chen Ran and Amy Tan accentuate the power of sisterhood, through which their heroines can not only reconnect a maternal link severed by the phallocentric order, but also provide mutual support to each other out of a shared fate of misery and male subjugation.

Chen's fiction "The Birth of a Hollow Man" depicts such interdependent bond between the boy's mother ("woman in purple") and Aunt Miao ${ }^{101}$ ("woman in black"). While the "woman in purple" endures her husband's maltreatment and humiliation, the "woman in black," a mysterious and aloof woman in the eyes of small-town people, leads an independent life of her own, pursuing her interest in music and reading. One night when the boy and his mother come back home a little bit late after listening to music at Aunt Miao's place, they are locked outside in darkness. Without a word, the mother tries to break in from the window, but just at that moment, the father storms out of the room and slaps the woman to the ground. Homeless and hopeless, the "woman in purple" moves to live with the "woman in black." In the boy's eyes, Aunt Miao is the kindest woman in the world, taking care of her ailing mother in every possible way. The two women seem to have endless things to do. They

\footnotetext{
101 Aunt Miao is a colleague and the best friend of the narrator's mother instead of her sister. Since Chinese place great value on the concept of family, they tend to address non-relatives by kinship terms, such as "aunt" for the parents' female friends or "uncle" for their male acquaintances.
} 
would chat in a low voice, the patient lying on bed with eyes closed when tired, listening quietly to the other woman reading from her favorites, "their faces radiating inexpressible serenity and warmth" (my translation, 224). As the narration goes:

Mom and Aunt Miao are even closer than sisters. They go to work together and come back home together, having so much to say that they couldn't get it all out. [...] Each one is willing and eager to cook the meal, urging the other to lie down and take some rest. But both insist on cooking, saying she is not tired at all. It ends up that if the "woman in black" is cooking, the "woman in purple" would definitely fetch the water, and if the latter is washing dishes, the former would undoubtedly sweep the floor. (my translation, 227)

When the boy is asleep, the two young women would take a walk on the old street of the town, "hand in hand and drawn intimate by darkness" (229). They support each other in life and enjoy each other's company in a harmonious world of sisterhood, discovering an awakening beauty and value in their lives.

Like the two women in "The Birth of a Hollow Man," Pearl's mother Winnie and Auntie Helen ${ }^{102}$ from Tan's The Kitchen God's Wife also provide each other with spiritual support in their life-long friendship. Unlike Winnie who is raised in a gentry family, Helen, or Hulan known by her Chinese name, comes from a poor background that enables her to make the best of what she has even in the harshest situation. Since both their husbands serve in the air force during the anti-Japanese war, Winnie and Hulan come to know each other and form a sisterly bond that supports them to survive the wartime terrors.

${ }^{102}$ To Pearl and most relatives, Winnie and Helen are sisters. But actually they are not related by blood. Winnie claims Helen to be her sister so that she could help Helen immigrate to America, a secret they have kept for a life time. 
On their long and arduous journey to escape from Nanking before the Japanese occupation of Kunming in southern China, Winnie remembers one night when she and Hulan lean against the mountain and look at the stars, silent but full of hope. Although she could no longer recall the patterns of the constellations representing immortal spirits in Chinese mythology they have discussed that night, Winnie still remembers "that feeling of friendship" as they look at the sky (KGW 228). It is through such sisterly companionship that Winnie and Hulan encourage each other to cherish the hope for a brighter future: "We all clung to little things like that - a make-believe story, a faraway star that becomes something closer to our hearts. Along our journey, we look for signs of contentment in the world, a peace that would never change" (ibid.). Because of the different backgrounds between Winnie and Hulan, they have so much to learn from each other and manage to complement each other's flaws. Just as Hulan is influenced by Winnie's "naivete, refinement, open-heartedness," Winnie relies on Hulan's "bald candor, homeliness, and pragmatism" (Snodgrass 151).

Mutual support and complementarity in sisterhood are also exemplified in the relationship between Winnie and Wan Betty, the widowed telegrapher in Nanking. Learning that Winnie's dowry money has been stealthily withdrawn by her husband Wen Fu and squandered away without even a word of apology, Betty reveals a similar experience. When her pilot husband died, all the 
survival money was taken by her family-in-law, who left nothing to Betty who was pregnant at the time but asked her to give them their grandchild after the baby was born. Hearing Betty's sarcastic comments "Do they think I'm a duck - laying eggs so they can eat them", Winnie couldn't help marveling at Betty's rebellious spirit and blunt talking: "That's how Wan Betty was, always speaking honestly, straight from her liver, the same bile in her words. And soon, I found myself talking in the same way" (KGW 209). If Betty helps Winnie spiritually to cultivate an independent and resilient sense of identity, Winnie, on the other hand, provides material assistance to Betty. With the sewing machine offered by Winnie and her unclaimed four hundred dollars, Betty manages to make a living in the most difficult times and flees from the Nanking massacre to safety in Shanghai.

Another example of empathy and complementarity in sisterhood is demonstrated in Winnie's special friendship with Min, a former vaudeville actress in Shanghai brought home by Wen $\mathrm{Fu}$ as a concubine under the pretense that the girl is the sister of one of his fellow pilots. Instead of being mad about her husband's affairs, Winnie is rather contented to escape from Wen Fu's sexual torture. But gradually she is drawn closer to Min for their natural affinity. As Winnie acknowledges: "Min and I were the same: pretty skin, foolish heart, strong will, scared bones," both dreaming of a day when they would reclaim their happy past "that never really existed" (272). Staying 
together in good company when Wen Fu is absent, Winnie enjoys hearing Min talk and watching "the way she rolled her eyes and waved her hands" (273). While Min teaches Winnie tango, waltz, foxtrot and lindy hop-hop, Winnie instructs Min to write her name and speak in a proper manner. Bonded by the same fate of male enslavement, the two women create an oasis of happiness in the desert of denial and deprivation. Min's abortion of Wen Fu's child and elopement with another man help Winnie realize the nature of her own marriage that pulls her apart, inch by inch, until her entire self is devoured without a trace (280). Feeling lucky for Min against public denunciation, Winnie begins to search for her lost self piece by piece.

As Snodgrass observes, the close tie between female characters is just like the interlinked silver chopsticks hidden in Winnie's suitcase lining, bearing "sterling qualities that outlast marriages, invasions, and the foundering of Chinese patriarchy" (152). Women's mutual help through sisterly alliance is epitomized in the underground female community described in the novel that accommodates nine women joined by the same fate, including Winnie's cousin Peanut. Though the women come from different backgrounds, they live together self-sufficiently after escaping their awful marriages. When Winnie pays a visit to Peanut in this secret hiding place, the other women happen to return home for lunch from various workplaces. Expressing their luckiness to leave their past miseries and become the master of their own lives, the 
passionate sisters of the community brainstorm for hours in helping Winnie out of her disastrous marriage.

In Tan's The Bonesetter's Daughter, the orphanage in Shanghai is a similar community characterized by women's mutual assistance. In this harmonious safe haven presided over by two American missionary ladies - the headmistress Miss Grutoff and the director Miss Towler, all the inhabitants, except for Teacher Pan, are female: thirty older girls, thirty younger girls, ten babies and the caretakers Mother Wang and Sister Yu. Though many girls are handicapped or deformed, they are treated equally in this abandoned monastery filled with love and compassion. These "Girls of New Destiny" form a solid alliance of mutual support. As LuLing observes when she first comes to the orphanage after the death of her mother: girls of different ages share the same living quarters, sleeping on three rows of beds with the youngest girls on the first row, who are taken care of by the in-between girls on the second row. Similarly, the oldest girls sleeping on the third row would be responsible for the girls on the second row. It is in such relationship that everyone is taking charge of someone else, all linked together in a supportive network as family members. The strong power of sisterhood in the orphanage not only heals the psychological pains of LuLing, restoring confidence and individual spirit to her broken heart, but also serves as a Noah's Ark that survives the Japanese invasion, shipping the orphaned girls and the rest strong-willed female 
members to safety and a promising new life.

Joining together in a sisterly alliance, heroines depicted by the two writers complement and empower each other in constructing a stronger self, an awakening woman with her own dreams and secrets.

\section{Shared Dreams, Shared Secrets}

A striking similarity between Chen Ran and Amy Tan in their portrayal of sisterhood is woman identification realized through the heroines' shared dreams and secrets with their female friends as mirroring models or the ideal ego of themselves. As Adrienne Rich argues, "[w]oman identification is a source of energy, a potential springhead of female power, curtailed and contained under the institution of heterosexuality" ("Compulsory Heterosexuality" 139). Sisterhood is like a mirror for the female characters in the two writers' fictions, reflecting each other's inner desires, life experiences and reformative power. It is in sisterhood that women are starting to recover their lost self identity.

In Chen Ran's A Private Life, the intergenerational friendship between Niuniu and Widow Ho is characterized by shared interest and commonality. From Niuniu's childhood, she has been aware of Ho's love of reading. But it is not until Niuniu gradually grows her interest in reading and talks more with Ho that she realizes how much they have in common. They would "spend hours discussing literature and life," both fascinated by foreign writers like "Borges, 
Joyce, Kafka, Poe, and Faulkner" (119-20). But what they talk most is outstanding female writers out of a shared "feminine view of life" (119). When discussing their favorite female poet $\mathrm{Yi} \mathrm{Lei}^{103}$, Ho reads in passion lines from Yi's sensational suite of poems at the time - "A Single Woman's Bedroom":

Do you know who I know?

She is one, she is many.

[...]

She is beautiful, without vitality,

She is three-dimensional, she is two-dimensional.

What she wants to give you, you cannot take,

She cannot belong to anyone.

... She is the $\mathrm{I}$ in the mirror.

[...]

You cannot come to live with me... (121)

Although the pronoun "she" refers to the poet's psychological projection in the mirror, the lines are recited by $\mathrm{Ho}$ as her declaration of sisterhood that plays the same role as a woman's "magic mirror". Ho's husband dieds abruptly of a mysterious fever, leaving Ho as a young widow "before she has time to get pregnant" or lay bare the truth about his affair with another woman (41). Worn down by diabetes and living on a disability allowance, Ho deems Niuniu as "her salvation and her future" (35). Niuniu symbolizes Ho's dream to be vigorous in power and rebellious in spirit. It is through Niuniu that Ho sees hope in her life, and her lonely soul finds harmonious resonance in a symphony of sisterhood. For Niuniu, Widow Ho is the shadow behind her on the horizon of time and

\footnotetext{
103 Yi Lei (1951-) is a contemporary Chinese poet who rose to fame in the 1980s with a series of poems reflecting her feminist stance and a bold search for one's individuality in modernity. Her representative work "A Single Woman's Bedroom" is composed of fourteen poems that explore the unique experience of women who are determined to blaze a trail of their spiritual selves. The poem quoted in the text is entitled "The Magic of the Mirror," in which Yi Lei celebrates female consciousness, multiplicity and spiritual autonomy through a woman's mirror reflection.
} 
seems to be her accomplice in every step she takes. As Ho is reciting the poem, Niuniu realizes that her sexual experience with Ti driven by a nameless desire without love at all could by no means be compared with her deep attachment to Ho: "I wanted to tell her that over the years she had always been the one I truly loved, [...] that I thought always of her intimacy and tenderness, and that as the months and years fell away, these unexpressed feelings grew stronger day by day" (122). As Kay Schaffer and Xianlin Song state, Niuniu's relationship with Ho is suggestive of "Irigaray's fluid feminine world of alterity beyond masculine boundaries, a world of playful jouissance" (167). Widow Ho is like what Irigaray describes as the speculum that would bring to light female experience omitted from the symbolic patriarchal order. While $\mathrm{Ti}$ is "desire made flesh," a tourist whose itinerary of the journey means nothing to Niuniu, Ho is "a labyrinth, the outer form of a cave" she has fallen into (A Private Life 35), "a house made of mirrors" that belongs to the innermost being of Niuniu and in which she could always see herself, no matter where she is (122). Later in the novel, when Niuniu is attracted by Yin Nan from the poet's club in their university, her first thought is to share the pleasure with Ho:

I had discovered that whenever anything happened, if I could face it together with her, whatever agitation or unpleasantness there might have been would dissipate like smoke. In my find, we were lifelong fellow conspirators who understood each other without the need for words. (137)

Similar to Niuniu and Widow Ho who identify with each other as a form of female empowerment, in "The Sound of Another Ear Knocking," Dai Er has the 
same feeling of affinity with her female neighbor Yi Duoren (homophonically meaning "A Fallen Woman"). The first encounter between Dai $\mathrm{Er}$ and $\mathrm{Yi}$ Daoren is on the stairway of their building when Dai $\mathrm{Er}$ is searching for her calendar notepad with all her secrets written on. Although Dai Er does not know the woman in person, she has dreamed of the same woman for countless times. This strange feeling of familiarity seizes Dai Er with entrancement. When they meet for the second time at Yi's home, Dai Er is intoxicated by Yi's heavenly beauty. Her heart is screaming and radiating with a dazzling yellow like that of the sunflower painted by Van Gogh. With an inexplicable intuition, Dai Er knows in an instant that $\mathrm{Yi}$ is her "previous existence and tutelary god" (my translation, "Sound" 122): "I even do not need to say a word to her before I fully understand her and get familiar with her. We have long been communed with each other. [...] How I need her, I need this woman, because no man is willing and able to take me away" (123).

Like heroines in Chen's fiction, the Joy Luck mothers in Tan's novel are linked by unspeakable tragedies of war and a shared dream to start their life anew. The four Joy Luck sisters are all trapped in dire threats of Japanese invasion. But instead of waiting passively for deaths "with proper somber faces," they decide to "hold parties and pretend each week had become the new year" for them to "forget past wrongs" and hope for joy and luck (JLC 25). Each week, one of the women would host the feast for good fortune: 
"dumplings shaped like silver money ingots, long rice needles for long life, boiled peanuts for conceiving sons, and [...] many good-luck oranges for a plentiful, sweet life" (23). Although these women have either lost homes and fortunes or are separated from their families, in the Joy Luck Club that binds them together, they put on a defiant gesture against adversity by playing mah jong together, telling the best stories to cheer each other up, enjoying delicacies and chatting late into night in loud laughter. Their weekly ritual that sustains even after their immigration to the U.S. keeps alive their shared dreams of leading an empowered life. As Chen Xiaomei notes, what the Joy Luck women are celebrating is "an end to their prescribed roles as heartbroken wives and mothers;" instead of confining themselves in "their traditional role of self-sacrifice" when their men perform "heroic deeds" in public, the four women "constructed their own form of knowledge and power by remapping a gender history" that subverted the official discourse of male domination (115-16).

The Joy Luck mothers not only cherish the same hope to pursue their self-defined happiness, they are also beset by the same secret worries. In order to fulfil the dream of June's deceased mother Suyuan Woo to get reunited with her long-lost twin daughters in China, the other three members of the Joy Luck Club reply the letter from the twins in the tone of Suyuan and promise to visit China soon for family reunion, an imaginary miracle they create to revive their beloved friend from death. When the Joy Luck aunties 
reveal the secret plan to June after the trip has been arranged with a check of $\$ 1200$ they have raised for the travel expenses, expecting June to tell her sisters everything about their mother, June's answer "What will I say? What can I tell them about my mother? I don't know anything" frightens the aunties, who share a common concern that their daughters would be "just as ignorant, just as unmindful of all the truths and hopes they have brought to America" (40). To some extent, the preparation for June's China trip to meet her half-sisters on her mother's behalf by the three Joy Luck mothers symbolizes their own dreams to be understood by their Americanized daughters while mending the severed link with their motherland.

In The Kitchen God's Wife, Winnie and Hulan develops a similar trustworthy bond of sisterhood, pouring out their worries and secrets to each other in a secluded pavilion that reminds Winnie of the greenhouse, her secret hiding place during childhood when she and Peanut run away from adult supervision. Raised up in a feudal family that stifles women's self-consciousness, Winnie reveals her ignorance about sex and the female body. According to Old Aunt, as Winnie recollects, a girl would bleed every month because her body has to purge the unclean thoughts in her mind, and once she becomes a good wife in a proper family chosen for her, the bleeding would stop. Based on such teaching, Winnie interprets the amenorrhea she is experiencing as a sign of her becoming a good wife. Condemning the absurd 
stories made up to cheat women into docility, Hulan explains the truths about women's menstrual period and childbirth. Actually, it is Hulan who first finds out the fact that Winnie has been pregnant. To dispel Winnie's doubt about her words, Hulan shares her own secrets of having witnessed a young girl dying in childbirth. The pilot who impregnates the girl not only refuses her entreaty to be taken as his wife or concubine, but slaps her so hard to the ground, resulting in the death of both the woman and the premature baby. It turns out that the girl in the story is Hulan's sister, and the pilot, Hulan's husband Jiaguo, who marries Hulan out of pity, guilt and the fear of the girl's death curse. Learning Hulan's past suffering, Winnie feels her heart linked to Hulan. Since then, the two women start "this telling and keeping of secrets" (186), showing sympathy and support to each other with a growing sense of female power.

Like the Joy Luck mothers, the same dream for a better life and a shared fate of suffering and misfortune seal Winnie and Helen together in lifelong friendship that sustains even after their immigration to America. Although not related by blood and having disagreements at times, Winnie and Helen are "related by fate" and "joined by debts" to an extent even closer than sisters. As Winnie says, "I have kept her secrets. She has kept mine. And we have a kind of loyalty that has no word in this country" (73). In the eyes of Pearl, her mother and Auntie Helen are the core of what she understands as "the whole family" (11); the flower shop the two women cofound twenty-five years ago right after 
the death of Winnie's husband and Helen's loss of her job symbolizes their "dream that would replace the disasters" (14). From the pavilion where Winnie and Hulan reveal secrets about the shared fate of women to the flower shop that carries their dream for a better life, it is in sisterhood that women find out the truth about their objectified status in a male-dominant world and set out to seek spiritual independence in defiance of the patriarchal norm.

\section{Reconstructing Female Identity in Sisterhood}

From the above analysis, we may discern some similarities in the two writers' depiction of sisterhood, through which the heroines could take refuge from the harsh reality, provide mutual help in time of difficulty and share dreams and secrets with affinitive understanding and a growing sense of self-identity. Although such sisterly bond is sometimes disrupted by misunderstandings or betrayed because of social pressures from heterosexual normativity in the works of the two writers, both Chen Ran and Amy Tan tend to associate, with different emphasis, sisterhood with the heroines' reconstruction of their female identities. While Chen Ran assumes a more radical stance by emphasizing sisterhood as a means for sexual initiation and deconstructing gender dichotomy, in Amy Tan novels, sisterhood serves as a catalyst for women's awakening awareness for independence and self-determination.

In Chen Ran's novel A Private Life, Niuniu's transition from an ignorant girl, who mistakes her budding breast for a sign of breast cancer, to becoming 
a woman with clear gender consciousness is facilitated by her friend Yi Qiu, the only one in the class who enjoys talking to Niuniu. Three years older than Niuniu, Yi Qiu is sexually mature and attractive. Although crippled as a result of polio sequelae, she "[takes] pleasure in her own sensuality," having no desire of concealing her full breasts that tremble with each step she takes and swaying her hips in a suggestive and erotic way (57). It is firmly believed by Niuniu that it is Yi Qiu who has "initiated [her] passage into womanhood" (68). In the chapter entitled "The Inner Room ${ }^{104}$," Chen Ran gives a detailed description of Niuniu's emotional turbulence when she catches sight of "a blood-soaked wad" amid the waste toilet paper in Yi Qiu's bathroom. Although Niuniu has witnessed similar scenes before, she used to think it irrelevant to her as it concerns only adults. When her companion Yi Qiu has the same problem, Niuniu couldn't help relating herself to the bleeding symptom that represents something unique to women. It is in Yi Qiu that Niuniu realizes the potentiality of her own maturing womanhood.

As stated by Julia Kristeva, the menstrual blood is a typical example of the pre-lingual notion of the "abject," which is beyond the symbolic law of the Father:

[It] stands for the danger issuing from within the identity (social or sexual); it threatens the relationship between the sexes within a

\footnotetext{
104 In the epigraph of this chapter, Chen Ran provides an explanation for the choice of the title. In Chinese, the "inner room" is also an addressing term for women. Metaphorically comparing the "inner room" with the female vagina, a wound "that comes along with birth, that others are not allowed to touch," Chen goes on to write in the novel, pointing out a fact commonly ignored: "Our maturation process involves our gradual acquiescence to and our seeking for and ultimate acceptance of 'entry.' During the process of seeking, our girlhood ends and we enter womanhood" (66).
} 
social aggregate and, through internalization, the identity of each sex in the face of sexual difference. (Powers of Horror 71)

The abjection of women's menstrual blood by the dominant patriarchal ideology is out of male necessity to expel the feminine threat the blood represents. According to Kristeva, women's menstrual blood reminds men of the violent and chaotic distortion they have been through at birth. For the males, the idea that once in their lives they were embedded in their mothers' body and controlled by the maternal power frightens them and must be dispelled in order to assert male subjectivity. In other words, men's dread of the female body and their refusal to acknowledge their maternal origin is determined by a fear of the splitting subject and the confusion of identities. Chen Ran's focus on the abject, namely Yi Qiu's menstrual blood, as a sign of Niuniu's sexual awakening could be interpreted as the writer's attempt to deconstruct the dominant discourse of patriarchy that denies female sexuality. Contrary to traditional understanding of the menstrual blood as something filthy and abhorrent, in Niuniu's eyes, it is mysterious and beautiful at the same time: her heart "pounded wildly," the red color "was like a budding flower that had burst into blossom hidden among a heap of white paper" (67). It is so intended by Chen Ran that Yi Qiu not only prompts Niuniu to discover the hidden power within women, but also exerts a physiological influence on Niuniu. The morning after Niuniu witnessed Yi Qiu's menstrual blood, she finds "a small patch of blood, like a living crimson plum blossom, among the printed 
green flowers on [her] sheets" (68).

Growing into a mature woman, Niuniu's "thirst for knowledge" is further quenched by her peeping at the love scene between Yi Qiu and her boyfriend Xi Dawang (72). Though physically handicapped and orphaned since childhood when her father destroys the whole family in a mental breakdown during a political movement ${ }^{105}$, Yi Qiu is radiating with female charm and bold in exploring the erotic ecstasy of women traditionally repressed by a society that honors female virginity. Like a released prisoner casting off the mental shackles, Niuniu describes her mixed feeling when secretly observing the love scene:

Shaking with fear outside that door, I experienced two different feelings: at first, every pore of my skin opened and dilated and I started to breathe heavily. My mouth hung open like the maw of a dead fish, and my entire body seemed to have increased in size, as if I had been smoking opium. The door in front of me also increased in height and breadth, and I pressed even closer to the window. Then I was overcome with a violent nausea and felt a sudden urge to throw up... (73)

Awoken from a deep slumber of her own sexuality, Niuniu still could not escape from the pervasive influence of the patriarchal abjection of female eroticism, as demonstrated in her intense feeling of nausea. However, a seed of exploring her own sexual identity has taken root in Niuniu's mind since that

\footnotetext{
105 Writing in a style generally known as "personalized writing," Chen Ran usually prioritizes the growing experience and the inner worlds of her female characters, detaching her plot from socio-historical backgrounds. However, it is insinuated in the novel that the political movement mentioned here refers to China's Cultural Revolution the writer also experienced in person. During the ten-year long cultural calamity from 1966-1976, many intellectuals were interrogated for their right opportunistic tendencies or sent to labor in poverty-stricken areas for reeducation. Yi Qiu's father, a school master in the novel, might be one of such intellectuals who could not bear the mental torture and therefore commits suicide, hanging both himself and his wife after dropping their daughter into the river.
} 
very moment. Later in the novel, when Niuniu is having physical contact with Mr. Ti and Widow Ho, she could always see the "animated images of Yi Qiu and Xi Dawang's entwined bodies," which stimulates her imagination and senses (104). Appreciating and embracing the subversive power of the female sexuality, passed through a magical link of sisterhood, Niuniu sets out to reclaim her repressed feminine subjectivity just like Yi Qiu.

If Niuniu's sisterly relationship with Yi Qiu helps her develop a sense of female sexuality, Miss Dai Er, the heroine in Chen's "Breaking Open," is enlightened by her female friend Yunnan, homophonically meaning "Fallen Male," to deconstruct the concept of gender difference. When describing the timidity of Dai Er, Yunnan first compares Dai to "a doe in a forest riddled with traps, a she-goat doomed to be slaughtered for a feast, a domesticated she-wolf who is howling her song of distress everywhere" ("Breaking Open" 49-50). But at second thought, Yunnan drops all the female qualifiers in front of these words ${ }^{106}$, uttering her rejection of the negative connotations related to the word "female": "stupidity, weakness, passivity, and powerlessness" (50). Correcting her previous diction, Yunnan rephrases her comment on Dai Er's "natural and unrestrained charm" as carrying an air of "little-brother-like kid sister" or "kid-sister-like little brother" (ibid.).

\footnotetext{
${ }^{106}$ In Chinese, there aren't words like "doe" and "stag," only a general word "deer." To specify the different sex of the animal, separate characters like “公” (male) “母” (female) would be added before the Chinese equivalent of deer "鹿." Similarly, the other two animals compared are also headed by the word "female" in the Chinese version. Here in this paper, the author is adopting the translation of Patricia Sieber in the published version of "Breaking Open."
} 
Yunnan's insightful remarks that challenge the naturalized gender norms fit in with the ideas of Judith Butler. In Gender Trouble, Butler deconstructs the notion of gender as cultural and ideological constructs. According to Butler, "[t]he heterosexualization of desire requires and institutes the production of discrete and asymmetrical oppositions between 'feminine' and 'masculine,' where these are understood as expressive attributes of 'male' and 'female'" (23). Therefore, certain types of "identities" in which "gender does follow from sex" cannot exist in cultural matrix that only allows intelligible gender identity (23-24). Taking a subversive approach, Butler argues that one's gender is constituted through performative acts instead of remaining solid and stable. The gender "woman," likewise, should be considered "an ongoing discursive practice" open to "intervention and resignification" (43). From this perspective, Yunnan's final choice of words of "little-brother-like kid sister" or "kid-sister-like little brother" embodies a similar subversive act called for by Butler to trouble the gender and constitutes a fluidity of identities.

Denying the connotations of negativity and powerlessness in femininity, Yunnan calls on Dai Er to recognize the power of women and their bond with each other: "Don't you know that you are a kind of god? [...] Don't you think that when we are together it is as if there were no sexes? That question $[\ldots]$ seems to retreat to a place of no importance" ("Breaking Open" 59). The question in Yunnan's mind, namely, the lesbian existence beyond the definition 
of heterosexual normativity, constitutes a radical challenge to the patriarchal gender identity. To the same effect of Butler's destabilization of the notion of "sex," which is also interpreted as a product of cultural discourse that operates through "a system of compulsory sexual reproduction" and presupposes the male body "as the active agent" (Gender Trouble 141), Yunnan overthrows traditional perception of female dependence on men:

I cannot think what women need men for, aside from having babies. We can take care of almost everything by ourselves, can't we? As for having babies, as long as we women have our ovaries, things are fine; with the present scientific advances, it is enough for a woman to have ovaries to give birth to her own child. ("Breaking Open" 61)

Enlightened by the rebellious words of Yunnan and her question "Why is it that only men can kiss women," Dai Er voices her own doubt about the heterosexual restrictions: "This is an era that seems to be made out of glass: many rules will be shattered for sure, one after the other, by the sound of steps leading forward" (65). The novella centers on the two women's preparation for a women's association truly free of gender dichotomy and discrimination. Aiming at bringing together all the talented women as sisters, the association is named "Breaking Open" instead of the other alternative "The Second Sex," since the later version still implies a confirmation of men as the first sex. Although both Dai Er and Yunnan are committed to establishing such a female society bonded through sisterhood, it is Yunnan who keeps on guiding Dai Er to follow her natural intimacy with women and construct her own identity that 
transcends heterosexuality. Feeling uneasy to answer Yunnan's sharp questions touching on the "sensitive and taxing topic" of lesbianism, Dai Er evokes in her mind a scenario differing from that described in the Genesis:

[l]f multiplying were not humankind's only objective in coming together, perhaps Adam could have had a better rapport and tacit understanding with his brothers as Eve could have had a better understanding with her sisters. (65)

The unspeakable answer to Yunnan's question whether Dai Er would marry her if she were a man is verbalized in Dai's dream: "I want to tell her: if I cannot live with you, then I want you to be my closest neighbor, because I cannot stand anymore living alone, without a companion" (68). Experiencing a rebirth after an imagined air crash in her dream, Dai Er finally gets hold of her own desiring identity and utters a loud proclamation of sisterhood to Yunnan, "I want you to go home with me! I need to feel at home, I need to have somebody to face the world with" (71).

In contrast to Chen Ran's prioritization of sisterhood as a crucial element in the heroines' construction of their self identities that counteract the heterosexual constraints on women, in Amy Tan's novels, sisterhood functions as a driving force for the female characters to change from a submissive and feeble-minded woman to a strong-willed individual resolute in pursuing the self-defined happiness. Take The Kitchen God's Wife as an example; it is under the influence of her female friends, especially Hulan, that Winnie gradually develops her own identity consciousness. Although being Winnie's 
best friend and fellow sufferer, Hulan is totally different from Winnie in terms of personality. Unlike Winnie who resigns to everything without questioning, Hulan "twists things around to her way of thinking" and contradicts everything Winnie says (KGW 192). It is also because of such sharp contrast that a big fight breaks out between the two, which forces Winnie to "argue with [herself] to know what is really true" (ibid.). The fight is triggered by Winnie's pessimistic remark that they should seriously consider the tragedy that the war might bring about instead of letting "[their] own happiness take over" (191). Refusing to accept their uncertain destiny, Hulan flies into a rage and accuses Winnie of "poisonous words" and back-luck thinking that attract only bad things (ibid.).

Hulan's mocking attitude towards Winnie's passive acceptance of her fate contradicts to the feudalist teachings Winnie have been imbued with since childhood. After the fierce quarrel, she goes back to her room in disgust, takes out some cloth given by New Aunt and prepares to make a dress she has seen in Shanghai. The cloth made by one of Winnie's family factories symbolizes the patriarchal definition of women that is challenged by Hulan but persistes in effecting Winnie's life. As Winnie imagines herself as a carefree girl "floating by in a green dress," admired by all her friends who worship both her clothes and her fine manners, she seems to hear the loud voice of Hulan: "Too fancy to wear after a husband has just died" (193). It is almost at the same time that Winnie makes a wrong cut on the cloth. "Look what she did! Affected my 
concentration. Worse! - twisted my thinking and put a very bad thought into my head" (ibid.). The more Winnie tries to get rid of Hulan's curse from her mind, the more powerful Hulan's words becomes as if Winnie is chasing the "bad thought" that her husband would "[fall] from the sky" (ibid.). It is not until then that Winnie suddenly realizes her own awakening identity that has been sleeping so long. It might not be such a bad thing if her sadist husband really dies, Winnie's thought runs in another direction, "Next time I will choose my own husband. [...] I realized that I truly was wishing Wen Fu might die" $(193-94)$.

Growing stronger under the influence of Hulan in her attitude towards life and marriage, Winnie gradually learns to rebel against Wen Fu's spiritual enslavement. She insists on saying that Wen Fu's favorite dish of sweet cabbage tastes bitter, even at the cost of being forced to eat the same and only dish for two weeks. The strike ends with the ultimate success of Winnie, whose stomach "prove[s] stronger than his temper" (282). Though the incident seems meaningless, it means special for Winnie: "If I didn't fight, wouldn't that be like admitting my life was finished?" (ibid.). Winnie's emerging selfhood is further strengthened after she listens to a patriotic speech against the Japanese invaders in the market square. Standing among a big rally of tribal people from different nationalities cheering for the speaker's call to "sacrifice every last drop of [the] Han blood," Winnie feels herself no different from the rest of the 
audience who deceive themselves to be equal with the dominating class even though they speak a different language and have been treated "like the lowest kind of person, just like animals made only to carry things" (284). After that day, Winnie starts to change her attitude little by little from a pessimistic outlook scolded by Hulan to one with confidence and hope:

I did not think I was ready to die, not yet. But I thought about it this way: If I have to die soon, then maybe I won't have to suffer too much longer in this marriage. And if I do not die soon, then maybe I can find a way to escape. (ibid.)

With the help of Betty, Hulan and Auntie Du, Winnie does manage to escape from her miserable marriage with Wen Fu. The four women act out an ingenious plan. In order to get a "valuable" parcel from Betty who works in the Telegraph Office, Wen $\mathrm{Fu}$ is forced to sign on a paper announcing his divorce with Winnie under the watchful eyes of his bossy new wife and the sneering onlookers. While Winnie and her female allies are celebrating the success of their battle of independence, the greedy couple leaves in humiliation with the parcel stuffed with "dry cakes of donkey dung" (392). But the demonic Wen Fu wouldn't take his defeat lying down. Just before Winnie is about to leave for the U.S. as the wife of James Louie, her room is broken in by Wen Fu, who tears up the divorce paper into pieces, grabs the visa and air tickets for reselling and rapes Winnie at gunpoint. But instead of swallowing the insult as before, Winnie seizes the opportunity when Wen Fu goes to the bathroom and takes up the gun on the table. The gunshot sending a bullet over Wen Fu's head 
symbolizes the rebirth of a new Winnie with a reconstructed self-identity. Collaborating with newly-arrived Hulan, Winnie not only get back her tickets and the immigration documents, but also succeed in ordering Wen Fu to take off his pants, which are thrown out of the window together with his male dethroned authority.

If Hulan and the other female characters in The Kitchen God's Wife inspire Winnie to decide her own fate in her heterosexual relationship with men, it is also attributed to Hulan that Winnie mends her estranged relationship with her daughter Pearl. Like the Joy Luck aunties who meticulously arrange for Jing-mei's root-seeking trip as her mother's incarnate, fulfilling Suyuan's life-long dream to be forgiven by her forsaken daughters, Hulan "represents the continuity of life and the connection between past and present" (Huntley 91). Claiming herself to be dying of malignant brain tumor, Hulan urges Winnie and Pearl to confess to each other their respective secrets weighing heavily on their hearts for years. In fact, it is Hulan's desire to thank Winnie for her years of friendship that sets the revelation in motion, substitutes narrative for the distancing silence, and bridges the cultural and generational gap between the mother and the daughter (Ryan 107). When Pearl learns the true intention behind Auntie Helen's sweet lie, she decides to accompany her mother and Hulan to China for the magic cure of Hulan's feigned brain tumor and her own sclerosis. She is not only grateful for Hulan's efforts to reconcile her 
relationship with Winnie, but also deeply moved by the firm friendship between her mother and Auntie Helen, "their own form of loyalty, a devotion beyond anything that can ever be spoken" (409).

Although both Chen Ran and Amy Tan portray sisterhood as an extension of maternal love, a source of complementarity and a mirror of commonality, the two have different priorities when it comes to the role of sisterhood in the heroines' identity construction. Compared with Tan's association of sisterhood with the heroines' matrilineal heritage and a realization of their true values as an independent individual, sisterhood in Chen's fiction functions as a catalyst for the protagonists' sexual awakening and a vague implication of lesbian eroticism. To account for such difference, it might be helpful if we take a closer look at the cultural particularities and literary representations on sisterhood in China and the United States respectively.

\section{Acceptance of Sisterhood: A Cross-Cultural Comparison}

Tracing China's modern and contemporary socio-historical realities and literary traditions, we may better understand the evolution of Chinese academic contentions on sisterhood, which constitute an important motif in Chen Ran's writing. As a matter of fact, Chinese culture has been relatively tolerant of sisterhood in history. Because of the common practice of polygamy 
in ancient Chinese culture until late Qing Dynasty, women's affectionate relationship with each other, either among concubines or servant girls, is not only publicly allowed, but rather encouraged for the sake of maintaining familial and social stability. From the photographs of female intimacies carried in the inaugural issue of Meiyu, ${ }^{107}$ a Shanghai literary magazine published in 1914, Tze-lan Sang points out the fact that female same-sex love ${ }^{108}$ was not recognized "as love of the same significance and magnitude" as erotic desires between males. Rather, it was categorized in much general terms such as feelings among sisters and friends (5). Sisterhood was not only a respectable public sight in big cities like Shanghai, it was also practiced in some rural regions in various adaptations. Two studied cases of sisterhood societies concern those formed by peasant silk workers in Shunde, a rural area in Guangdong province during early nineteenth century and those formed by young widows in Chuansha area near Shanghai in the early twentieth century. The sisterhood at Shunde was formed by "self-wedded women" (zishunü) ${ }^{109}$ who vowed to remain single and lived in Buddhist vegetarian halls

\footnotetext{
${ }^{107}$ Please refer to Figure 1 in Sang's Emerging Lesbian on page 2. Among the four photographs entitled "Chinese beauties' activities of leisure," one (entitled "a long uninterrupted chat") portrays two young women dressed in the style of late Qing and early Republican era, one sitting on the lap of the other with her arm holding the shoulder of her smiling friend, who in return puts her arms around the former's waist. In another photo, two women sit hand in hand in a single sofa with another woman standing behind, bending slight forward. Further illustrations of public acceptance of sisterhood are included in Figure 5 and 6 on page 18 to 19 in the form of calendar posters and advertisement paintings of the Republican era that favored female intimacies as a popular motif.

${ }_{108}$ In her book The Emerging Lesbian: Female Same-Sex Desire in Modern China, Tze-lan Sang adopts the term "female same-sex love" to describe a close female bonding, which could also be encompassed in the extended notion of sisterhood in the current dissertation.

109 Zishunü literally means self-combing women. For a woman to be recognized as a zishunü, a special ceremony would be held in public, on which the girl would vow spinsterhood by drinking rooster's blood and combing her braids into a special chignon. The oath is perpetual, the violation of which might result in severe punishment.
} 
self-sufficiently. For young widows in Chuansha, they formed sisterhood while making a living in cotton spinning and weaving. Both forms of sisterhood are characterized by "[t]heir affiliation with lay Buddhist sects, their independent income, and their desire to live outside the traditional family system" (Honig 214). These sworn sisters pooled financial resources for emergencies. Some would forge "practical, emotional, and sexual bonds" with each other, and some female couples or single women would adopt daughters to carry on the tradition (Sieber 5).

Unlike male homosexuality that was demonized and socially denunciated, "emotional and physical intimacies" between women were not considered "an object of moral admonition," since the Confucian doctrine of female chastity neither criminalizes female same-sex eroticism nor mentions such desires at all (Sang 21). Sisterhood among women, either in the form of spiritual longings or physical contacts did not constitute "a significant source of anxiety for men;" instead, it was appropriated by the "male polygamous imagination [...] either to enhance or to collaborate with male desire for female bodies" (ibid.). The subject of female same-sex desires could be found both in the Kunqu opera of "Cherishing a Fragrant Companion" (lianxiang ban) written by $\mathrm{Li} \mathrm{Yu}^{110}$ and classical works such as Cao Xueqin's A Dream of Red Mansions (honglou

\footnotetext{
${ }^{110} \mathrm{Li} \mathrm{Yu}(1610-1680)$ is a Chinese playwright and novelist during late Ming and early Qing Dynasties. In the opera of "Cherishing a Fragrant Companion," the author focuses on the story between Cui Jianyun and Cao Yuhua. Falling in love with Cao while visiting a temple, Cui tried all means for her husband to marry Cao, even giving up her status as the first wife, so as to be living with Cao for a lifetime. Li Yu also touches upon the topic of same-sex love in other stories such as "House of Gathered Refinements" (cui ya lou) and "Silent Operas" (wusheng xi). For more information on Li Yu, please refer to Patrick Hanan's book The Invention of Li Yu.
} 
meng) ${ }^{111}$ and Pu Songling's Strange Tales from a Chinese Studio. ${ }^{112}$

However, it should be noted that the indulgence in sisterhood as granted by the traditional Chinese culture is not a cause of celebration, but rather a testimony of women's objectified status in feudal times. All the heroines in the above literary examples are still strapped in heterosexual marriages or an overpowering patriarchal society. What's more, as Giovanni Vitiello observes in his study of late Ming fiction, compared to male homosexuality, female-female eroticism appears far less in traditional Chinese literature ${ }^{113}$. He cites the example of Qing Shi (the anatomy of love), which "includes chapters on love between plants and stones, but ignores love between women" (173, qtd. in Sang 21).

It was not until the 1920 s when some women were gaining recognition as individuated persons with increasing economic independence and access to education that female same-sex desire came into public notice, becoming a source of anxiety and fear for males. Along with the May Fourth Movement that aimed to awaken the Chinese nation with the introduction of science and

\footnotetext{
${ }^{111}$ Cao Xueqin (1724 or 1715-1763/4) is a famous Chinese writer during the Qing Dynasty, best known for his representative work A Dream of Red Mansions, one of the Four Classical Novels of the Chinese literature. The novel not only describes ambiguous gay relationships such as those between the protagonist Baoyu and his kinsman Qinzhong, Baoyu and the male actor Jiang yuhan, but also female same-sex love among actresses Ou Guan, Yao Guan and Rui Guan. Acting as husband and wife on stage, Ou Guan develops a deep love for Yao Guan and grieves to death when the latter dies. Later she falls in love with another actress Rui Guan and ends up living as nuns together.

${ }^{112}$ Pu Songling (1640-1715) is a Chinese writer during the early Qing Dynasty best known for his mythical work Strange Tales from a Chinese Studio. In the story "Lady Feng," Lady Fan (fan shiyi niang) falls in love with Lady Feng (feng san niang), a fox fairy. Conscious of her real identity, Lady Feng matches Lady Fan with a young scholar and brings her back to life after Lady Fan commits suicide because of her arranged marriage with a local bully. Though exhausting her means, Lady Fan fails to talk Lady Feng into living with her. Fulfilling her promise to give Lady Fan an affluent life with the young scholar, Lady Feng finally disappears regrettably without a trace. ${ }^{113}$ For a list of Chinese historical fiction on same-sex love during the periods of Ming and Qing Dynasties, please refer to "Same-Sex Love and Desire in Chinese Historical Fiction" Color Q World. $<$ http://www.colorq.org/articles/article. aspx?d $=$ qhistory \& $\mathrm{x}=$ cnovel $>$.
} 
democracy, many Western works on sexology were translated into Chinese. The sexual enlightenment enabled people to make sense of the prevalent phenomenon of female same-sex attachment in the 1920s, but it was also confined by its own ideological limitations. As Sang puts it, an essential constituent of "modern authoritarian projects" initiated by European psychologists like Richard Krafft-Ebing and Havelock Ellis, which was later borrowed by May Fourth intellectuals, mostly males, was the endeavor to conceptually "grasp, contain, and regulate female sexuality" so that it would not challenge the existing patriarchal family structure in face of women's growing power (24). As a result of such ideology, during the 1920s and 1930s, female same-sex love was generally considered as "a psychological or sexual perversion" according to "modern science" of sexual psychology, which served as the main rationale for a legitimate discrimination against female as well as male homoeroticism in modern Chinese culture (ibid.). Nevertheless, women writers of the May Fourth generation like Lu Yin (1898-1934) and Ling Shuhua (1904-1990) persistently depicted in their fictions the romantic desires for alternative lifestyles in sisterhood among many New Women as students and teachers in boarding schools.

Regulated by the feudalist motto that "a woman without talent is virtuous", Chinese women had long been denied school education in history. It was not until the second half of the nineteenth century that the first batch of schools for 
girls was set up by Western missionaries. ${ }^{114}$ The attendants of these schools mostly came from relatively wealthy and liberal families and thus belonged to the select group of intellectual New Women, for whom "school friendship occupied a special place" as a matter of "camaraderie and a creative search for the self" (Sang 135). Such female friendship was explored in depth by Lu Yin in her novella "Old Acquaintances by the Seaside" (haibin guren, 1923) and short story "Li Shi's Diary" (lishi de riji, 1923). In the first work, the protagonist Lu Sha and the other four female schoolmates are best friends who keep no secrets from each other. Though of different personalities, the five girls remain glued in their sisterly alliance. They wish to build a house by the sea where they could live together, celebrating their sisterhood while pursuing their literary and teaching dreams with intellectual gratifications. But faced with a growing apprehension for national rejuvenation, the traditional requirements on filial piety and the unrelenting pressure for social conformity, their dream of sisterhood finally scatter as the girls get married one after another upon graduation and give up their career ambitions, leaving only Lu Sha in the end with "the despondent longing $[\ldots]$ for the camaraderie of her school days as a paradise lost" (Sang 137). In the other story, the protagonist

\footnotetext{
114 It is recorded in Book of Major Education Events in China (zhongguo jiaoyu dashi dian) that the first girls' school in mainland China was established in Ning Bo, Zhejiang Province in 1844 by Miss Aldersey, a British missionary, teaching mainly religion and foreign languages. "China's First Girls' School." 2 Aug. 2010 $<$ http://www.dangan.ningbo.gov.cn/dakw/1/jbxd/200712/t20071224_6026.html >. The first girls' school managed by Chinese was founded in 1898 with the purpose of training virtuous wives and mothers and was closed by the Qing government after two years. Since girls' schools obtained legal status at beginning of the twentieth century, they opened in rapid succession and played a major role in the enlightenment of Chinese women. "Girls' Schools Have Had a Testing Time in China." 2 Aug. $2010<$ http://appl.chinadaily.com.cn/star/2003/0306/fo5-3.html>.
} 
Li Shi is also a female student of gentle and sensitive nature, who finds spiritual comfort in her schoolmate Yuan Qing. Taking marriage as boredom and shackles, the two girls are excited about their dream to live together in sisterly harmony. But their plan is interrupted by Yuan Qing's forced date with her cousin at her mother's request as a prelude to an arranged marriage. Moving to another city away from Lishi, Yuan Qing completely changes her attitude from regretting for Lishi being born as a woman instead of a man to persuading her sworn sister to wake up from the dream of sisterhood that would never be allowed by the society. Unable to take the fatal blow of Yuan Qing's betrayal, Li Shi soon dies of melancholia.

Compared with Lu Yin's representation of female friendship, which is in essence platonic without erotic implications, Ling Shuhua, another May Fourth woman writer, "provides carefully chosen details hinting at girls' kissing and fondling" (Sang 148). In "Rumor Has it Something Like This Happened" (shou you zhemo yihui shi, 1926), a rewriting based on Yang Zhansheng's fiction "Why Did She Suddenly Go Crazy" (ta weishenmo huran fafeng le, 1926) at his request, Ling recounts a love story between two female students in a girls' school. The heroines Ying Man and Yun Luo, homophonically alluding to "Should Conceal" and "Falling Down," fall in love with each other when cast as Romeo and Juliet in their school performance. Teased as a couple by their schoolmates, the two girls are immersed in the pleasure and warmth their 
intimate relationship brings about. They takes strolls in campus hand in hand, appreciate the radiating beauty of the other's sensuous body and even sleep together with intimate touches. Proclaimed as they are, when Yun Luo is pressured by her family to get married, she faces the same dilemma as heroines in Lu Yin's fiction as to whether she should pursue her own happiness with Ying Man or conform to social convention of heterosexual love. For Ying Man, though she tries to persuade Yun Luo to follow the example of two of their female teachers, who have been living together for five years as a family, she is still unable to change her fate of fainting at the end of the story over the news that Yun Luo has finally married the man following the wish of her brother and her mother.

It should be admitted that both Lu Yin and Ling Shuhua take a ground-breaking step forward in their depiction of sisterhood, a theme rarely touched in Chinese literature, as a starting point for women to probe their inner desires as a way out of patriarchal oppression. However, the sisterly bond forged among female students during the Republic period is too fragile to stand the test of the overpowering social and ideological pressure, as reflected both in the tragic endings of Lu's semi-autobiographical fiction and the detached tone implied in the title of Ling's story narrated in third person narrative. A more pessimistic or even critical view about sisterhood could be found in Ding Ling's "Summer Break" (shujia zhong, 1928), which describes the conflicting attitudes 
of five female school teachers who live together during the summer vacation. Determined to remain single so as to lead a productive life of female emancipation, the women find themselves trapped in pathetic spinsterhood and secretly regret their decision when boredom and jealous bickering among them aggravate as time goes by. Contrary to the aesthetic description of sisterhood by Lu Yin and Ling Shuhua, Ding Ling bluntly discloses the erotic nature of the relationship between some women teachers, but the plot "degrades lesbian eroticism to the level of second-rate sexual outlet and a form of self-deception" (Sang 151). For May Fourth women writers trapped in a world dominated by male supremacy and heterosexuality, sisterhood, or a fulfilling female union, only remains as a utopian dream. Even with relative economic independence, few women could resist "the material and symbolic benefits that marriage provides," nor are they able to truly value their female friends as liberated individuals "deserving of trust, devotion, commitment" (152). Therefore, among the sporadic literary representations of sisterhood or reserved description of female homoerotic relationships in the 1920s, what dominate the scene as the curtain descends are rather disillusionment and betrayal.

The onset of the Anti-Japanese War throughout the 1930s and 1940s extinguished the flickering spark of fictional references to female same-sex love, which was considered self-indulgent to national survival and was 
therefore submerged in the revolutionary themes of social engagement. The founding of the PRC in 1949 witnessed an even more tightened grip on either the acknowledgement of or the literary representation of homosexuality. In the following three decades, the term same-sex love, both for men and women, "became unmentionable, an abomination, and disappeared altogether from circulated print (Sang 164). Making the procreative nuclear family as "the bedrock of socialist renewal," all other forms of "sexual inactivity or activity" including extramarital sex and same-sex liaisons were constructed as a refusal to perform one's due role as a responsible citizen or even amounted to "a form of dissidence punishable by social, economic, medical, or criminal sanctions" (Sieber 6).

With the implementation of the reform and opening-up policy in 1978, China was reintegrated into the global capitalist system, opening its door to the outside world both economically and ideologically. Among earth-shaking social transformations are "the resumption of transnational flows of sexual epistemology, images, and practices into and out of China, a phenomenal new spate of public discussions of love and sexuality, and the rise of the second wave of liberal feminism" since the May Fourth Movement generally deemed as its first wave (Sang 166). Against such backgrounds, especially when the literary search for an ideal man was proved a failure, some women writers began to re-explore the theme of sisterhood as a possible way out for women. 
But the fragile and platonic nature of sisterly alliance depicted by women writers of the 1980 s seems to be a rehashed version of the fiction by Lu Yin and Ling Shuhua. Be it Zhang Jie's novella "The Ark" (fangzhou, 1982) that portrays the "Widows' Club" formed by three divorced intellectual women ${ }^{115}$ who have lost all hope in men and resolutely march into the battlefield for female independence, or Wang Anyi's fiction "Brothers" (Dixiongmen, 1989) that tells the story of three married women as college roommates who wish to sustain their spiritual bond with each other as closest soul mates, the castle of sisterhood quickly collapses in face of social pressure or women's submission to their fatalistic roles as wife and mother ${ }^{116}$. What deserves our attention is that for both Zhang Jie and Wang Anyi, although they have realized the power of sisterhood as a means of pursuing women's self identity, it seems that they still follow the phallocentric discourse in their definition of womanhood. The three divorced women in Zhang's fiction "The Ark" are all masculinized, determined to put away all the feminine ornamentation. Paying no attention to their physical appearance, they are good at drinking, smoking, hurling abuse at will and neglect all the housework, leaving the room unattended, the kettle empty and the dishes piled up. As for the story of "Brothers" by Wang Anyi, the

\footnotetext{
115 Among the three female characters, Cao Jinghua, a Manist theoretician, is divorced by her husband for failing to perform her duty to produce a child to carry the family line after she has an abortion out of practical concerns, and Liu Quan, an excellent interpreter, fights a protracted battle to divorce her lascivious husband who takes her only as an outlet for his sexual drive. Although Liang Qian, a film director and the third member of the club does not get divorced in the legal sense, her marriage has long been non-existent except in name.

116 For the three female characters in Wang's fiction, Lao San (the third brother) is the first to betray the sisterly alliance by turning down a job opportunity at the university in order to return to her husband in a small town. The sworn sisterhood between Lao Da (the oldest brother) and Lao Er (the second brother) is also destroyed because of Lao Da's maternal love for her child that superseds her love for Lao Er.
} 
title itself is apparent enough to demonstrate the author's ambivalent attitude towards sisterhood: even if women wish to tie up with each other spiritually, they still have to adopt the patriarchal discourse of "brothers" while continuing their marriage materially.

Another similarity between Zhang Jie and Wang Anyi is that they too, like the May Fourth writers, cautiously evade from erotic desires in theirdepiction of sisterhood. Even with a large influx of materials on Western sexology, including the knowledge about homosexuality, the depiction of women's erotic desires in sisterhood was still rare in Chinese literary scene during the 1980s. The subsequent 1990 s is an era of much openness about homosexuality. At the first Meeting on AIDS Education and Special Sex Problems held in 1994, the depathologization of homosexuality was confirmed in a joint statement made by over fifty experts from various fields. The interviews and questionnaire surveys on Chinese gay community conducted by Li Yinhe and Wang Xiaobo in 1992 and the publication of Fang Gang's work Homosexuals in China (tongxinglian zai zhongguo) in 1995 brought for the first time the situation of Chinese homosexuals to public attention (Sang 168-69). Beijing's hosting of the UN Fourth World Conference on Women in 1995 is accompanied with an amplification of "[o]fficial feminism, academic women's studies, and commercial distribution of women's work" (Sieber 7). Since then, more progress has been made for the right of female homosexuals, including 
the convening of the first mainland Chinese Lesbians Conference in October 1998 and the launch of the first lesbian community newsletter Sky in March 1999. Against this socio-historical background, the sexual and erotic implications in sisterhood would not seem strange to literary experiments by feminist writers like Chen Ran and Lin Bai ${ }^{117}$ in the 1990s. As Chinese critic Xu Kun incisively puts it, women writers in the 1980 s stand side by side with their male counterparts in a joint effort to reignite and continue the May Fourth search for individual emancipation that has been severely repressed during the devastating Cultural Revolution, but the individual identity quested during the $1980 \mathrm{~s}$ is a masculinized one. In the 1990s, an era of pluralistic and opening environment, women writers emerge from their silent and marginalized trudge to the forefront, unearthing the oblivious dream of female self-discovery beneath the banner of a liberated "human" ("Double Tunes" 149). According to Dai Jinhua, one of the leading feminist scholars in China, "the most noteworthy works" of the 1990s are the autobiographical and semi-autobiographical writings "that articulate the fear of and longing for sisterhood and lesbian relationships" ("Rewriting Chinese Women" 203). Sisterhood probed in the fictions of Chen Ran and Lin Bai are representative of such works that go beyond pure spiritual love based on women's shared fate

\footnotetext{
117 The allusion to women's desires for sisterhood and homoeroticism could also be found in Lin Bai's fiction, especially in stories of "The Bench on the Interior Balcony" (huilang zhi yi, 1993) and "Water in A Bottle" (pingzhong zhi shui, 1993) as well as her representative novel One Person's War (yigeren de zhanzheng, 1993). For a thorough analysis of Lin Bai's narratives of female homoerotic desires, please refer to Chapter Seven of Sang's The Emerging Lesbian (175-99).
} 
of subjugation to incorporate female sexual awakening and same-sex erotic desires as an essential component of women's identity construction. Acknowledging her influence from Western feminist ideas, Chen Ran decisively takes up the weapon of sisterhood against heterosexual hegemony as the root cause leading to the depravation of female subjectivity.

Compared with the delayed arrival of public recognition for the phenomenon of homosexuality in China not until early 1990s, the American society has achieved great success since the late 1940s concerning gay and lesbian rights. Under the pervasive influence of anti-communist sentiments after the end of the Second World War, homosexuals were identified by the U.S. government as "subversive groups" posing security risks (Adam 57). Therefore, the practice of homosexuality was mainly concealed from the public eye. The publication of Sexual Behavior in the Human Male (1948) and Sexual Behavior in the Human Female (1953), known as the "Kinsey Reports" by the American biologist Alfred Kinsey "provided scientific evidence for the fighting of gays and lesbians for equal rights" (Sun Hong 122). In 1955, Daughters of Bilitis (DOB), the first lesbian rights organization was founded in San Francisco, educating women who dared not come out about their rights and history. Through DOB's primary publication The Ladder, the first nationally distributed lesbian journal that came about in 1956, more and more lesbians had a channel of communication, gaining consciousness and confidence in their fight 
against unjust discrimination. The social environment of the 1950 s also gave rise to the popularity of lesbian-themed books written by female authors like Ann Bannon, Valerie Taylor and Marijane Meaker, ${ }^{118}$ who "present an honest, even positive view of lesbian life" (Bronski 3).

The 1960s witnessed "increasingly relaxed censorship standards" that gave more freedom to an expression of explicit erotic content in lesbian novels, followed by "abolishment of most censorship" by the end of the decade. However, American homosexual community was still marginalized by the mainstream society. On June 28,1969 , the Stonewall riots in the form of violent demonstrations against a police raid at the Stonewall Inn, a gay bar in the Greenwich Village of New York City, marked the beginning of a nationwide gay rights movement in America. Within six months, two gay activist organizations were established in New York and three newspapers were produced, advocating confrontational tactics and the rights of homosexuals. ${ }^{119}$ In a few years, organizations for homosexual rights were founded across the nation, ushering in a resurge of the female "coming-out" narratives in American literary scene amid the second-wave feminist movement during the 1970s. Rita Mae Brown's novel Rubyfruit Jungle is one of such "coming-out" narratives that won immediate claim upon its publication in 1973 "as a lesbian

\footnotetext{
118 Ann Bannon (1932-) is famous for six lesbian pulp fiction novels written from 1957 to 1962 known as The Beebo Brinker Chronicles that addresses homosexual relationships and the construction of a lesbian identity. The enduring popularity of the book also earns Bannon the title "Queen of Lesbian Pulp Fiction." Like Ann Bannon, Valerie Taylor (1913-1997) and Marijane Meaker (1927-) are all popular female writers of books in the lesbian pulp fiction genre of the $1950 \mathrm{~s}$ and $1960 \mathrm{~s}$.

$P_{19}$ "Stonewall Riots" Wikipedia. 5 Aug. $2010<\mathrm{http} / / /$ en.wikipedia.org/wiki/Stonewall_riots>.
} 
'cult' novel" (Bloom, Lesbian 24). In this lesbian/feminist manifesto that resembles the author's own active involvement in lesbian and feminist causes, Brown depicts the growing experience of Molly Bolt, an adopted daughter of a working-class family. Taking pride in her lesbian identity from early childhood, Molly forces her way through all the injustice and discrimination against lesbians with boldness and candidness. The publication of lesbian-themed fictions by female authors like Alice Walker and Lee Lynch $^{120}$ during the 1980 s reinforces the lesbian narrative tradition in American literature. As Cheri Register points out, an essential component of American feminist movement is to "create a feeling of sisterhood, a new sense of community among women" out of shared experience of male oppression so as to get over "group self-hatred," the hostility against each other due to "isolation, competition for male attention, and belief in female inferiority" (238).

From the above review of Chinese and American socio-historical backgrounds and the corresponding literary manifestations, we may get a clue about the two writers' varying focus in their exploration of sisterhood. While Chen Ran makes an attempt to prioritize sisterhood as a means for her heroines to discover their long-neglected sexual desires and deconstruct the

\footnotetext{
${ }^{120}$ As a renowned African-American author, Alice Walker (1944-) is most famous for her Pulitzer-winning, epistolary novel The Color Purple published in 1982, which describes the story of a young black woman named Celie fighting her way through both racial and gender discriminations. What highlights the novel is also the sisterly relationship among female characters, especially that between Celie and Shug. Originally being a mistress of Celie's husband, Shug changes her attitude towards Celie from hostility to strong attachment. By showing Celie the wonders of life and her body, Shug helps Celie construct her own identity both emotionally and spiritually. Lee Lynch (1945-) started writing on lesbianism since 1960s as a frequent contributor to The Ladder. Her lesbian novels include Toothpick House (1983) and The Swashbuckler (1985).
} 
collectively-masculinized gender roles assigned to Chinese women since the 1950s, Amy Tan, writing in a culture much more open with lesbianism, both socially and literarily, seems to be more concerned about the role of sisterhood in uniting women, especially for her female characters from the Old China before immigrating to the U.S., to struggle against feudalist patriarchy. As a Chinese American woman writer caught between two cultures, Tan is, at the same time, keen on relating herself to her inseparable cultural root in China. Therefore, sisterhood in her writing plays another role of facilitating a matrilineal bond between the American-born daughters with their Chinese mothers, thus stressing the cross cultural connection as well as the bonding of her characters across time and space.

Even though both Chen Ran and Amy Tan attempt to empower their heroines with sisterhood, they are also confined, to some extent, by the overwhelming paradigm of phallocentrism and heterosexual normality. That explains why sisterhood in Chen Ran's works is depicted as a dilemma, especially when it comes to the erotic implication of lesbianism. In "Nowhere to Bid Farewell," the protagonist Dai Er is caught in a dilemma between women's mutual attraction to each other and their conscious fear of being labeled as lesbians. Dai Er and Liao Yi remain glued all the time, sharing joy and sorrow from the bottom of their heart. However, when night falls, they have to return to the room. Even sleeping on the same bed, Dai $\mathrm{Er}$ is quite conscious that she 
and Liao Yi are "separated by their gender, by the due distance between the same sex" (my translation, "Nowhere" 93).

It is implied that while seeking female bond, Chen's characters still have to draw a careful line between female friendship and lesbianism. Once there is the slightest tendency of crossing the boundary, they must either bury their emotional and sexual longings or confront the unknown consequences for their violation of social norms. Therefore, the rebellious Widow Ho in A Private Life, who not only arouses Niuniu's sexuality with gentle caress and kiss, but also indulges her sexual desires by exposing her peach-like breasts for Niuniu to suck like a child, dies accidentally from the explosion of her refrigerator. Likewise, for the "woman in purple" in the story "The Birth of a Hollow Man," the day after she gave up her "reason" to passion by sleeping with the "woman in black," she is raped by her brutal husband and ends her tragic life by committing suicide. Chen's cautiousness about sisterhood might also explain the ending of "Breaking Open." When Dai Er finally plucks up her courage to ask her congenial friend Yunnan to face the world together, "the string of sparkling and crystal clear stones" given by a mother goddess in Dai Er's dream falls out of the protagonist's pocket with the stones scattering on the ground. Realizing the tremendous difficulty in bringing women together for self-empowerment, Dai $\mathrm{Er}$ confesses in the last sentence of the story "My tongue deadlocks in my mouth, as though I had swallowed a tile in one bite" 
("Breaking Open" 71). In "The Sound of Another Ear Knocking," the protagonist

Dai Er is also struggling between rebellion and conformity. It is through the mirror of Yi Duoren that Dai Er finally finds her long-lost self. However, as Dai Er is moving closer to her psychological double, she could always hear in her mind a "sound of reason" (130), calling her to step back to her previous life within the confinement of heterosexual servitude and patriarchal imprisonment. Similarly, in Amy Tan's The Kitchen God's Wife, it is the intimidating male power that prevents Hulan from voicing a word of indignation when Winnie is publicly insulted by her husband Wen Fu. The two friends' first quarrel is also triggered by their conflicting life attitudes in regards to whether a woman could change her fate prescribed by a male-dominant society.

Conditioned by their respective socio-cultural environment, Chen Ran and Amy Tan have developed their distinctive writing strategies to have their voice heard by the discerning readers in cultures that are still far from genuine gender equality. To transcend the boundaries of thematic expressive power, both writers resort to stylistic devices of imagery with feminist connotations in their pursuit of women's sexual and cultural identities, which will be further analyzed in the following chapter. 


\section{CHAPTER V}

\section{A COMPARISON OF METAPHORICAL IMAGERIES}

As contemporary women writers of Chinese origin, Chen Ran and Amy Tan not only share marked similarities in their exploration of a woman's identity construction through the three overriding themes of mother-daughter relationship, heterosexual relations and sisterhood; they also apply the same imageries to uncover the subconscious anxiety and desires of women concealed or prohibited by phallocentric narratives. It is argued by the current author that the two writers' depiction of the heroines' dreams and illusions, their infatuation with the mirror and the imageries of birds serve as metaphorical implications of women's realization of their identity crisis and their attempt to rediscover and empower themselves for a life of independence.

\section{A. Dreams, Illusions and Women's Identity Crisis}

In his influential work The Interpretation of Dreams published in 1899 , Sigmund Freud postulates the idea that dreams embody repressed desires and conflicts that cannot be expressed by an individual during the waking hours. Those desires and conflicts therefore are transformed into more 
manageable imageries in dreams for the dreamer to come to terms with (Huntley 96). Expanding Freud's research, Swiss psychiatrist Carl Jung coined the term "collective unconscious" in the early twentieth century to encompass the "primordial and universal images" that appear in narratives of disparate cultures through manifestations of "dreams, rituals, myths, religious beliefs, and literature" (142). In the fictions by both Chen Ran and Amy Tan, when the heroines are struggling with a fate beyond their own control, the only psychological outlet left is through their dreams and illusions, which, on the one hand, reflect their subconscious fears of the suppressive power of patriarchy and heterosexuality, and on the other hand, their eruptive desires to be bonded with maternal and sisterly power pertaining to the construction of women's deprived identity.

For female protagonists in Chen Ran's fiction, what comprises their dreams is mainly an inexplicable anxiety about sisterhood and a terrible fear of male dominance. As demonstrated in the previous chapter, sisterhood is greatly valued in Chen's fiction by heroines who are disappointed in or tortured by their male counterparts. However, constrained by deep-rooted social norms of heterosexual hegemony and a long-standing collective culture in which one cannot totally ignore public opinion, these suffering women who find empathy from each other are rather anxious about their transgressive desire, which is manifested in their dreams. In Chen's fiction "The Birth of a Hollow Man," the 
day after the assertive "woman in black" urges the timid "woman in purple" to divorce her brutal husband and take confidence for the future of their sisterly relationship, the "woman in purple" describes a dream she had the previous night when the "woman in black" is praising her figure and recommending her to try on a newfangled bra. In that dream, the "woman in purple" finds herself confronted all the time by a tiger-striped cat with a head so big that she couldn't forget. As a response, the "woman in black" puts her hand on her friend's shoulder, strokes it gently and recounts her coincidental dream about a cat the same night. In contrast to the menacing cat in the first dream, the cat dreamed by the "woman in black" is "sick, dirty and as thin as a lath, its fur darkish and shaggy and its eyes full of terror, doubt and hatred" (my translation, "Birth" 232). It jumps in through the window even though the door is locked and bumps into the woman's leg as she is rushing out of the room. It is clearly implied that the two cats of totally different nature are just like the two women with their conflicting attitudes towards sisterhood between them. Whereas the "woman in purple" feels uneasy pressure from social convention when steeped in her female companion's gestures of intimacy, which intimidates her as the tiger-looking cat does, she is compared by the "woman in black" to a stray cat that needs protection and care in a spiritual home lighted with female affection. In addition to subconscious fear of sisterhood with its unknown consequences, the dreams described in Chen's fiction reflect the heroines' 
depressed mood in a world dominated by patriarchal power women cannot escape from. In "Nowhere to Bid Farewell," when Miss Dai Er returns home from aimless wondering on the street after another bitter quarrel with her authoritative mother, she hides herself in bed and envisions a nightmarish scene in darkness. She could hear, above her head, "countless tongues groaning with a hissing sound, countless strands of black hair dancing in the air, countless pale arms pouring on her forehead like icy spouts of water, countless pairs of women's breasts dangling in the sky like fancy lanterns, countless penises growing into towering trees on black soil [...]" (my translation, "Nowhere" 112). Here, the dream imageries of "tongues," "arms" and "penises" might be interpreted as symbolism for phallocentric narratives that attempt to deny female subjectivity. While the towering tree of male power has taken root "on black soil," the female symbols of dancing hair and dangling breasts are only of decorative nature, flowing rootless in the air. Dai Er's illusions therefore reflect women's hidden anxiety concerning their objectified fate and erased identity.

In comparison, the illusions of Ying-ying about the Moon Lady in Amy Tan's The Joy Luck Club also reveal the harsh fact of women's rootless status in a world with all its rules prescribed by men. The story unveils when Ying-ying is a willful four-year old girl raised in a well-off family in Wuxi, a relatively prosperous city in central-eastern China. Running about on a large 
boat her family rent for a cruise on the Lake Taihu in celebration of the Moon Festival, ${ }^{121}$ Ying-ying accidentally tumbles into the lake. She is soon rescued by a fishnet, but is mistaken by the fishermen as a beggar girl, lost without her family. Wondering among a crowd of strangers by the riverside, Ying-ying suffers from her identity confusion: without her fine clothes and family's good fortune, she is indeed no different as a beggar girl. It is at that desperate moment that Ying-ying is attracted by an ongoing shadow show about the Moon Lady. ${ }^{122}$ As the Moon Lady is lamenting on her lonely life on the moon, forever lost to the world and banished for her "untempered passions," Ying-ying cries in deep sorrow, feeling emphathetic for the same identity crisis she is going through. She rushes to the backstage as soon as the play ends, eager to confess her secret wish. But it turns out that the beautiful Moon Lady is performed by a man with "shrunken cheeks, a broad oily nose, large glaring teeth, and red-strained eyes" (JLC 82). Though later found by her family, Ying-ying is no longer the same girl with absolute confidence. As Xu Wenying comments, the fact that the Moon Lady is acted by a man points to the reality that the "femininity" of women is "ultimately determined by patriarchal ideology," while the "ugliness" of the Moon Lady's face reveals "the ugliness of

\footnotetext{
121 The Moon Festival, also known as Mid-Autumn Festival, is a traditional Chinese festival held annually on the fifteenth day of the eighth lunar month according to the lunar calendar. People would eat moon cakes while worshipping the moon and celebrate family reunion. Other folk activities include lighting lanterns and burning incense in honor of deities including Chang' $e$, or the Moon Lady.

122 The Moon Lady, or the goddess of the moon according to Chinese folklore, is named Chang' $e$, who swallowed out of curiosity the elixir of immortality her husband Houyi obtained from the Queen Mother of the Western Skies and floated into the sky until she landed on the moon. While Houyi the Archer is known for his bravery to save the scorching earth by shooting down nine suns, thus representing brightness and masculinity, Chang'e, though deified as the Moon Lady, leads a lonely life in cold and cheerless palace of the moon and cautions people against negative traits like greediness and jealousy traditionally associated with women.
} 
women's victimization" and the dark secret behind the patriarchal myth that "subjugated women and turned them into sexed subjects" (60-61). For Ying-ying, the night of the Moon Festival is a night of change, an epiphany in her life. Finding out the cruel truth behind the illusion of the Moon Lady, the narrator Ying-ying in her late years realizes she has long lost herself, and her secret wish "to be found" could not be fulfilled by anyone but herself.

Women's objectified fate is also reflected in the dream of Winnie, the heroine of Tan's The Kitchen God's Wife. On the night that her mother mysteriously disappears, Winnie is troubled by many dreams in her sleep. Amid the senseless, disjointed images, the most indelible ones are related to her mother (Huntley 97). When the little Winnie weaves through her mother's hair with her fingers, what she discovers is not hair at all, but "embroidery and jewels" (KGW 97). Replacing the deceased second wife of her husband Jiang, Winnie's mother takes a low position in the family, looked down upon not only by Jiang but his other concubines as the "Double Second." Though living an affluent life, this beautiful woman is only a decoration on male supremacy, the worth of her words measured not by the content but the clothes and jewelry she is wearing. Winnie's dream therefore signifies the soulless life of her mother, and countless women like her who lived without any dignity in the feudalist and androcentric Old China.

While Winnie's dream about her mother denotes the message of female 
objectification, in the dream of Rose, one of the daughters in The Joy Luck Club, her mother appears as an accomplice of patriarchal imprisonment of women. Being an obedient child, Rose believes in her mother's words that the door into dreams is guarded by a man named Old Mr. Chou. In a dream Rose remembers, she feels through a hole of the old man's floor into a nighttime garden filled with color-changing snapdragons and plants with veins of blood. But before she has time to appreciate the beauty of the garden, she is scared away by the angry shouts of Old Mr. Chou and eventually finds herself in a giant playground with rows of square sandboxes and a new doll in each box. Hearing her mother telling Old Mr. Chou that she has already known which doll her daughter would pick up, Rose deliberately disobeys her mother's wish by picking another doll. Just at the moment when Rose tries to escape from the chasing man, she suddenly becomes paralyzed, "too scared to move in any direction" (JLC 186). In this dream scene similar to Alice's adventure in wonderland, Rose unleashes her rebellious desire by making a choice against her mother's will. But in doing so, she experiences an anticipated penalty of paralysis. What is worth noting is that her mother is collaborating with an authoritative male figure of Old Mr. Chou, who not only guards women's dreams, but also keeps under his strict control the magical garden, which probably symbolizes female vitality and creativity. The dolls in the middle of square sandboxes carry a metaphorical implication of women's expected 
submission to male rules. Deprived of their identities, for these angels of the house, any attempt to step beyond the boundary of the box would incur a similar punishment as Rose: unable to move and nowhere to run away from.

Based on the above analysis, we may see that the depiction of dream scenes and illusions plays an important role in Chen's and Tan's fictions in terms of disclosing the heroines' internal fears of their endangered identities. While the two writers converge in their description of dreams and illusions as an indirect revolt against patriarchal repression of women, they have their distinctive focus when it comes to women's salvation of themselves. Losing hope in heterosexual relations, heroines in Chen Ran's fiction lay special emphasis on sisterhood as power of subversion, while Tan's characters ultimately return to their mothers to regain their lost voice. Although the aforementioned dream scenes reflect, to some extent, a subconscious uncertainty about forging sisterly alliance for Chen's characters, or fear of erased identity threatened by overly maternal control in Tan's case, it is through the eruptive power of the dreams as journeys of self-discovery that the heroines are able to explore the devalued potentials of sisterhood and maternal guidance that help them construct their respective sexual and ethnic identities.

In Chen Ran's A Private Life, the protagonist Niuniu takes Widow Ho as a mirror of her heart. Whatever joys or pains experienced, she could always find 
a soothing response from this caring woman. But in a homophobic society, Niuniu's intense longings for Ho are confined within the spiritual realm, repressing the erotic desires only to the subconscious level of her dreams. Having realized that $\mathrm{Ho}$ is the one she truly loves compared to her sex-driven involvement with $\mathrm{Ti}$, Niuniu dreames of a dance party, on which her hand is taken by Ho's warm hand that has been persistently seeking her. Urged by Ho to dance with her, Niuniu is pulled onto the dance floor, held closely to Ho, afraid to be lost in a moment of inattention. The description from Niuniu's perspective is no different from that for an amorous couple:

Like the sound of the little drum in an opera orchestra, her heart beat wildly against my breast. Her body emitted an intangible heat as she pressed herself tightly against me. She held my young buttocks firmly in her hands, so exciting me that I began to gasp for breath. (A Private Life 125-126)

Coaxed by Ho's bright eyes, Niuniu follows Ho to a deserted garden away from the crowd. There, Ho starts to undo the blouse of Niuniu and herself, stepping back while facing her so that they could appreciate the body of each other. In Niuniu's eyes, each single movement and gesture of Ho overcomes her with its perfect beauty, and burns her desire:

I longed feverishly for her to reveal her beauty to me totally. [...] She was my mirror.

[...] I had never before seen such a suggestive look in such an intelligent and passionate female face. Her short, neat, glossy hair and the serious lines at the corners of her mouth perfectly embodied her calm profundity and her rich life experience. [...]

A giddy feeling of joy began to rise up from the soles of my feet. (126)

In this sensual dream of Niuniu, the social taboo of lesbianism is finally broken 
down. Through the fixed gaze of the mirroring female body with its dazzling beauty and hidden power, Niuniu regains her obliterated sexual identity and boldly plunges into Ho's kisses and touching that rekindle a childhood or pre-oedipal memory of familiarity: "my pulse quickened and I began to tremble, until at last I listened to her with my heart, held her within my heart of hearts" (126-27).

It could be stated that such description of lesbian eroticism is unprecedented in Chinese women's literature. In a literary and cultural environment that is still quite conservative about homosexual eroticism, Chen Ran's experimental words through the heroine's dream scenes embody acclaimed female same-sex desires and sexuality in a powerful yet concealed way. However, when Niuniu is symbolically having sex with Ho during the dream dance, she still needs the assistance of a familiar "third hand" coming out of nowhere for "a shuddering consummation," and as she recovers from "tense, numbing excitement," she finds out that her dance partner has changed into a male, who proudly declares himself to be Niuniu's "real inner need" (127). Backing further away from the conquering man, Niuniu shouts a firm breakup with the male world: "I don't need you, I don't need you at all..." (ibid.). The contradictory implications of the dream reflect Niuniu's dilemma in her love relationship with Ho. Expressing her physical desire for another woman in her dreams, Niuniu still cannot do without the help of the "third 
hand," a symbol for male genital, nor can she escape from the omnipresent shadow of the man. According to Sang Tze-lan, the dream scene with male presence in the end can be interpreted as Chen's strategy for "describing lesbian sex in a language that is acceptable to the heterosexist society and state" (214).

The dreams described in Chen's fiction not only fulfil the heroines' libido drives otherwise restricted in sisterhood, but also empower women to realize their uniqueness and the immeasurable power of female bonding. In "Breaking Open," the narrator Dai Er dreams of a plane crash when she and her female friend Yunnan are flying to the city of $\mathrm{N}$ to establish a female society. Assuming herself dead in the accident, Dai Er feels her spirit entering a fairyland with unspoiled beauty. There, she couldn't help marveling at the sharp contrast between conventional portrait of death as "dark, scary, and horrifying" and the real sight before her eyes in this "enchanting, luxuriant, and holy place" ("Breaking Open" 67). As she approaches a heavenly hall standing "tall and upright" in front of her, Dai Er discovers that the walls of the dark red building are "covered with cavities that look like eyes, big and wide open," allowing its owner to "look outside from every angle and point of view" (ibid.). Walking into this maze-like mansion with hidden doors, the protagonist is greeted by an old woman, a familiar stranger symbolizing the female god, who urges Dai to return to her physical body to take care of her mother and keep company with 
Yunnan: "You must work together, close as sisters, like mouth and teeth, like hair and brush, like socks and feet, barrel and bullet, because only women can really understand women - only they can really empathize with each other" $(67-68)$. Although the voice of the old woman seems to come from far away "like an echo resounding in an empty valley," it penetrats the narrator's soul in an unusual way: "I feel that I am not listening with my ears, but with my whole face, I am inhaling her voice. That voice is not muddled at all, I can hear it distinctly" (68). After Dai Er pours out her hidden desire to live together with Yunnan and all the talented women of the world as close sisters, the old woman puts "a string of shiny, white stones" in Dai's hand, saying that the pebbles, which are ordinary taken separately, could "send forth a peculiar brilliance" when stringed together (69).

The dream, in which the protagonist fancies about "a utopian woman's nation" and is reminded through a holy voice the vital importance of female alliance, constitutes "a feminist-lesbian manifesto" (Sang 212). The red mansion covered with wide-open cavities is just like the multiple perspectives and limitless potential of women who have long been neglected and downtrodden by a male-supremacist society. And Dai Er's self-imposed death in her dream for fear of emotional and physical intimacies with her female friend Yunnan proves to be a comforting journey with rediscovered source of power instead of a terrifying experience in a dark abyss as the way lesbianism 
has been demonized by the heterosexual discourse. Though the pebbles scatter around in reality at the end of the novel, implying the enormous difficulty for women to struggle against compulsory heterosexuality, it is through the dream that the writer Chen Ran embeds her message on the great value of sisterhood, and the narrator finally plucks her courage to confirm her lesbian identity with a loud proclamation "I want you to go home with me" ("Breaking Open" 71)!

If Chen's characters reconstruct their sexual identity through dreams of erotic desires and united power in sisterhood, heroines in Tan's fiction are awakened in dreams to their lost selfhood and ethnic identities. Living in the shadow of her husband Ted for fifteen years, Rose is all adrift when Ted wants a divorce from her. Instead of confronting Ted to discuss the matter between them, Rose puts all her trust in her psychiatrist and vents her desire for revenge only in dreams. Once, Rose dreams of inviting Ted to dinner at a trendy place. After Ted starts the first course in joy and relaxation, Rose takes out a voodoo doll and aims her fork "at a strategic spot" of the doll, shouting loud enough for everyone to hear: “Ted, you're just such an impotent bastard and I'm going to make sure you stay that way" (JLC 189). The dream reflects the crux of the problem in Rose's marriage. Behind the seeming harmony in their daily life, what is actually at work is Rose's willing submission of her own voice to that of Ted, who, however, becomes spiritually impotent after losing a 
malpractice lawsuit and refrains from making any further decisions ever since. Rose's imagined revenge not only provides an outlet for her anger at Ted's cowardice, but also helps her awaken to the fact that it is her own subjugation to male authority that dooms her marriage as a failure. The dream gives Rose a feeling of racing "to the top of a big turning point" with a reborn self-identity (ibid.), but when Rose describes the symbolic dream to her psychiatrist, the latter looks bored and sleepy-eyed, and soon calls an end to the consultation. As a matter of fact, it is at the urge of her mother to speak up for herself instead of blindly following the psychiatrist's advice that Rose finally fights back for her lawful rights, gaining her lost voice by shouting to Ted's face, "You can't just pull me out of your life and throw me away" (196). That night, Rose dreams of a garden totally different from that in her first dream. There, she sees her mother hovering over something like tending a baby, and beneath her all along the ground are "weeds already spilling out over the edges, running wild in every direction" (ibid.). The dream symbolizes the ultimate reconciliation between the mother and daughter. Over the years, Rose has misunderstood her mother to be over-protective, treating her like a doll in the middle of a sandbox with clear demarcation designated by male dictatorship. The dream at the end of the story brings the daughter back to her mother as a gardener of female spirituality. The weeds the mother plants both for Rose and for herself signify women's self-identification, which is no longer confined by the "edges" 
of male definition and has exuberant vitality full of possibilities beyond male control.

While Rose's dreams imply women's spiritual growth from being paralyzed by patriarchal domination to becoming masters of their own lives, through the dream of Ruth, Luling's daughter in The Bonesetter's Daughter, Tan seems to express a deep concern over the identity crisis of Chinese immigrants as ethnic minorities in American society. In this dream, Ruth recalls that the curtains of her bedroom turn out to be transparent, and she is naked, "her most private moments, her most private parts" being watched by her grinning neighbors. Before she has time to cover herself, the radio starts to glare, followed by an explanation that the American Broadcasting System is testing early-warning signal for disaster preparedness. But at the same time another voice comes on, the voice of Ruth's mother, "No, no, this is not test! This real" (BSD 20). And quick as a wink, everything is swept over by the "the dark shape in the bay" that rises into "a tidal wave" (ibid.). Even for the second-generation of Chinese Americans like Amy Tan, or Ruth as Tan's fictional representative, who are immersed in American culture since birth and have a successful career, they still experience "a sense of alienation and strangeness" in the American society (Amy Ling 105). As Amy Ling points out, the "double consciousness," or the sense of "always looking at one's self through the eyes of others, of measuring one's soul by the tape of a world that 
looks on in amused contempt and pity" in the words of W. E. B. Du Bois when characterizing African Americans, also apply to Chinese Americans (Bois 45, qtd. in Amy Ling 105). Such an anxiety of feeling under constant surveillance with one's value measured not by oneself but by those privileged in the mainstream society, therefore, creeps into the subconscious dream scenes of Chinese Americans like Ruth. The "transparent curtains" exposing the private bedroom of the protagonist and her nakedness mocked by the contemptuous neighbors are pertaining to a sense of insecurity and loss of ethnic identity. The surging wave about to engulf the entire house is emblematic of the assimilative power of the American culture. The imperceptible obliteration of one's racial origins without any trace at all is just like the sham announcement of the national radio, claiming it is only a test warning. Like the phone call from Rose's mother who finally talks Rose into facing Ted in her own voice, the shout of Ruth's mother cautioning her daughter to run away from the incoming tide constitutes the mother's desperate attempt to protect their Chinese ethnic identity from being totally erased by the overpowering American culture.

To summarize, dreams depicted in the fictions of Chen Ran and Amy Tan are the embodiment of both women's deep worries about male oppression and their growing awareness for their endangering identity in a hostile world. Imprinted with divergent cultural particularities as introduced in previous chapters, Chen's heroines utter a spiritual declaration, through their dreams, 
on women's sexual identity and solidarity in sisterhood, while Tan's characters find in dreams their true selves and realize the value of their ethnic identities with the help of their mothers.

\section{B. The Mirror and Women's Self Recognition}

The mirror has always been associated with the subject's construction of his or her self-identity. The most influential theory on the mirror is probably Lacan's psychoanalytical formulation of the mirror stage. Inspired by the research of psychologist Henri Wallon on disparate behaviors of human infants and chimpanzees in response to their reflections in the mirror, Lacan proposes in the 1930s his concept on the mirror stage as a milestone in the development of human subjectivity. For Lacan, the mirror stage that starts when the infant is six months old and continues up to the eighteenth month is characterized by the infant's recognition of and jubilant interest in his image in the mirror, which lays the foundation for the formation of the child's ego (Ecrits 3-4). By the 1950s, Lacan broadens his concept on mirror stage not only to interpret child psychology, but also to represent a general structure of subjectivity in which the subject is captivated by his or her own image in the mirror. In "Some Reflections on the Ego," Lacan further clarifies the implications of the mirror stage, to which he assigns "a twofold value":

In the first place, it has historical value as it marks a decisive turning-point in the mental development of the child. In the second place, it typifies an essential libidinal relationship with the body 
image. (Lacan, "Reflections" 14)

A key point in Lacan's description of the mirror stage is the formation of one's Ego through the process of objectification. The child's vision of the whole body image through the mirror is in sharp contrast with his fragmented understanding of himself due to a lack of muscular and sensory coordination. Once the child develops a narcissistic identification with his mirror image, he begins to have a sense of self-identity. Therefore, the Ego is formed as a result of the discrepancy between one's perceived mirror reflection and one's emotional experience. According to Lacan, it is through identification with an internalized ideal image in the mirror, a process of alienation and misrecognition, that one achieves subjective consciousness. The mirror in Lacan's mind is not confined to its literal meaning, but is symbolic of all kinds of specular images projected by individual imitative gestures and socio-cultural configurations (Evans 193).

Lacan's theory on the role of the mirror in the formation of one's self-identity has exerted great influence among feminist theorists. In The Second Sex, Beauvoir explains the magic of the mirror for woman to project herself and to attain self-identification. While man considers himself as an active subject and therefore has no interest in his specular image, for woman, who is deemed as an object of desire, the image in the mirror "is identified with the ego," since the reflection is an objectified other just like herself, and she "gives life through her admiration and desire to the imaged qualities she sees" 
(Beauvoir 631).

Like Beauvoir, Irigaray also attaches importance to the power of the mirror for woman. Though originally a follower of Lacan as a member of the Freudian School in Paris, a Lacanian psychoanalytic institute founded in 1964, Irigaray deviates from the theoretical models of both Freud and Lacan that put phallus in the central position as the "signifier of all signifiers," leaving no place for the female subject (Burke 293). In "The Looking Glass, from the Other Side," the preface to This Sex Which is Not One, Irigaray experiments with her notion of female writing while reviewing a Swiss film with a heroine who is reminiscent of Lewis Carroll's Alice through the looking-glass. ${ }^{123}$ According to Irigaray, women are exiled from their true selves while trying to conform to masculine projections in a "masquerade of femininity" ("Questions" 135-36). Objectified as the mirror to reflect male desires, women are perceived as the lack or the Other without their own identities. In the preface, Irigaray expresses through the words of Alice, the heroine of the film, woman's loss of identity to objectified images in the social mirror:

I keep on pushing through to the other side, $[\ldots]$ because on this side of the screen of their projections, on this plane of their representations, I can't live. I'm stuck, paralyzed by all those images, words, fantasies. Frozen. [...] So either I don't have any "self," or else I have a multitude of "selves" appropriated by them, for them, according to their needs or desires. [...] I'm completely lost. ("The Looking Glass" 17)

\footnotetext{
123 Through the Looking-Glass, and What Alice Found There (1871) written by Lewis Carroll is a sequel to his first well-known children's book Alice's Adventures in Wonderland (1865). In this work full of imagination and illogical ideas, Alice goes through another magic journey in an alternative world behind the mirror of the fireplace, where everything runs counter to the common sense of the readers.
} 
Just like the adventurous Alice who enters into the Looking-Glass Land where everything is out of logical order, it is implied by Irigaray that a woman should rediscover herself "in a new psychic space" behind the mirror of patriarchal discourse, an emotional and intellectual realm where she "is no longer defined in relation to man as his negative, other, or as lack" (Burke 296).

As a main metaphor for "imaginary/ideological force" in psychoanalytic and feminist theories, the mirror plays significant roles "in the process of recognition/identification and the formation of gendered self-consciousness" (Wang Lingzhen 180). In the fictions of both Chen Ran and Amy Tan, the mirror serves as an enlightening tool for the heroines to cast away the feminine image under the male gaze, penetrate their own souls, realize their real desires and exploit their untapped potentials.

A familiar scene in Chen's fiction is the protagonist's narcissistic observation of her body through the mirror. In "A Toast to the Past," the protagonist Xiao Meng, a pubescent girl living a solitary life in a deserted nunnery, is driven by an undercurrent to study her budding body. Lying naked on her bed soggy with sweat, like a slippery fish basking on the sunny beach, and holding a mirror at hand that moves up and down, the girl compares the images of her body with those on a textbook of gynecology. Yet such soft hand, this blushing face, tearful eyes and blossoming, firm breasts seem so strange that she could hardly recognize them ("Toast" 25-26). Throughout the human 
history, women have been alienated from their own bodies, which are simply perceived as sexual objects for male consumption. To unleash the hidden power of the female body against patriarchal appropriation, the first step is to demystify woman's body by her self-gazing and self-identification through the mirror. Xiao Meng's shocking discovery of her maturing body in the mirror not only alludes to women's institutionalized alienation from their bodily potential, but also is accompanied with the protagonist's awakening sexual awareness and a growing sense of self-identity.

The discrepancy between women's disguised images projected by men and their real selves emerging from the other side of the mirror under female self-gazing is also hinted in Chen's A Private Life. Before going out on a date with Yin Nan, Niuniu carefully assesses her appearance in the mirror:

As I looked closely at this young but very beautiful girl in the mirror, I saw her suddenly turn away, and when she turned back again she had taken off all her clothes, or, I should say, they had simply disappeared. Her naked figure was flagrantly bare in the mirror, her deep red nipples glowing as if bathed in sunlight, her smooth white breasts following my eyes like a pair of plump sunflowers following the sun. (145)

If the innocent, well-dressed girl in front of the mirror conforms to male-desired image of a woman as the angel of purity, the naked figure in the mirror represents Niuniu's hidden desire to master her own body full of radiating vitality. But the unexpected eruption of Niuniu's subconscious self is soon deformed into a self-denying image kneeling to male ruling. In this dreamlike vision through the mirror, Niuniu sees herself "whimpering helplessly with tears 
streaming down" and her body, "frail as a feather," floating lightly into the arms of someone who looks exactly like Yin Nan (ibid.). The gentle caress of this man ignites in her "an overwhelming desire to be his prisoner" and to lose herself to his embrace (ibid.). The hallucination prompted by Niuniu's self-reading in the mirror reveals her hidden anxiety to be captured by man as a soulless accessory. In the imagined conversation with Yin Nan that follows, Niuniu firmly contradicts Yin Nan's idealist impression of her as a girl of innocence in an attempt to define her own identity:

The voice said, "You captivate me. You're pure and noble." I said, "I'm not the least bit pure. You have no idea what kind of person I am."

The voice said, "I understand you."

I said, "You don't understand me. You have no idea how shameless I have been in the face of desire."

The voice said, "I like your shameless innocence." I said, "You can't understand me. You're too young. And I am already old beyond my years." (146)

In Chen Ran's writing, the mirror is an entry into a woman's subconscious realm, offering "a conscious and imaginary confirmation of an alienated self in and through the other [in which] the self is projected in the distance for imaginary re-creation, erotic desire and pleasure" (Wang Lingzhen 183-84). Having experienced a loveless sexual entanglement with $\mathrm{Mr}$. Ti, an unfulfilling love relationship with Yin Nan, the death of her beloved Widow Ho and her mother in rapid succession, Niuniu finally retreats to her bathtub, across which hangs a big mirror. In this secluded female world of Niuniu and "a young woman lying on her side in a tiny, swaying white boat" as seen from the 
mirror (A Private Life 207), women have reclaimed their true selves, which, defying male definition, are finally reunited into a powerful force. Realizing for the first time "how intriguingly beautiful the passive languor of a reclining body could be," Niuniu sets free her libidinous drive in front of the mirror, bringing perfectly together "[t]he experience of beauty and the fulfillment of desire" (208).

While Chen Ran prioritizes the role of the mirror in women's rediscovery of their bodily power by the heroines' identification with their reflections "in" the mirror, Amy Tan plots her characters to realize, through their specular images, women's victimized fate of the Other as well as disparaging social projections on Chinese Americans so as to walk "out" of the mirror with an enlightened affirmation of their spiritual power. In The Joy Luck Club, when little June keeps on failing the expectation of her mother to become a prodigy in order to stand a better chance while climbing the social ladder as a Chinese immigrant, she looks in the mirror above the bathroom sink. There, she sees an "ordinary face" of a "sad, ugly girl" staring back (JLC 134). In an attempt to reject this pathetic image that might be comparable to stereotypical social image for Chinese Americans, June makes "high-pitched noises like a crazed animal, trying to scratch out the face in the mirror" (ibid.). Just at that moment, June discovers the prodigy side of her in the mirror reflection, a face she has never seen before: 
The girl staring back at me was angry, powerful. This girl and I were the same. I had new thoughts, willful thoughts, or rather thoughts filled with lots of won'ts. I won't let her change me, I promised myself. I won't be what l'm not. (ibid.)

The mirror provides a woman with a spiritual home of her own, leading her into a pre-linguistic world not yet polluted by the phallocentric order. Keeping a distance from her mirror reflection as if observing another person, the woman could rebuild her deprived sense of subjectivity and find out her shining points that have been filtered out by the spectacles of patriarchy.

If June confirms her self value by driving away the stereotypical image of Chinese immigrants in the American society, Winnie's mother walks out of her mirror image of humble male foils to pursue her independent identity. Just like her husband who assumes absolute authority over his objectified wives, Winnie's mother takes the mirror as a means for her to affirm her self-naming subjectivity. Every night, she would look in the mirror, observing her reflections in a detached manner. Refusing to accept her fate as the "Double Second," a replacement for the dead second wife, she would "spend many hours in front of her mirror, accusing the double second that stared back at her" (KGW 93). When she sees no hope in her degraded marriage life, she resolutely smashes her mirror image and leaves home for a life chosen by herself. Similar to the various versions of her elopement, the fate of Winnie's mother is no longer within the control of a single male definition. Whether her mother runs away for love, or becomes a revolutionary or nun with her hair cut off as a sign never to 
turn back, or suddenly takes sick and dies, women have liberated themselves from the mirror to carry multiple possibilities.

Like Winnie's mother who projects her undesired image into the mirror for self-confirmation, Peanut, Winnie's cousin who escapes her homosexual husband and becomes a revolutionary, discards her mirror image with strong self-consciousness. When Winnie presents to Peanut an exquisite silver mirror, a gift from Old Aunt, during their long-awaited reunion, Peanut recalls her last encounter with Old Aunt. When the old woman laments the disappearance of the pretty girl she once knew, Peanut replies in unequivocal terms: "I did not have a mirror to see myself, but pretty or not, I did know I existed" (KGW 349). Holding the mirror in hand, Peanut understands immediately the intention of Old Aunt: the mirror is a reminder of the lavish life Peanut could enjoy by playing her feminine roles. But rebellious and free-spirited, Peanut puts down the mirror (ibid.), determined to define her own fate beyond specular reflections.

For both Chen Ran and Amy Tan, the mirror functions as an essential tool for women to reconstruct their identities in defiance of male arbitration. In a world where phallocentric narrative is the only frame of reference, it is through the mirror that heroines in the fictions of the two writers embark on a psychological journey of self-searching and self-fulfillment. 


\section{Birds and Women's Dream of Independence}

The bird imagery can be found in literary works across different times and cultures. Being earthly creatures that have the ability to fly high up in the sky, the birds are always associated with freedom, love and joy. Among Western and Chinese literary masterpieces, we can easily find bird imagery as an embodiment of the writers' dream for spiritual freedom and a desire to break away from social constraints.

In John Keats' poem "Ode to a Nightingale," the poet expresses his longing to escape the burdensome human world by fleeing to the bird's state of immortality. ${ }^{124}$ As for Shelley's "To a Skylark," the imagery of a skylark could be interpreted as the poet's incarnation, soaring into the blue sky, singling songs from Heaven as a blithe spirit. Bird imagery also appears in the works of female writers like Charlotte Bronte. In her famous novel Jane Eyre, the heroine Jane changes, in the eyes of Mr. Rochester, from "a curious sort of bird through the close-set bars of a cage" (Jane Eyre 147) to a wild "eager bird" with enough confidence to fly free in the sky (335). In Kate Chopin's The Awakening, bird imagery plays an important role in the writer's depiction of the protagonist's quest for self-discovery and independence in defiance to social expectations on women's femininity. The images of a caged parrot and a

\footnotetext{
124 The imagery of a nightingale appears more frequently in western literature than any other bird. As Albert Chandler writes in "The Nightingale in Greek and Latin Poetry," references to this kind of bird "are found all along the way from Homer to T. S. Eliot" (78)
} 
mocking bird that can only repeat limited words In Chopin's fiction are symbolic of the domesticated fate of Victorian women, trapped in male confinement as birds in gilded cages. For Maxine Hong Kingston, a renowned Chinese American woman writer and a contemporary of Amy Tan, the bird imagery carries her dream to live a carefree life away from the daily stress: "I'll be free to live. I won't be a workhorse anymore; I'll be a skylark, free of obligations" (To be the Poet 3). In a poem entitled "Birds," Kingston expresses the peace of mind she enjoys from the birds' company: "the birds enlace their nests / with my white hair. / I'd like their recognizing me in return" ("Birds" 2-4; To Be a Poet 41).

Coming to the Chinese scene, the bird imagery is also deeply situated in its literary tradition. In the first poem of The Book of Songs (shijing), the earliest collection of poems from 1000 B.C. to 5000 B.C., ${ }^{125}$ the imagery of turtle doves is adopted as an indication of love and marriage. In "Enjoyment in Untroubled Ease," the first writing of Zhuangzi, the image of a giant bird called peng embodies Zhuangzi's Taoist philosophy of transcending secular concerns for spiritual freedom. ${ }^{126}$ In the poems of Tao Yuanming, ${ }^{127}$ the

\footnotetext{
125 The poem compares the cooing and wooing of a pair of turtle doves with a young man's love and pursuit of a fair maiden.

${ }_{126}$ Zhuangzi is the collection of works by Zhuangzi, or sometimes spelled as Chuang Tsu or Master Chuang, who is an influential Chinese philosophy around $4^{\text {th }}$ century B.C. during the Warring States Period. For a detailed study of Zhuangzi and his works, please refer to The Complete Works of Chuang Tzu translated by Burton Watson.

127 Tao Yuanming (365-427) is one of the most influential Chinese romantic poets during the Eastern Jin Dynasty before the Tang Dynasty. Known as a "Poet of the Field," his poems are characterized by an idyllic depiction of a pastoral life and nature. As Zhou Junling states, among 122 existing poems, 38 have reference to birds (137). Tao is also well-known for his utopian ideas expressed in the prose of "Peach Blossom Spring" (taohuayuan ji). For a discussion of bird imageries in Tao Yuanming's poems, please refer to journal articles by Gao Weihong (2006), Hong Jingyun (2007), Chen Lin (2008), and Zhou Junling (2009).
} 
recurring bird imagery represents both the poet's political aspirations in his early years and his later goals of keeping aloof from the world in pastoral peacefulness. In Ai Qing's well-known poem "If I were a Bird" (jiaru woshi yizhi niao), the poet is compared to a bird singing till its death a deep love for the land as its home. It could be stated that throughout the Chinese literary tradition, the bird imagery, always applied as the personification of the writer, embodies the writer's ideals that are often challenged by harsh social realities.

Based on the above review, it is clear that literary references to birds proceed from universal human experience and cognitive environment that transcend time and culture. In the fictions of Chen Ran and Amy Tan, the bird images serve as metaphors both for women's unbearable sufferings in a patriarchal world as in the fate of caged birds, and for their cherished hope to obtain freedom and independence like wild birds flying in the sky.

A reoccurring image in Chen Ran's fiction is birds without wings. In "Sunshine between the Lips," when the male dentist is about to inject anesthetic into Dai Er's soft gums before extracting the impacted wisdom tooth, the approaching hypodermic sent chills up the protagonist's spine. Feeling her face cold, "the corners of her mouth and the tip of her nose twitch[ing] uncontrollably," her mind blank and her body "spinning upward," Dai Er closes her eyes and sees in her mind's eye a gruesome scene:

One dense, heavy cloud followed another, as though the sky were covered by the dark-gray wings of a multitude of birds. The air was 
damp. The huge birds, hovering in the universe like fine steeds, swooned earthward. Their feathers were shot down one by one by peals of thunder and thudding raindrops, and the dark-grayness fell at a leisurely pace to stick on the window. ("Sunshine" 121)

Here, the imagery of birds symbolizes women's fate in a male-dominant world. Though dreaming to hover in unmeasured vastness of the universe, the birds still cannot break through the thick clouds, emblematic of overwhelming patriarchal forces, hanging over them. The "dark-grey wings" seem to foreshadow the tragic endings to the huge yet fragile birds, which "swooned earthward" with their feathers shooting down one by one by "peals of thunder and thudding raindrops." What is worth noting is that the demise of the bird flock is brought about "at a leisurely pace," which might imply women's unconscious process of being assimilated and brainwashed by the phallocentric ideology. Women's sense of selfhood is just like the window not only "covered" by but "stuck" with the dark-gray corpse of wingless birds, allowing no sunshine shining through. Therefore, the bird imagery in Chen's writing reveals the heroine's subconscious anxiety of losing her self-identity to phallocentric supremacy as represented by the hypodermic filled with anesthetic. While Dai Er's hysteric scream of rejection renders her an insane woman in this well-functioning patriarchal world in comparison to the dentist's calmness and rationality, the bird imagery in the protagonist's illusions rings a self-saving alarm to women who are at the verge of male conversion.

Similar images reappear in Chen's A Private Life. The death of her 
mother and Widow Ho cuts off Niuniu's last ties with the world. Suffering from schizophrenic symptoms, Niuniu shuts herself at home, scribbling madly whimsical ideas and absurd argumentations. In a passage with a title "Concerning Miss Nothing," Niuniu renames herself Miss Nothing, meaning, in her words, "there is no me" (A Private Life 190). Following a description of three segments of her hair and her mind that parallel the Freudian distinction among the id, the ego and the super-ego, ${ }^{128}$ Niuniu writes about herself standing in front of a mirror with black wings moving overhead: "Those black wings, the color of June, suddenly snapped, but the bird on my head flew away, leaving only a thick heap of feathers" (ibid.).

Same as the previous example, the imagery of the bird deprived of its wings when flying in the sky symbolizes patriarchal oppression of women, who find it impossible either to display their talents or explore their hidden potentials. But different from that in the first case, here the bird does not fall down to earth along with its feathers; instead, it keeps on flying even without the wings. Comparing the plots of "Sunshine between the Lips" and A Private Life, we may better understand divergent implications of bird imageries in the two examples. Just like the fallen birds that block the window to women's heart, the

\footnotetext{
128 In The Ego and the Id (1923), Freud introduces the terms of "id," "ego" and "super-ego," the three components of one's conscious and unconscious psyche. The id represents the unconscious self with all the instinctual impulses and desires to satisfy one's primitive needs; the super-ego plays an ethical and moralizing role, distinguishing right from wrong and punishing one's desire-driven misbehaviors through a sense of guilt; while the ego stands for the external reality and one's conscious self to strike a balance between the id and the super-ego. It is in the same manner that Niuniu describes the three strands of hair representing three sections of her mind: "The part on the left is my unwillingness, which goes against my wishes; in the middle sits my equivocation - yes but no; and on the right, my desire" (A Private Life 190).
} 
protagonist in the first fiction conceals her subconscious anxieties about self-annihilation by being assimilated into the role of female submission, as indicated in her calm acceptance of the needle and the extraction of her wisdom tooth, symbolically women's wisdom, at the end of the story. In contrast, Niuniu, the heroine of A Private Life, is clearly conscious of her denied identity as seen from her self-naming as Miss Nothing. Even though she is like a bird without wings, she is resolute to continue flying and struggling in this hostile world by recording her stories to awaken more women.

Comparable with birds without wings in Chen's fiction, the imagery of a pelican in Amy Tan's The Joy Luck Club carries a similar implication of women's suffering under male-hegemonic control. In the story "The Moon Lady," the little Ying-ying is attracted by the scene of a pelican catching fish for two boys. Releasing the squawking bird from a bamboo cage, one boy wraps his arms around the bird's wings, while the other ties a thick rope to a metal ring around the long neck of the bird. Then the bird is allowed to dive under the water. Each time it emerges with "its head struggling to hold onto a large fish" (JLC 75), the ring around its neck would prevent it from swallowing the fish. The fish would then be snatched from the bird's mouth by the boys before the pelican dives into the water again for another round of fruitless labor. Though Ying-ying in her carefree childhood simply watches the scene for fun, from her subsequent experience of being lost after dropping into the water and never 
finding herself, a fate similar to the pelican, we might infer the metaphorical meanings imbedded in the above bird imagery. Like the pelican that is confined either in a cage, or within the reachable range of the rope, women are expected to stay at home serving male needs. The ring around the bird's neck performs a similar function as various kinds of institutional constraints that deny women's right to enjoy their productive outcomes.

Another similarity between Amy Tan and Chen Ran is that they both choose the imagery of black birds to insinuate the tragic life as well as the subversive power of their female characters. In Tan's The Bonesetter's Daughter, when LuLing's real mother, whose identity remains disguised as Precious Auntie, commits suicide in despair for her inability to change the disposable fate of both her daughter and herself, her deserted body attracts a large cloud of black birds that nearly block out the sun with their big wings like umbrellas ( $B S D$ 337). Believing the birds as the spirit of Precious Auntie and her army of ghosts ready to take revenge, the Old Cook who was told to drop the body is terrified and returns to perform a proper burial while the birds stay above him watching (ibid.). Like the black-winged bird that keeps on flying without the wings, the large gathering of black birds after the death of Precious Auntie symbolizes women's tenacious spirit and eruptive power against male control.

If the imagery of the pelican and black birds in Tan's novels carry an 
ill-omened message about women's sufferings, the imagery of singing magpies suggests women's self-contented illusion that conceals their subordinated status. In the story "Magpie" from The Joy Luck Club, the narrator An-mei Hu remembers a story her mother told before leaving her to be the third concubine of a rich man. In the story in which An-mei's mother was still a little girl, she was instructed by Popo ${ }^{129}$ not to shout, "or run, or sit on the ground to catch crickets" (JLC 217); she was not supposed to cry even if disappointed and must remain silent in any case. Otherwise, as threatened by Popo, she would be sent to live in a nunnery with her hair cut off. That night, the girl cried sadly by the pond when she saw a turtle swimming over, eating her drops of tears one by one as soon as they touched the water. Then the turtle began to talk about the uselessness of crying, and poured out from its beak seven pearly eggs, from which emerged seven magpies singing in pretty voices and "drinking greedily". But when the girl tried to capture the "birds of joy," "they all rose up, beat their black wings in [her] face, and flew up into the air, laughing" (ibid.). Here, the turtle could be seen as the personification of women like Popo and An-mei's mother as she turns out to be, who have been taught to "swallow [their] own tears" and cover their deepest sorrows by transforming into magpies in pretentious happiness.

The imagery of magpies as a metaphor for women's self-denial and spiritual paralysis tallies with the image of "painted bird" discussed by Mary

${ }^{129}$ Popo is the transliteration of "grandma," here referring to Au-mei's grandma. 
Daly. In Gyn/Ecology, Daly reverses Jerzy Kosinski's ${ }^{130}$ tale of the "painted bird" whose glittering painted feathers incur jealousy from natural-looking birds that cause its final destruction. According to Daly, as a symbolic projection of women, the wild birds suffer much more than the feminized painted birds. Standing for those women who submit their identities to male appropriation in order to enjoy the empty glory granted by their male masters, the painted birds function "in the anti-process of double-crossing her sisters, polluting them with poisonous paint" (334, qtd. in Tong 105). ${ }^{131}$ In comparison, the wild birds represent those courageous women who insist on pursuing their true selves, peeling "patriarchal paint off their minds and bodies" (ibid.).

If An-mei's mother serves as an example of "painted bird" domesticated and numbed by her mother's story in a self-deceiving way, An-mei already suffers an unspeakable uneasiness as a natural bird. As her mother finishes the tale, An-mei begins to cry; for deep in her heart, she knows that both she and her mother live "like two turtles seeing the watery world together from the bottom of the little pond" (JLC 217). It is her mother's suicide that teaches An-mei to cry out her desires as a wild bird. Just like An-mei's mother who imparts to the daughter a stronger spirit by killing her own weak one, An-mei tries to save her daughter Rose from living a self-negating life. To awaken

\footnotetext{
${ }^{130}$ Jerzy Kosinski (1933-1991) is a Polish-American novelist best known for his award-winning novels The Painted Bird (1965), Steps (1968) and Being There (1971).

131 The quotation is selected from Tong's Feminist Thought: A Comprehensive Introduction published in 1989. The other book of Tong published in 2009 has a similar name as Feminist Thought: A More Comprehensive Introduction, but is much different in content and organization. Except otherwise specified in the footnote, all the rest quotations from Tong are based on the updated version of 2009.
} 
Rose from indecisiveness and reliance on the fairy tales created by men, An-mei advises Rose not to depend on the psychiatrist to solve her marriage problems:

You do not need a psychiatrist to do this. A psychiatrist does not want you to wake up. He tells you to dream some more, to find the pond and pour more tears into it. And really, he is just another bird drinking from your misery. (241)

The imagery of sorrow-free birds that keep on singing joyful songs implies the strong forces of those men and women, who either endeavor to cover up the pervasive phenomenon of male suppression, or turn a blind eye to it by accentuating female fulfillment. Therefore, An-mei is rather heartened by the news about the "Great Sparrow Campaign"132 in New China during late 1950s that killed millions of sparrows. Subverting traditional critique of the campaign, An-mei takes it as a symbol of women's self-definition. With the death of those singing birds as an embodiment of women's awakening to their subjugated fate, women "no longer have to swallow their own tears or suffer the taunts of magpies" (ibid.).

Although the birds are mostly portrayed by the two writers to suggest women's doomed fate in a world dominated by unchallengeable patriarchal power, there are also instances of bird imageries that carry a positive meaning of women's dream for freedom and equality. The chapter "Scissors and

132 "The Great Sparrow Campaign," also know as "Four Pests Campaign," (to kill flies, mosquitoes, rats and sparrows) was initiated by Chairman Mao as a prelude to the zealous, nationwide movement of the "Great Leap Forward" from 1958 to 1962. As instructed by Chairman Mao for the reason that sparrows would harm agriculture by eating grain seeds, all the peasants in China were mobilized to make loud noises to frighten away the sparrows, destroy their nests and kill the nestlings. Although the government later realized that sparrows did more good than harm and therefore put an end to the killing in 1960, the campaign had already caused fatal consequences to the eco-environment, resulting in severe plague of locusts and Three Years of Natural Disasters (1959-1961). 
Seduction" of Chen Ran's A Private Life begins with the following epigraph:

The pair of scissors dominating the dressing table, like a bird perched on the topmost branch of a magnolia, had long been waiting their moment. After deciding what to do and how to do it, they flew into my head and borrowed my hands to complete their work. (29)

The chapter is about Niuniu's audacious action to cut her father's trousers in order to release her subconscious patricidal drive. Here, Chen Ran applies a simile to compare the scissors with a bird that has been biting its time to implement the plan. Perching "on the topmost branch" of a magnolia tree, which stands for fortitude and nobility in the Chinese culture, ${ }^{133}$ the bird signifies women's courage and lofty ideals to subvert the phallocentric authority for self-liberation. On the other hand, the imaginary bird in the form of the scissors may indicate women's predicament to extricate themselves from male tyranny. Because contrary to conventional way of expression, it is not Niuniu's hands that take up the scissors, but the scissors of the bird spirit that "flew into" Niuniu's head and "borrowed" her hands to take revenge.

While the bird-incarnated scissors in Chen's novel represent women's innermost aspiration for spiritual freedom, the fable of a duck-turned swan in Tan's The Joy Luck Club is the epitome of the dream of immigrant women to

\footnotetext{
133 It is interesting to note that the Chinese equivalent to the word "magnolia" is pronounced as Mulan, the heroine of a Chinese ancient poem The Ballad of Mulan (mulan ci) first recorded in the $6^{\text {th }}$ century before the Tang Dynasty. The ballad describes the story of Hua Mulan, who masqueraded as a man in order to get enlisted in the army on behalf of her infirm father and fought bravely on the battlefield, winning glories and respect from her male peers. Enjoying great popularity among Chinese, the story serves as a moralizing example for filial piety. Viewing from feminist perspectives, however, Chen's reference to magnolia might be interpreted as a demonstration of her belief in women's hidden power that casts men in the shade. Mulan's masquerading experience similar in effect to Butler's view on a troubled gender might also be a footnote to Chen Ran's notion for "gender-transcendent consciousness" which would be discussed in the next chapter.
} 
walk out of their past shadows into a new life of confidence and independence. The imagery of the swan symbolizes unswerving, heterosexual love in traditional Chinese culture. By taking it as a reference to mother-daughter relationships across cultural and generational gaps, Tan actually subverts the patriarchal narratives of heterosexual normativity by tracing a matrilineal origin as a source of women's empowerment. The swan that the old woman brings to America across the vast ocean alludes to the Joy Luck mothers' inheritance from their mothers' painful past and their wish to pass down to their daughters a life that knows no sufferings and female subordination. Just as the swan's fate is sealed when she is brutally seized by the immigration officials, the woman finds herself disconnected from both her foregone Chinese past and her Americanized daughters. Nevertheless, the woman is still hopeful to rebuild the link. Clutching the only feather at hand that signifies a matrilineal link bonding women together, she plunges headfirst into a brave new world, waiting for the day to tell the story of the single swan feather to her daughter in perfect American English, "This feather may look worthless, but it comes from afar and carries with it all my good intentions" (JLC 17).

Through imageries of dreams, illusions, the mirror and the bird, both Chen Ran and Amy Tan present us, from metaphorical perspectives, their converging concerns on the deprivation and reconstruction of women's identities. However, as the above analysis demonstrates, among the marked 
stylistic similarities based on the same feminist concerns about women's identity-construction, the two writers also differ from each other in their treatment of the same imagery, which might be accounted for by their respective writing strategies framed in different socio-cultural contexts, a subject of investigation for the last chapter. 


\section{CHAPTER VI}

\section{WRITING STRATEGIES OF CHEN RAN AND AMY TAN}

Following a textual comparison of Chen Ran and Amy Tan from thematic and metaphorical perspectives, this chapter would focus on the two writers' distinctive writing strategies as conditioned by their respective cultural environment. The author aims to prove that the divergent strategies that characterize the fictions of Chen Ran and Amy Tan both belong to personal narratives and are driven by the same pursuit of reconstructing identities that transcend gender and cultural confinements.

\section{A. Chen Ran - Personalized Writing and Gender-Transcendent \\ Consciousness}

Chen Ran is generally considered a precursor of "personalized writing" that surfaced in the literary scene during the third peak of Chinese female literature in the $1990 \mathrm{~s}^{134}$ The notion of "personalized writing" (gerenhua xiezuo) first comes to the public attention in Xiao Gang's 1995 interview of Chen Ran entitled "Another Door Open" (ling yishan kaiqi de men), which is

\footnotetext{
${ }^{134}$ For a detailed discussion of the three peaks in Chinese female literature, please refer back to the first section of Chapter Three.
} 
included as the appendix of Chen's $A$ Private Life when the novel was published in 1996. While addressing Xiao's comment that female author's personalized writing is usually trivialized into a marginal space, yet it constitutes an enormous challenge to the readers' traditional aesthetical experience, Chen Ran shares her view of personalized writing from two perspectives. Firstly, human beings are composed of each and every individual; the uniqueness of one's personalized experiences is just the representation of the multiplicity of the entire human race. Therefore, the difference between one person and a hundred people is only a matter of quantity, not quality. Secondly, as a result of Chinese cultural traditions that regard individual persons as incomplete and insignificant, protagonists in mainstream literary works are usually filtered personas of commonality molded by the social discourse, who could hardly be distinguished from each other. Chen believes that only by returning to the distinctive living experiences of each individual can a writer produce works of most universal significance (Chen Ran and Xiao Gang 249-50). Deviating from the grand narratives of her predecessors whose characters and settings are more or less related with social realities and moral ideals, Chen Ran proceeds from the trivial details of her heroines' state of existence, both physically and mentally, in an attempt to restore authenticity to the life of a woman.

Though Chen's interpretation of her personalized writing style is mostly in 
the form of casual comments instead of systematic theorization, her obsession with self-conscious and psychological "dissection of the contemporary self" resonants in the hearts of both the reading public and major cultural critics at the time (Sieber 184). In "Chen Ran: Personalized and Female Writing" (Chen Ran: geren he nüxing de shuxie) carried in Contemporary Writer's Review (dangdai zuojia pinglun), Dai Jinhua, an influential Chinese feminist critic, makes the first theoretical attempt to account for Chen's personalized writing strategy. According to Dai, personalized writing refers to the writer's preoccupation with an individual state of life by describing the private experiences, spiritual contemplations, psychological complexities and sexual desires of a person who is deliberately detached from social realities and collective ideologies. As a subversive strategy, it aims to articulate the unspoken stories of women hidden behind the dominant discourse of patriarchal collectivism: "Against the socio-cultural environment of the time, individualized or personalized writing is indicative of a reticent rebellion against concentrically-ringed social constructivism" (48). In this sense, Chen's amoralized stories "not only extend the wings of freedom for emancipation of individuality, but also are considered as a kind of subversion, or at least shaking of the dominant discourse of moralization" (ibid.).

Another Chinese critic Tao Dongfeng proposes a more comprehensive 
characterization of personalized writing. ${ }^{135}$ According to Tao, the concept of personalized writing could be understood from the following four perspectives. Firstly, in terms of its content, instead of touching upon the public experience or collective ideology, the authors of personalized writing only write about their private experiences, both conscious and unconscious, especially those restrained, repelled and concealed by the public morality and universal ethics in a socialist society, experiences that are generally classified into "abnormality" and the "dark" side of oneself, such as same-sex love, the protagonist's patricide or Electra complex, Oedipus complex and narcissism, etc. Secondly, from the perspective of the writing style, most personalized writings share similar features of "neo-memoirs" (xin huiyi lu) or "neo-biographical narratives" (xin zhuanji shi xushu). Different from traditional memoirs and biographical writings in the Chinese scene, which always point to the realization of one's revolutionary ideals, this new form of narratives are characterized by fragmented descriptions of one's private life experiences and free-flowing stream of consciousness beyond logical delineation. Thirdly, as for the role of the author, s/he is no longer a capitalized "I" as a surrogate for the group or the general public, but an individualized "i" in the small letter, expressing only personal experiences and private perceptions of the surrounding world. Fourthly, the motivation of personalized writing has little to

\footnotetext{
135 In the article, Tao uses the term "privatized writing" (sirenhua xiezuo), which, as he states in the first sentence, is also termed as "personalized writing" and "privatized fiction" (si xiaoshuo). To keep consistence in terminology, this dissertation adopts the notion of "personalized writing."
} 
do with social enhancement or national rejuvenation, but is driven by the author's psychological thirst to narrate his/her inner desires that have been left as a virgin land by the public narratives (Tao Dengfeng 172-73).

According to Tao's four-point characterization, Chen Ran's fiction could be regarded as a typical representation of personalized writing. Her infatuation with women's repressed desires for patricide and sisterhood, her thematic explorations of the protagonists' growing experiences narrated in a "neo-biographical" manner, and her stylistic experimentations on metaphorical imageries to assert women's spiritual and sexual identities are all encompassed under the author's strategy of personalized writing. Though the current author agrees with Tao's first two points on the content and the narrative style of personalized writing, his last two points seem to downplay the power of the personal. For a woman writer like Chen Ran, the underlying reason behind her personalized writing is far more significant than narrating her private life experiences; it is to capture the universal human nature and the dilemma everyone faces in modernity by presenting a true-to-life picture of an intensely real person. Such motivation has been explained by Chen Ran on several occasions, ${ }^{136}$ and also through Niuniu's words at the end of A Private Life. Coming back home from the psychiatric hospital, Niuniu is leafing through the notes she had taken before her mental breakdown. The detailed notes as a

${ }^{136}$ Besides in interviews like the above-mentioned one with Xiao Gang, Chen Ran responds to some critics" narrow understanding of personalized writing in several of her prose articles, such as "My Personalization" (wode geren hua) and 'Personalization and Myself' (geren hua yu wo ziji), both included in Chen's prose collection Flashback in Time (shiguang daoliu) 
record of her private life call on her to write down her "personal history" with all her "individual peculiarities," from which she could assume her place "as one of the many unique entities that make up the multiplicity of humankind" ( $A$ Private Life 196). Contemplating on the interconnection among human beings, Chen Ran expresses her understanding of personalization through Niuniu's thoughts:

Though every person is alone, a single isolated entity, with a history that is different from everyone else's, she cannot live without connection to her fellow human beings. She has no choice but to share in the joys and sorrows of the people of her time.

So although she is a unique entity, she is also a representative facet of what it is to be human. (A Private Life 196)

It is quite clear that although Chen Ran's personalized writing takes on the form of private discourse, it actually transcends personal restriction and aims to touch upon the core components of what it means to be a human. Approaching from such perspectives, we may understand an important feature of Chen's personalized writing, namely, the implication of the writer's humanistic concerns of one's existentialist anxieties in a modern society. In Chen's novella "Nowhere to Bid Farewell," the writer expresses her deep worries about the impassiveness and alienation of a modern person through Miss Dai Er's eyes:

The crowd floated like indifferent wind. [...] Wherever it was, she felt like a lonely tree deserted at the bank of the stream of people. [...] Each face was a citadel. Trapped within countless citadels, she felt tired, dolorous and freezing, like a big fool. (my translation, "Nowhere" 102)

Feeling threatened to be deprived of her remaining vitality and turned into one 
of the numb crowd, Miss Dai Er keeps on escaping from people around her and retreats to her private world where she could be sure of her real existence. However, as the title of the novella suggests, no matter where she hides herself, the attempt of Miss Dai Er is doomed to failure, since there is simply no escape and "nowhere to bid farewell."

Apart from unsettling anxiousness about the solitude in the modern society, which is "a perennial dilemma all have to face" ("Nowhere" 113), Chen Ran also expresses in her writings great anxiety about one's meaningless existence in an ice-cold world that is dominated by advanced technology. While looking at the crisscrossing electrical wires above the city street like an inescapable web wrapping a steel fortress, Miss Dai Er imagines in her mind what might happen to a suicide who jumps off a building: She might be counteracted by the web and then falls on the ground without much harm done. "Twisting her body for a while, she would then struggle up and walk away like a loser" (125). In black humor, Chen voices her deep concern about one's fate in a modern society. With the assistance of high technology, human beings have gradually lost control of their own lives, even the right to die. Just like the suicide, who has to "walk away like a loser," modern people would have to drag on their meaningless life without any dignity at all. Chen's doubt about the meaning of existence is similar to Sartre's existentialist idea that "existence precedes essence." As a result of totalitarian aggression and sanguinary world 
wars that shattered people's firm belief in God coupled with the alienation and estrangement in the modern society, people are forced to retreat to their own world void of moral guidance and spiritual support. With nothing to trust except their own state of existence, human beings are condemned to make free choices and would have to "bear the overwhelming burden of total responsibility" (Fiero 6: 70).

The existentialist concerns in Chen's personalized writing are closely related to China's social environment of the 1990s that shared much similarity with the Western cultural settings after World War II when existentialism gained popularity. China experienced rapid socio-economic development during the 1990s, a decade after the adoption of the Reform and Opening-up Policy. However, along with blossoming marketization and consumerism, there emerged problems of bureaucratic corruption, increasing laid-off workers, incoming liberalistic shock from the west and the unknown future of China's political reform after the disintegration of former socialist countries in late 1980s. Consequently, though Chinese people were granted greater individual freedom, they lost their sense of direction and certainty about the future, a state of existence that has been acutely captured in Chen Ran's fiction. By deploying the strategy of personalized writing, Chen Ran is trying to provide a solution to the modern predicament. The protagonist is singled out both as a representative of the suffering crowd in aimless wandering, and as a living 
example of the human struggle to reclaim their lost selves by piecing together the shining moments of their concrete existence.

The second feature of Chen Ran's personalized writing, as perceived by the current author, is her prioritization of women's sexual desires and bodily potential as a means of women's identity construction. The protagonist of Chen's fictions is always a young female intellectual, arguably a literary reflection of the author herself, who lives an aloof and secluded urban life. Shutting herself in a room of her own, the heroine indulges in her wildest fantasies and self-exploration in the private sphere of a woman's body that has long been denied means of expression by collective and patriarchal narratives. The body consciousness has taken an important role in Chen's female characters ever since their childhood. From Xiao Meng's careful study of her budding body through a mirror and Niuniu's daily talk with her arms and legs, which she names as "Misses Don't" and "Misses Do," the girls have begun to assert their self-identity by waking their bodies from a deep slumber, taking control of their bodily power from the very beginning. When the girls grow up into adulthood, they take a bold step forward to challenge the patriarchal repression of the female body by admiring their bodily beauty and bringing it to its full potentials.

In rhetorical and ornamental language unprecedented in Chinese female literature, Chen Ran passionately sings her ode to the female body, especially 
woman's breasts from which pour out life-giving springs. The imageries of firm, round breasts embody the writer's proud proclamation of woman's distinctive identities. In Chen Ran's fictions, the breasts are compared to the "homeland" and a place to return to ("Toast" 49,54 ), to "plump sunflowers" (A Private Life 145), and to "plump, firm apple[s] bursting with juice" (A Private Life 149). ${ }^{137}$ More elaborated description could be found in "The Sound of Another Ear Knocking," shining under a spotlight of sunbeam that projects through a chink in the window, Dai Er's firm breasts are like "two blooming pink flowers with full-blown pistils, crimson as claret and hanging down as agates" (my translation, "Sound" 119). The heroine's narcissistic love of her mature body as a means to assert woman's unique identity is best manifested in A Private Life. By the time Niuniu graduates from high school, she suddenly realizes the great changes that have been undergoing within her body:

My breasts, now round and soft, were like two peaches stuffed into the top of my pajamas. My groin had suddenly become broad and flat like a field that seemed big enough to grow lush and fragrant wheat. My buttocks now boldly asserted themselves, full, round, and heavy, curving out from my waist so that I couldn't lie flat on the bed anymore, and my thighs were long, firm, and lithe, like a pair of exclamation marks (A Private Life 91).

Here, the female body seems to come alive, being worshiped as the fountain of women's long suppressed power, a volcano waiting to erupt to subvert the collective discourse that has denaturalized and masculinized women's bodies.

\footnotetext{
${ }^{137}$ Similar comparison could also be found in Chen's story "The Silent Left Breast," in which the breasts of the narrator are like "two red apples that popped out from behind a thin fruit tree" when the heroine seduces an inexperienced male hairdresser into sex (my translation, "The Silent Left Breast" 210).
} 
As Chinese feminist critic Li Xiaojiang points out, the Maoist subject of woman has no body. Reckoned by the state to hold up half the sky like her male counterparts, a Chinese woman could not affirm her difference from man; her ideologically constructed body "did not menstruate, give birth, feel sexual desire, or seek out pleasure" (Barlow, Question of Women 275). Therefore, the poetic comparison of Niuniu's breasts and groin to ripe fruits and harvesting field, and a proud exclamation of her protruding buttocks and charming thighs in Chen Ran's text are revolutionary in Chinese female literature. Fully confident of a women's bodily potential, Chen Ran attempts to reinstate women's control of their lives through a private discourse of the female body.

Chen Ran's personalized writing is reflected not only in the heroines' discovery and celebration of their bodily power, but also in their conscious exploration of such power through female autoeroticism. The notion of autoeroticism is put forward by Irigaray as a powerful strategy to subvert the male-defined sameness of female sexuality. It argues that a woman is not "pleasure-giving" to men but "self-embracing" with multiple possibilities in her sexuality (Irigaray, This Sex 24). In Chen's novella "Nowhere to Bid Farewell," when Miss Dai Er is "truly by herself," she "couldn't help reaching for her breasts, which she embraces tightly as if reviving an old dream, or savoring a lasting taste" (my translation, 77). In the last scene of A Private Life, Niuniu achieves sexual ecstasy while caressing her body in the bathtub with her two 
dearest lovers - Widow Ho and Yin Nan in mind. The exquisite language the writer deploys in the following quotation enters into a mysterious realm of female sexuality that arouses and blends different sensory experiences from the unique perspectives of a woman:

When my fingers caressed my round, full breasts, in my mind they had already become Ho's fingers, her exquisitely slender fingers, touching my skin, those two spheres soft as swan's down ... fingers like pure white feathers floating, dancing, turning ... the fragrant delight of rose petals ... rich red cherries swollen till they burst ... the thick fragrance of maple leaves in autumn brushing your lips, entwining your neck ... my breath quickened, the blood in my veins caught fire. (A Private Life 208)

While turning to women's subjective experience exclusively belonging to themselves, one cannot avoid mentioning the uniqueness of the female body and the multiple possibilities that could be released from within. According to Cixous, the only way to escape the overpowering patriarchal discourse is to write the body. Since our sexuality is inextricably linked with the symbolic language system, the writing about the female body is a means to flee reality, "to escape hierarchical bonds and thereby come closer to what Cixous terms as joissance, which can be defined as a virtually metaphysical fulfillment of desire that goes far beyond satisfaction" (Gilbert xvii). In her influential work "Laugh of the Medusa" (1975), Cixous calls upon women to love their body and write about it with pride and passion: "Write your self. Your body must be heard. Only then will the immense resources of the unconscious spring forth" (880). Body writing, in Cixous' eyes, is a weapon to overthrow the phallocentric 
tradition by inventing a new language for women: "[S]he throws her trembling body forward; she lets go of herself, she flies; all of her passes into her voice, and it's with her body that she vitally supports the 'logic' of her speech. Her flesh speaks true" (881). By writing about the body as a signifying tool of her thinking, a woman revives her own stories in a private space not yet confiscated by the symbolic system established by man.

Coincidentally, the state of flying is also referred to by Chen Ran. In an essay entitled "As If 'Flying'," Chen summarizes human being's "flying" experiences in life through the following four means:

1. Physiological instinct: sex;

2. Psychological experience: emotional climax (spiritual power not driven by the sex instinct, such as the feeling of being attracted by noble personality, wisdom and aesthetic appreciation);

3. Passive means: drug or strong alcoholic drinks;

4. Positive means: artistic creation. (my translation, Flashback 41) Among the four forms of "flying," the last one of artistic creation, in Chen Ran's mind, combines both passion and calmness and grants her the highest level of gratification. Therefore, although Chen Ran adopts a similar strategy of body writing advocated by Cixous, her description of a woman's body and sexuality is always tinged with an aesthetic color. The imageries of "swan's down," dancing feathers that are "pure white," "rich red cherries swollen till they burst" and "thick fragrance of maple leaves" in the above excerpt lead the readers into an idyllic world with unique female experience.

The aesthetic depiction of the female body as a means for woman's 
self-awakening constitutes an essential component of Chen's personalized

writing. It is also unprecedented in the literary tradition of Chinese women writers. But compared with French feminists' bold experiments with body writing in order to subvert the phallocentric discourse system, Chen Ran's personalized writing about the female body is much more reserved in nature. To account for such difference, the author attempts to propose the following three reasons from socio-cultural perspectives.

Firstly, Chinese and the Western world have different value orientations concerning the concept of body and sex. As a result of improved methods of contraception and "the activity of the media (especially TV and film) in broadcasting sexually explicit entertainment (Fiero 6: 117), the Western world experienced "increasing sexual permissiveness" since the 1960s. In comparison, sex and erotic desires have always been considered as a social taboo in the Chinese culture. For example, in Zhang Jie's famous story "Love Must Not Be Forgotten," which is hailed for its detailed depiction of a woman's passion for love, the first of its kind in contemporary Chinese female literature, ${ }^{138}$ the expression of desire is still confined within the spiritual realm. Cherishing her deep love through a diary secretly kept till her last days, the heroine has not even touched the hand of her lover, a married man who suffers from the same struggle between spiritual love and family responsibility. It

\footnotetext{
138 Among women writers of the 1980 s, Zhang Jie is the first to depart from the national construction of women's personal experiences. As Wang Lingzhen comments, Zhang's story "Love Must Not Be Forgotten" separats love from the dominant social ideologies and has voiced "the necessity to find a new language to explore personal experiences of love after a period of tight social and political control" (163)
} 
should be admitted that Chinese people have enjoyed greater freedom in love and sex since the 1990s under the influence of China's market economic reform and continuing influx of Western liberalist ideas. However, it was not until the turn of the 21st century that unrestrained descriptions of body and sex appeared in the works of so called "Beauty Writers" (meinü zuojia) born in the 1970s. For Chen Ran, who spent her childhood during the Cultural Revolution, a "sexless" period brutally constraining people's sexual desires, it is not difficult to understand why her personalized body discourse carries an aesthetic note while aiming at awakening women to their sexual identity.

Secondly, in terms of the history of the feminist movement, China and the West underwent totally different paths of evolution. Western feminism originates from women's suffrage movement to fight for equal rights not only in political life, but also in education, work and family. Through three waves of the feminist movement interwoven with flourishing literary theories, Western feminists gradually realize the power of discourse to overhaul the patriarchal symbolic order. The proposal of postmodern feminists to write about the multiplicity of the female body represents one of such revolutionary strategies to reclaim the uncultivated territory lost in patriarchal signification. Only by creating a female language can women be truly released from the suppressed fate and acquire equal status with men. Compared with the Western feminist movement, which is more radical and complete in nature, China does not have 
feminist movements in a real sense. The awakening of women's awareness is only a byproduct of May 4th Movement striving for cultural rejuvenation. When People's Republic of China was founded in 1949, women were granted equal rights in voting and education through government legislation from the very beginning. In both "The Common Program of the Chinese People's Political Consultative Conference" (adopted on Sep. 29, 1949) and "Constitution of People's Republic of China" (promulgated on Sep. 20,1954), it is clearly stated that Chinese women enjoy equal rights with men in all spheres of life. ${ }^{139}$ Women's equality with men has been an integral part of all the ensuring laws and regulations, including "The Marriage Law" (1950) and "The Law on the Protection of Rights and Interests of Women" (1992). Therefore, it has never been a major concern for Chinese women writers to radically overthrow the national discourse on women. Against such background, it could be argued that Chen Ran's personalized discourse of desire is more driven by the writer's clear female consciousness and aesthetic pursuit of a woman's sublimation and self-realization.

Thirdly, with growing commercialism, consumerism and hedonism in China's modern society, the Western strategy of body writing, if radically applied, could easily be utilized to satisfy the sensual and voyeuristic desire of male readers, placing woman once again within the control range of man.

\footnotetext{
139 Please refer to Article 6 and Article 32 of "The Common Program of the Chincse Pcople's Political Consultative Conference" and Article 48 of "Constitution of People's Republic of China".
} 
Actually, the works of "Beauty Writers" like Wei Hui, Mian Mian and Muzi Mei, which caused great sensation and controversy in the Chinese society a decade ago, ${ }^{140}$ are characterized by blunt descriptions of promiscuous behaviors, body exposure and degenerated scenes of alcoholic and drug addiction. For these writers, the female body has nothing to do with a woman's spiritual pursuit. Rather, it is degraded into a meaningless object of self-consumption. Unlike heroines in Chen Ran's fictions who are always searching for spiritual love that transcends a woman's bodily desires, in the semi-autobiographical narratives of these "Beauty Writers," female protagonists lead a lascivious and schizophrenic lifestyle, drowning their remaining sense of selves in narcotics and dancing parties. As Dai Jinhua clearly states, the "audacious autobiographical writings" by women can be "arrestingly dangerous" if they are packaged and rewritten through powerful commercial operation. Body writing, when defined by commercial requirement and the voyeuristic perspectives of the male, could be internalized unconsciously into these women writers if they are not "vigilant and sober-minded enough." The prosperity of female personalized writing might have an exactly opposite effect of "entrapping women back into the snare of patriarchal culture" (my translation, Through a Looking Glass 204). Therefore,

\footnotetext{
${ }^{140}$ The semi-autobiographical work of Wei Hui's Shanghai Baby (shanghai baobei) aroused great public sensation since its publication in September, 1999. But only six months later, the novel was banned nationwide for its outright depiction of female masturbation, lesbianism and drug addiction. Mian Mian's representative novel Sugar (tang) was also banned four months after its publication in 2000. Though Muzi Mei adopts another path of blog writing, she is notoriously denunciated for her licentious lifestyle.
} 
Chen Ran's aestheticization of her body writing is both a literary breakthrough and a rational choice that complies with the socio-cultural realities of contemporary China. For Chen Ran, an exploration into the female body with its beauty and repressed desires is a necessary means for a woman to seek her lost identity. But the ultimate goal of such attempts is not to replace a phallocentric discourse of desire with a feminine one, but to deconstruct and harmonize the binary oppositions between man and woman in order to promote the "gender-transcendent consciousness."

The notion of "gender-transcendent consciousness" was first proposed by Chen Ran during her stay in Britain in $1994 .^{141}$ In her lecture notes entitled "Gender-Transcendent Consciousness and My Creative Writing", Chen writes: When love is gradually separated from the primal purpose of reproduction and detached from the relationship of economic and material dependence; when love is simply for love's sake and is as pure as an art not diluted with any purpose other than love, the history dominated by conventional "love" is over. [...] The hegemony of heterosexuality will eventually corrupt, and from its ruins would arise the gender-transcendent consciousness. (my translation, 102)

Sharing Virginia Woolf's vision of androgyny, ${ }^{142}$ Chen continues to write that a writer should not base his or her position from the perspective of a single gender. Only when the male and female powers in one's mind are

\footnotetext{
${ }^{141}$ Chen Ran delivered the lecture on several occasions, including the Oxford University, London University, the University of Edinburgh and Great Britain-China Center. Her lecture note entitled "Gender-Transcendent Consciousness and My Creative Writing" was first published in the $6^{\text {th }}$ issue of Zhongshan Magazine in 1994. The citation is translated into English by the current author.

${ }^{142}$ In $A$ Room of One's Own, Woolf ponders on Coleridge's saying that "a great mind is androgynous" and believes that the "normal and comfortable state of being" is achieved when the two parts of one's mind representing male and female powers "live in harmony together, spiritually co-operating" (Woolf 98). For historical tracing of the notion of androgyny and critical discussions, please refer to Carolyn Heilbrun's Toward $a$ Recognition of Androgyny and Nancy Topping Bazin's Virginia Woolf and the Androgynous Vision.
} 
harmoniously combined into one, can a writer attain absolute clarity and purity in the expression of one's thoughts and feelings (103).

According to the current author, Chen Ran's "gender-transcendent consciousness" might be interpreted from three perspectives. First of all, it reflects Chen's enhanced awareness for women's self-identity, which could only be realized by dismantling essentialist gender prescriptions. In "Breaking Open," a fiction laden with assertive feminist remarks, Chen Ran elaborates on her ideas through the words of Yun Nan:

We must say that becoming indifferent to [gender] ${ }^{143}$ difference is an advance in the culture of humankind. We are first of all persons, and only secondarily women. Some men always draw attention to our sexual difference, while they feign a deep respect; actually, behind this façade, they hide sinister intentions, namely to shelve, to lay aside, and to neglect us women, to leave us out in the cold, to not get to know us - it is a carefully disguised sexual hostility. [...] In future generations, the greatest war will arise because of the divide between the sexes. ("Breaking Open" 52)

Here, it is sharply pointed out that people's emphasis on gender difference is actually perpetuating the patriarchal hierarchy in which women are deemed inferior even if they seem to receive "deep respect." The speaker Yun Nan, or the literary projection of Chen Ran, has seen through the "sinister intentions" of men and locates the "disguised sexual hostility" as the underlying reason for cultural encouragement of gender difference. In Chen Ran's writings, the dissolution of gender confrontation has been upgraded into a sign of cultural

\footnotetext{
143 The original translation by Paola Zamperini is "sexual difference." But according to the context, it seems the speaker is referring to one's gender as a result of social construction. To avoid confusion, the diction is changed to "gender difference" by the current author.
} 
advancement and a crucial step forward to avoid "the greatest war" in future generations. By abandoning the patriarchal signification of the female gender, women awakened to their true selves are saying a loud no to playing their expected feminine roles. With clear self-consciousness, they embark on their own path of identity-construction that cannot be defined in gender terms. As the narrator explains, the women's association she and Yun Nan prepare to establish with the name of "Breaking Open" aims to strive for real equality between men and women, for gender-transcendent consciousness and for shattering "the long-standing, well-established, and exclusively male rules and standards that pervade life, culture, and art" ("Breaking Open" 55). Therefore, Chen Ran's advocacy of "gender-transcendent consciousness" embodies the writer's liberal ideals for women to walk out of gender stereotype and discrimination and boldly pursue their unique identities.

Secondly, like the existentialist concerns exhibited in Chen Ran's personalized writing, her "gender-transcendent consciousness" implies a similar ontological quest for one's meaning of life. From the examples cited in the first section of this chapter on the indifferent crowds and desperate suicide, we can find existential angst of a modrn persona that is not exclusively from male or female perspective. While calling for the need to transcend gender difference, Chen Ran attempts to draw people's attention to the commonality between the two genders, which serves as a ground for genuine social 
harmony. However, It shoud be admitted that although Chen Ran claims her writing as transcending genders, she mainly proceeds from the writer's introspective experience as a woman and emphasizes a woman's unique experience of the body and the mind as a representation of human universality.

Thirdly, it could be argued that the notion of "gender-transcendent consciousness" provides Chen Ran a theoretical basis as well as protective shell for her adventurous depiction of sisterhood with its erotic implications. Since true love derives from genuine appreciation and mutual understanding that transcend gender boundaries, the compulsory heterosexuality sustained in the patriarchal order is on a shaky ground. While explaining women's innate affinity towards each other, Chen Ran writes: "Sometimes, it's easier for those of the same sex to reach understanding and tacit agreement. It is natural and follows one's nature, just like the way water understands the fish, and what air means to mankind" (my translation, "My Creative Writing" 101). However, such precious bond among women has been severed and denunciated. In a society that deems heteronormativity as the only yardstick to measure a person against, it takes great courage for a woman to develop the full human potential by restoring the female link with another woman. In "Breaking Open," the narrator Dai Er, another voice of Chen Ren, recalls in a long paragraph the gradual change in her mind to "break open" the heterosexual gender normality. Having been waiting in vain for her Mr. Right for thirty years, Dai Er finally 
discards "the gender specification," realizing that "the concept that a woman can or must only wait for a man is an age-old but coercive custom," an antagonistic world order which leaves a woman no other choice but to choose a man in order to be "normal" as a member of the "majority" (55). In the text that follows, Dai Er expressively voices her determination to rebel against the deep-rooted heteronormativity:

I am willing to disregard a person's gender identity in favor of their personal qualities. I do not care anymore about the difference between male and female, and I do not care about being part of a "minority" either; I do not even see it as "abnormal." I feel that an affinity between two people does not only appear between a man and a woman but that it is indeed also a kind of latent vital energy that has long been neglected among us women. (ibid.)

Based on the "gender-transcendent consciousness", one implication of the revolt against compulsory heterosexuality is the affirmation of sisterhood, which, in Chen Ran's fiction, is represented by various forms of close ties among women: the interdependence between Niuniu and Widow Ho in $A$ Private Life, the inseparability between the "woman in purple" and the "woman in black" in "The Birth of a Hollow Man," the secret longing that draws Dai Er closer to her neighbor Yi Duoren in "The Sound of Another Ear Knocking," and the assertive alliance between the narrator and Yun Nan in "Breaking Open," to name just a few. In another story "Nowhere to Bid Farewell," Chen Ran depicts the interdependent emotional bond between the heroine Miss $\mathrm{Dai} \mathrm{Er}$ and her best female friend Liao Yi. Dai Er and Liao Yi always miss each other in desperation if they couldn't meet for a single week. They have also sworn 
not to get married. They share with each other their past experience, dreams and the painful pursuit of love, "their soul gradually permeated by an ancient call" (my translation, 93).

The mentioning of the "ancient call" in the above citation shares some similarity with postmodern feminists' return to the pre-oedipal female bond as a means to reclaim women's lost voice in a symbolic system that has already been branded with the patriarchal stamp. Such a voice from a pre-linguistic realm is characterized by the girl's love of the maternal body before she acquires gender consciousness and accepts her expected fate of subjugation to male love. A similar voice is uttered from Widow Ho, Niuniu's beloved neighbor in A Private Life, who, as Chen Ran acknowledges, is an incarnation of "an ideal woman with all the best qualities one could think of". ${ }^{144}$ Like Dai Er, who is drawn to Liao Yi by "an ancient call," Niuniu is also enchanted by the "soft and soothing" voice of Ho. On the morning before Niuniu takes the symbolic patricidal revenge on her father, she hears "the faint voice of a woman singing somewhere far away across the ruins of temples and crumbling walls." The voice carries "a kind of seductive sensuality that [is] both masculine and feminine in quality," or gender-free maternity ${ }^{145}$ (A Private Life 32). Gaining power from the ancient call as an adhesive bond of women,

\footnotetext{
144 The quotation is from an online interview of Chen Ran by sina.com. "Writer Chen Ran at Sina Online Chatting Room: A Live Record [ 作家陈染做客新浪访谈实录].” Sina Reading. 18 Sep. 2010 $<$ http://vip.book.sina.com.cn/book/ chapter_37551_18948.html >

${ }_{145}$ In the English version translated by Howard-Gibbon, the phrase is termed as "or feminine with masculine undertones." However, according to the current author, a more faithful translation of the original Chinese should be "or gender-free maternity."
} 
heroines in Chen Ran's fictions are no longer ambivalent about their road ahead. The same call reverberates in Irigaray's theory of tracing the genealogy of women. In Divine Women, Irigaray points out that women are imprisoned by the male imaginary, "buried alive in the culture" so as to "ensure the maintenance of patriarchy" (Whitford 159). According to Irigaray, the maternal genealogy and reciprocal woman-to-woman relationship serve as a mirror or ideal for women to regain their real subjectivity in the symbolic order. Sharing a similar strategy for women's identity reaffirmation, Chen Ran boldly probes into sisterhood in the sense of female same-sex love, a topic rarely touched by previous women writers and justified by Chen Ran in her proposal of "gender-transcendent consciousness."

The three dimensions of Chen Ran's "gender-transcendent consciousness" are best synthesized in Dai Er's three frequently-occurring dream scenes described in "Nowhere to Bid Farewell." In the first scene, Dai Er is trudging alone in a barren, inhospitable desert while her dress is constantly blown up by gusts of wind. Walking endlessly, she could never reach the destination. The second scene positions Dai Er in a dense mess of high-rise buildings. Chased by a large crowd, Dai Er keeps on running. But never could she shake off her pursuers who are ambushed everywhere, making surprise attacks on her from unexpected directions. In the third scene, there are always one or two dark-colored cats catching Dai Er's feet. The look 
in the cats' eyes is a mixture of wildness, morbidity and desperation. As the narrator summarizes, "the endless desert is an epitome of [Dai Er's] life; the crowded buildings symbolize the troublous arena of love, and the mournful cats imply the dangerous female friendship" (my translation, "Nowhere" 116). Chen Ran's "gender-transcendent consciousness" captures the exact three areas of the writer's underlying concerns, namely, the existentialist anxieties of each person trying to seek meaning out of the modern predicament, the invulnerable fate of woman trapped in inescapable dragnet of the male ideology and the potential risk of female same-sex love posed by socio-cultural pressures. According to Chen Ran, only by transcending gender can one retrieve the key to all these perennial problems.

To summarize, Chen Ran's personalized writing style and her "gender-transcendent consciousness" reflect her ontological quest for one's meaning of life in the modern society with existentialist dilemmas. By focusing on the authentic living experiences of individual personas, Chen attempts to deviate from the collective narrative tradition that has reigned in China's literary scene for decades. In the mean time, she is trying to explore a woman's repressed identity through aesthetic description of the female body and rediscovery of female autoerotic potentials. By advocating "gender-transcendent consciousness," Chen not only expresses her hope for an enhancement of women's identity awareness, but also provides a 
theoretical justification for her unconventional portrait of sisterhood.

\section{B. Amy Tan - Talk-Story and Matrilineal Reconstruction}

A marked feature of Amy Tan's novels is the talk-story narrative, through which different voices could be heard relating life stories across time and space. Talk-story is defined by Maxine Hong Kingston as "an oral tradition of history, mythology, genealogy, bedtime stories, and how-to stories that have been passed down through generations, an essential part of family and community life" (Medoff 257). The genre of talk-story favored by Asian American writers like Kingston and Amy Tan represents a deep desire among the diasporic immigrants to trace their cultural root by narrating their own stories in a shared language of oral nature beyond the reach of logocentric discourse. The talk-story narrative is closely related to the Chinese cultural tradition. According to Qing-yun Wu, China's storytelling tradition could be traced to Si Maqian's ${ }^{146}$ Historical Records (shi ji) that recounts more than two thousand years of Chinese history "in the form of biographical tales with fictive element" (Wu 86). The Complete Biographical Romance of Yue Fei (shuo yue quanzhuan), a famous historical novel of the Qing Dynasty, is also based on the oral story of Yue Fei (1103-1141), a patriotic hero and military general of

\footnotetext{
146 Si Maqian (145-89 B.C.) is the most pronounced Chinese historian during the Western Han Dynasty, famous for his compilation of Historical Records, China's first masterpiece of history that provides a comprehensive biographical record of dynastic empires from the Yellow Emperor (reigning from 2697-2597 B.C.) to Emperor Han Wudi (reigning from 141-87 B.C.).
} 
the late Song Dynasty. ${ }^{147}$ Besides, the legendary stories of Hua Mulan and Mu Guiying are cited by $\mathrm{Wu}$ as examples to prove a close relationship between fictional creations ${ }^{148}$ and "day-to-day storytelling" that incorporates warrior women into the "Chinese cultural tradition" (ibid.). As Elisabeth Croll observes, young daughters in Chinese "gentry and peasant households" were brought up on stories portraying warrior women "in wide open spaces combining male and female roles" (14, qtd. in Ho, Mother's House 147). Such stories were passed down either in the domestic settings by their grandmas, mothers and nannies, or on public stages embellished by itinerant storytellers. Enjoying the simple stories "told in rhythmic and popular language," the women audience project their own selves on the heroines "against the growing gender-specific social realities" (Ho 147).

Deeply rooted in traditional Chinese culture, the talk-story tradition "remains the most popular form of literary entertainment in the countryside" and has "a large audience in the cities" via radio or TV programs (85). While focusing on historical characters and germinal plots, talk-stories are never confined by the written text. The telling itself is both a process of construction and deconstruction of the original, depending on the idiosyncratic perspective of the storyteller. Such form of narrative strategy, therefore, "provides space in

\footnotetext{
${ }^{147}$ The story of Yue Fei, who fought bravely against the Jin intruders but was wrongly killed by a treacherous court official Qin Hui, has become an important source of material for Chinese folk storytellers (minjian shuoshu ren) since late Southern Song Dynasty (1127-1279).

${ }_{148}$ As introduced in Wu (85), the story of Hua Mulan is first recounted in "A Poem for Mulan" (mulan shi), a ballad of the Northern Dynasty (386-534). Mu Guiying, another patriotic heroine during late Northern Song Dynasty (960-1127), is a character from Generals of the Yang Clan (yang jia jiang), a popular novel of the Ming Dynasty (1368-1644).
} 
which Chinese women may tell their own stories, instead of being told how to think, write, or tell" (108). As a source of agency for Chinese American women writers, the talk-story narrative creates a new mode of discourse transgressing traditional Western narrative structure, giving validity to the voice of Chinese immigrants whose stories are never heard or passed down.

Growing up with her mother's stories, Amy Tan is a master in storytelling. As Tan recalls, stories and anecdotes become an important part of her family life ever since her childhood: "There was a lot of storytelling going on in our house: family stories, gossip, what happened to the people left behind in China. The gossip about people's character that went around as my aunt and my mother shelled peas on the dining table covered with newspaper" (Shields 21-22). The talk-story narrative of Amy Tan is best represented in her first novel The Joy Luck Club, which could be analyzed from the perspectives of content and formal features for a better understanding of the significant role talk-story plays in Tan's fiction.

In terms of the content, The Joy Luck Club is characterized by the heroines' retrospective accounts of their life stories between two worlds across temporal and spacial borders; namely, the sufferings of the mothers' and grandmothers' generations in feudalist Old China and the subaltern experiences of immigrant mothers and their American-born daughters in the U.S. society. Tan artistically intertwines sixteen stories narrated by four pairs of 
mother-daughter dyads. These stories are grouped into four sections. Except for Jing-mei, who tells four stories on behalf of her decease mother Suyuan Woo, each mother or daughter tells two stories in the novel. The first section "Feathers From A Thousand Li Away" centers on the mothers' childhood in China and how they obtain strength and identity consciousness either from her mother's tragic death in a masculinist society as in An-mei's case, or from their self-awakening to women's subjugated fate as in Lindo's story of the "red candle" and Ying-ying's disillusionment with the Moon Lady. The second section "The Twenty-Six Malignant Gates" is mainly composed of the daughters' childhood memories of the mothers' overexpectations that run counter to the daughters' emerging identities. While little Waverly and Jing-mei suffer from and rebel against their mothers' great ambition to turn them into prodigies, Lena is troubled by her mother's lifeless silence, which she is determined to break by imaginative matricide empowered by the girl next door. Another story in this section is Rose's narration of her crisis-ridden marriage of absolute equalitarianism with her Caucasian husband and a childhood incident that foreshadows her self-abased character. The third section "American Translation" still from the daughters' perspective follows Rose's line of narration and focuses on the daughters' cross-cultural conflicts in love and mother-daughter relations. Under the influence of their mothers, Lena and Rose begin to realize the potential problems in their respective interracial 
marriage. Waverly and Jing-mei, on the other hand, gradually clear up previous misunderstandings of their mothers and form a mother-daughter bond in renewed reconciliation. The last section "Queen Mother of the Western Skies" shifts back to the voice of the mothers with their multiple perspectives. For An-mei and Ying-ying, they have regained a strong will power by narrating their past lives of self-denial. Feeling intensely the bewilderment of Rose and Lena in marriages in which they do not have a voice, the mothers are determined to pass on power to their daughters exactly like their younger selves to reclaim the lost identities. Lindo, on the other hand, expresses her sincere wish for Waverly to be proud of their affinity as women with the "best character" in the "best circumstances," even if both of them suffer from a displacement, intentionally or unintentionally, in a culture they can never truly merge into. Although the deceased Suyuan could not speak for herself, her voice is interwoven with that of Jing-mei and heard by all her three daughters who are united at the end of the novel.

Compared with the theme of women's multidimentional state of existence in pursuit of independence and interconnection in The Joy Luck Club, the formal features of the novel's talk-story strategy are also worth noticing. As already touched upon in the previous analysis, a remarkable feature of the novel is its multiple monologues in exquisite structure and perfect balance. The stories told by seven characters are separate from each other, presenting the 
readers with the unique life experience and inner thoughts of each woman from her own point of view. Independent as they are, the individual monologues are also in the form of collective storytelling. Just like the four corners of the mah jong table, each essential and inseparable in order to play a mah jong game, the four sections of the novel construct in a harmonious way the various aspects of a woman's life, her relationship with her mother, her husband, her daughter and herself, etc. These stories, when taken as a whole, complement and contrast with one another to realize a dialogistic intertexuality of a woman's diversified identities framed by gender, class, ethnicity, and cultural particularities. The second formal feature of The Joy Luck Club is the symbolic order of the four sections. It is interesting to note that the first and last sections narrated by the mothers or on memories of the mothers are like extending arms embracing the daughters' narratives in the intermediate sections. It also symbolizes a dynamic flow of talking in and out of history as a source of women's self-empowerment. Similar forms are evident in Tan's The Kitchen God's Wife and The Bonesetter's Daughter, though with a slight difference. While The Kitchen God's Wife begins the narration with the daughter's voice and ends with that of the mother, The Bonesetter's Daughter adopts a reverse order, starting with the mother and ending with the daughter. Nevertheless, the main parts of both novels travel back in time, wrapping up the bygone experiences of the mother and grandmother in the Chinese setting, 
whose stories are like a bridge, healing psychological wounds for inter-generational identification.

Based on the above analysis of the content and formal features of Tan's narrative strategy, we may conclude the following roles talk-story plays in Tan's novels. Firstly, talk-story allows the heroines to break silence in an attempt to search for their real identities. By tracing their unique experiences across the boundaries of time, culture, and places, female characters in Tan's novels give voice to their specific subjectivity, rewriting their own history in the process of storytelling. As Winnie, the heroine of The Kitchen God's Wife, gradually remembers and articulates the shaping moments of her life, she herself "progresses on the journey toward verbal authority and eloquence" (Huntley 109). In The Bonesetter's Daughter, the story told by LuLing both restores metaphorical vitality in an old woman suffering from the Alzheimer's disease and mends her relationship with her daughter Ruth. While reading her mother's life stories, Ruth is also deeply touched by Bao Bomu's ${ }^{149}$ love for LuLing. After Ruth reclaims the surname of her grandmother at the end of the novel, she has miraculously found a voice of her own.

Secondly, following the narrative tradition of talk-story, Amy Tan enriches her characters and plots with multi-layer intermingling of different voices and settings as a counteract to the singular, fixed and stereotypical representations

149 Meaning Nanny Bao, another way of addressing Precious Auntie. The word "Bao" has a similar meaning as "precious" in Chinese. 
of both Chinese immigrants in the U.S. society and women in a patriarchal world. As Victoria Chen notes, Tan deploys talk-story narrative not just as "a tool to reflect upon the past or to celebrate the present;" rather, it is treated "as a political means to allow Chinese American women to articulate their silenced lives, their otherwise voiceless positions in this society" (90). Heroines in Tan's fictions have divergent personalities, growing experiences, careers and family backgrounds. Their different images and distinctive voices signify the hybrid nature of Chinese Americans that cannot be summarized in a simple sentence. Unique as they are, the stories also carry a universal truth of women's shared fate in a male-dominant society. By resurrecting women's "untold personal stories of daily survival and resistance" from a masculinist tomb of female erasure, Tan's talk-stories in a multi-layer structure counter "the monolithic imperialist, patriarchal gaze and narratives that have denied them agency, complexity, and visibility in not only their own ethnic communities but also in the dominant Western culture in the U.S." (Ho, "Swan-Feather Mothers" 100). It is through the strategy of talk-story that women enter their dust-laden memory of oppression and victimization, which, when given full expression, becomes a powerful weapon for women's self-affirmation and iconoclastic allegories.

Thirdly, talk-story is an important means to build an emotional lifeline between mothers and daughters out of previous misunderstanding and 
confrontation due to generational and cultural differences. As Huntley states, storytelling enables Tan's fictional mothers to keep the past alive, bridge the past with the present and transmit "cultural codes and rituals" with an aim to imprint "the essence of their selves on the next generation" (15). The mothers bestow their life stories and those of the grandmothers as a precious gift to the daughters. While listening to the stories, the daughters, on the other hand, are ushered into the thoughts and inner world of their mothers, who used to be just as rebellious and heartbreaking when they were daughters. Learning to appreciate their mothers' endless love, the daughters would pass the same stories to the granddaughters in a matrilineal chain of everlasting love.

Matrilineage, or the line of descent traced through the mother or the maternal ancestors, is an invariable theme in Amy Tan's novels. It is manifested through the implication of similar experiences and a mystical empathy between different generations of Tan's female characters. The remote bond that guides the daughters along a similar path as their mothers and grandmothers is epitomized by An-mei when she sees in Rose the exact traits of desiring nothing, swallowing others' misery and eating one's own bitterness she has been taught to acquire since childhood. As An-mei confesses:

[E]ven though I taught my daughter the opposite, still she came out the same way! Maybe it is because she was born to me and she was born a girl. And I was born to my mother and I was born a girl. All of us are like stairs, one step after another, going up and down, but all going the same way. (JLC 215)

The similarities in personalities and life experiences exist not simply 
between mothers and daughters; in The Bonesetter's Daughter, it travels across generational boundaries through space and time, establishing an inseparable link between the deceased grandmother Precious Auntie in the feudalist Old China, the immigrant mother LuLing living between the two cultures and the American-born daughter Ruth. As the stories told by LuLing slowly unrolls, the readers might piece together shocking analogies among the three women.

For Precious Auntie and her granddaughter Ruth, both of them make a living as a doctor of some kind. Precious Auntie's family has been bonesetters in China for nine hundred years (BSD 162). Observing how her father cures patients who suffers from various kinds of bone injuries, Precious Auntie familiarizes herself with the name of all medicines in her father's shop and is at home with the art of healing. Ruth, on the other hand, is a "book doctor" (45), a ghost writer recasting the unattractive words and incoherent thoughts of her customers into popular books with "articulate, intelligent, and important" wording (39). Besides, both Precious Auntie and Ruth have "Days of No Talk," the former, after the tragic wedding day with both her father and husband killed in a premeditated murder, and the latter, every year for a weeklong verbal silence in August. Another similarity worth noting is that both Precious Auntie and Ruth grasp the key to an unknown secret. After the death of her father, Precious Auntie is the only one who knows the exact location of the dragon 
bones, the miraculous ingredient for bone-setting, which turn out to be priceless fossils from the skullcap of Peking Man, one of the oldest human ancestors more than half a million years ago. Similar in a certain sense, Ruth is the one who recovers her grandmother's name as the origin of her mother and the maternal genealogy LuLing has been seeking throughout her life.

As for LuLing and Ruth, both serve as a mouthpiece for their mothers. As a result of a failed attempt of suicide by pouring hot ink into her mouth, Precious Auntie couldn't speak or utter any voice except for gasps and wheezes. Raised up by this woman as her nanny, LuLing learns the whole world from Precious Auntie, who speaks "with grimaces and groans, dancing eyebrows and darting eyes" in a language that combines soundless "[h] and-talk, face-talk, and chalk-talk". (2). Of the whole family, LuLing is the only one who could understand Precious Auntie's unique way of communication and has to say aloud what she means (3). Likewise, due to LuLing's poor English, Ruth is also forced to be the mouthpiece of her widowed mother:

By the time she was ten, Ruth was the English-speaking "Mrs. LuLing Young" on the telephone, the one who made appointments for the doctor, who wrote letters to the bank. Once she even had to compose a humiliating letter to the minister. (45)

Ruth is not only speaking on behalf of her mother, but also a messenger between her mother and grandmother. While LuLing's stories set up a connection between Precious Auntie and Ruth; in the eyes of LuLing, Ruth is 
the only one who can hear the secret messages from Precious Auntie through the "magic" sand tray. Originally a tool for Ruth to practice Chinese calligraphy, the sand tray becomes the customary means of communication between Ruth and LuLing since the daughter refuses to talk after an accident in the schoolyard. ${ }^{150}$ One day when Ruth scratches "Doggie" in the sand, expressing her wish to have a dog, the word that coincides with LuLing's pet name is taken by LuLing as a sign for the ghostly presence of Precious Auntie. From that day on, LuLing routinely urges Ruth to write Precious Auntie's guidance, from stock tips to major decisions in her life. Although Ruth writes randomly most of the time, LuLing would always interpret meaningful message out of it. The words in the sand sustains LuLing's spiritual link with Precious Auntie, healing the irreparable harm the daughter has caused to her silent mother.

Besides binding similarities, women of different generations also have an empathetic understanding of each other in a mythical way. In The Joy Luck Club, one of the Joy Luck mothers An-mei describes in the story "Scar" how she identifies with her mother she has not seen for years. Living with Popo who describes An-mei's mother as a ghostly figure because of her disgraceful conducts, ${ }^{151}$ An-mei has a fearful feeling of her mother. But when her mother

\footnotetext{
150 The accident happens when Ruth is a first-grader. As a gesture of ignoring LuLing's caution, Ruth intentionally throws herself down the slide headfirst and is seriously injured. Instead of scolding Ruth, LuLing takes great care of her daughter by cooking delicious food. Ever since then, Ruth remains silent for the fear that once she speaks as a normal kid, all her special privileges would disappear.

151 As introduced before, An-mei's mother becomes the third concubine of a rich man after being raped by him. In fact, the rape is arranged by the second concubine of the man. As a widow without any help, An-mei's mother has no choice but to marry the man. But nobody would bother to know the latter half of the story and deems the woman a shame to the family.
} 
returns several years later, all the fear vanishes completely. As An-mei recalles, her mother's voice is so familiar as if coming from "a forgotten dream," and when her mother looks at her into the eyes, An-mei feels like seeing her own face looking back at her (JLC 45). The mother's gentle rubbing of An-mei's scar on the neck seems to bring back all the previous memory "back into her skin," and the mother's wailing sound shares so much similarity with the voice An-mei always hears in dreams about her mother (46). Comparable to An-mei's inexplicable attachment to the mother, her mother's emotional link with Popo is even more touching against the latter's cruel rejection. In an attempt to save Popo from dying, An-mei's mother cuts a piece of flesh from her own arm without any hesitation for a recovery soup according to folk recipe. The soup certainly does not prevent Popo's death, but the very act of honoring one's mother with flesh and blood is deeply engraved in An-mei's life. It is in her mother that An-mei sees what is beneath her skin and inside her bones (48). The moving scene reinforces An-mei's love for her mother, a love she would pass on to her daughter and granddaughter.

An-mei's empathetic union with her mother is not unique in The Joy Luck Club; the same sense of emotional identification is also felt by Jing-mei even after her mother's death. When invited to take Suyuan's place for the mah jong game, Jing-mei could tell intuitively that her place is on the East corner of the table and suddenly recalls her mother's words that the East is where 
everything begins, "the direction from which the sun rises, where the wind comes from" (JLC 33). When Jing-mei sits in the place where Suyuan used to be, the life of the mother is regenerated and passed through the daughter in the most natural way. In the climax scene of the novel, Jing-mei and her two half-sisters stand, "arms around each other," laughing and crying for this long-awaited reunion. Nobody speaks a word, but deep in their hearts, they feel their mother's spirit merging into their own: "Together we look like our mother. Her same eyes, her same mouth, open in surprise to see, at last, her long-cherished wish" (JLC 288).

As Amy Ling incisively points out, by giving a prominent place to Jing-mei's position at the East where the novel opens and ends, Tan is alluding to China, "where the mothers' lives began" (132). Just like the four corners of the table, the four sections of the novel begin with the life experiences of the four mothers in China and end with Jing-mei's root-seeking trip to China, her homeland in the east, as a continuation of the matrilineal line. Almost in each of Amy Tan's novels, we can find an underlying motif of matrilineal rupture and recovery. The scar on An-mei's neck and the death of Jing-mei's mother are both emblematic of an unspeakable pain of separation buried deep in the hearts of Chinese diasporas who have been uprooted from their mother culture. It is through the identification with their mothers, either in physical or spiritual sense, that the painful scar is finally healed. 
The worries of matrilineal rupture and the search for its restoration are also evident in the other two novels discussed in this dissertation. In The Kitchen God's Wife, Winnie's mother disappeared when she was six years old. Since then, Winnie has been trying to preserve the memory of her mother by keeping the latter's hair and holding her painting for careful observation. One day, when discovering a mold spot on her mother's pale painted cheek, Winnie attempts to wipe off the stain with a soft cloth. But the harder she washes, the darker the cheek becomes. In the end, half of her mother's face is rubbed off completely. Losing the last connection to the mother, Winnie is never sure whether her memory is right or wrong:

Over the years, I tried to remember her face, the words she said, the things we did together. [...] I have been thinking about my mother for almost seventy years, so it must be ten thousand different times. And it must be that she has changed ten thousand different ways, each time I recalled her. (KGW 89)

The smeared painting here stands for the daughter's misty recollections of her mother/motherland. Though her mother is never found, Winnie has been cherishing a hope for a recovered line of matrilineage, which she would pass on to her daughter as their shared source of power. Like the ending of The Joy Luck Club that fulfills Suyuan's wish to be bonded with her daughters by the same Chinese root, The Kitchen God's Wife concludes with the mother and the daughter confiding lifelong secrets and worshipping the statue of a goddess Winnie presents Pearl as a gift. By naming the goddess "Lady Sorrowfree," Winnie reestablishes a matrilineal link she has lost since her mother's 
departure. The goddess sitting in the red altar that Pearl inherites from Grand Auntie Du, a mother figure for Winnie, signifies a continuation of the maternal lifeline and women's self-empowerment. The creation of a feminine god represents a restoration of the maternal power that is located in the feminine imaginary. As Luce Irigaray asserts, the feminine god "is yet to come," giving form to difference, multiplicity, flows and rhythms (Divine Women 8). As its name indicates, the goddess as a symbol of the ancestral root of maternity will bring happiness and hope to women's life free of sorrow or regrets.

In The Bonesetter's Daughter, the disconnection and seeking of matrilineage is symbolized by LuLing's oblivion of and Ruth's retrieving of Precious Auntie's family name. In the opening vignette of the novel, LuLing recounts how Precious Auntie values her family name. Sliding into the ancestral hall of her in-law's family, Precious Auntie takes out a scrap of paper with her name on it from the lining of her shoe. Telling LuLing that she should never forget this name, "the name of all bonesetters," Precious Auntie places the paper name on the altar and bows in greatest respect (BSD 5). As LuLing approaches her old age, however, she is deeply troubled by the loss of the name. The first section of the novel thus unveils itself amid LuLing's innermost cry for help: "Precious Auntie, what is our name? I always meant to claim it as my own. Come help me remember" (ibid.). When LuLing finally knows the truth that Precious Auntie is her real mother, who dies with a deep regret because of 
LuLing's misunderstanding and rejection, it has already been too late to mend the severed tie. Years later, as LuLing is looking at the only photo of Precious Auntie, she suddenly realizes a rejuvenation of her mother's spirit in herself. The more LuLing looks at the photo, the more she feels closer to Precious Auntie: "Her face, her hope, her knowledge, her sadness - they were mine" (237). Throughout her drifting days, from China to America, LuLing is forever searching for her mother's name as the origin of her life. "A mother is always the beginning. She is how things begin" (263).

It is out of a fear for the loss of the matrilineal clue that LuLing writes down her life stories for Ruth to follow her steps towards their maternal origin. Reading LuLing's memoirs, Ruth not only understands her mother's love and over-protection, but also feels the spiritual force from her grandmother Precious Auntie. The feeling, as Ruth confesses, is as if she has "found the magic thread to mend a torn-up quilt" (310). When Ruth finally knows her grandma's name "Gu Liu Xin" with the help of Auntie GaoLing, she couldn't control crying for the ultimate affirmation of her maternal line. Deep in her heart, she is assured that her grandmother, her mother and herself all belong to the same family with a name that has been there all along, "like a stone stuck in the crevices of a gorge, $[\ldots]$ etching itself indelibly in Ruth's mind" (350). Like the symbolic endings as in a family reunion in The Joy Luck Club and worshipping the renamed goddess in The Kitchen God's Wife, the epilogue of 
The Bonesetter's Daughter closes with Ruth instilled with the spirit of Precious Auntie. "And side by side, Ruth and her grandmother begin. Words flow. They have become the same person" (352). Reclaiming her voice on the Day of Silence, Ruth sits down at the table with "the picture of her grandmother in front of her" (351), and starts to write a story "for her grandmother, for herself, for the little girl who became her mother" (353).

The heroines' perennial tracing of their matrilineal ties in Amy Tan's novels is symbolic of a nostalgic longing for the motherland and China's cultural root by Chinese American immigrants in the U.S.. While identifying with their mothers and grandmothers, Tan's fictional daughters as a personification of the writer herself are also answering a cultural call from their shared memories. No matter how far they have drifted away from home, the Chinese imprint stamped in their blood and soul will always be maintained through this line of matrilineage, guiding their way to a shared origin from the East, where things begin.

\section{Divergent Strategies, Same Pursuit}

Based on a clarification of the two writers' narrative strategies and their significance against socio-cultural backgrounds, we can find some converging points between Chen Ran's personalized writing with a "gender-transcendent consciousness" and Amy Tan's talk-stories tracing a matrilineal origin. 
First of all, it could be argued that both writers resort to personal narratives as a political means to acclaim their submerged voice. The feminist slogan "the personal is political" was coined by Carol Hanisch in 1970 during the second-wave feminist movement. It aims to prioritize women's distinctive experience "within that sphere that has been socially lived as the personal private, emotional, interiorized, particular, individuated, intimate - so that what it is to know the politics of woman's situation is to know women's personal lives" (italicized in the original, Mackinnon 21). At the onset of the third-wave feminism under the impact of postmodern and post-structualist theories, personal narrative has been foregrounded to provide "an intersectional and multiperspectival version of feminism" in its rejection of grand narratives and essentialist category of "woman" (Snyder 175). Although driven by different motivations, both Chen Ran and Amy Tan narrate their stories in a personal manner that exhibit some features of women's autobiographical writings. While Chen's heroines share the author's characteristics as an urban intellectual woman of sensitivity and sentimentality, Tan draws inexhaustible inspiration for her fictional creation from her mother's life stories in China and her own experiences as a Chinese American writer. ${ }^{152}$ For a "late born"153 woman

\footnotetext{
${ }^{152}$ In each of Tan's three novels, we may find a daughter figure who shares some similarity with Amy Tan in terms of personality and career. Among the three American-born daughters, namely, Jing-mei in $J L C$, Pearl in $K G W$ and Ruth in $B S D$, all lost their fathers in childhood and had troublesome relationship with their widowed mothers, and all make a living out of writing. Similar to Tan's experience as a technical speech-writer for corporate executives in early $1980 \mathrm{~s}$, Jing-mei is a freelance writer for company advertising. Pearl's career as a speech therapist tallies with Tan's experience of directing "a San Francisco project for developmentally handicapped children" in 1980 (Snodgrass 14). And Ruth's transition from a ghost writer to a creative writer of her family stories after reading her mother's memoirs is probably based on Tan's own experience. Tan became eager to write for herself, especially about her mother's legendary life after Daisy's unexpected angina and their ensuing China
} 
writer like Chen Ran, her heroines' individual struggles to "break loose from the trappings of men and their world" resemble the writer's constant and restless attempt to rebel against the universal form of social realism and the invariable content of national collective life that smothers the personal voice "through almost a century of cultural and political reinforcement" (Zheng Yi 49-50). Compared with Chen's challenge to the dominant collective narrative in the Chinese arena, Tan's talk-story narrative, as demonstrated in the cited examples, incorporates multiple identities of her female characters across cultural, historical and ethnic boundaries as well as from different stages of a woman's life that permeates in-between.

Secondly, as it is analyzed before, both Chen Ran and Amy Tan are not restricted by their personal narratives and attempt to reach into a deeper level of universality. Situated in a rapidly changing socio-cultural environment of China during the early 1990s, Chen Ran is voicing a deep worry about the modern predicament as reflected in an individual's dilemma of existentialist struggles. In comparison, Amy Tan's multi-layered talk-stories aim to subvert the Western stereotyping of Oriental women into submissive passivity. By allowing her heroines to narrate their personal stories from their unique perspectives, Tan gives voice to all the silenced women of the Chinese origin to recover and to be proud of their unyielding spirit that would triumph over all trip in 1985 .

${ }_{153}$ The "Late Born Generation" usually refers to those writers who were born in the 1960 s and came to fame in the 1990s. As Zheng Yi explains, the "Late Born Generation" gets its name because this generation of writers is born "too late to be implicated in the dramatic events of recent Chinese history" (Zheng Yi 48 ). 
obstacles and hardship.

Thirdly, revisited from postmodern feminist theories, distinctive writing strategies of Chen Ran and Amy Tan achieve the same effect of deconstructing the gender dichotomy and the symbolic discourse of patriarchy aimed at by postmodern feminists. "Following Derrida's deconstructive approach towards binary thought and proceeding from a psychoanalytic frame of reference, Cixous declaims against male-centered writing that "is rooted in a man's genital and libidinal economy [...] emblemized by the phallus" and has reigned supremacy in a patriarchal society (Tong 275). Cixous challenges women to put themselves into words through feminine writing, which is "open and multiple, varied and rhythmic, full of pleasures and, more important, full of possibilities" (277). Passionate and optimistic, Cixous hails the feminine writing as "a springboard for subversive thought, the precursory movement of a transformation of social and cultural standards" ("The Laugh of Medusa" 879). In her notion of "sext" that combines sex and text, she attempts to realize the potential power of women by writing about femininity and sexuality, "about their eroticization, sudden turn-ons of a certain miniscule-immense area of their bodies" (885).

Luce Irigaray also believes that "women lack access to language appropriate to the expression of their desire" (Burke 289). In her advocacy of a new feminine language to articulate female sexuality, Irigaray absorbs and 
reinterprets Lacanian psychoanalytic ideas on sexuation. Lacan's rejection of Freud's biological determinism through the symbolic system of language, ${ }^{154}$ in which "woman" is deemed a signifier instead of a biological female, and his analysis of the pre-oedipal phase with a close bond between the child and the mother is borrowed and revised by Irigaray in her interpretation of the multiplicity of woman's desire. In an attempt to explore a feminine language beyond the phallocentric discourse system underpinning the patriarchal dominance, Irigaray calls for a self-renaming of women's desires through a new system of language, which, like the fluidity of female genitals, should be "plural, autoerotic, diffuse, and undefinable within the familiar rules of (masculine) logic" (ibid.). To achieve such a goal, it is necessary, in the eyes of Irigaray, to explore the geography of female pleasure. Borrowing Lacan's interpretation, Irigaray situates the origin of female pleasure in the pre-oedipal phase, when there is a close bond and sensual relationship between the child and the mother's body not yet polluted by the symbolic patriarchal system. She believes that it is with other women that a woman may find the "means for overcoming that loss of the first relationship with the mother's body" ("Women's Exile" 76). She argues that only by rediscovering a language of

\footnotetext{
${ }^{154}$ According to Frend, women's desires originate from their biological lack of the penis. Because of penis envy, a girl desires to find a substitute for her lack by possessing a penis or giving birth to a baby. In doing so, she has to divert her desire from the mother as her first lover towards male over the phallic phase, suppressing the active elements of her sexuality and strengthening feminine sexual passitivity (Elliott 23). Such ideas featured by biologic determinism not only put Freud under severe attack from many feminist thinkers, but also is rejected by the disciples of the Freudian psychoanalytic theory including Lacan. For Lacan, the self and sexual subjectivity is imaginary, structured through the phallus not as a physical organ but a signifier for the presence and absence of access to power and self-definition, a symbolic object dividing the two sexes by giving power to those who have it.
} 
love among women can women get hold of and be able to describe the sexual pleasure beyond the law of the phallus.

Deviating from the Freudian-Lacanian understanding that paternal threats of castration anxiety cause the child to leave the safe haven of the maternal body to form one's sexual identity, Kristeva argues that subjective and group identities are formed through institutionalized "abjection" of the maternal body and women's subsequent depression of their sexuality. To get over such "abjection" that reduces women merely to maternal reproduction for the purpose of maintaining patriarchal supremacy, Kristeva advocates for "a new discourse of maternity that acknowledges the importance of the maternal function in the development of subjectivity and in culture."155 In Black Sun: Depression and Melancholia, Kristeva points out the need of not only creating a discourse of maternity but also a discourse on mother-daughter relationship and one "that does not prohibit the lesbian love between women through which female subjectivity is born." ${ }^{156}$ Similar to Irigaray, Kristeva locates the origin of such a maternal discourse in the pre-linguistic, pre-oedipal realm, or the domain of the Imaginary, where one can "remain identified with one's first love, the mother, and develop with her new ways of speaking and writing, of constituting one's subjectivity" free from the symbolic order of patriarchal oppression (Tong 7).

\footnotetext{
155 Oliver, Kelly. "Kristeva and Feminism," Feminișt Theory Website: Julia Kristeva. Center for Digital Discourse and Culture, Virginia Tech University. 6 April. $2010<\mathrm{http} / / \mathrm{www}$. cddc.vt.cdu/feminism/kristeva.html $>$. 156 (ibid.)
} 
Besides, as noted before in textual analysis, the deconstructive attack on gender implied in Chen Ran's writings has much in common with American philosopher and postmodern feminist Judith Butler. According to Butler, the notion of gender is understood as "a performance that produces the illusion of an inner sex or essence or psychic gender core" (Butler, "Imitation" 134); it is "tenuously constituted in time, instituted in an exterior space through a stylized repetition of acts" (179), a routinized reiteration that generates an illusion of a stable self. As Butler puts it, "Such acts, gestures and enactments, generally construed, are performative in the sense that the essence of identity that they otherwise purport to express are fabrications manufactured and sustained through corporeal signs and other discursive means" (173). The "performativity" of gender as an act of signification and representation is realized through discursive power or what Butler terms as the "heterosexual matrix," "a set of precepts and practices through which our notions of ourselves, our bodies and our sexuality are made intelligible to us within a predominantly heterosexual world" (Bradley 74).

Based on the above review of postmodern feminist ideas, we may conclude that Chen Ran's rediscovery of the beauty and power of the female body presents Chinese analogies to Cixous's notion of body writing and Irigaray's advocacy of a new feminine language as a site of resistance to the dominant male discourse. And Chen's notion of "gender-transcendent 
consciousness" achieves a similar effect as Butler's ideas on gender performativity. Sharing a similar feminist agenda, the multivalent structure of Tan's talk-stories exemplifies the multiple possibilities of the feminine writing that demands diachronic and synchronic readings at the same time. The matrilineal themes of her novels seem to echo Irigaray's theory of tracing the "genealogy of women" and Kristeva's urge for a return to pre-oedipal maternity that breaks down borders between femininity and masculinity. It should be admitted that, as conditioned by their respective social environment, Chen Ran's "gender-transcendent consciousness" leads her to a bold celebration of sisterhood, which differs from Tan's prioritization of mother-daughter relationship of matrilineage. However, both writers share postmodern feminist ideas to establish a female bond among women. While Chen's heroines rediscover their repressed self-consciousness and sexual identity from their female lovers, in their gradual recovery of the maternal bond with mothers and grandmothers, female characters in Tan's novels find courage and a renewed power to unshackle the colonialist and patriarchal chains on their spirit and start a new life of spiritual independence. 


\section{CONCLUSION}

Either in its earlier stages with the main focus on European and American literature, or during its "most recent development" characterized by an expansion "to embrace the literature of the Orient as well as the West" (Aldridge iii), comparative literature has established itself as a promising academic discipline facilitating cross-cultural dialogues and mutual understandings amid the general trend of multiculturalism and global integration. However, against China's profound cultural background and its growing visibility in the geopolitical world order, Chinese comparative literature is still marginalized in the international academia (Zhang Yingjin 8-9).

To promote an active engagement of Chinese literature with the global literary scene, Zhang Yingjin summarizes three options confronted by Chinese comparatists in the introduction of China in a Polycentric World. The first option as represented by scholars like Rey Chow is to launch a critique of Western theoretical thinking by testing it in the Chinese context. The second option pioneered by scholars like James J. Y. Liu and Pauline Yu aims to introduce Chinese aesthetics to the Western poetics from a comparative point of view. The third option is to "practice a critical, theoretically informed reading of Chinese literature and culture" (9). According to Zhang Yingjin, the first option 
ironically ends up in turning "oppositional" discourse to a cooperative one that enhances the Western theory and its sustained status of hegemony. On the other hand, since it usually prioritizes "Western issues over Chinese concerns," such an option makes the easiest way into institutionalized acknowledgement by the Western academia (ibid.). The second option that contests the limit of Western theory with its Chinese focus "has produced the most remarkable scholarship in Chinese-Western comparative literature," though as perceived by the current author, it requires the researcher to be proficiently grounded in both Chinese and Western theories as well as literary traditions. The third option adopted by the new generation of Chinese comparatists takes a more open attitude of replacing the "either/or" choice between Western theory and Chinese literature with the strategic preference of "both/and:" "we can never return to a pristine state of Chinese literature, uncontaminated by any critical language, nor can we aspire to be anything but cross-cultural, comparative critics as we approach the next millennium" (7).

Adopting a similar approach as those choosing the third option, the current author attempts to incorporate Western theories from different schools of thought in a comparative study of two contemporary women writers from the same root of the Chinese culture. In regard to some critics who still question the validity of applying Western theories to interpreting Chinese literary works because of cultural specificity, the author couldn't agree more with the incisive 
comments by a well-known Chinese comparatist Zhang Longxi. Disclaiming the above concern as a problem, Zhang argues that the "theoreticality" of a theory "is precisely its potential to transcend cultural specificities and historical contingencies;" such transcending quality is what makes theory "transferable" so as to serve as "the basis or framework" for comparative studies between the East and the West (31). Defining the nature of cross-cultural comparative studies, Zhang states:

East-West comparative studies cannot simply be a matter of application of Western theory or critical methodology to Eastern texts but must be based on theoretical issues that are common and shared by Chinese and Western traditions in different but comparable manifestations. (34)

By studying Chen Ran's and Amy Tan's fictions from the perspectives of postmodern feminism, psychoanalysis and identity theories, the author hopes to highlight a shared pursuit for the upgraded status and enhanced identity awareness among women writers, whether Chinese or Chinese American, or of any other national, cultural, ethnic, class, and social backgrounds. From a detailed textual analysis of mother-daughter relationship, heterosexual relations and sisterhood, the three overriding themes in the fictions of Chen Ran and Amy Tan, we can draw close analogies not only between the two writers across geographical boundaries, but also between Western theories and literary creations by writers from Eastern origin. Interpreted from a feminist perspective, both writers express in their fictions a deep concern for women's loss of identities in a male-dominant society, and both attempt to reclaim 
women's identities through their heroines' self-empowerment and female bonding that constitute a real challenge to institutionalized phallocentrism and heteronormativity. Feeling the tremendous pressure from the pervasive discourse system of patriarchal symbolism, both Chen Ran and Amy Tan resort to women's imaginary world of metaphorical imageries. Through their heroines' dreams and illusions and their resignification of the mirror and birds, the two writers have reinscribed women's unique perspectives of multiplicity and fluidity as an unsettling chord in the master narrative.

Through an exploration of the three major themes and the stylistic devices of imageries, we can sense women's gradual awakening from passive submission to conscious identity-construction. The transition, as argued by the current author, is realized through the heroines' sexual affirmation and gender deconstruction as promised by sisterhood in Chen's fictions and the breaking of silence and the male myth with a restored maternal bond for Tan's characters. To explain such variations out of similar concerns, the author reviews the evolution of literary representations on each theme in both Chinese and American literary traditions. An elaboration on the distinctive writing strategies of Chen Ran and Amy Tan is also included in the last chapter of this dissertation in order to recapture the two writers' similarities and differences in their thematic explorations and imagery encodings.

Taking the approach of cultural studies, the author proposes a refreshed 
understanding of Chen Ran's personalized writing with a "gender-transcendent consciousness" and Amy Tan's talk-story narrative of matrilineal tracing. In their reconstruction of women's identity consciousness, Chen Ran and Amy Tan accentuate sisterhood and mother-daughter bond respectively for women's spiritual empowerment. But both converge on the writing strategy of personal narratives. Through personal narrations about a woman's bodily experiences and existentialist anxieties in Chen's fictions and survival stories of Chinese American immigrants extending through generations of mothers and daughters, the two writers have expressed their shared humanistic ideals for women's spiritual independence free from inequality and discrimination. Drawing upon postmodern feminist theories, the fictions of both writers embody a strong female consciousness. Chen Ran's aesthetic description of the female body achieves a similar effect as the feminine language advocated by Hélène Cixous and Luce Irigaray, and Chen's deconstruction of gender categories as implied in her "gender-transcendent consciousness" is essentially the same as Judith Butler's proposal of gender performativity. In comparison, the multi-voiced and intercrossed narrative structure of Amy Tan's talk-story that aims to repair a broken tie of matrilineage is much in common with Luce Irigaray's pursuit of women's genealogy and Julia Kristeva's maternity theory by returning to the pre-oedipal realm of the Imaginary beyond patriarchal and colonialist signification. 
As Jonathan Culler comments, literary works have always been concerned with the issue of identity and offer us implicit or explicit models of how identity is formed by following the "the fortunes of characters as they define themselves and are defined by various combinations of their past, the choices they make, and the social forces that act upon them" (106). Though living in different countries, both Chen Ran and Amy Tan share the same urge to define and portray women's identities, and both express, through their writings, the experiences, perceptions and inner feelings from the distinctive perspectives of their female characters. While acknowledging the differences between the two writers framed by their respective socio-cultural discourse, the author attempts to prove their merging similarities based on a comparative texual analysis from a feminist point of view. Through their touching stories, Chen Ran and Amy Tan, two women writers sharing the same cultural origin, reveal to us women's root-seeking journies for their undefined identities and a relentless pursuit for a spiritual home of their own.

There is undoubtedly much room for further development of this project, especially in terms of theoretical penetration and the need for a more comprehensive diachronic and synchronic comparison of Chinese and American literary traditions, though space and time limit further considerations. Nevertheless, the fruitful outcome of this dissertation that brings together Chen Ran and Amy Tan within a Western theoretical frame of reference, 
demonstrates the vigor and vitality of comparative literature as a colorful rainbow between the East and the West. Proceeding from this tiny step towards a cross-cultural dialogue undertaken with great delight and understanding smiles, the author wishes to draw more academic attention to marginal literary works and cultural expressions that share the same appreciation of the beauty of life and the spirit of humanism. 


\section{REFERENCES}

Abbey, Sharon and Charlott Harris. "Motherline Connections Across Cultures and Generations." Mothers and Daughters: Connection, Empowerment, and Transformation. Eds. Andrea O'Reilly and Sharon Abbey. 247-66.

Adam, Barry D. The Rise of a Gay and Lesbian Movement. New York: Twayne Publishers, 1987.

Adams, Bella. "Representing History in Amy Tan's The Kitchen God's Wife." MELUS 28.2 (2003): 9-30.

---. Amy Tan. Manchester and New York: Manchester University Press, 2005.

Aldrich, Jean Pomeroy. "Writing the Wrong: Female Identity and the Postmodern Feminist Novel of Manners in America." Diss. The Union Institute, 1994.

Aldridge, A. Owen. "Introduction." China and the West: Comparative Literature Studies. Eds. William Tay, Ying-hsiung Chou and Heh-hsiang Yuan. Hong Kong: The Chinese University Press, 1980. iii-xiii.

Amato, Jean M. "The Representation of Ancestral Home and Homeland in Chinese American Fiction (1960s -1990s)." Diss. University of Oregon, 2005.

Anderson, Hollis June Davis. "The Relationship of Mothers and Daughters in Beloved, The House of Mirth and The Joy Luck Club." Diss. University of Houston-Clear Lake, 2004.

Anderson, Kathryn and Dana C. Jack. "Learning to Listen: Interview Techniques and Analyses." Women's Words: The Feminist Practice of Oral History. Eds. Sherna Berger Gluck and Daphne Patai. New York: Routledge, 1991. 11.

Bai, Ying (白颖) and Xiaoyu Fei (费小玉). “从沉默到爆发，从压抑到释放一对谭 
恩美《灶神之妻》的女性主义批评解读 [From Silence to Outbreak, from Oppression to Liberation: A Feminist Reading of Amy Tan's The Kitchen God's Wife]." 理论界 [Theory Horizon]. 7 (2008): 132-33.

Barlow, Tani E., ed. Gender Politics in Modern China: Writing and Feminism. Durham: Duke University Press, 1993.

---. The Question of Women in Chinese Feminism. Durham: Duke University Press, 2004.

Bassin, Donna, Margaret Honey and Meryle Mahrer Kaplan, eds. Representations of Motherhood. New Haven and London: Yale University Press, 1994.

Beasley, Chris. Gender \& Sexuality: Critical Theories, Critical Thinkers. London, Thousand Oaks and New Delhi: SAGE Publications, 2005.

Beauvoir, Simone de. Le Deuxième Sexe. Paris: Gallimard, 1949; Trans. and Ed. by H. M. Parshley as The Second Sex. 1952. New York: Alfred A. Knopf, 1976.

Berger, PI L. and T. Luckmann. The Social Construction of Reality. New York: Doubleday, 1966.

Bermudez, Marisela and Laura R. Burleigh. "Mother-Daughter Relationships During Puberty." Adolescent Development: Current Issues. Ed. Shane R. Jimerson. Santa Barbara, University of California. 19 May. 2010. $<$ http://education.ucsb.edu/jimerson/adolescenceissues/ADmomrel.html $>$.

Blackburn, Di Gan. "Christianity in Contemporary Asian-American Literature: (Mis)-Translations of the Word." Diss. Baylor University, 2004.

Bloom, Harold, ed. and introd. Lesbian and Bisexual Fiction Writers. Philadelphia: Chelsea House Publishers, 1997.

---. Amy Tan. Philadelphia: Chelsea House Publishers, 2000.

Bowie, Malcolm. Lacan. Great Britain: Fontana Press, 1991. 
Bradley, Harriet. Gender. Cambridge and Malden: Polity Press, 2007.

Braidotti, Rosi. "Nomadic Subjects: Embodiment and Sexual Difference in Contemporary Feminist Theory." Feminist Literary Theory: A Reader. Ed. Mary Eagleton 411-20.

Bronski, Michael. Pulp Friction: Uncovering the Golden Age of Gay Male Pulps. New York: St. Martin's Press, 2003.

Bronte, Charlotte. Jane Eyre. 1848. New York: Bantem Dell, 2003.

Brown, Rita Mae. Rubyfruit Jungle. Plainfield: Daughters Inc., 1973.

Bunch, Charlotte and Claudia Hinojosa. "Lesbians Travel the Roads of Feminism Globally." Creating Change: Sexuality, Public Policy, and Civil Rights. Eds. John D'Emilio, William B. Turner and Urvashi Vaid. New York: St. Martin's Press, 2000.

Burk, Maggie. "Luce Irigaray's 'contradictions': poststructuralism and feminism." Signs 17.1 (Autumn 1991): 50-70.

Burke, Carolyn. "Irigaray through the Looking Glass." Feminist Studies 7.2 (1981): 288-306.

Butler, Judith. "Sex and Gender in Simone de Beauvoir's Second Sex." Yale French Studies 72 (1986): 35-49.

---. Gender Trouble: Feminism and the Subversion of Identity. New York: Routledge, 1999.

---. Bodies That Matter: On The Discursive Limits of "Sex". New York and London: Routledge, 1993.

---. "Imitation and Gender Insubordination." The Judith Butler Reader. Eds. Sara Salih and Judith Butler. Malden: Blackwell Publishing, 2004: 119-37.

Cao, Xueqin and Gao E. A Dream of Red Mansions. Trans. Yang Xianyi and Gladys Yang. Beijing: Foreign Languages Press, 1978-1980.

Carlson, Kathie. In Her Image: The Unhealed Daughter's Search for Her Mother. Boston and Shaftesbury, Shambhala Publications, Inc., 1989. 
Chandler, Albert R. "The Nightingale in Greek and Latin Poetry." The Classical Journal 30.2 (Nov. 1934): 78-84.

Chantharothai, Sasitorn. "Transforming Self, Family, and Community: Women in the Novels of Anne Tyler, Toni Morrison, and Amy Tan." Diss. Indiana University of Pennsylvania, 2003.

Chen, Fu-jen. "Beyond 'Real' and 'Fake': A Lacanian Reading of Asian-American Literature." Diss. Northern Illinois University, 2001.

Chen, Lin (陈琳). “从鸟意象看阮籍和陶浰明的不同 [Differences between Ruan Ji and Tao Yuanming - From the Perspective of Bird Imagery]." 安徽文 学 (评论研究) [Anhui Literature (Criticism and Research)] 6 (2008): 138-39.

Chen, Ran (陈染). 纸片 [Paper Scrap]. Beijing: The Writers Publishing House (作家出版社), 1989.

---. "Sunshine between the Lips." Trans. Shelley Wing Chan. Chairman Mao would Not Be Amused: Fiction from Today's China. Ed. Howard Goldblatt, New York: Grove Press, 1995. 112-29.

---. 陈染文集 [Select Works of Chen Ran]. 4 vols. Yangzhou：Jiangsu Literature \& Arts Publishing House (江苏文艺出版社), 1996.

---. 陈染小说精粹 [Selected Fictions of Chen Ran]. Chengdu : Sichuan People's Publishing House (四川人民出版社), 1998.

--.. “与往事干杯 [A Toast to the Past]." 嘴唇里的阳光 [Sunshine between the Lips]. Wuhan: Changjiang Literature \& Arts Publishing House (长江文艺 
出版社), 2001. 1-73.

---. “无处告别 [Nowhere to Bid Farewell].” 嘴唇里的阳光 [Sunshine between the Lips] 74-128.

--- “角色累整 [Redundant Roles]." 昆唇里的阳光 [Sunshine between the Lips] $129-218$

---. “空心人的诞生 [The Birth of a Hollow Man]." 嘴唇里的阳光 [Sunshine between the Lips] 219-41.

--.. “空的窗 [An Empty Window].” 嘴唇里的阳光 [Sunshine between the Lips] 242-57.

---. 我们能否与生活和解 [Can We Reconcile with Life]. Beijing: The Writers Publishing House (作家出版社), 2001.

---. "Breaking Open." Trans. Paola Zamperini. Red is not the Only Color: Contemporary Chinese Fiction on Love and Sex between Women. Collected Stories. Ed. Patricia Sieber. Lanham: Rowman \& Littlefield Publishers, Inc., 2001. 49-66.

--.. 声声断断 [lntermittent Words]. Beijing: The Writers Publishing House (作 家出版社), 2002.

---. 不可言说 [Beyond Words]. Beijing: The Writers Publishing House (作家出 版社), 2002.

--.. “超性别意识与同性爱 [Gender-Transcendent Consciousness and Same-Sex Love]." Interview by Tze-lan Sang (桑梓蘭). 不可言说 
[Beyond Words]. Ed. Chen Ran. Beijing: The Writers Publishing House (作家出版社), 2002. 101-39.

--. 时光倒流: 陈染散文集 [Flashback in Time: A Collection of Chen Ran's

Prose]. Beijing: Xinhua Publishing House (新华出版社), 2003.

--.. “没结局 [Without an Ending]." 时光倒流 [Flashback in Time] 2-13.

---. “我的“个人化' [My Personalization].” 时光倒流 [Flashback in Time] 28-32.

--.. “如同‘飞着' [As If 'Flying'].” 时光倒流 [Flashback in Time] 38-42.

--.. “个人化”与我自己” [Personalization and Myself].” 时光倒流 [Flashback in Timel 204-08.

--.. "家居琐记 [Jottings about My Home Life]." 时光倒流 [Flashback in Time] 304-10.

---. 离异的人 [The Divorced]. Beijing: Shenghuo-Dushu-Xinzhi Joint Publishing Company (生活·读书·新知三联书店), 2004.

---. A Private Life. Trans. Howard-Gibbon. New York: Columbia University Press, 2004.

--.. “另一只耳朵的敲击声 [The Sound of Another Ear Knocking]." 无处告别 [Nowhere to Bid Farewell]. Nanjing: Jiangsu Literature \& Arts Publishing House (江苏文艺出版社), 2005. 101-39.

--.. “凡墙都是门 [All Walls Are Gates]." 无处告别 [Nowhere to Bid Farewell] 
174-96.

--. “沉默的左乳 [The Silent Left Breast].” 无处告别 [Nowhere to Bid Farewell] $197-212$

--.. “潜性逸事 [A Hidden Matter].”无处告别 [Nowhere to Bid Farewell] 213-37.

---. “饥饿的口袋 [A Hungry Pocket].” 无处告别 [Nowhere to Bid Farewell] 238-51.

---. “超性别意识与我的创作 [Gender-Transcendent Consciousness and My Creative Writing]." 中国新时期女性文学研究资料 [Research Materials of Chinese Women Literature in the New Period]. Ed. Qinghua Zhang (张清 华). Shandong: Shangdong Publishing House of Literature and Art (山东 文艺出版社), 2006. 99-103.

---. 谁掠夺了我们的脸 [Who Robbed Our Face]. Beijing: The Writers Publishing House (作家出版社), 2007.

---. 私人生活 [A Private Life]. Beijing: The Writers Publishing House (作家出版 社), 1996.

Chen, Ran (陈染) and Xiao Gang (萧刚). “另一扇开启的门 [Another Door Open].”私人生活 [A Private Life] 247-77.

Chen, Shu-Ling. "Mothers and Daughters in Morrison, Tan, Marshall, and Kincaid." Diss. University of Washington, 2000. 
Chen, Victoria. "Chinese American Women, Language, and Moving Subjectivity." Amy Tan. Bloom, Harold. Philadelphia: Chelsea House Publishers, 2000. 83-92.

Chen, Xiaohui (陈晓晖). 当代美国华人文学中的“她”写作一对汤婷婷、谭恩美、 严歌苓等几位华人女作家的多面分析 [The Feminine Stage of Woman's Writing within Contemporary Chinese National Literature in U.S.A: The Interpretation of the Texts by Maxine Hong Kingston, Amy Tan and Yan Gelingl. Beijing: Oversea Publishing House (中国华侨出版社), 2007.

Chen, Xiaomei. "Reading Mother's Tale-Reconstructing Women's Space in Amy Tan and Zhang Jie." Chinese Literature: Essays, Articles, Reviews (CLEAR) 16 (1994): 111-32.

Cheng, Aimin (程爱民). “论谭恩美小说中的母亲形象及母女关系的文化内涵 [The Cultural Significance of the Mother Image and the Mother Daughter Relationship in Amy Tan s Novels].”南京师大学报(社会科学版) [Journal of Nanjing Normal University (Social Science Edition)] 4 (July. 2001): 107-13.

Cheng, Aimin (程爱民) and Yi Hao (邵怡). “女性言说一论汤亭亭、谭恩美的叙事

策略 [A Feminine Story: On Narrative Strategies of Maxine Hong Kingston and Amy Tan]." 当代外国文学 [Contemporary Foreign Literature] 4 (2006): 58-64.

Chevrel, Yves. Comparative Literature Today: Methods \& Perspectives. Trans. Farida Elizabeth Dahab. Kirksville: The Thomas Jefferson University Press, 1989.

Chodorow, Nancy J. The Reproduction of Mothering: Psychoanalysis and the Sociology of Gender. 1978. Berkeley, Los Angeles and London: University of California Press, 1999. 
Chow, Ray. Women and Chinese Modernity: The Politics of Reading Between West and East. Minneapolis: The University of Minnesota Press, 1991.

Cixous, Hélène. "The Laugh of Medusa." Trans. Keith Cohen and Paula Cohen. Signs 1.4 (Summer 1976): 875-93.

Collins, Patricia Hill. "Shifting the Center: Race, Class, and Feminist Theorizing about Motherhood." Mothering: Ideology, Experience, and Agency. Eds. Evelyn Nakano Glenn, Grace Chang and Linda Rennie Forcey. New York and London: Routledge, 1994. 45-66.

Conceison, Claire A. "Translating Collaboration: the Joy Luck Club and Intercultural Theatre." TDR (1988-) 39.3 (1995): 151-66.

Cote, James E. and Charles G. Levine. Identity Formation, Agency, and Culture: A Social Psychological Synthesis. New Jersey: Lawrence Erlbaum Associates, Inc., 2002.

Cott, Nancy F. The Bonds of Womanhood: "Woman's Sphere" in New England, 1780-1835. New Haven and London: Yale University Press, 1977.

Croll, Elisabeth. 1995. Changing Identities of Chinese women: Rhetoric, Experience and Self-perception in Twentieth-century China. London: Zed Books.

Culler, Jonathan. Literary Theory: A Very Short Introduction. New York: Oxford University Press, 2000.

Curton, Carman C. "Women Becoming: A Feminist Critical Analysis of Mother-Daughter Relationships in Amy Tan's The Joy Luck Club and The Kitchen God's Wife." Diss. University of North Texas, 1993.

Dahab, Farida Elizabeth. "Translator's Introduction." Comparative Literature Today: Methods and Perspectives. Yves Chevrel. Trans. Farida Elizabeth Dahab. Kirksville: The Thomas Jefferson University Press, 2004. xi-xv.

Dai, Fan (戴凡). “《喜福会》的人物话语和思想表达方式一叙述学和文体学分析 [Speech and Thought Presentation in The Joy Luck Club: From the perspectives of Narratology and Stylistics]." 外语与外语教学 [Foreign Languages and Their Teaching] 198.9 (2005): 56-59. 
Dai, Jinhua (戴锦华). “陈染：个人和女性的书写 [Chen Ran: Personalized and Female Writing]". 当代作家评论 [Contemporary Writers Review] 3 (1996): 47-56.

---. "Rewriting Chinese Women: Gender Production and Cultural Space in the Eighties and Nineties." Spaces of Their Own: Women's Public Sphere in Transnational China. Ed. Mayfair Mei-hui Yang. Minneapolis: University of Minnesota Press, 1999: 191-206.

---. 犹在镜中一戴锦华访谈录 [Through A Looking Glass: Collection of Interviews by Dai Jinhual. Beijing: China Knowledge Press (知识出版社), 1999.

Daly, Mary. Gyn/Ecology: The Metaethics of Radical Feminism. Boston: Beacon Press, 1978.

deBold, Elizabeth, Marie Wilson and Idelisse Malave. Mother Daughter Revolution: from Good Girls to Great Women. New York: Bantam Books, 1994.

Ding, Ling (丁玲). “Summer Break [暑假中]. 丁玲文选 [Selected Writings by Ding Lingl. Shanghai: Qizhi Book Store (上海启智书局), 1936: 145-206.

--- I Myself am A Woman: Selected Writings of Ding Ling. Eds. Tani E. Barlow and Gary J. Bjorge. Boston: Beacon Press, 1989.

---. "Miss Sophia's Diary." Trans. Tani E. Barlow. I Myself am A Woman 49-81.

---. "When I was in Xia Village." Trans. Tani E. Barlow. I Myself am A Woman 298-315.

Dooling, Amy D. Women's Literary Feminism in Twentieth Century China. New York: Palgrave Macmillan, 2005. 
Du Bois, W. E. B. The Souls of Black Folk. 1903. New York: Signet, 1982.

Dunick, Lisa M. S. "The Silencing Effect of Canonicity: Authorship and the Written Word in Amy Tan's Novels." MELUS 31.2 (2006): 3-20.

Eagleton, Mary, ed. Feminist Literary Theory: A Reader. 2th ed. Malden, Oxford and Carlton: Blackwell Publishing, 1996.

Ebert, Teresa L. Ludic Feminism and After: Postmodernism, Desire, and Labor in Late Capitalism. Michigan: University of Michigan, 1996.

Elliott, Anthony. Psychoanalytic Theory: An Introduction. 2th ed. Durham: Duke University Press, 2002.

Erikson, Erik H. Identity, Youth and Crisis. 1968. New York: W. W. Norton \& Company, Inc., 1994.

---. "Reflections on Dr Borg's Life Cycle." Daedualus 105.2 (Spring 1976): 1-28.

--. Identity and the Life Cycle. 1980. New York: W. W. Norton \& Company, Inc., 1994.

Evans, Dylan. An Introductory Dictionary of Lacanian Psychoanalysis. Taylor \& Francis e-Library, 2006.

Fang, Gang (方刚). 目性恋在中国 [Homosexuals in China]. Changchun: Jilin People's Publishing House (吉林人民出版社), 1995.

Fang, Fang (房芳). “杜拉斯与陈染叙事言语之比较 [A Comparison of Narrative Theory in Duras' and Chen Ran's Fiction]." Diss. 华中科技大学 [Huazhong University of Science \& Technology], 2008.

Faries, Nathan C. "The Narratives of Contemporary Chinese Christianity." Diss. The Pennsylvania State University, 2005.

Feng, Yidai (冯亦代). “谭恩美与《喜福会》[Amy Tan and The Joy Luck Club]." 读书[Du Shu] 5 (1993): 115-18. 
Fiero, Gloria K. The Humanistic Tradition. 6 vols. 5th ed. New York: McGraw-Hill, 2006.

Flotow, Luise von. Translation and Gender: Translating in the "Era of Feminism". Shanghai: Shanghai Foreign Language Education Press, 2004.

Fokkema, Douwe W. "New Strategies in the Comparative Study of Literature and Their Application to Contemporary Chinese Literature." China and the West: Comparative Literature Studies. Eds. William Tay, Ying-hsiung Chou and Heh-hsiang Yuan. Hong Kong: The Chinese University Press, 1980. 1-7.

Foucault, Michel. Technologies of the Self: A Seminar with Michel Foucault. Eds. Luther H. Martin, Huck Gutman, and Patrick H. Hutton. Amherst: University of Massachusetts Press, 1988.

Freud, Sigmund. The Ego and the Id. Trans. Joan Riviere. London: Hogarth Press, 1927.

---. The Interpretation of Dreams. Trans. A. A. Brill and Ed. James Strachey. New York: Basic Books, 1955.

Friedan, Betty. The Feminine Mystique. 2001 ed. New York: W. W. Norton \& Company, Inc., 2001.

Fry, Donna. "The Joy and Luck of Amy Tan." Seattle Times, 7, July. 1991: 3-4.

Fu, Binbin. "Corporeal Reform: Figuring the Body in Contemporary Chinese Narrative." Diss. Purdue University, 1999.

Fu, Xiaoling (傅晓鴒). “从秘密花园到喧闹酒吧一浅论陈染、林白与卫慧的创作 [From Secret Garden to Bustling Bars: A tentative Study of Literary Creation by Chen Ran, Lin Bai and Weihui].”福州大学学报(哲学社会科 学版) [Journal of Fuzhou University (Philosophy and Social Sciences Edition)l 73.1 (2006): 70-73.

Gao, Weihong (高卫红). “论陶㪄明诗中的鸟意象 [On Bird Imagery in Tao 
Yuanming's Poems]." 华北水利水电学院学报(社科版) [Journal of North China Institute of Water Conservancy and Hydroelectric Power (Social Science) 22.4 (Nov. 2006): 82-84.

Gaffney, Karen Jean. "Narrating Difference: Contemporary American Women Writers V. Critical Race Theorists." Diss. University of Delaware, 2003.

Gecas, V. and P. J. Burke. "Self and Identity." Sociological Perspectives on Social Psychology. Eds. K. S. Cook, G. A. Fine and J. S. House. Boston: Allyn \& Bacon, 1995. 41-67.

Giddens, A. Modernity and Self-Identity: Self and Society in the Late Modern Age. Stanford: Stanford University Press, 1991.

Girard, Kristin Ann. 'Mother/Cultures and 'New World' Daughters: Ethnic Identity Formation and the Mother-Daughter Relationship in Contemporary American Literature." Diss. State University of New York at Stony Brook, 2006.

Glover, David and Cora Kaplan. Genders. London and New York: Routledge, 2000.

Goldblatt, Howard, ed. Chairman Mao Would Not Be Amused: Fiction From Today's China. New York: Grove Press, 1995.

Gough, Kathleen. "The Origin of the Family." Toward An Anthropology of Women. Ed. Rayna Reiter. New York: Monthly Review Press, 1975: 69-70.

Griffiths, Morwenna. Feminisms and the Self: The Web of Identity. London and New York: Routledge, 1995.

Grosz, Elizabeth. Sexual Subversions: Three French Feminists. Sydney: Allen \& Unwin, 1989

Habermas, J. "On Social Identity." Telos 19 (1974): 91-103.

Hamilton, Patricia L. "Feng Shui, Astrology, and the Five Elements: Traditional Chinese Belief in Amy Tan's The Joy Luck Club." MELUS 24.2 (1999): 125-45. 
Hanan, Patrick. The Invention of Li Yu. Cambridge, Mass.: Harvard University Press, 1988.

Harrison, Wendy Cealey and John Hood-Williams. Beyond Sex and Gender. London, Thousand Oaks and New Delhi: SAGE Publications, 2002.

Heilbrun, Carolyn. Toward a Recognition of Androgyny. New York: Norton, 1964.

Heinrich, Larissa N. "Good-bye Mr. Nixon." Rev. of A Private Life, by Chen Ran, Tr. by John Howard-Gibbon. MCLC Resource Center Publication Jan. 2005. 8 March 2010 http://mclc.osu.edu/rc/pubs/reviews/heinrich.htm $>$.

Heung, Marina. "Daughter-Text/Mother-Text: Matrilineage in Amy Tan's Joy Luck Club." Feminist Studies 19.3 (1993): 597-616.

Hirsch, Marianne. The Mother/Daughter Plot: Narrative, Psychoanalysis, Feminism. Bloomington and Indianapolis: Indiana University Press, 1989.

Ho, Wendy Ann. "Mother-and-Daughter Writing and the Politics of Location in Maxine Hong Kingston's The Woman Warrior and Amy Tan's The Joy Luck Club." Diss. The University of Wisconsin - Madison, 1993.

---. In Her Mother's House: The Politics of Asian American Mother-daughter Writing. Walnut Creek and Oxford: AltaMira Press, 1999.

---. "Swan-Feather Mothers and Coca-Cola Daughters: Teaching Amy Tan's The Joy Luck Club." Amy Tan. Bloom, Harold. Philadelphia: Chelsea House Publishers, 2000. 99-114.

Holmlund, Christine. "The Lesbian, The Mother, The Heterosexual Lover: Irigaray's Recoding of Difference." Feminist Studies 17.2 (Summer 1991): 283-308.

Holmstrom, Nancy. "The Socialist Feminist Project." Monthly Review Press 54.10 (2002): 1.

Hong, Jingyun (洪静云). “陶淵明诗中鸟意象探析 [An Analysis of Bird Imagery in Tao Yuanming's Poems]." 文教资料 [Data of Culture and Education] 
23 (2007): 90-93.

Honig, Emily. Sisters and Strangers: Women in the Shanghai Cotton Mills, 1919-1949. Stanford: Stanford University Press, 1986.

Howard-Gibbon, J. "Translator's Note." A Private Life. Chen Ran. Trans. J. Howard-Gibbon. New York: Columbia University Press, 2004. i-xv.

Huang, Lin (荒林). “文本内外一陈染访谈” [In and Out of Text: An Interview on Chen Ran].”文学、艺术与性别 [Literature, Arts and Gender]. Ed. Xiaojiang Li (李小江). Nanjing: Jiangsu Literature \& Arts Publishing House (江苏文艺出版社)，2002.91-102.

Huang, Ling (黄玲). “分裂的叙事：多丽丝·莱辛《金色笔记》中的安娜与陈染的 《私人生活》中倪拗拗两位“分裂的自我'形象比较 [The Image of the Split Self Anna in Lessing's The Golden Notebook and Ni Niuniu in Chen Ran's A Private Life - A Comparative Study]." Diss. 贯州大学 [Guizhou University], 2007.

Huang, Shu-ying. "The Social Construction of Female Selves in the Fiction of Li Ang, Wang Anyi, and Amy Tan." Diss. University of Georgia, 1999.

Humm, Maggie, ed. and introd. Feminisms: A Reader. New York \& London: Harvester Wheatsheaf, 1992.

Huntley, E. D. Amy Tan: A Critical Companion. Connecticut and London: Greenwood Press, 1998.

Huot, Claire. China's New Cultural Scene: A Handbook of Changes. Durham and Londong: Duke University Press, 2000.

Irigaray, Luce. "Women's Exile." Ideology \& Consciousness 1 (1977): 63-74. 
---. Powers of Horror: An Essay on Abjection. New York: Columbia University Press, 1982.

---. Ethique de la difference sexuelle. Paris: Minuit, 1984.

--- Speculum of the Other Woman. Trans. Gillian C. Gill. New York: Cornell University Press, 1985.

---. This Sex which is Not One. Trans. Catherine Porter. New York: Cornell University, 1985.

--. "The Looking Glass, from the Other Side." This Sex Which is Not One 9-22.

---. "When Our Lips Speak Together." This Sex Which is Not One 205-18.

---. Divine Women. Trans. Stephen Muecke. Sydney: Local Consumption, 1986.

---. "The Bodily Encounter with the Mother." The Irigaray Reader. Ed. Margaret Whitford. Cambridge: Blackwell Publishers Inc., 1991.

---. The Irigaray Reader. Ed. and Introd. Margaret Whitford. 1991. Cambridge: Blackwell Publishers Inc., 1995.

---. "Questions." The Irigaray Reader 133-39.

--- "Women-Amongst-Themselves: Creating a Woman-to-Woman Society." The Irigaray Reader 190-97.

Jacobi, Kara E. "they Will Invent What they Need to Survive": Narrating Trauma in Contemporary Ethnic American Women's Fiction." Diss. University of Miami, 2009.

Jay, Karla and Joanne Glasgow, eds. Lesbian Texts and Contexts: Radical Revisions. New York: New York University Press, 1990.

Jeffreys, Sheila. Unpacking Queer Politics. Cambridge: Policy Press, 2003.

Jia, Linlin (䍐琳琳). “叙事的魅力一浅析美籍华人女作家谭恩美的《喜福会》[The Charm of Narration: An Analysis of Chinese American Woman Writer Amy Tan's The Joy Luck Club]." 名作欣赏 [Appreciation of Famous 
Literary Works] 12 (2004): 93-96.

Jiang, Bo (姜波). 自我精神人格的守护一评陈染的小说创作 [The Guardian of Self-Spirit Personality - Comments on Chen Ran's Novel Creation ]." 北 方论丛 [The Northern Forum]. 187.5. (2004): 49-52.

Jung, Carl Gustav. The Archetypes and the Collective Unconscious. Trans. R. F. C. Hull. 1959. Princeton: Princeton University, 1968.

Kang, Lirong (康利荣). “他乡的名分, 故乡的误读一浅谈谭恩美的《喜福会》中 的“东方主义' [Title of An Alien Land, Misinterpretation of Homeland: On 'Orientalism' in Amy Tan's The Joy Luck Club]." 安徽文学(下半月) [Anhui Literaturel 7 (2008): 37-39.

Kanner, Ellen. "From Amy Tan, a Superb Novel of Two Sisters, Two Worlds, and a Few Ghosts." Bookpage (Dec. 1995): 3.

Keaton, Hetty Lanier. "Feeding Hungry Ghosts: Food, Family, and Desire in Stories by Contemporary Chinese American Women." Diss. The University of Tulsa, 2002.

Kent, Kathryn R. Making Girls into Women: American Women's Writing and the Rise of Lesbian Identity. Durham and London: Duke University Press, 2003.

Kingston, Maxine Hong. To Be a Poet. Kindle Edition, 2002.

Kinsey, Alfred C, Wardell B. Pomeroy and Clyde E. Martin. Sexual Behavior in the Human Male. Philadelphia: W. B. Saunders Company, 1948.

Kinsey, Alfred C, et al. Sexual Behavior in the Human Female. Philadelphia: W. B. Saunders Company, 1953.

Kolmar, Wendy K. and Frances Bartkowski, eds. Feminist Theory: A Reader. 2nd ed. Boston and New York: McGraw-Hill, 2005. 
Kosinski, Jerzy. The Painted Bird. Boston: Houghton Mifflin, 1965.

Kreiner, Leslie E. "Sudden Hues of Red and Green: The New Utopian Impulse in the Female Literary Tradition." Diss. The Claremont Graduate University, 2001.

Kristeva, Julia. Powers of Horror: An Essay on Abjection. Trans. Leon S. Roudiez. New York: Columbia University Press, 1982.

---. Black Sun: Depression and Melancholia. Trans. Leon S. Roudiez. New York: Columbia University Press, 1989.

---. “Women Can Never Be Defined." Feminist Literary Theory: A Reader. Ed. Mary Eagleton 267-68.

---. "Women's Time." New Maladies of the Soul Trans. Ross Guberman, New York: Columbia University Press, 1995. 201-24.

Lacan, Jacques. (1953). "Some Reflections on the Ego." International Journal of Psychoanalysis 34 (1953): 11-17.

Lacan, Jacques and the école freudienne. Feminine Sexuality. Eds. Juliet Mitchell and Jacqueline Rose. Trans. Jacqueline Rose. Hampshire and London: The Macmillan Press Ltd., 1982.

--- Ecrits: A Selection. Trans. Bruce Fink. New York: W. W. Norton \& Company, Inc., 2002.

Larson, Wendy. "Women and the Discourse of Desire in Postrevolutionary China: The Awkward Postmodernism of Chen Ran." Boundary 224.3 (fall 1997): 201-23.

Lautin, Lacqueline. "A Woman's Legacy: Conflict in the Mother-Daughter Relationship in Contemporary American Fiction." Diss. City University of New York, 2007.

Leary, M. R. and J. P. Tangney. Handbook of Self and Identity. New York: Guilford Press, 2003.

Lechte, John and Maria Margaroni. Julia Kristeva: Live Theory. London and 
New York: Continuum, 2004.

Li, Guicang. "The Literature of Chinese American Identity." Diss. Indiana University of Pennsylvania, 2002.

Li, Huihui. "Representations of Code Switching in Asian American Women's Literature." Diss. Texas A \& M University, 2001.

$\mathrm{Li}$, Jinrong (李金荣). “从陈染、林白到卫慧、棉棉: 论 20 世纪 90 年代新生代女 性小说走向 [From Chen Ran, Lin Bai to Wei Hui and Mian Mian: On the Trend of Feminine Novels of the New Generation in the 1990's]." Diss. 山东师范大学 [Shandong Normal University], 2006.

Li, Xiaojiang. "With What Discourse Do We Reflect on Chinese Women? Thoughts on Transnational Feminism in China." Spaces of Their Own: Women's Public Sphere in Transnational China. Ed. Mayfair Mei-hui Yang. Minneapolis: University of Minnesota Press, 1999. 261-77.

Li, Xinshuang (李欣霜). “走出传统的藩䉓一论伍尔夫与陈染创作中的女性意识 [Out of the Shackles of Convention: On Feminine Consciousness in Woolf's and Chen Ran's Creation]." Diss. 吉林大学 [Jilin University], 2004.

Li, Yinhe (李银河) and Wang Xiaobo (王小波). 他们的世界：中国男同性恋群落 透视 [Their World: A Penetrating Look into the Chinese Gay Male Communityl. Hong Kong: Cosmos Books Ltd. (天地图书有限公司), 1992.

Li, Youliang (李有亮). 给男人命名：20世纪女性文学中男权批判意识的流变

[To Name Men: Ideological Evolution of Criticizing Men's Rights in the $20^{\text {th }}$ Century Female Literature]. Beijing: Social Sciences Academic Press (社会科学文献出版社), 2005. 
$\mathrm{Li}, \mathrm{Yu}$ (李渔). 李渔全集 [Complete Works of Li Yu]. 20 vols. Hangzhou: Zhejiang Classics Publishing House (浙江古籍出版社), 1992.

Liang, Suqin (梁素琴) and Chu Jing (判楚). “寻梦人的心灵世界一谭恩美小说喜 福会中的文化冲突探析 [The Inner World of the Dream Pursuers: On the Cultural Conflicts in Amy Tan's The Joy Luck Club]." 北京科技大学学报 (社会科学版) [Journal of University of Science and Technology Beijing (Social Sciences Edition)] 17.4 (Dec. 2001): 56-60.

Liang, Xiangwei (梁香伟). “俳徊在轨道上的“安娜”：父权统治下的牺牲品及其反 抗 [Anna Loitering on the Rail: The Sacrifice and Struggle under Patriarchy - Interpretation of Feminism in the Works of Chen Ran and Lin Bai]." 洛阳师范学院学报 [Journal of Luoyang Normal University] 27.4 (2008): 79-81.

Lieberman, Sally Taylor. The Mother and Narrative Politics in Modern China. Charlottesville and London: University Press of Virginia, 1998.

Lin, Bai (林白). 一个人的战争 [One Person's War]. Taiyuan: Gansu People's Publishing House (甘肃人民出版社), 1994.

---. 林白文集 [The Collected Works of Lin Bail. 4 vols. Nanjing: Jiangsu Literature \& Arts Publishing House (江苏文艺出版社), 1997.

--.. “回廊之椅 [The Bench on the Interior Balcony].”林白文集 [The Collected Works of Lin Bail 1. 199-234.

--. “瓶中之水 [Water in A Bottle].”林白文集 [The Collected Works of Lin Bai] 
Lin, Zhou (林舟) and Hong Qi (齐红). “女性个体经验的书写与超越：陈染访谈录 [Writing and Transcending Female Personal Experience]." 花城 [Flower City] 2 (1996): 92-97.

Ling, Amy. Between Worlds: Women Writers of Chinese Ancestry. New York: Pergamon Press, Inc., 1990.

Ling, Shuhua (凌淑华). 凌淑华小说集[Collected Short Stories by Ling Shuhual. 2 vols. Taipei: Hongfan Book Store (洪范书店), 1984.

---. “说有这么一回事 [Rumor Has It That Something Like This Happened].” 凌 淑华小说集 [Collected Short Stories by Ling Shuhua] 1. 89-101.

Liu, Hong. "Representing the 'Other': Images of China and the Chinese in the Works of Jade Snow Wong, Maxine Hong Kingston and Amy Tan." Diss. The University of Toledo, 1998.

Liu, Lydia H. "The Female Tradition in Modern Chinese Literature: Negotiating Feminisms across East/West Boundaries." Genders 12 (1991): 22-44.

Liu, Siqian (刘思谦) and Li Xiaozheng (李校争). “黑暗中的舞者一性别视角下陈 染小说知识女性形象分析 [Dancing in Darkness-- the female intellectual image of Chen Ran's fiction from feminist perspective]." 湘嘾大学学报 (哲学社会科学版) [Journal of Xiangtan University (Philosophy and Social Sciences)l 30.3 (May. 2006): 46-49.

Liu, Yingjie (刘英杰), ed. 中国教育大事典 [Book of Major Education Events in Chinal. Hangzhou: Zhejiang Education Press (浙江教育出版社), 2001. 
Lo, Man-wa. "Body Politics and Female Subjectivity in Modern English and Chinese Fiction." Diss. The Chinese University of Hong Kong, 2001.

Long, Jinhui (龙锦辉)。“流散与融聚一谭恩美与严歌苓文化认同之比较 [Diaspora and Integration: A Comparative Study of Amy Tan and Geling Yan's Cultural Identity]." 新余高专学报 [Journal of Xinyu College] 14.2 (Apr. 2009): 24-26.

Lorde, Audre. "Uses of the Erotic: The Erotic as Power." Sister Outsider. New York: Crossing Press, 1984.

Lu, Shujiang. "Rereading the Past and Reshaping the Future: Narrative Texts by Asian North American Women Writers." Diss. The University of Western Ontario (Canada), 2001.

Lu, Tonglin, ed. Gender and Sexuality in Twentieth-Century Chinese Literature and Society. New York: State University of New York Press, 1993.

Lu, Xiaofeng (陆孝峰). “陈染、林白的女性写作 [Feminine Writing of Chen Ran and Lin Bai]." 文艺争鸣 [Contention in Literature and Art] 8 (2007): 152-55.

Lu, Yin (卢隐). 卢隐选集 [Selected Works of Lu Yin]. Ed. Qiang Hong (钱虹). 2 vols. Fuzhou: Fujian People's Publishing House (福建人民出版社), 1985.

Lu, Yu (卢玉). “女性的自我言说 [A Story of Her Own]." Diss. 华中科技大学 [Huazhong University of Science \& Technology], 2006.

Lynch, Lee. Toothpick House. Tallahassee: Naiad Press, 1983.

---. The Swashbuckler. Tallahassee: Naiad Press, 1985.

Ma, Sheng-mei. "'Chinese and Dogs' in Amy Tan's The Hundred Secret Senses: Ethnicizing the Primitive A La New Age." MELUS 26.1 (2001): 
MacKinnon, Catharine A. "Feminism, Marxism, Method, and the State: An Agenda for Theory." Feminist Theory: A Critique of Ideology. Eds. Nannerl Keohane et al., Chicago: University of Chicago Press, 1980. $1-30$.

Madsen, Deborah L. Feminist Theory and Literary Practice. Beijing: Foreign Language Teaching and Research Press, 2006.

Maxey, Ruth. 'The East is Where Things Begin': Writing the Ancestral Homeland in Amy Tan and Maxine Hong Kingston." Orbis Litterarum 60.1 (2005): 1-15.

McDaniels, Preselfannie W. "Mothering Modes: Analyzing Mother Roles in Novels by Twentieth-Century United States Women Writers." Diss. Louisiana State University and Agricultural \& Mechanical College, 2004.

McDougall, Bonnie S. Fictional Authors, Imaginary Audiences: Modern Chinese Literature in the Twentieth Century. Hong Kong: Chinese University Press, 2003.

--. "Discourse on Privacy by Women Writers in Late Twentieth-Century China." China Information 19.1 (2005): 97-119. 12 March 2007 < http://cin.sagepub.com/cgi/content/abstract/19/1/97 >.

Medoff, Jeslyn. "Maxine Hong Kingston." Modern American Women Writers. Eds. Showalter, Elaine, Lea Baechler and A. Walton Litz. New York: Charles Scribner's Sons, 1991: 251-60.

Meng, Yue (孟悦) and Jinghua Dai (戴锦华). 浮出历史地表 : 现代妇女文学研究 [Emerging from the Surface of History: A Research on Modern Women's Literature]. Beijing: China Renmin University Press (中国人民大学出版 社), 2004.

Mian, Mian (棉棉). 糖 [Sugar]. Zhuhai: Zhuhai Publishing House (珠海出版社), 2009. 
Millett, Kate. Sexual Politics. New York: Avon Books, 1969.

Mitchell, David Thomas. "Conjured Communities: The Multiperspectival Novels of Amy Tan, Toni Morrison, Julia Alvarez, Louise Erdrich and Cristina Garcia." Diss. University of Michigan, 1993.

Mitchell, Juliet. "Introduction." Feminine Sexuality. Lacan, Jacques and the $e$ cole freudienne. Eds. Juliet Mitchell and Jacqueline Rose. Trans. Jacqueline Rose. Hampshire and London: The Macmillan Press Ltd., 1982: $1-57$.

Moers, Ellen. Literary Women. New York: Anchor, 1977.

Nelson, Emmanuel S., ed. Asian American Novelists: A Bio-Bibliographical Critical Sourcebook. Connecticut \& London: Greenwood Press, 2000.

Nice, Vivien E. Mothers and Daughters: The Distortion of a Relationship. New York: St. Martin's Press, 1992.

Oliver, Kelly. "Kristeva and Feminism." Feminist Theory Website: Julia Kristeva. Center for Digital Discourse and Culture, Virginia Tech University. 6 April. $2010<$ http://www.cddc.vt.edu/feminism/kristeva.html $>$.

Om, Tina Suyong. "Creating Identity: An Exploration of Second-Generation Asian Americans in The Joy Luck Club, Mona in the Promised Land, and Native Speaker." Diss. California State University, Long Beach, 1999.

O'Reilly, Andrea. "I Come From A Long Line of Uppity Irate Black Women': African-American Feminist Thought on Motherhood, the Moterline, and the Mother-Daughter Relationship." Mothers and Daughters: Connection, Empowerment, and Transformation. Eds. Andrea O'Reilly and Sharon Abbey. Lanham, Boulder, New York and Oxford: Rowman \& Littlefield Publishers, Inc., 2000.

O'Reilly, Andrea and Sharon Abbey. Mothers and Daughters: Connection, Empowerment, and Transformation. Lanham, Boulder, New York and Oxford: Rowman \& Littlefield Publishers, Inc., 2000.

Parsons, T. "The Position of Identity in the General Theory of Action." The Self in Social Interaction. Eds. C. Gordon and K. J. Gergen. New York: Wiley, 1968. 
Pichois, Claude and André-M. Rousseau. La Littérature Comparée. Paris: A. Colin, 1967.

$\mathrm{Pu}$, Songling. Strange Tales from a Chinese Studio. Trans. Herbert A. Giles. London: T. De La Rue, 1880.

Qi, Fugang (漆福刚). “从心理学视角看王安忆、陈染的创作个性 [A Psychological Study of the Idiosyncrasy in Wang Anyi's and Chen Ran's Literary Creation]." 中南民族大学学报 (人文社会科学版) [Journal of South-Central University for Nationalities (Humanities and Social Sciences)] 24 (Aug. 2004): 60-61.

Qiao, Yigang (乔以钢) and Ning Wang (王宁). “自恋与自审间的灵魂历险一陈 染、林白、徐小斌的女性观及其创作 [A Spiritual Adventure between Narcissism and Self-Reflection: On Feminist Ideas and Writings of Chen Ran, Lin Bai and Xu Xiaobin].” 江汉论坛 [Jianghan Tribune] 3 (2007): 116-20.

Raymond, Janice. A Passion for Friends. Boston: Beacon Press, 1986.

Register, Cheri. "American Feminist Literary Criticism: A Bibliographical Introduction." Feminist Literary Theory: A Reader. Ed. Mary Eagleton 236-41.

Reid, E. Shelley. "The Compound I: Narrative and Identity in the Novels of Toni Morrison, Louise Erdrich, and Amy Tan." Diss. State University of New York at Buffalo, 1994.

Rich, Adrienne. Of Women Born: Motherhood as Experience and Institution. New York: W. W. Norton \& Company. Inc., 1976.

---. "Compulsory Heterosexuality and Lesbian Existence." Feminism and Sexuality: A Reader. Eds. Stevi Jackson and Sue Scott. New York: Columbia University Press, 1996. 130-43.

Ryan, Marya Mac. "Gender and community: Womanist and feminist 
perspectives in the fiction of Toni Morrison, Amy Tan, Sandra Cisneros, and Louise Erdrich." Diss. University of Illinois at Umana-Champaign, 1995

Sang, Tze-lan D. The Emerging Lesbian: Female Same-Sex Desire in Modern China. Chicago: University of Chicago Press, 2003.

Schofield, Cynthia Lynn. "Chronotope and the Female Journey." Diss. Michigan State University, 1996.

Selden, Raman. A Reader's Guide to Contemporary Literary Theory. New York: Harvester Wheatsheaf, 1989.

Schaffer, Kay and Xianlin Song. "Narrative, Trauma and Memory: Chen Ran's A Private Life, Tiananmen Square and Female Embodiment." Asian Studies Review 30 (June 2006): 161-73.

---. "Writing Beyond the Wall: Translation, Cross-cultural Exchange and Chen Ran's A Private Life." Journal of Multidisciplinary International Studies 3.2 (July 2006): 1-20.

Shen, Dalei (沈大雷). “杜拉斯与陈染作品中的女权思想比较一以《情人》和《与 往事干杯》为例 [A Comparison of Feminist Ideas in Duras' and Chen Ran's Writing: A Case Study of The Love and A Toast to the Past]." 文教 资料 [Data of Culture and Education] 28 (Oct. 2008): 211-12.

Shen, Rong. "At Middle Age." Trans. Yu Fangin and Wang Mingjie. At Middle Age. Beijing: Panda Books, 1987: 9-85.

Shi, Pingping (石平萍). [母女关系与性别、种族的政治 : 美国华裔妇女文学研究] The Mother-Daughter Relationship and the Politics of Gender and Race: A Study of Chinese American Women's Writings. Kaifeng: Henan University Publishing House (河南大学出版社), 2004

Shields, Charles J. Amy Tan. Philadelphia: Chelsea House Publishers, 2002. 
Shou, Jingxin (寿静心). [女性文学的革命：中国当代女性主义文学研究] A Revolution of Female Literature: A Study of Feminist Literature in Contemporary China. Beijing: China Social Sciences Press (中国社会科 学出版社), 2007.

Showalter, Elaine, ed. The New Feminist Criticism: Essays on Women, Literature, and Theory. New York: Pantheon Books, 1985.

---. “Toward a Feminist Poetics." The New Feminist Criticism 125-43.

---. "Feminist Criticism in the Wilderness." The New Feminist Criticism 243-70.

--. Sister's Choice: Tradition and Change in American Women's Writing. Oxford: Clarendon Press, 1991.

--. A Literature of Their Own: British Women Novelists From Bronte to Lessing Expanded ed. Princeton, New Jersey: Princeton University Press, 1999.

Showalter, Elaine, Lea Baechler and A. Walton Litz, eds. Modern American Women Writers. New York: Charles Scribner's Sons, 1991.

Sieber, Patricia, ed. Red is not the Only Color: Contemporary Chinese Fiction on Love and Sex between Women, Collected Stories. Lanham: Rowman \& Littlefield Publishers, Inc., 2001.

Smurthwaite, Lori F. "Why Doesn't Anybody Tell them their Own Mothers Have Stories?': Representations of Mother/Daughter Relationships in Contemporary American Fiction." University of Southern California, 1998.

Snodgrass, M. Ellen, ed. Amy Tan: A Literary Companion. Jefferson and London: McFarland \& Company, Inc., 2004.

Snyder, R. Claire. "What is Third-Wave Feminism? A New Directions Essay." Signs: Journal of Women in Culture and Society 34.1 (2008): 175-96.

Stevens, Richard. Erik Erikson: An Introduction. New York: St. Martin's Press, 1983. 
Su, Suocai. "Inventing Transnational Chinese American Identities in Amy Tan's The Joy Luck Club, Shirley Geok-Lin Lim's Among the White Moon Faces, and Shawn Hsu Wong's American Knees." Diss. Ball State University, 2004.

Suleiman, Susan Rubin. "Playing the Motherhood; or, How to Get the Most Out of the Avant-Garde." Representations of Motherhood. Eds. Donna Bassin, Margaret Honey and Meryle Mahrer Kaplan. New Haven and London: Yale University Press, 1994. 272-82.

Sun, Gang (孙刚). “从后殖民女性主义文学批评角度解读谭恩美的'喜福会' [A Post-Colonial Feminist Interpretation of Amy Tan's The Joy Luck Club]." 湖北社会科学 [Hubei Social Sciences] 4 (2008): 138-40.

Sun, Hong (孙宏). “石墙酒吧造反”前后同性恋文学在美国的演变 [The Evolution of Pre- and Post- Stonewall Gay Literature in America]." 外国 文学研究 [Foreign Literature Studies] 2 (2006): 122-28.

Suzuki, Michiko. Becoming Modern Women: Love and Female Identity In Prewar Japanese Literature and Culture. Stanford, California: Stanford University Press, 2010.

Tan, Amy. The Joy Luck Club. 1989. New York: Penguin books, 2006.

--- The Kitchen God's Wife. New York: G. P. Putnam's Sons, 1991.

---. The Moon Lady. Hong Kong: Aladdin, 1992.

---. The Chinese Siamese Cat. Hong Kong: Aladdin, 1994.

---. The Hundred Secret Senses. New York: Ivy Books, 1995.

---. The Bonesetter's Daughter. New York: G. P. Putnam's Sons, 2001.

---. The Opposite of Fate. New York: G. P. Putnam's Sons, 2003. 
---. Saving Fish from Drowning. New York: Ballantine Books, 2006.

---. "How Stories Written for Mother Became Amy Tan's Best Seller," Interview by Julie Lew. New York Times 4 July 1989, 19 (N).

Tan, Anqing (谭岸青). “论谭恩美两部长需小说的叙事风格 [On the Narrative Style of Amy Tan's Two Novels]." 当代文坛 [Modern Literature Magazine] 2 (2004): 52-54.

---. “女性“讲古”的新体式一论谭恩美四部小说的叙事策略 [A New Mode of “Talk Story" by Women: On Amy Tan s Narrative Strategies in her Four Novels]." 暨南学报(人文科学与社会科学版) [Journal of Jinan University (Humanities and Social Sciences Edition)] 108.1 (2004): 94-99.

Tao, Dongfeng (陶东风). “提升私人化写作 [Sublimation of Privatized Writing]." 长城 [Chang Cheng] 6 (1996): 172-74.

Tay, William, Ying-hsiung Chou and Heh-hsiang Yuan, eds. China and the West: Comparative Literature Studies. Hong Kong: The Chinese University Press, 1980.

Tian, Liling (田丽玲). “拉德克利夫·霍尔的《孤寂深洲》和陈染的《私人生活》两 部小说中的同性恋主题比较研究 [On the Theme of Lesbianism in Radcliffe's The Well of Loneliness and Chen Ran's A Private Life]." Diss. 贵州大学 [Guizhou University], 2008.

Tie, Ning (铁凝). 玫瑰门[Rose Door]. Beijing: The Writers Publishing House (作家出版社), 1991.

Todd, Janet. Feminist Literary History. New York: Routledge, 1988. 
Tong, Rosemarie. Feminist Thought: A Comprehensive Introduction. Colorado: Westview Press, 1989.

---. Feminist Thought: A More Comprehensive Introduction 3rd ed. Colorado: Westview Press, 2009.

Topping Bazin, Nancy. Virginia Woolf and the Androgynous Vision. New York: Rutger's University Press, 1973.

Tuttle, L. Encyclopedia of Feminism. London: Arrow Books, 1986.

Tyson, Lois. Critical Theory Today: A User-Friendly Guide. New York \& London: Garland Publishing, Inc., 1999.

Visser, Robin Lynne. "The Urban Subject in the Literary Imagination of Twentieth Century China." Diss. Columbia University, 2000.

---. "Privacy and Its III-Effects in Post-Mao Urban Fiction." Chinese Concepts of Privacy. Eds. Bonnie S. McDougall and Anders Hansson. Boston: Brill Academic Publishers, 2002. 171-94.

Vitiello, Giovanni. "Exemplary Sodomites: Male Homosexuality in Late Ming Fiction." Diss. University of California, Berkeley, 1994.

Walker, Alice. The Color Purple. New York : Harcourt Brace Jovanovich, 1982.

---. In Search of Our Mothers' Gardens. San Diego, New York and London: Harcourt Brace Jovanovich, Publishers, 1983.

Wang, Anyi (王安忆). “弟兄们 [Brothers].”收获 [Harvest] 3 (1989): 4-30.

---. 㞵上的世纪 [A Century on the Hillock]. Beijing: Beijing Normal University Press (北京师范大学出版社), 1993.

---. 纪实与虚构 [Truthful and Fictitious]. Beijing: People's Literature Publishing House (人民文学出版社), 2001. 
---. Love in a Small Town. Trans. Eva Huang. Hong Kong: Renditions, 1988.

---. Love on a Barren Mountain. Trans. Eva Hung. Hong Kong: Renditions, 1991.

---. Brocade Valley. Trans. Bonnie McDougall and Chen Maiping. New York: New Directions, 1992.

Wang, Fang (王芳). “《喜福会》的女权主义解读 [An Feminist Interpretation of The Joy Luck Club]." 安徽文学 (下半月) [Anhui Literature] 2 (2008): 338-39.

Wang, Guanghua (王光华). “林白、陈染等女性小说创作的个人视线探析 $[A$ Probe in the Personal View of Lin Bai's and Chen Ran's Fiction Writing]." 黄河水利职业技术学院学报 [Journal of Yellow River Conservancy Technical Institute] 20.1 (Jan. 2008): 96-98.

Wang, Lingzhen. Personal Matters: Women's Autobiographical Practice in the Twentieth-Century China. Stanford: Stanford University Press, 2004.

Wang, Meng (王蒙). “陌生的陈染 [The Unfamiliar Chen Ran].”陈染文集 [The Collected Works of Chen Ranl. 4 vols. Yangzhou : Jiangsu Literature \& Arts Publishing House (江苏文艺出版社), 1996. 1-4.

Wang, Xiulian (王秀莲). “从中西方文化视角看谭恩美作品中的伦理主题 [On Ethical Themes in Amy Tan's Works from Cross-Cultural Perspective]." 黑龙江教育学院学报 [Journal of Heilongiiang College of Education] 28.9 (Sep. 2009): 117-18.

Wang, Yongmei (王咏梅). “文化的“返乡”. 论谭恩美小说中的文化冲突与融合 [A Cultural "Homecoming": the Conflict and Reconciliation of the Culture in Amy Tan s Novels]" 西南师范大学学报(人文社会科学版) [Journal of 
Southwest China Normal University (Philosophy \& Social Sciences Edition)] 30.6 (Nov. 2004): 161-64.

Wei, Hui (卫慧). 上海宝贝 [Shanghai Baby]. Shenyang: Chunfeng Wenyi Press (春风文艺出版社), 1999.

Wei, Yanmei. "Femininity and Mother-Daughter Relationships in Twentieth-Century Chinese Literature." Diss. State University of New York at Stony Brook, 1999.

Weigert, A. J., J. Smith Teitge and Dennis W. Teitge. Society and Identity: Toward A Sociological Psychology. Cambridge: Cambridge University Press, 1973.

Wen, Jing (文晶)。“谭恩美对女性的关注及其“根'情结 [Amy Tan's Concern on Women and Her "Root-Seeking" Complex]." 黑龙江教育学院学报 [Journal of Heilongiiang Journal of Education] 26.8 (Aug. 2007): 101-03.

Whitford, Margaret, ed. and introd. The Irigaray Reader. 1991. Oxford and Cambridge: Blackwell Publishers Ltd., 1995.

Williams, Terra Ann. "Matrilineaology: Mother-Daughter Relationships in Contemporary Fiction." Diss. University of Nevada, Las Vegas, 1999.

Wittig, Monique. "The Straight Mind." Feminist Theory: A Reader 343-46.

Womack, Kenneth, ed. The Greenwood Encyclopedia of New American Reading. 4 vols. Westport and London: Greenwood Press, 2008.

Wong, Hiu Wing. "'Talk-stories' in the Fictions of Maxine Hong Kingston and Amy Tan." Diss. University of Warwick, 2006.

Wong, Sau-Ling Cynthia. "Ethnic Subject, Ethnic Sign, and the Difficulty of Rehabilitative Representation: Chinatown in some Works of Chinese American Fiction." The Yearbook of English Studies 24 (1994): 251-62.

Wong, Sui Sum Grace. "Conceptualizing Transnationalism and Transculturalism in Chinese American Women Narratives and Memoirs: 
Jade Snow Wong, Ruthanne Lum Mccunn, and Amy Tan." Diss. University of Hong Kong (Hong Kong), 2003.

Woolf, Virginia. A Room of One's Own. 1929. Florida: Harcourt Brace \& Company, 1989.

Wright, Elizabeth, ed. Feminism and Psychoanalysis: A Critical Dictionary. Oxford: Basil Blackwell Ltd, 1992.

Wu, Qing-yun. "A Chinese Reader's Response to Maxine Hong Kingston's China Men." MELUS 17.3 Varieties of Ethnic Criticism (Autumn, 1991 Autumn, 1992): 85-94.

Xiao, Hong. Tales of Hulan River. Hong Kong: Joint Publishing Co., 1988.

Xiao, Wei (肖薇). “异质文化语境下的女性书写一海外华人女性写作比较研究 [Feminine Writing within the Hybrid Cultural Context: A Comparative Study of Overseas Chinese Women Writings]." Diss. 四川大学 [Sichuan University], 2002.

Xu, Ben. "Memory and the Ethnic Self: Reading Amy Tan's The Joy Luck Club." MELUS 19.1 (1994): 3-18.

Xu，Kun (徐坤). “重重穷幕密遮灯一九十年代的中国女性文学写作 [Lamp Light Behind Layers of Curtains: Chinese Female Writing in the 1990s]." 作家 [Writers] 8 (1997): 15-22.

---. “双调夜行船 : 九十年代的女性写作 [Double Tunes on A Night Boat: Female Writing of the 1990s]." 小说界 [Fiction World] 4 (1998): 147-61.

--- “文学中的疯狂'女性' : 二十世纪中国女性写作的演进 [The 'Crazy' Femininity in Literature: Evolution of Women's Writing in $20^{\text {th }}$ Century China]." Diss. 中国社会科学院研究生院 [Graduate School of Chinese Academy of Social Sciences], 2003. 
Xu, Shan (徐珊). “私人生活一欲说还休的女性故事一论陈染的《私人生活》和林 白的《一个人的战争》[Private Life-Unspoken Female Story: On Chen Ran's A Private Life and Lin Bai's The War of One's Own]." 北京教育学 院学报 [Journal of Beiiing Institute of Education] 17.2 (June. 2003): 44-49.

Xu, Wenying. "A Womanist Production of Truths: The Use of Myths in Amy Tan." A Journal of Multicultural Literature 12 (Autumn 1995): 60-61.

Ye, Zhen (叶珍). “美国非白人移民文学中的族裔文化认同研究一以托妮·莫里森 和谭恩美的创作为例 [Case Study: Ethnic Cultural Identity in Non-White Immigrant Literature]." 株洲师范高等专科学校学报 [Journal of Zhuzhou Teachers College] 12.1 (2007): 40-43.

Yi，Fang (易芳). “对女性生命意识的关怀一论陈染、林白、海男的小说创作 [Concerns About Female Life Consciousness: On Fiction Writing by Chen Ran, Lin Bai and Hai Nan]." 荆门职业技术学院学报 [Journal of Jinmen Technical College] 19.2 (2004): 43-47.

Yin, Guoming (殷国明). “历史的追寻，记忆的重建一一评美籍华人作家谭恩美的 小说创作 [Searching For History and Reconstructing Memory]." 慜南学 报（哲学社会科学版) [Journal of Jinan University (Philosophy \& Social Science Edition)] 15.4 (Oct. 1993): 98-105.

Young, Mary Eleanor. "'Aunt Jemima and the Dragon Lady': Ethnicity and Gender in the Selected Writings of African-American and Chinese-American Women Writers." Diss. Saint Louis University, 1990.

Yu, Luojin. A Chinese Winter's Tale. Trans. Rachel May. Hong Kong: 
Renditions Books, 1986.

Yu, Xiujuan (于秀娟). “双重身份下的双重写作一谈谭恩美、汤亭亭作品中的异国 形象 [Twofold Writing in Double Identity: On Exotic Images in Amy Tan and Maxine Hong Kingston's Works].”聊城大学学报(社会科学版) [Journal of Liaocheng University (Scial Sciences Edition)] 2 (2003): 103-05.

Yu, Zhansui (于展绥). “从铁凝、陈染到卫慧 : 女人在路上 [From Tie Ning to Chen Ran and Wei Hui: Women on the Road]." 小说评论 [Novel Review] 1 (2001): 28-32.

Yu, Zhiping (余志平) and Zhenlin Zhang (张振林). “复活的女娲长歌当哭一评陈 染、林白女性写作的爱情主题 [Renascent Nüwa's Grief Songs: On the Theme of Love in Chen Ran's and Lin Bai's Writing]." 当代文坛 [Modern Literary Magazine] 2 (2003): 33-36.

Zeng, Li (曾理). “两个世界, 还是一个世界? 一 论美国华裔文学作品中华人的“文 化认同'问题." [Two Worlds, or One World? - On Chinese Cultural Identification in Chinese American Literary Works] 华侨华人历史研究 [Overseas Chinese History Studies] 57.1 (Mar. 2002): 9-15.

--.. "Asian American Literature." The Greenwood Encyclopedia of New American Reading. Ed. Kenneth Womack. vol. 1. Westport and London: Greenwood Press, 2008. 66-87.

Zhan, Qiao (詹乔). “解读谭恩美《百种隐秘感官》中的“种族影像” [Interpreting "The Racial Shadow" of Amy Tan's The Hundred Secret Senses]." 暨南 学报(哲学社会科学版) [Joumal of Jinan University (Philosphy and Social 
Science)] 120.1 (2006): 73-78.

Zhang, Hongwei (张洪伟) and Lin Yue (岳林). “挥之不去的'东方主义情结”一解 读谭恩美小说《灵感女孩》[Pervasive “Orientalist Complex": An Interpretation of Amy Tan's The Hundred Secret Senses]." 外国语言文学 研究 [Research in Foreign Language \& Literature] 6.1 (Mar. 2006): 77-81.

Zhang, Jie. Love Must Not Be Forgotten. Trans. Gladys Yang. San Francisco: China Books \& Periodicals; Beijing: China Panda Books, 1986.

---. "The Ark." Love Must Not Be Forgotten 1-13.

--- 世界上最疼我的那个人去了 [Gone is the Person Who Loved Me Most]. Jinan: Shandong Pictorial Publishing House (山东画报出版社), 2000.

Zhang, Liling (张莉玲) and Jiahai Peng (彭家海). “谭恩美作品的女性主义解读 [A Feminist Interpretation of Amy Tan's Works]."中国集体经济 (下半月) [China Collective Economy] 5 (2007): 195-96.

Zhang, Longxi. "The Challenge of East-West Comparative Literature." Yingjin Zhang, China in a Polycentric World: Essays in Chinese Comparative Literature 21-35.

Zhang, Ruihua (张瑞华). “对谭恩美作品的文化思考 [A Cultural Critique of Amy Tan's Novels]." 辽宁师范大学学报(社会科学版) [Journal of Liaoning Normal University (Social Science Edition)] 24.6 (Nov. 2001): 77-81.

Zhang, Yiwu and Michael Berry. "Postmodernism and Chinese Novels of the Nineties." Boundary 24.2 (Autumn 1997): 247-59.

Zhang, Yingjin, ed. and introd. China in a Polycentric World: Essays in 
Chinese Comparative Literature. California: Stanford University Press, 1998.

---. "Introduction: Engaging Chinese Comparative Literature and Cultural Studies." China in a Polycentric World: Essays in Chinese Comparative Literature 1-20.

Zhao, Leiyan (赵䃌岩). “张爱玲与谭恩美作品中母亲形象比较 [A Comparison of the Mother Image in Ailing Zhang and Amy Tan's Works]."广西教育 学院学报 [Journal of Guangxi College of Education] 80.6 (2005): 117-19.

Zhao, Lingxia (赵令霞). “美国华裔女性作家的“自我”书写一以黄玉雪、汤婷婷、 谭恩美为例 [The Self-Writing of Chinese American Women Writers: A Case Study of Jade Snow Wong, Maxine Hong Kingston and Amy Tan]." 文教资料 [Data of Culture and Education] 25 (Sep. 2009): 24-26.

Zhao, Mengying (赵梦颖). “从飞升到隹落:陈染与卫慧创作比较 [From Rising to Falling: A Comparison of Chen Ran and Wei Hui]." 中州大学学报 [Journal of Zhongshan University] 21.1 (Jan. 2004): 43-46.

Zheng, Yi. '"Personalized Writing' and Its Enthusiastic Critic: Women and Writing of the Chinese 'Post-New Era'." Tulsa Studies in Women's Literature 23.1 (Spring 2004): 45-64.

Zhong, Yi (钟怡). “杜拉斯和陈染小说的女性主义比较 [A Feminist Comparisn of Duras' and Chen Ran's Fiction]." 安徽文学 [Anhui Literature] 3 (2008): $11-12$

Zhou, Jiuling (周俊玲). “论陶渊明诗鸟意象的艺术特色 [Artistic Characteristics of Bird Images in Tao Yuanming's Poetry]." 南昌大学学报( 人文社会科学 
版 ) [Journal of Nanchang University (Humanities and Social Sciences)] 40.2 (Mar. 2009): 137-42.

Zhou, Ke (周柯). “践：寂廖而不安分的文学探索 [Afterword: Solitary but Restless Literary Quest]." 嘴唇里的阳光 [Sunshine between the Lips]. Ran Chen (陈染) 311-20.

Zhuang, Zi. The Complete Works of Chuang Tzu. Trans. Burton Watson. New York: Columbia University Press, 1968.

Zou, Jianjun (邹建军). “和”的正向与反向 [Positive and Negative Dimensions of 'Harmony']." Diss. 华中师范大学 [Huazhong Normal University], 2008. 


\section{CURRICULUM VITAE}

NAME: $\quad$ Jing $\mathrm{He}$

ADDRESS: $\quad 4-405$, No. 5, Jingyuanlu Road, Shijingshan District, Beijing 100043, P. R. China

DOB: $\quad$ Changsha, China - October 22, 1979

\section{EDUCATION}

\& TRAINING: B.A., English Language and Literature Beijing Foreign Studies University 1998-2002

M.A., Translation Theory and Practice Beijing Foreign Studies University 2002-2005

M.A. Training Program, Simultaneous Interpretation Beijing Foreign Studies University 2002-2003

Ph.D. in Humanities University of Louisville 2006-2010

\section{PROFESSIONAL SOCIETIES:}

2007- International Association for Intercultural Communication Studies (IAICS)

2007- China Association for Intercultural Communication (CAIC)

\section{PUBLICATIONS:}

English-Chinese Translator, "Feast under the Arctic Ice Block" and "Living as One." Youth Journal, 2000 
Author, "On the Accommodation in the Translation of English and Chinese Puns - an analytical review of the four Chinese versions of Alice's Adventure in Wonderland." Journal of Sichuan Foreign Language University, 2004 (6).

Author, "A Tentative Study on the Translation of Puns - From the Perspective of Relevance Theory." Anthology of the School of English and International Studies, BFSU. Beiiing: Foreign Language Teaching and Research Press, 2006.

Chief Editor, College English Fast Reading. Beijing: Peking University Press, 2006.

English-Chinese Co-Translator, Ten Mile Inn. Beijing: China Press of Literature and History, 2007.

Author, "Discourse Analysis of Liu Xiang's Victory in Athens Olympics in Chinese and American Sports Reports." BFSU English Journal. Beijing: Foreign Language Teaching and Research Press, 2007.

Author, "Seeking the Meaning of Life: A Comparison of Lao Tzu's 'Tao' and Emerson's 'Oversoul'." Intercultural Communication Studies, Vol. XVII. 1. (2008): 218-27.

Author, English Interpreting (Level III): A Textbook for National Accreditation Examinations for Translators and Interpreters. Beijing: Foreign Language Teaching and Research Press, 2010.

Author, "The Translation of English and Chinese Puns from the Perspective of Relevance Theory." JosTrans, 13 (2010): 81-99.

Author, "The Effects of Listening Support on Business English Listening Performance of EFL Students in China." BFSU English Journal. Beijing: Foreign Language Teaching and Research Press, 2010.

NATIONAL MEETING PRESENTATIONS:

"The Validity of Sapir-Whorf Hypothesis - Rethinking the Relationship among Language, Thought and Culture," 2007 International Conference on Intercultural Communication, June 22-24, 2007, Harbin, Heilongjiang, P.R. China

"A Feminist Reinterpretation of Untranslatability," 2007 Annual Academic 
Conference, School of English and International Studies, Beijing Foreign Studies University, May 25-27, 2007, Beijing, China

"Discourse Analysis of Liu Xiang's Victory in Athens Olympics in Chinese and American Sports Reports," 2007 Annual Academic Conference, School of English and International Studies, Beijing Foreign Studies University, May 25-27, 2007, Beijing, China

"The Effects of Listening Support on Business English Listening Performance of EFL Students in China," 2009 Annual Academic Conference, School of English and International Studies, Beijing Foreign Studies University, May 16, 2009, Beijing, China 